\title{
Archeological Testing of Sites 41GD113 and 41GD114 in Goliad County, Texas
}

Russell D. Greaves

Follow this and additional works at: https://scholarworks.sfasu.edu/ita

Part of the American Material Culture Commons, Archaeological Anthropology Commons, Environmental Studies Commons, Other American Studies Commons, Other Arts and Humanities Commons, Other History of Art, Architecture, and Archaeology Commons, and the United States History Commons

Tell us how this article helped you.

This Article is brought to you for free and open access by the Center for Regional Heritage Research at SFA ScholarWorks. It has been accepted for inclusion in Index of Texas Archaeology: Open Access Gray Literature from the Lone Star State by an authorized editor of SFA ScholarWorks. For more information, please contact cdsscholarworks@sfasu.edu. 


\section{Archeological Testing of Sites 41GD113 and 41GD114 in Goliad County, Texas}

\section{Licensing Statement}

This is a work produced for the Texas Department of Transportation (TxDOT) by the report producer. TxDOT and the report producer jointly own all rights, title, and interest in and to all intellectual property developed under TXDOT's contract with the report producer. The report may be cited and brief passages from this publication may be reproduced without permission provided that credit is given to both TxDOT and the report producer. Permission to reprint an entire chapter, section, figures or tables must be obtained in advance from either the Supervisor of the Archeological Studies Branch, Environmental Affairs Division, Texas Department of Transportation, 125 East 11th Street, Austin, Texas, 78701 or from the report producer. 


\section{Archeological Testing of Sites 41GD113 and 41GD114 in Goliad County, Texas}

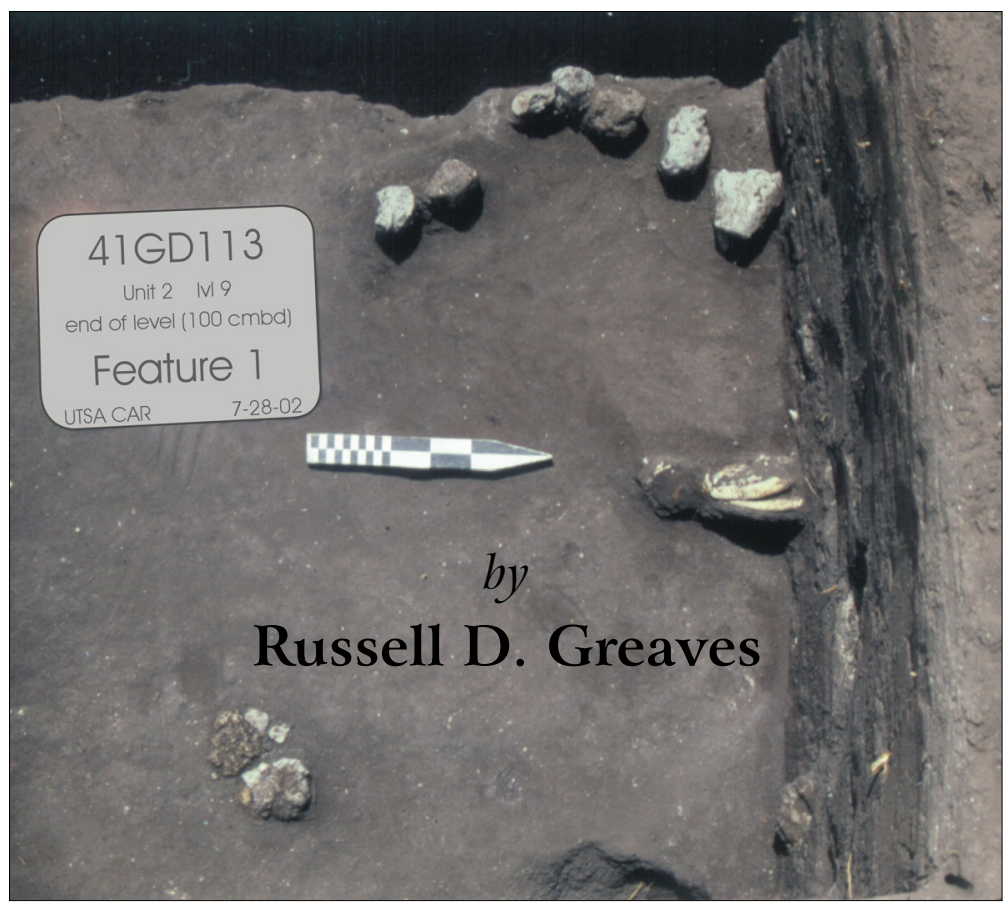

with a Contribution by

Jason D. Weston

Appendices by

Lee C. Nordt \& Corey A. Crawford

and

Raymond P. Mauldin

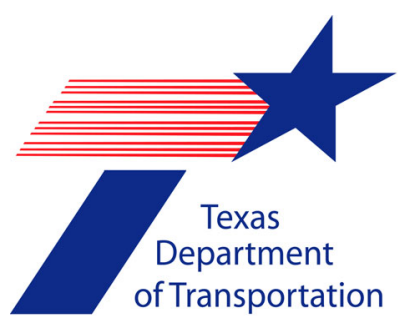

Environmental Affairs Division

Texas Department of Transportation

Archeological Studies Program, Report No. 62

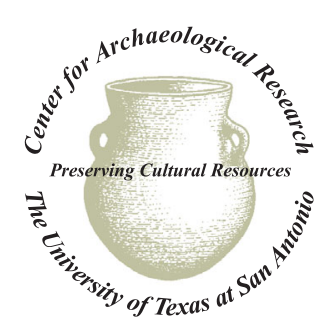

Center for Archaeological Research The University of Texas at San Antonio Archaeological Survey Report, No. 344 


\title{
Archeological Testing of Sites 41GD113 and 41GD114 in Goliad County, Texas
}

\author{
by \\ Russell D. Greaves \\ with a Contribution by \\ Jason D. Weston \\ and Appendices by \\ Lee C. Nordt and Corey A. Crawford \\ and \\ Raymond P. Mauldin
}

Texas Antiquities Committee Permit No. 2899

Raymond P. Mauldin

Principal Investigator

Work Authorization No. 57308 SA002

Contract No. 573 XX SA002

CSJ: 0088-03-030

Prepared for:

Environmental Affairs Division

Texas Department of Transportation

Archeological Studies Program, Report No. 62

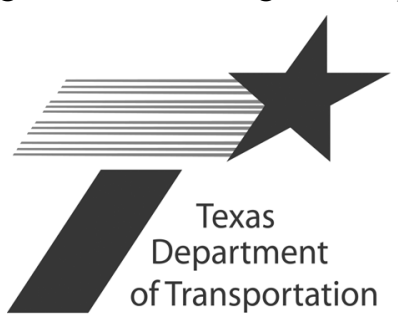

Prepared by:

Center for Archaeological Research The University of Texas at San Antonio Archaeological Survey Report, No. 344

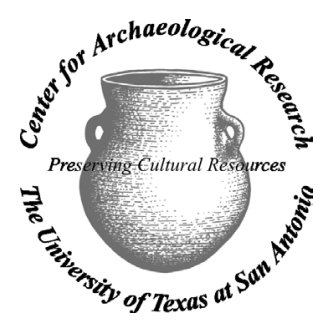




\title{
Archeological Testing of Sites 41GD1 13 and 41GD114 in Goliad County, Texas
}

\author{
Copyright ${ }^{{ }^{\circ}} 2004$ \\ Texas Department of Transportation (TxDOT) and Center for Archaeological Research, \\ The University of Texas at San Antonio (CAR-UTSA)
}

\begin{abstract}
All rights reserved
TxDOT and CAR-UTSA jointly own all rights, title, and interest in and to all data and other information developed for this project under Contract $573 \mathrm{XX}$ SA002. Brief passages from this publication may be reproduced without permission provided that credit is given to TxDOT and CAR-UTSA. Permission to reprint an entire chapter, section, figures or tables must be obtained in advance from the Supervisor of the Archeological Studies Program, Environmental Affairs Division, Texas Department of Transportation, 125 East 11th Street, Austin, 78701. Copies of this publication have been deposited with the Texas State Library in compliance with the State Depository requirements.
\end{abstract}

Printed by Kwik Kopy on Main, San Antonio, Texas

2004

jointly published by

Texas Department of Transportation

Environmental Affairs Division

Archeological Studies Program

Owen Lindauer, Ph.D., Supervisor

Archeological Studies Program, Report No. 62

A. McGraw, Series Editor

and

Center for Archaeological Research

The University of Texas at San Antonio

Archaeological Survey Report, No. 344

Printed on acid-free, $60 \mathrm{lb}$. paper

ISBN: 1-930788-32-0 


\section{Management Summary}

Archeological testing of two previously identified prehistoric archeological sites in Goliad County, Texas, was performed by the Center for Archaeological Research (CAR) at The University of Texas at San Antonio. Testing examined 41GD113 and 41GD114 to determine their potential eligibility for listing on the National Register of Historic Places (NRHP) and whether they warranted designation as State Archeological Landmarks (SAL). The work was performed for the Texas Department of Transportation (TxDOT) on July 24-August 2, 2002. Archeological testing was performed in relation to a proposed highway realignment to avoid the Noble Cemetery currently adjacent U.S. Highway 59. These investigations were conducted under Texas Antiquities Permit No. 2899, with Dr. Raymond P. Mauldin serving as Principal Investigator.

41GD113 is a Late Archaic site that is a palimpsest deposit of multiple, probably short-term, occupations. Five backhoe trenches and seven 1-x-1-m test units were excavated on this site. Geoarcheological investigations identified the site as a floodplain setting subject to periodic, fine, low-energy deposition. No intact features were identified, although fire-cracked rock was present and is almost certainly derived from cultural thermal use. A single late stage biface fragment, three flake tools, one core, and a relatively small debitage assemblage $(n=866)$ was recovered. Most of these lithics came from two excavation units within intact deposits and another from a highly disturbed context. No diagnostic artifacts were encountered. The few faunal remains recovered cannot be unambiguously associated with past human activity.

The portion of 41GD114 within the TxDOT right-of-way was extensively mechanically disturbed prior to these testing efforts. Three backhoe trenches and two 1-x-1-m test units were excavated on this site. Soils in the test units were shallow and encountered bedrock or gravel deposits at approximately $60 \mathrm{~cm}$ below surface. No tools or diagnostic artifacts were recovered and only 65 pieces of debitage were collected from controlled excavations.

Subsequent to laboratory analyses, natural gravels, gastropods, and mussel shell remains from 41GD113 were discarded. All of the magnetic susceptibility samples from 41GD113 and 41GD114 were discarded following analysis. The entire assemblage from $41 \mathrm{GD} 114$ also was disposed of after analyses and will not be curated. All discarded materials were disposed of following proper artifact disposal procedures with the pre-approval of TxDOT and the Texas Historical Commission. All other materials and samples from 41GD113 were curated at the CAR permanent curation facility.

Following the field investigation and analyses by CAR, neither 41GD113 nor 41GD114 is considered to be eligible for nomination for NRHP listing nor warrant designation as a SAL. Based on this testing effort no additional archeological investigations are considered necessary and it is recommended that construction of the proposed highway bypass be allowed to proceed. 


\section{Table of Contents:}

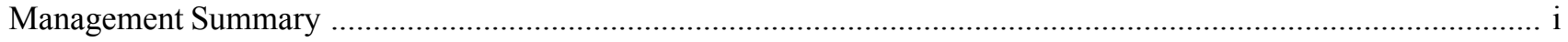

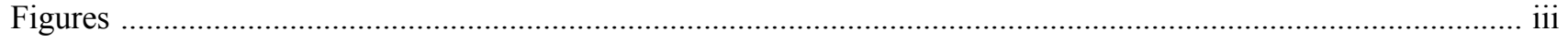

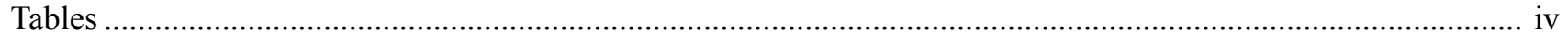

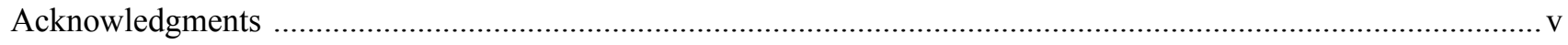

Chapter 1: Introduction
Introduction

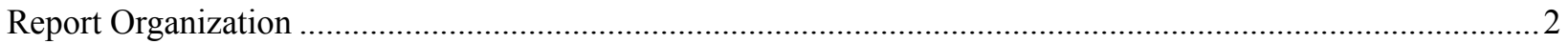

Chapter 2: Environmental and Archeological Background

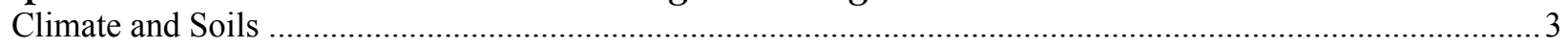

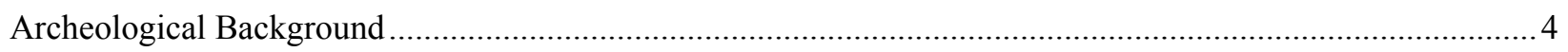

Previous Archeological Investigations at 41GD113 and 41GD114 ….................................................. 6

Chapter 3: Research Design and Methods

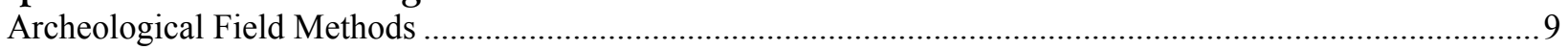

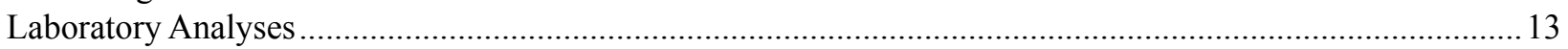

Chapter 4: Results of Archeological Testing

$41 \mathrm{GD} 113$

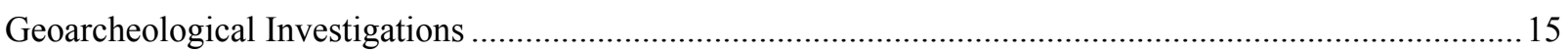

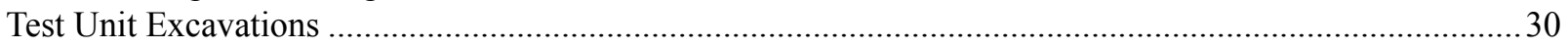

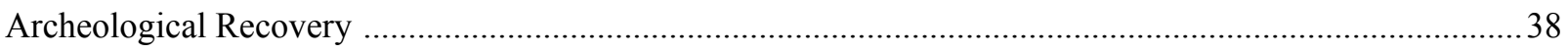

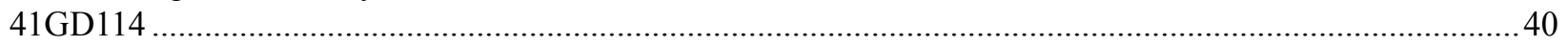

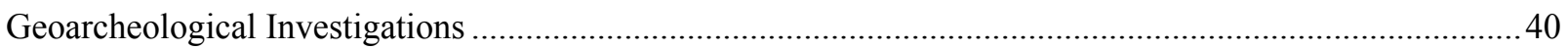

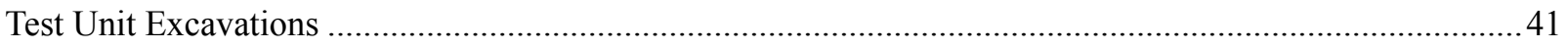

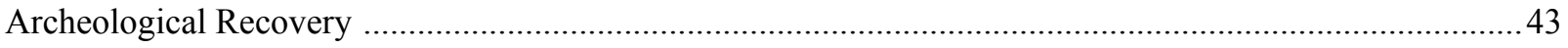

Chapter 5: Laboratory Analyses of Recovered Archeological Material

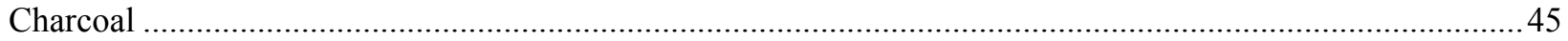

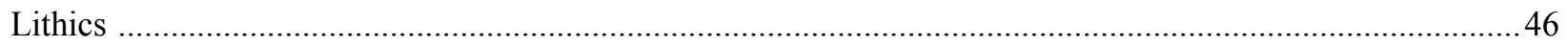

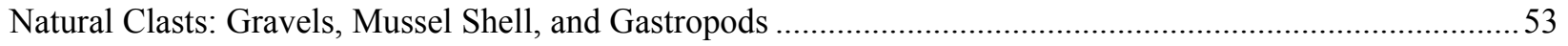

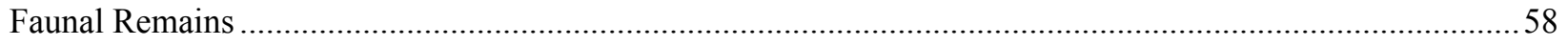

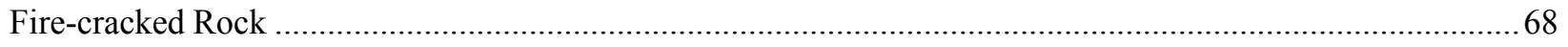

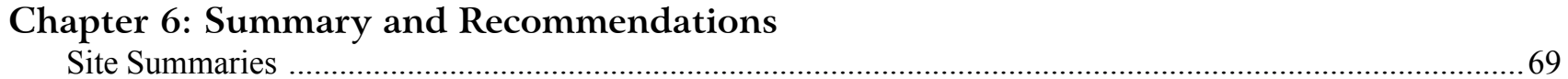

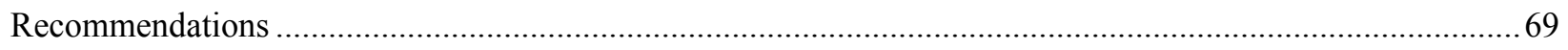

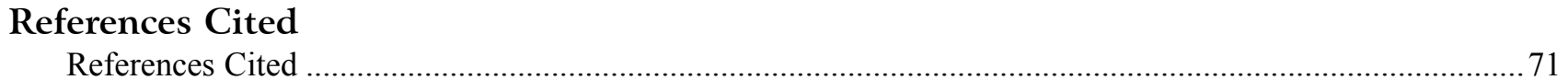

Appendix A: Geomorphology and Geoarcheology by Lee C. Nordt and Corey A. Crawford

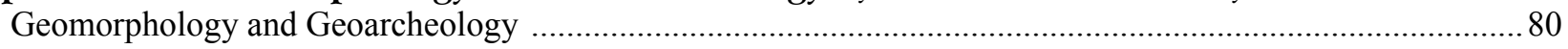

Appendix B: Radiocarbon Dating Results

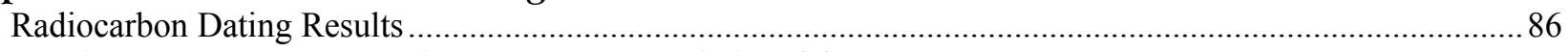

Appendix C: Magnetic Sediment Susceptibility Testing by Raymond P. Mauldin

Magnetic Sediment Susceptibility Testing ……........................................................................................ 92 


\section{Figures:}

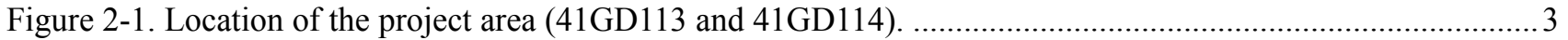

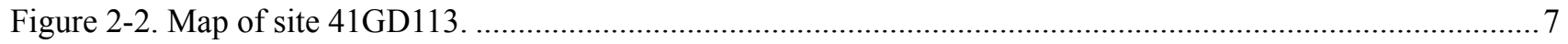

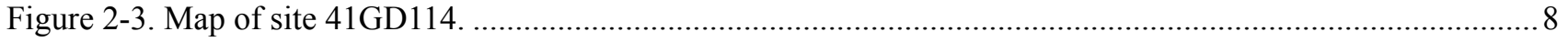

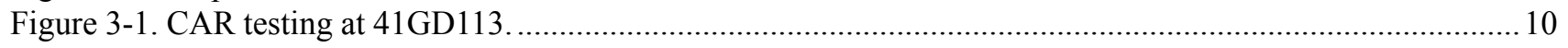

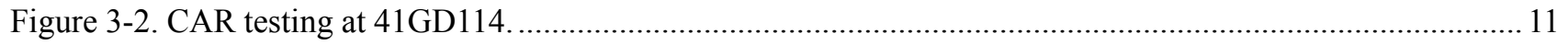

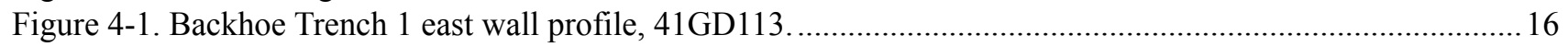

Figure 4-2. Backhoe Trench 2 east wall profile, 41GD113 ............................................................................. 19

Figure 4-3. Detail of fire-cracked rock distribution in Backhoe Trench 2, 41GD113........................................20

Figure 4-4. Backhoe Trench 3 east wall profile, 41GD113 ........................................................................22

Figure 4-5. Backhoe Trench 4 east wall profile, false color showing depositional units, 41GD113. .....................25

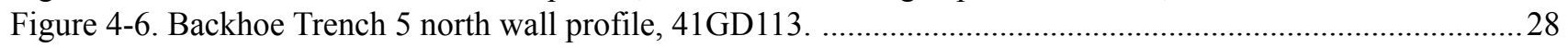

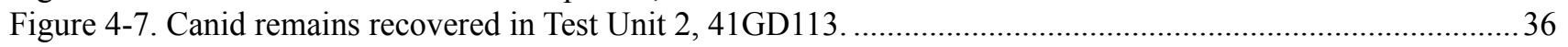

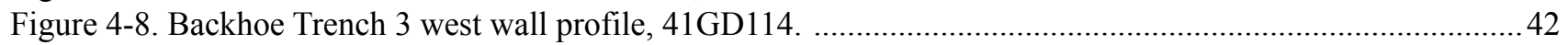

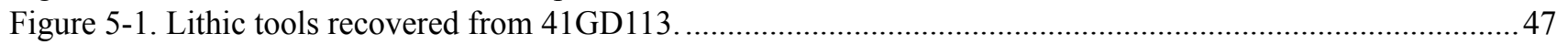

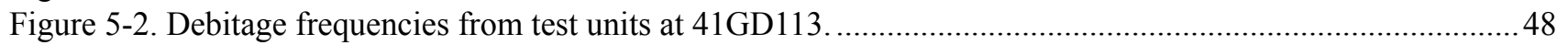

Figure 5-3. Vertical debitage frequencies for Test Units 2, 5, and 6 at 41GD113 ................................................50

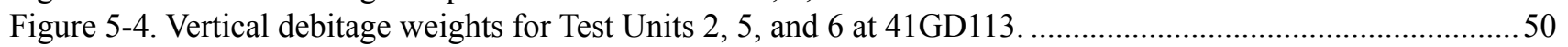

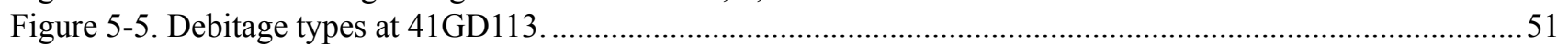

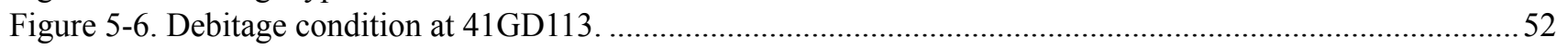

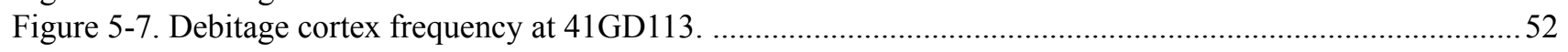

Figure 5-8. Vertical debitage frequencies for Test Units 1 and 2 at 41GD114 .................................................54

Figure 5-9. Vertical debitage weights for Test Units 1 and 2 at 41GD114 ......................................................5

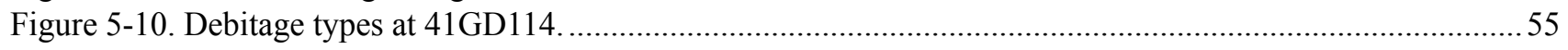

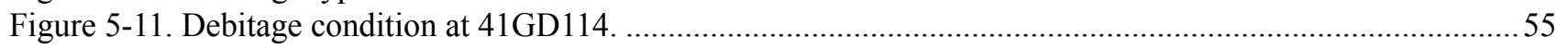

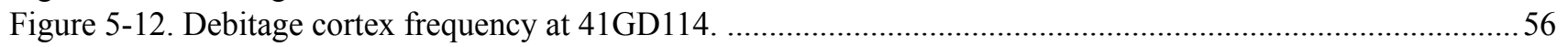

Figure A-1. Geoarcheology profiles of backhoe trenches at 41GD113 and 41GD114 .................................... 81

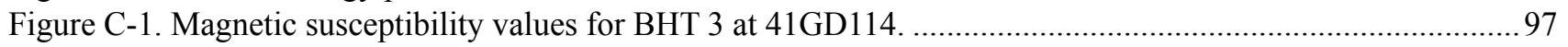

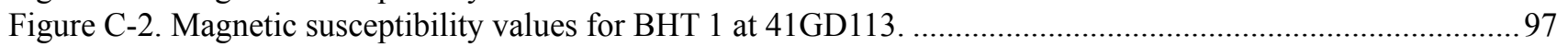

Figure C-3. Magnetic susceptibility values for BHT 2 at 41GD113...............................................................98

Figure C-4. Magnetic susceptibility values for BHT 3 at 41GD113.............................................................98

Figure C-5. Magnetic susceptibility values for BHT 4 at 41GD113.................................................................99

Figure C-6. Magnetic susceptibility values for BHT 5 at 41GD113 ........................................................... 99 


\section{Tables:}

Table 4-1. Soil Description for Backhoe Trench 1, 41 GD113 17

Table 4-2. Soil Description for Backhoe Trench 2, 41 GD113

Table 4-3. Soil Description for Backhoe Trench 3, 41GD113

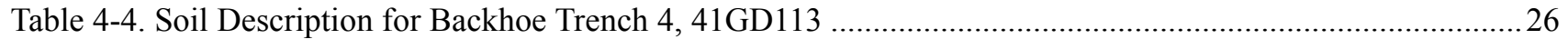

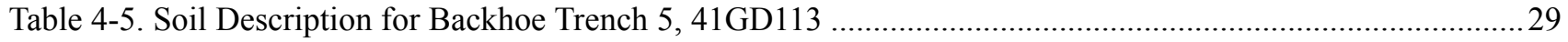

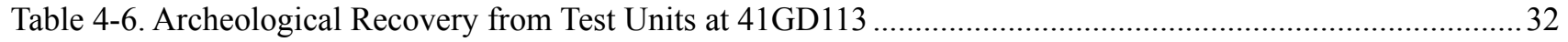

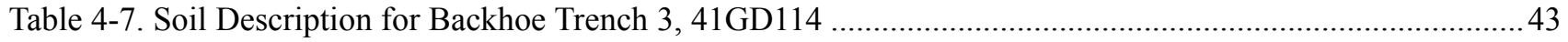

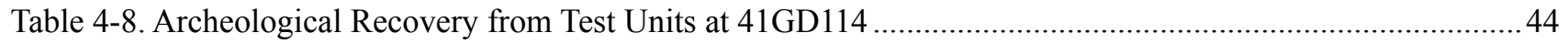

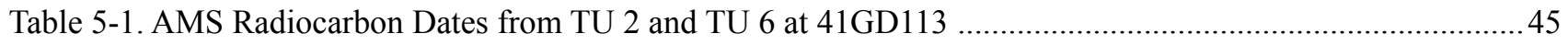

Table 5-2. Faunal Remains Recovered from 41GD113, Sorted by Unit ............................................................59

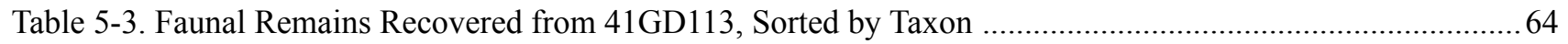

Table C-1. Magnetic Sediment Susceptibility Data for a Variety of Substances ..................................................93

Table C-2. Presence/absence of Cultural Material and Mass Specific Sediment Susceptibility Scores for

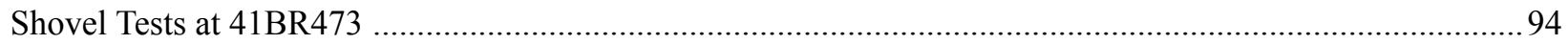

Table C-3. Magnetic Susceptibility Results from 41GD113 and 41GD114 .......................................................95 


\section{Acknowledgments}

Many individuals have contributed hard work to help in the completion of this project. Tim Meade of TxDOT provided guidance and information throughout the project. Several other individuals at TxDOT have assisted with this project, especially Dr. Lain Ellis and Dr. James Abbott. Richard Mahoney, CAR staff archeologist, established the research protocol and provided significant logistical assistance prior to the initiation of fieldwork. Rebecca Galdeano, Bryant Saner, Matt Senn, Stacy Wagner, and Jason Weston performed the fieldwork. Jason Weston also served as crew chief and performed the lithic analysis. Mike Fulghum provided expert backhoe service that was critical to evaluation of these sites and offered his observations from previous visits to the site during the landowner's mechanical investigation of 41GD113 and 41GD114. Bruce Moses and Raymond Mauldin mapped the site. Bill Birmingham and the late Smitty Schmiedlin discussed their observations of the landowner's excavations and made available their notes on the site. Lee Nordt and Corey Crawford performed geoarcheological examination of both sites. Wes Miller from the USDA Natural Resources Conservation Service in Victoria, Texas visited the site, discussed the geoarcheological investigations at 41GD113, and offered valuable insights. Laboratory work was overseen by Marybeth Tomka and Rebecca Galdeano. The expert drafting of Bruce Moses and Rick Young has tremendously improved the quality of this presentation. Johanna Hunziker prepared the final report for production. Dr. Raymond Mauldin served as the Principal Investigator and oversaw all aspects of the fieldwork, laboratory analysis, and report production. Both Dr. Raymond Mauldin and Dr. Steve Tomka provided critical support and assistance throughout this project. 



\section{Chapter 1: Introduction}

Archeological testing of two previously identified prehistoric sites (41GD113 and 41GD114) in Goliad County, Texas, was performed by the Center for Archaeological Research (CAR) at The University of Texas at San Antonio. This work was performed for the Texas Department of Transportation (TxDOT) during July 24-August 2, 2002. The work was conducted under Work Authorization No. 57308 SA002 to Contract No. 573 XX SA002. The testing was conducted to determine eligibility for listing on the National Register of Historic Places (NRHP) and whether the sites warranted listing as State Archeological Landmarks (SAL). Testing provided sufficient information to evaluate the research significance of these cultural resources.

Archeological testing was performed in relation to a proposed highway realignment to avoid the Noble Cemetery currently adjacent U.S. Highway 59 in Goliad County. A previous Impact Evaluation and testing identified buried cultural deposits at 41GD113 and 41GD114 (Fields et al. 2002:57). The current testing project was conducted in compliance with Section 106, NEPA, and the Antiquities Code of Texas (Title 9, Chapter 191 of the Texas Natural Resources Code of 1977, as amended), its attendant Rules of Practice and Procedure (Texas Administrative Code, Title 13, Part II, Chapter 26), and the Council of Texas Archeologists Guidelines (1992). Work was performed under Texas Antiquities Permit No. 2899 issued to Raymond P. Mauldin. All work was carried out under the terms of the Programmatic Agreement between TxDOT, the Federal Highway Administration, the Texas Historical Commission and the Advisory Council on Historic Preservation.

Archeological testing was performed in accordance with the initial scope of work approved by TxDOT and the Texas Historical Commission (THC) with a few alterations in effort dictated by unanticipated field conditions. The fieldwork varied from the initial scope of work and research design for two reasons. The initial scope of work identified $41 \mathrm{GD} 113$ as the site requiring less effort than 41GD114. The deposits of 41GD114 were initially thought to be intact based on the site survey excavation and recording by Prewitt and Associates, Inc. (Fields et al. 2002). This initial examination was performed following reports by stewards of the Texas Stewards Network (under direction of the Texas Historic Commission) who examined the landowner's excavations of these sites (Fields 2002:2). The landowner had mechanically excavated both 41GD113 and 41GD114 with a bulldozer. The portion of 41GD114 remaining within the right-of-way for the proposed road improvements was highly disturbed. The research potential of the deposits at $41 \mathrm{GD} 114$ had been severely compromised and there were few areas of intact deposits within the right-of-way ( $25 \%$ of the total site area) to examine during this field effort. When this destruction became known to CAR at the initiation of fieldwork, a greater effort was placed on the testing of the more intact archeological deposits at 41GD113. The density and variety of materials recovered from 41GD113 also merited more intensive testing than the deposits of 41GD114 that were within the right-of-way.

$41 \mathrm{GD} 113$ is a Late Archaic site that is a palimpsest deposit of multiple, probably short-term occupations. Five backhoe trenches and seven 1-x-1-m test units were excavated on this site. Geoarcheological investigations identified the site as a floodplain setting subject to periodic, fine, low-energy deposition. No intact features were identified, although fire-cracked rock was present and is almost certainly derived from cultural use. Only a single late stage biface fragment, three flake tools, one core and a relatively small debitage assemblage $(n=866)$ were recovered. Most of these lithics came from two excavation units within intact deposits and another from a highly disturbed context. No diagnostic artifacts were encountered. The faunal remains recovered cannot be unambiguously associated with past human activity.

The portion of 41GD114 within the TxDOT right-of-way was extensively mechanically disturbed. Three backhoe trenches and two 1-x-1-m test units were excavated on this site. Soils in the test units were shallow and encountered bedrock or gravel deposits at approximately $60 \mathrm{~cm}$ below surface. No lithic tools or diagnostic artifacts were recovered and only 65 pieces of debitage were collected from controlled excavations.

Following the field investigations and analyses by CAR, neither 41 GD113 nor 41 GD114 is considered to be eligible for nomination for NRHP listing nor warrant designation as a SAL. Based on this testing effort, no additional archeological investigations are considered necessary and it is recommended that construction of the proposed highway realignment be allowed to proceed. 


\section{Report Organization}

This report is divided into six chapters and three appendices. Following this introductory chapter, Chapter 2 outlines the natural setting where 41GD113 and 41GD114 are located, archeological background of this area, and the recent archeological investigations of these two sites prior to testing by CAR. Chapter 3 describes the research design, archeological field methods employed during this investigation, and laboratory analyses goals and procedures. Chapter 4 presents the results of geoarcheological investigations and test excavations at 41GD113 and 41GD114. Chapter 5 discusses the results of laboratory analyses of the materials excavated during this project. A brief summary of each site is presented at the end of this chapter. Finally, Chapter 6 summarizes the management recommendations regarding $41 \mathrm{GD} 113$ and $41 \mathrm{GD} 114$.

Appendix A presents the field data and interpretation of geoarcheological investigations of 41GD113 and 41GD114 by Lee C. Nordt and Corey A. Crawford. Appendix B provides the complete data from Beta Analytic's AMS dating of the three charcoal samples submitted from Test Units 2 and 6 on 41GD113. Appendix C provides the results of the magnetic susceptibility analysis. 


\section{Chapter 2: Environmental and Archeological Background}

The two sites examined during this project, 41GD113 and 41GD114, are located in the southeastern portion of Goliad County, Texas (Figure 2-1). Goliad County is located in the coastal prairies of the Gulf Coastal Plain. The sites are within the floodplain of Perdido Creek in mixed prairie and forested riparian vegetation.

\section{Climate and Soils}

Weather data available for Victoria (Bomar 1995:Table C-2) indicate that the mean annual precipitation is 37.41 inches. The wettest months are May-June (4.5 and 4.89 inches respectively) and September (5.6 inches); March is the driest month (1.55 inches). There is an average of 52 days with 0.10 inches of rainfall or more each year, ranging from 4-6 days per individual month (Bomar 1995:Table C-6). The current mean annual high temperature in Victoria is $79.8^{\circ} \mathrm{F}$; ranging from $62.8^{\circ} \mathrm{F}$ for January to $93.5^{\circ} \mathrm{F}$ for
July (Bomar 1995:Table B-7). The mean annual cold temperature is $60^{\circ} \mathrm{F}$; ranging from $42.5^{\circ} \mathrm{F}$ (January) to $74.6^{\circ} \mathrm{F}$ (July). This area is among the most humid regions of Texas (Bomar 1995:Table F-4).

41 GD113 and 41GD114 are located within the modern floodplain on the northern bank of the Payton Branch of Perdido Creek, approximately $2.4 \mathrm{~km}$ (1.5 miles) east of the town of Fannin. Payton Branch is a first order tributary of Perdido Creek; both of these are perennial streams. Perdido Creek is a third order tributary of Coleto Creek, now dammed to form Coleto Reservoir just northeast of the project location. Coleto Creek is a fourth order tributary of the Guadalupe River. The current channel of the San Antonio River is located approximately $8 \mathrm{~km}$ ( 5 miles) south of the project area. The area is generally flat with low topographic relief. The older alluvial deposits identified at 41GD113 are probably from ancient meanders of Perdido Creek. The

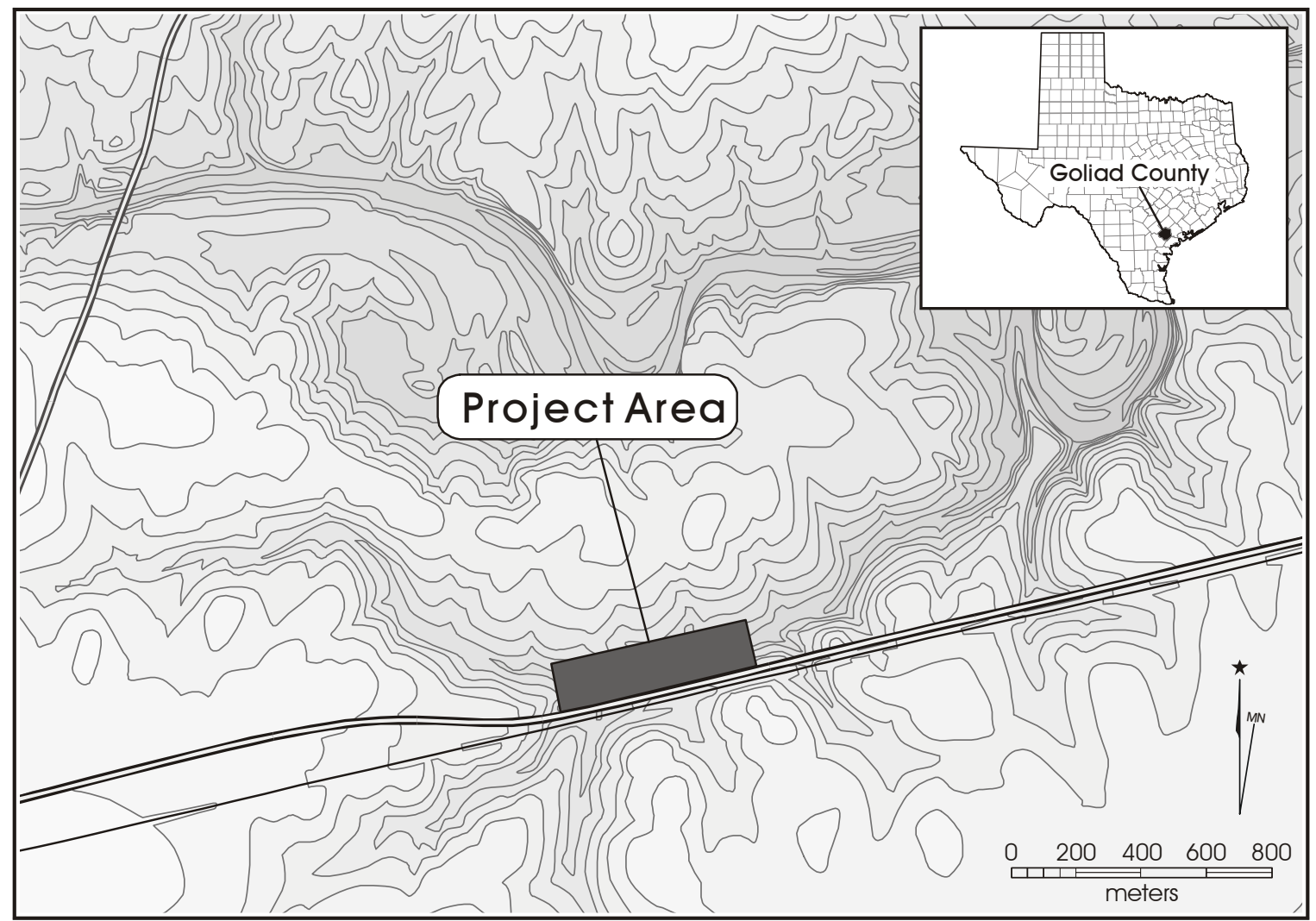

Figure 2-1. Location of the project area (41GD113 and 41GD114). 
sites are situated between 100-105 feet (30.5-32 m) AMSL. Both sites are located on the scarp between two terrace treads. There is a higher, older terrace north of the sites. This older terrace surface is bordered by the current unimproved roadway along its southern margin, just north of $41 \mathrm{GD} 113$. South of the sites is a lower, more recent terrace of the Payton Branch. Evidence from geoarcheological investigations at 41GD113 suggests that floodplain deposition migrated southward, towards the modern floodplain, shortly after the majority of artifacts were left at this site.

Soils in this portion of Goliad County are classified as Alfisols formed on Quaternary alluvium resting on top of Pleistocene Lissie Formation sands, silts, and clays (Barnes 1975). The source for the carbonate-rich lowest horizons encountered in backhoe trenching is derived from calcium carbonate rich facies of the Lissie Formation. Detailed information on local soils is currently unavailable. The U.S. Department of Agriculture soil survey for Goliad County has not yet been published. The topography of this area is generally flat with low hills. River drainages, such as Perdido Creek and Coleto Creek, are responsible for major landform variability through downcutting and formation of broad alluvial plains. Most of the fire-cracked rock recovered from 41GD113 appears to be a coarse conglomerate sandstone derived from the Pliocene Goliad Formation that is expressed north and west of the project area (Barnes 1975). Some of these rocks were likely obtained as clasts from the nearby drainages of Perdido Creek or the Payton Branch that originate to the northwest of 41GD113 and 41GD114 on the Goliad Formation. None of the clasts encountered exhibit worn cortex, indicating they were not entrained for long distances. At 41GD114, heavily weathered bedrock was encountered at less than $50 \mathrm{~cm}$ below the modern ground surface in the two excavation units (although not in the three backhoe trenches). This indicates there are localized outcrops of the Goliad Formation sandstone very near ground surface in the vicinity of these sites.

The area around Goliad is in a transitional zone that includes the Coastal Prairie, Post Oak Savanna, South Texas Brush country, and littoral zone of the Gulf Coast (Blair 1950). The presence of major drainages, such as the San Antonio River and Coleto Creek, add riparian habitats to this ecotone environment. Vegetation in the area is a mix of tall grass prairie, oak-hickory forests, and mesquite thorn brush of the Tamaulipan Province. Woodlands are dominated by live oak (Quercus virginiana), post oak (Q. stellata), blackjack oak (Q. marilandica), black hickory (Carya texana), Texas sugar hackberry (Celtis laevigata var. texana), spiny hackberry (C. pallida), honey mesquite (Prosopis juliflora var. glandulosa), black brush (Acacia rigidula), huisache (A. farnesiana), Texas persimmon (Diospyros texana), and prickly pear (Opuntia sp.; Vines 1960). Open grasslands are predominantly tall grasses such as Agropyron smithii, Andropogon saccharoides, Andropogon scoparius, Stipa leucotricha, and Troila pilosa (Blair 1950:100).

\section{Archeological Background}

Sites 41GD113 and 41GD114 are located along tributary drainages within the San Antonio and Guadalupe river basins. Much of the information about culture history and adaptation dynamics rely on analogies to more thoroughly investigated regions. Previous archeological research has identified abundant use of the adjacent Coleto Creek area. According to the Texas Archeological Sites Atlas, surveys along portions of Turkey Creek, Sulphur Creek, and Perdido Creek have identified few sites away from their confluences with Coleto Creek. Prior to the initiation of archeological survey of the Coleto Reservoir and the associated coal fired electric generating plant, the culture history of this area was poorly known. At that time, Hester (1975:8) noted that only nine sites had been recorded in Goliad County, including both prehistoric and historic sites. Survey of the Coleto Creek drainage has contributed the greatest knowledge about prehistoric use of this area. However, the region as a whole is still considered less well studied than other parts of Texas (Black 1989:39). Archeological investigations of nearby sites include several projects focused on Coleto Creek and sites on Sulphur and Perdido creeks. (Fox 1979; Fox et al. 1979; Fox and Hester 1976). Sites near to the current project area include several small localities (Fox et al. 1979:Figure 1; Fox and Hester 1976:Figure 3). These investigations demonstrated occupations spanning the Paleoindian period through the Late Prehistoric period. Archaic period sites predominate and relatively few Late Prehistoric sites have been identified (Fox et al. 1979:61). Cultural chronologies applicable to this portion of the Central Coastal Corridor and the better-known central portion of the state are summarized concisely by Nickels (2001:Table 2-1). Historically, this area has been visited by some of the earliest European visitors to the Texas coastal prairies and plains (Hester 1975:54-55, 1999). The earliest European settlements were associated with the mid-eighteenth-century Spanish establishment of the relocated Mission Espíritu Santo de Zúñiga and Presidio la Bahía.

Paleoindian chronology in Texas is similar to other parts of the western United States. Most researchers agree that the earliest accepted Paleoindian dates are approximately 11,500 
$\mathrm{BP}$, and the termination of Paleoindian lifeways is associated with the Early Holocene. The Paleoindian period is usually assigned a final date of approximately 9000-8000 BP. Local evidence of Paleoindian occupation is limited to a dated feature (Brown 1983:26, 88) that may not be cultural at Berger Bluff site (41GD30); the WPA excavations (Campbell 1976) at the deeply stratified Morhiss site (41VT1); Folsom, Yuma, and Clearfork implements were found with Pleistocene fauna (Sellards 1940) at Berclair Terrace site (41BE2); and more recent recovery at the Manahuilla Creek site (41GD50). At the Morhiss site, Angostura, Plainview, and Meserve points were recovered during this large-scale WPA excavation from an eroded terrace deposit that was $31 \mathrm{~cm}$ or less in thickness. These points were found in association with Archaic point forms and Pleistocene fauna that show evidence of alluvial redeposition. A deep (maximally $\sim 3.7 \mathrm{~m}$ thick) overlying deposit at the Morhiss sire contained abundant evidence of Archaic occupational debris, burials, hearths, and a small number of Late Prehistoric point forms and ceramics. A charcoal sample (TX-3569) taken from a thermal feature at $41 \mathrm{GD} 30$ was dated to $11,500 \pm 800 \mathrm{BP}$, but was not associated with any cultural materials. More recent examination of 41 GD50 recovered a fragment of a lanceolate point that resembles Plainview and identified a discrete buried deposit of Late Paleoindian/Early Archaic age (Texas Historical Commission [THC 2003]). Portions of the Manahuilla Creek site could still yield additional information about this time period. Because of the dearth of excavated sites, Paleoindian use of this area is poorly known (Black 1989:48).

Archaic adaptations are better known from investigations of the lower San Antonio and Guadalupe rivers (Black 1989:49-51; Fox et al. 1974; Nickels 2001:14-16) and Choke Canyon (Hall et al. 1986; Scott 1982) than in the immediate vicinity of the project area. Researchers consider these better-studied areas to likely be similar to those represented at sites in the Coleto Creek drainage. Archaic chronologies for South Texas and the Central Coastal Corridor generally agree in the dating of these periods, but researchers recognize slight differences in stylistic emphasis and inferred subsistence activities (Nickels 2001:Table 2-1, 14-16). Chronologies refer primarily to stylistic projectile point differences. The Early Archaic is dated between approximately $8000 \mathrm{BP}$ and $4450 \mathrm{BP}$, and Bell and Andice points, Guadalupe tools, and Clear Fork implements are the common horizon markers from the Central Coastal Corridor. The Middle Archaic is dated to 4450-2350 BP. Morhiss and Kinney are common Middle Archaic point forms in the Texas Central Coastal Corridor and Bulverde or Pedernales points also may appear as diagnostics. Early
Archaic sites are uncommon (Black 1989:49) and Middle Archaic sites from this region are only slightly better represented (Aten 1983:156; Black 1989:49). There is agreement that the beginning of the Late Archaic is approximately $2350 \mathrm{BP}$, but its termination is sometimes split into a Transitional Archaic (Hester 1995). The end of Late Archaic is assigned as approximately $1200 \mathrm{BP}$, but is recognized to be somewhat arbitrary (Collins 1995:385; Hester 1995:442). Ensor and Frio point forms are the common diagnostics of this period. Late Archaic sites are more common than those from the Early and Middle Archaic. The Late Archaic data from Choke Canyon are interpreted to suggest a broad-spectrum, plant-based diet associated with increased population density (Black 1989:51; Hall et al. 1986:402; Nickels 2001:15). Aten (1983:157) points out that ambiguity about Early and Middle Archaic subsistence and lifeways makes it difficult to interpret the nature of possible Late Archaic adaptive changes. The three dated charcoal samples from 41GD113 indicate a Late Archaic occupation is represented by the densest material concentration found at this site (see Chapter 5 and Appendix B).

Although the beginning of the Late Prehistoric is difficult to distinguish from the Late Archaic, by approximately 650800 BP the presence of small Scallorn and Perdiz arrow points, as well as ceramics, readily identify Late Prehistoric occupations. Late Prehistoric sites are common across Texas. Partly because of their surface proximity and greater preservation (Black 1989:52), significantly more is known about chronosequences, technology, subsistence, and lifeways. Data from Choke Canyon and 41GD4, the Berclair site, are particularly relevant to the current project area (Hester and Parker 1970; Steele 1986; Steele and Hunter 1986).

The Goliad area is one portion of Texas' early Spanish occupation that has received much archeological attention (Fox 1989:86-87). Significant investigations of historical archeology have been performed at Mission Espíritu Santo de Zúñiga (Hunziker and Fox 1998; Mounger 1959), Mission Nuestra Señora del Rosario (deFrance 1999; Gilmore 1974, 1975; Nickels 2000; Ricklis 1999), and Presidio la Bahía (Fox 1977). Historic Native Americans who used the vicinity included the Aranama, Tamique, and some Karankawan groups (Fox and Hester 1976:7; Newcomb 1961:31, Map 1). Karankawan and Coahuiltecan peoples were occasional inhabitants of Mission Rosario in Goliad (Aten 1983:30; Newcomb 1961:37; Ricklis 1996:144, 149-168). Recent work on the LaBelle shipwreck (Arnold 1996) and at Fort St. Louis highlight some of the earliest European contacts with Native American populations in this region. 


\section{Previous Archeological Investigations at $41 \mathrm{GD} 113$ and $41 \mathrm{GD} 114$}

The local landowner has apparently known about both sites 41GD113 and 41GD114 for a considerable time. The landowner, Greg Gordon, partially mechanically excavated 41 GD113 and 41GD114 because he feared that no archeological investigations of these sites would be performed prior to the realignment of U.S. Highway 59. This examination was not performed under an Antiquities Permit and TxDOT was unaware at the time of the landowner's activities. TxDOT had planned to conduct an archeological inventory that included this area during the summer of 2001. Mike Fulghum, the backhoe operator hired by CAR, had visited the site and described bulldozer excavations that extended approximately 4 feet $(\sim 122 \mathrm{~cm})$ deep on 41 GD114 (Mike Fulghum, personal communication June 25, 2002). The landowner indicated that the excavations were only 2 feet $(\sim 60 \mathrm{~cm})$ deep (Greg Gordon, personal communication June 26, 2002). Two local Texas Stewards, Bill Birmingham and the late Smitty Schmiedlin, had been invited by the landowner to observe the bulldozer investigation of 41GD113 and 41GD114. Schmiedlin reported his visit of February 17,2001 . He noted the presence of cultural deposits approximately $30-40 \mathrm{~cm}$ below ground surface at both sites containing bone fragments, a few lithics, charcoal, mussel shells, and snail shells (Schmiedlin 2001). Schmiedlin recorded UTM coordinates for both sites and assigned them provisional field numbers. Birmingham recorded that the landowner contacted him on February 14, 2001, and he and Schmiedlin visited the sites on February 15 (Birmingham 2001). His records do not indicate the nature of the excavations, but he remembered seeing the bulldozer cuts into the sites (Bill Birmingham, personal communication June 30, 2002). Schmiedlin provided his observations to Mike Davis at the THC (Fields 2002:2). As discussed subsequently, backhoe trenching during CAR's testing identified extensive impacts to the deposits on 41GD114 to a depth in excess of $1.5 \mathrm{~m}$ in some areas. Apparently, the mechanical excavations into 41GD113 were less extensive. Only a single 1-x-1-m unit (TU 5) from CAR's testing encountered disturbed deposits. TU 5 exhibited complete disturbance to a depth of $2.18 \mathrm{~m}$ that most likely represents a more limited horizontal bulldozer excavation of the northern portion of $41 \mathrm{GD} 113$.

Subsequent to Schmiedlin's report to the THC, TxDOT was alerted to the presence of these two sites and initiated investigations. Prewitt and Associates, Inc. examined both sites in June of 2001 (Fields et al. 2002:54) as part of an impact evaluation performed for TxDOT in anticipation of the proposed road realignment project. In October of 2001, Prewitt and Associates performed shovel test survey and official recording of both sites (Fields 2002:2-4; Fields et al. 2002:54-55). Six shovel tests were excavated on 41 GD113 and another six on 41GD114 during this investigation (Fields et al. 2002:54-55). Trinomial assignments were made from information collected during the October survey. At that time, Prewitt and Associates' staff did not see any evidence of the landowner's bulldozer cuts in 41GD113 and 41GD114. Road construction and maintenance disturbance adjacent the northern portion of $41 \mathrm{GD} 113$ was estimated to have affected approximately $30 \%$ of the site. A single biface fragment, debitage, and snail shells (Rabdotus sp.) were noted in the drainage ditch associated with the road. It was estimated that 41GD114 was probably nearly $100 \%$ intact (Fields 2002:3; Fields et al. 2002:54). Both locations were considered likely to contain buried archeological deposits of unknown significance (Fields 2002:4; Fields et al. 2002).

Prewitt and Associates excavated six shovel test units within each of these sites. Their 2001 shovel tests are identified by the designation "ST" on Figures 2-2 and 2-3. Five of the shovel tests on 41GD113 were excavated to a depth of 100 $\mathrm{cm}$ below the modern ground surface and the sixth unit was terminated at $80 \mathrm{~cm}$ below surface. The shovel tests documented the presence of a relatively thick upper solum containing artifacts (Fields 2002:3; Fields et al. 2002:54). Twenty-nine pieces of debitage, four bone fragments, and two mussel shell umbo fragments were collected from Shovel Tests 1-5. The highest density was identified in the two southern shovel tests. Shovel Test 2 (ST 2) contained eight artifacts and ST 4 contained 13 items (Figure 2-2). Much of the assemblage (13 pieces of debitage and all of the large bone fragments) was recovered from $60-100 \mathrm{~cm}$ below surface. On 41 GD114 (Figure 2-3), ST 2 and ST 4 were the only shovel tests from Prewitt and Associates' work that fall within the TxDOT right-of-way. Neither shovel test contained artifacts. Though outside the right-of-way, STs 1 and 6 contained lithics and animal bone.

Both of these sites were considered to contain deposits that had the potential for good contextual relationships that could address issues of anthropic and geomorphic formation of pimple mounds in this region (Abbott 2001:91-97). Based on Prewitt and Associates' survey, additional testing was recommended to determine the potential eligibility of $41 \mathrm{GD} 113$ and 41GD114 for listing on the NRHP and designation as SALs. 


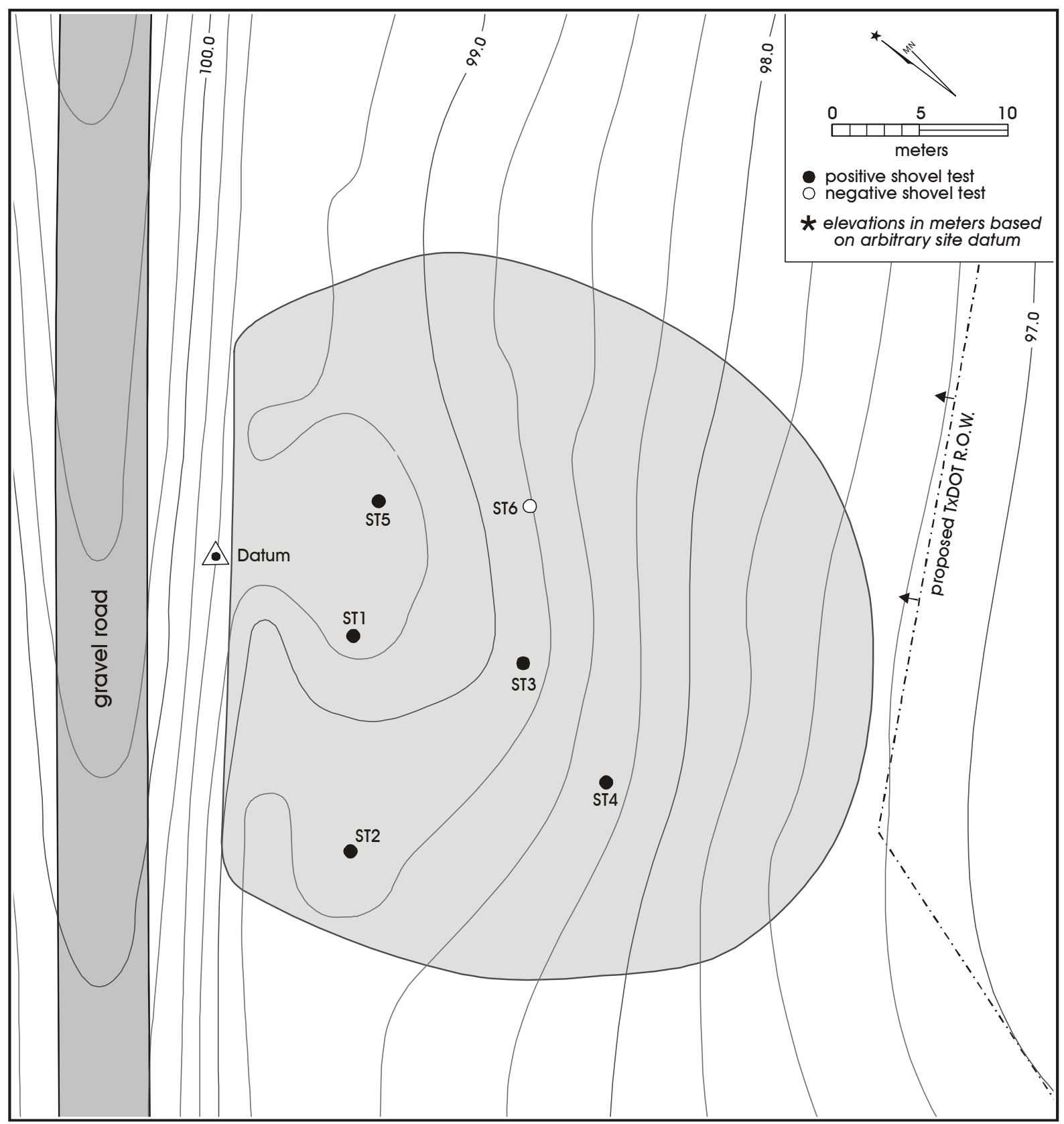

Figure 2-2. Map of site 41GD113. 


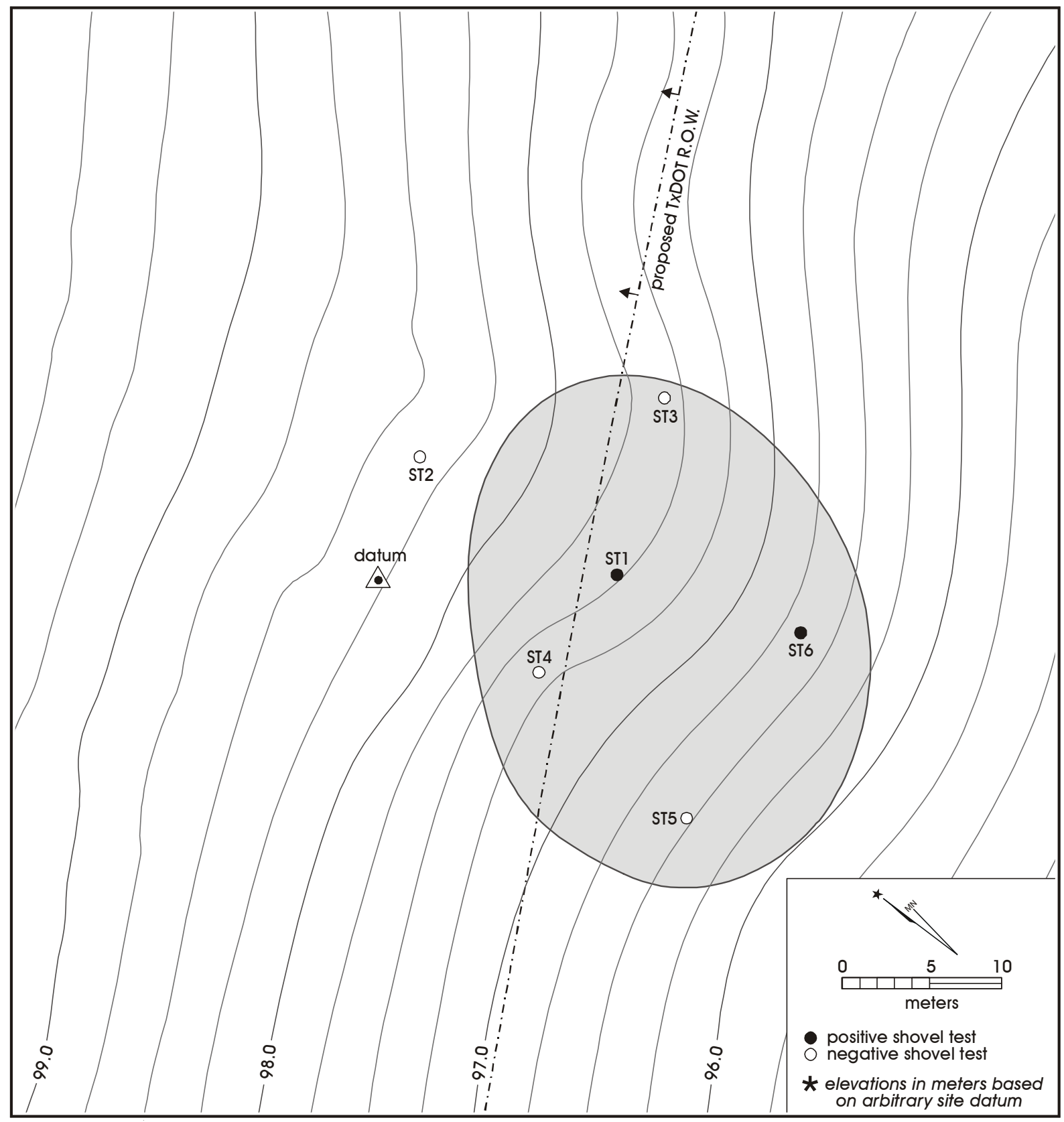

Figure 2-3. Map of site 41GD114. 


\section{Chapter 3: Research Design and Methods}

Shovel testing performed by Prewitt and Associates (Fields at al. 2002:54-55) identified the presence of buried cultural deposits at 41GD113 and 41GD114. Additional evaluation of both sites was necessary to determine their research significance and their potential designation as SAL and NRHP eligible properties. Controlled excavations were performed to obtain sufficient information to evaluate site significance and the need for any additional mitigation efforts. Archeological testing was performed to (1) determine whether intact deposits were present, (2) determine the spatial and stratigraphic (taphonomic) integrity of the archeological deposits, and (3) evaluate the cultural chronology of the archeological deposits. A combination of hand-excavated test units and backhoe trenching provided opportunities to examine the sites for potential buried features, perform geoarcheological investigation of site formation, and obtain sufficiently controlled samples of artifacts, charcoal, and specialized soil samples for laboratory analyses. Prior to information about the landowner's excavations, three backhoe trenches were proposed to investigate 41GD113 and five were planned for 41GD114. Inspection of the sites at the initiation of fieldwork identified the destruction of much of 41GD114 and that most of the previously identified site area of 41GD114 was outside of the staked right-of-way. In response to these conditions, CAR altered the excavation emphasis to more thoroughly examine $41 \mathrm{GD} 113$ and less intensively investigate the more disturbed 41GD114. Five backhoe trenches were considered necessary to investigate $41 \mathrm{GD} 113$ and three trenches were excavated on 41GD114. It was anticipated that a maximum of $5 \mathrm{~m}^{3}$ of controlled test excavations would be necessary to make determinations about the potential significance of 41GD113 and that $3 \mathrm{~m}^{3}$ were sufficient to characterize 41GD114. All 1-x-1-m test excavation units were placed to sample different areas of each site, to maximize recovery of artifacts, and permit evaluation of potential features on the sites.

\section{Archeological Field Methods}

\section{Backhoe Trenches}

The first effort involved the excavation of five backhoe trenches on 41GD113 and three trenches on 41GD114. Backhoe trenches were placed on both sites to provide two kinds of information. Within relatively unknown deposits, backhoe trenching is an effective means to determine the nature of the archeological deposits at a site by providing large exposures that allow critical views of soils and sediments necessary to address site formation, the potential presence of discrete archeological horizons, stratified deposits, features, or disturbances that are difficult to identify through testing using a small number of scattered $1-x-1-m$ test units. Backhoe trenching also provides the most useful geoarcheological testing method to identify the nature of sedimentary and soil deposits at an archeological site. The specific sampling rational for each of the two sites investigated is discussed below. Backhoe trenches were established at approximate grid locations in reference to an arbitrary datum. All trenches were oriented to an arbitrary site grid (referenced to magnetic north). A professional backhoe operator with extensive archeological experience excavated the trenches.

Backhoe trenches on 41GD113 were placed along the eastern and southwestern portions of the site (Figure 3-1). Backhoe trenching was not performed within the central portion of 41GD113 because of the dense cover of trees that would have necessitated significant disruption of soils in the upper portion of the profile, where most of the archeological artifacts are located. Backhoe trenches were excavated across the northern portion of 41GD114 (Figure 3-2). The entire southern half of the site is outside of the current right-of-way, and the southern area of the site within the project boundary was moderately wooded. As with 41GD113, trenching was not performed where tree roots were likely to provide poor profiling opportunities.

Each backhoe trench (BHT) was excavated to a target depth of $1.5 \mathrm{~m}$ below the modern ground surface. This was below the anticipated maximum depth of impact for the roadway improvements (Tim Meade, TxDOT Staff Archeologist, personal communication July 24, 2002). While the majority of all excavations did not exceed this depth, portions of three trenches were excavated slightly deeper than the target elevation. At $41 \mathrm{GD} 113$, BHT $2 \mathrm{had}$ an area that was $1.6 \mathrm{~m}$ deep and a portion of BHT 4 was $1.57 \mathrm{~m}$ deep. A small part of BHT 1 on 41GD114 was excavated to $1.6 \mathrm{~m}$ below the modern ground surface. There were no indications that any archeological deposits were present below the maximum depth of each trench. All backhoe trenches were examined by professional geoarcheologists (see Appendix A) and by the project archeologist (Greaves). Two of the three trenches (BHTs 1 and 2) on 41GD114 (Figure 3-2) showed extensive disturbance from the recent bulldozing noted previously. These two trenches were not fully described because the 


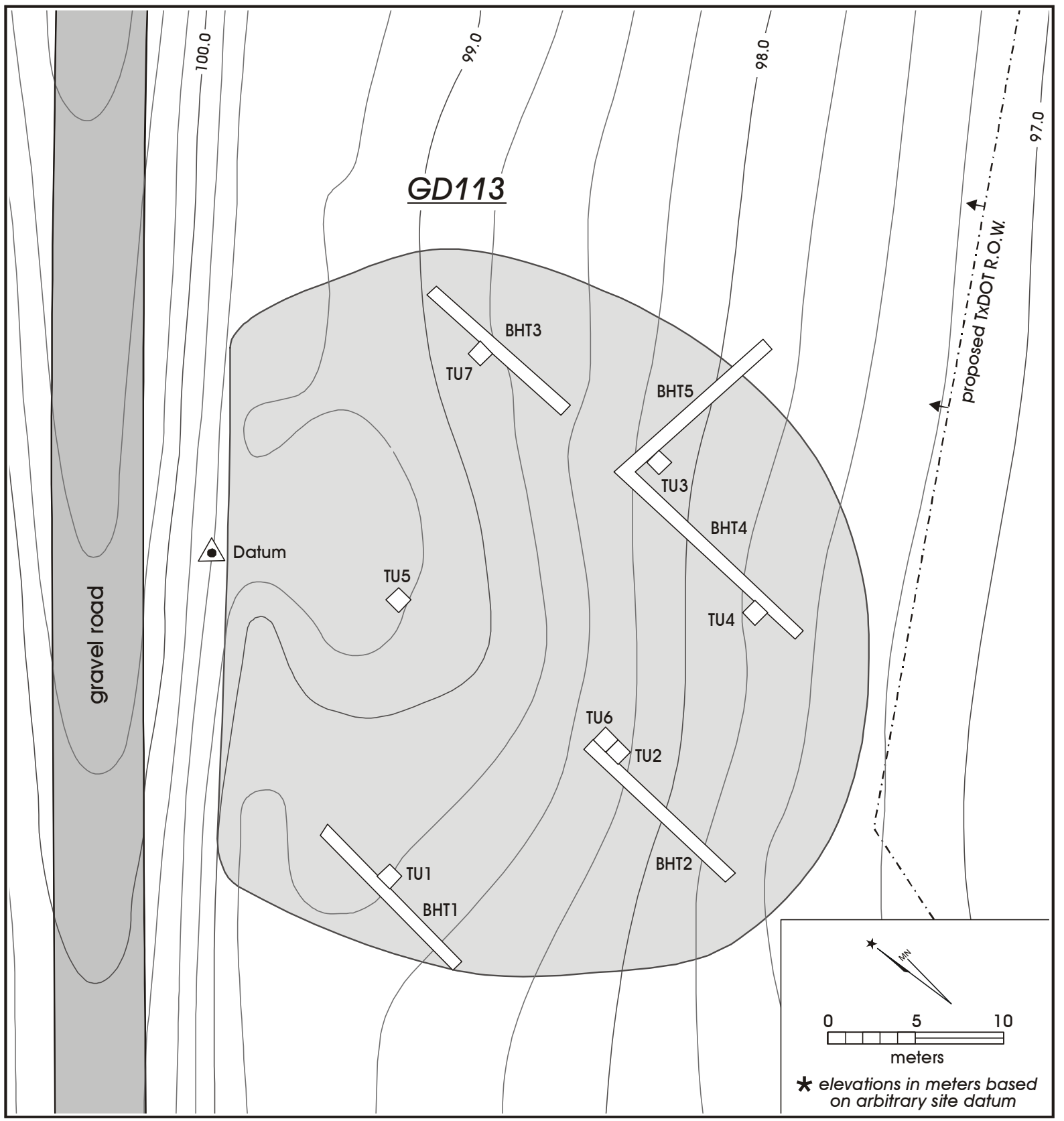

Figure 3-1. CAR testing at 41GD113.

exposed deposits were primarily backfill from mechanical excavation performed in February 2001 prior to archeological investigations. Corey Crawford performed field descriptions of trenches 1, 2, 3, and 4 on 41GD113 (Figure 3-1; Appendix A) and trenches 2 and 3 on 41GD114 (Figure 3-2). In addition, all five backhoe trenches on 41GD113 and one on 41GD114 (BHT 3) were profiled, described, and sampled for magnetic sediment susceptibility.
Profiling involved standard soil profiling methods employed in soil science (Soil Survey Staff 1975:459-481, 1993:117$168,172-180,184-193)$. A profile was drawn for one face of each backhoe trench. Soil descriptions were completed for every identified sedimentary and soil horizon from each profile. Color slide photographs were taken of all profiles. Field observations included soil texture, consistence (wet and dry), presence and morphology of clay films, grain 


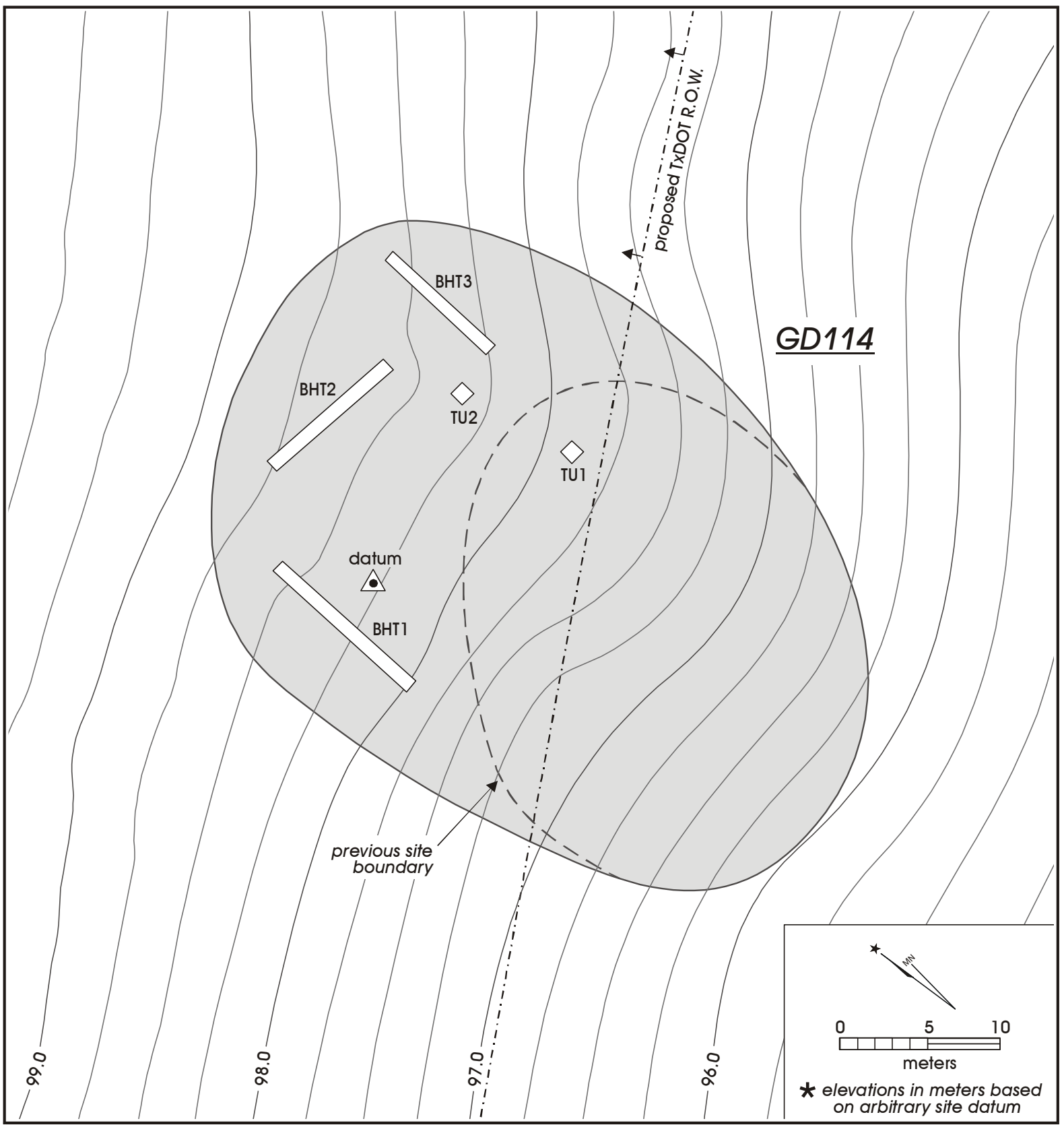

Figure 3-2. CAR testing at 41GD114.

coatings, structure, abundance and size of roots, abundance and size of pores, $\mathrm{HCl}$ reaction, horizon boundaries, and Munsell colors (wet and dry). These attributes permit designation of the soil and sedimentary horizons in standard soil nomenclature (Soil Survey Staff 1993:117-135). The abundance and size of clasts also was recorded.
The only specialized soil samples were those collected for magnetic susceptibility analysis. Sediment samples for soil magnetic susceptibility (MS) analysis were taken at discrete 5 -cm intervals within a column from each profile. Standard sized samples were taken from a sample column in each of five trenches on 41GD113 and one trench on 41GD114. 
Samples were collected without the use of metal tools as these may affect the magnetic susceptibility signatures. Soil susceptibility samples were collected for use in identifying paleosols, surfaces, zones of organic enrichment, or heating that may relate to past human activities.

\section{Controlled Excavations}

Following preliminary examination of the backhoe trenches, test unit (TU) excavations were initiated adjacent to trench exposures on 41GD113. Because of the amount of disturbance encountered at 41GD114, test units were placed in areas with a higher probability of encountering intact cultural deposits away from trenches. Placement of test units was determined judgmentally on the basis of the results of the previous shovel testing and geomorphic interpretation derived from the backhoe trenches. All standard 1-x-1-m test units were located on an approximate grid established using tapes referenced to an arbitrary datum at each site. Areas of the sites with deep deposits and containing a high diversity of artifacts were targeted. Seven 1-x-1-m test units were dug on 41GD113 (Figure 3-1) and two test units were excavated on 41GD114 (Figure 3-2). All units on 41GD113 terminated either at the contact with the Pleistocene Bt soil horizon or the older calcic soil. The test units on 41GD114 were excavated to contact with bedrock (TU 1) or an extensive gravel deposit (TU 2).

All 1-x-1-m test units were excavated in 10-cm levels using shovel skimming and careful troweling techniques. Elevations were referenced to fixed subdatum points representing the highest corner of each excavation unit (except TUs 2 and 6 on 41GD113). Because of the variable ground surface across each site, these elevations are not completely comparable between the different excavation units. On 41GD113, TUs 2 and 6 (see Figure 3-1) did employ the same subdatum reference to measure excavation elevations and vertical positions of mapped items. This subdatum was located 10$14 \mathrm{~cm}$ above the ground surface of these adjacent excavation units. Although slightly variable, soil profiles were similar across the site, and elevations reflect comparable vertical positions for artifacts. For the lithic analysis, vertical elevations of all excavation levels and piece-plotted lithics were adjusted to ground surface measurements so that their frequency distributions are comparable between all of the excavation units on 41GD113.

All soils and sediments removed were screened through 1/4-inch hardware cloth. All cultural artifacts were reserved for laboratory analyses. All natural gravel clasts, mussel shells, and snail shells were saved from two of the test units on 41GD113 (TUs 2 and 3). The gravels provide significant site formation information about the dynamics of sedimentological history of the different sedimentary units at this site. The pelecypod and gastropod remains show no evidence of human modification as food remains, but can provide significant information about site formation. The large number of both gravel and shell clasts within some levels suggested that a sampling strategy of total collection of these materials from just two test units would provide an adequate sample for analyses and would not represent an excessive field (and laboratory) commitment for this project. Standard level forms were used to record measurements, collected artifacts and samples, descriptions of sediments and archeological context, and to map any piece-plotted artifacts.

A soil auger was present if indications suggested a need for preliminary confirmation that deeply buried archeological deposits were present on either 41 GD113 or 41 GD114. None of the backhoe trenches contained any archeological horizons below the depth of anticipated hand excavation. Screening of test units provided secure information that artifacts were not present, or they were represented only at low densities (likely due to bioturbation), in the lowest levels excavated. Augering was performed only in TU 5 on $41 \mathrm{GD} 113$ to determine the maximum extent of mechanical disturbance in this area of the site.

Charcoal samples were collected through piece-plotting in TUs 2 and 6 on 41 GD113 (Figure 3-1). The context of these two units provided the densest artifact recovery and suggested proximity to a thermal feature or activity area. Eight samples of charcoal were collected from contexts 52 $\mathrm{cm}$ to $118 \mathrm{~cm}$ below the reference subdatum in TU 2 . Three charcoal samples and two hackberry seeds were pieceplotted in TU 6 between 90 and $100 \mathrm{~cm}$ below the subdatum. Three samples (Beta Sample Nos. 174045, 174046, and 174047) were submitted for dating. Those results are discussed in the following chapter.

All cultural artifacts were collected from the screened soils and sediments and separated by class. All historic debris is probably less than 50 years old, but was retained for analysis of potential disturbances of deposits. Debitage, bones, and fire-cracked rock made up the overwhelming majority of cultural debris encountered. Charcoal was collected opportunistically from screens as potential macrobotanical identification samples. The density of artifacts in TUs 2 and 
6 on 41GD113 warranted the piece-plotting of larger items ( $>5 \mathrm{~cm}$ maximum dimension) to determine the possibility of identifying ancient land or occupation surfaces. Thirtynine items were piece-plotted in TU 2, and 37 items were piece-plotted in TU 6 (Figure 3-1).

The presence of partially articulated remains of a canid discovered in 41GD113 initiated careful evaluation of the depositional context of these bones. Piece plotting of larger natural clasts, fire-cracked rock, lithics, bone, and charcoal was performed in the adjacent TUs 2 and 6 . This involved measurement of $\mathrm{x}$ and $\mathrm{y}$ horizontal coordinates and $\mathrm{z}$ elevational coordinates relative to the subdatum for these two units. All piece-plotted artifacts were drawn on excavation maps and retained separately for analysis and curation.

All of the natural gravel clasts, mussel shell, and snail shell from each excavation level in TU 2 and TU 3 on 41GD113 were collected from the screens for complementary site formation analysis. None of the mussel or snail shells are considered to be cultural debris. These appear to be natural background inclusions within these sediments and soils and do not represent food debris (see Chapters 4 and 5). The abundance of these materials was noted in the other test units, but snail shells, mussel shells, and unmodified gravels were not collected from any other excavation units.

Photographs (black and white and color slide images) were taken of characteristic and unique sections of each backhoe trench and of the dense archeological remains in TU 2 on 41GD113. A standard photographic log was used to record information regarding the date, photographer, subject of each photographic image, and direction of the view.

The locations of all backhoe trenches, excavation units, temporary datums, and all previous shovel tests were recorded for both sites using hand-held Trimble Geo Explorer 2 Global Positioning System (GPS) units. Additionally, more precise mapping and recording of the site area and excavations was performed for both sites using a Sokkia Set 6E total data station.

\section{Laboratory Analyses}

Analyses of materials excavated focused only on particular classes of artifacts. The initial research design did anticipate additional analyses, but based on recovery, the inferred lack of significance of the two sites, and the extensive disturbance in portions of the sites, it was determined in consultation with TxDOT that only a portion of the original projected analyses for these sites was warranted. Laboratory analyses focused on descriptive and basic attributes of the lithic assemblages, magnetic soil susceptibility, and the frequencies of natural clasts in the two sample units (TUs 2 and 3) on $41 \mathrm{GD} 113$.

Subsequent to laboratory analyses, natural gravels, snail shells, and mussel shells were discarded. Soil residues from the magnetic soil susceptibility samples from $41 \mathrm{GD} 113$ and 41 GD114 also were discarded after analysis. All other materials from $41 \mathrm{GD} 113$ were curated in accordance with TxDOT standards. No materials from 41GD114 were curated, given the extensive disturbance documented at this site.

\section{Lithics}

Understanding technological behavior from archeological sites focuses on lithic remains. Analytic emphasis on lithic debitage is significant because it provides large sample sizes and provides information about manufacturing, use, recycling, and discard of components of technical systems. Dramatic advances have been made in debitage studies that provide robust information about production and use of tools (Bamforth 1986; Bleed 1986; Bradley 1975; Collins 1975; Dibble 1988; Keeley 1980; Kuhn 1991, 1994; Wiant and Hassan 1985). There is only a small tool inventory from $41 \mathrm{GD} 113$ and none from 41GD114. Although this detracts from the research significance of these sites, it is still possible to use this small debitage sample to develop inferences about past technology. Because debitage usually represents the largest sample of cultural material it also can inform about the depositional history of archeological deposits. Given the range of geoarcheological, temporal, and taphonomic data available for 41GD113, a range of lithic analyses can productively be performed on this assemblage of 866 pieces of debitage. The small sample size from $41 \mathrm{GD} 114(\mathrm{n}=65)$ makes comparable characterization problematic. Minimal, basic descriptive analysis of this assemblage was performed.

Standard recording of lithics from 41GD113 and 41GD114 involved counts, weights, rough classes of raw materials represented, incidence of heating, flake classification, flake completeness, cortex presence, and flake size. In addition to recording technological attribute data, the vertical and horizontal distribution of debitage was analyzed. Curation of the assemblage from $41 \mathrm{GD} 113$ will permit potential future analyses of the lithics from this site. 


\section{Magnetic Sediment Susceptibility}

Magnetic susceptibility (MS) of sediments can be a useful analytic tool for identifying past human activity. This method is especially productive in sediments and soils that do not have readily apparent stratigraphy and where the nature of potential palimpsest deposits is ambiguous (Leigh 2001:286; Mauldin 2001:119-120; Mauldin and Broehm 2001:17-19). This is an increasingly common micromorphological approach in geoarcheology (Macphail and Cruise 2001:242, 248, 261). While signature values from MS analyses are related both to the organic content of sediments (Collins et al. 1994; McClean and Kean 1993; Singer and Fine 1989) and the decay of those materials (Reynolds and King 1995), it appears that heating of sediments may also be a major component of higher MS values (Crowther 2003; Morinaga et al. 1999; Rasmussen 2001). Variance in values produced from analysis of samples provides relative information about the comparative differences in past organic content and heating of sediment within adjacent sampled areas of a site. This analysis can identify vertical and horizontal areas that have experienced heating and organic enrichment, assist in determination of the stratigraphic position of buried soils, and help assess the integrity of archeological deposits. Horizontal comparisons of MS data can permit comparisons of the distribution of natural soil horizons of interest and variation in archeological occupation intensity within a single site or to identify sites across a broad area (Mauldin and Broehm 2001:17-20). This is an especially useful technique for examining deposits at 41GD113 and 41GD114. The lack of stratigraphy in the artifact bearing A horizons and the sandy texture of these sediments make definition of sedimentary or cultural horizons difficult. Although large sediment and soil units can be readily distinguished, finer-scale divisions in the vertical artifact distribution is problematic. MS analysis also can identify areas that have experienced significant thermal events to assist in finding features or houses (Crowther 2003; Kvamme 2001:357; Rapp and Hill 1998:182-185).

\section{Natural Clasts}

\section{(Gravel, Mussel Shell, and Snail Shell)}

All natural clasts from excavation units TU 2 and TU 3 on 41GD113 were collected to assist investigations of site formation. Only the weight of these materials was recorded. Because gravels vary in size and shells become fragmented during excavation and laboratory processing, weight is the most useful measure for use in comparisons. Quantifying a sample of these materials has several analytic uses. Gravels are entrained and deposited in direct correlation with the dynamics of streamflow and inform about energetic levels, periodicity of high volume flow, and the proximity of archeological deposits to the stream channel (Waters 1992:115-184). Pelecypods that are not food refuse become incorporated into sediments through alluvial deposition or by animal transportation (Claassen 1998:53). They offer another opportunity to examine site formation processes that can affect cultural artifacts, features, and their associations. Gastropod remains may be valuable to identify past soil surfaces, paleoenvironments, and small-scale spatial variability in archeological deposits (Claassen 1998:122-126). 


\section{Chapter 4: Results of Archeological Testing}

\section{$41 G D 113$}

This site is located on the southern margin of an older high terrace tread and the northern margin of the next youngest set of terrace surfaces. The southern end of the site is situated on the scarp to another lower terrace. Geoarcheological investigations of backhoe trenches at this site indicate that two major buried terrace settings are represented at 41GD113. There is a concentration of vegetation at this location. Honey mesquite (Prosopis juliflora var. glandulos $a$ ) is the dominant tree on the site. There also are oaks (Quercus sp.), black brush (Acacia rigidula), and huisache (A.farnesiana) present. Prickly pear (Opuntia sp.) are commonly associated with these areas of denser vegetation. The majority of the environment is broken woodland with significant areas of grassland, probably maintained through use of this area as cattle pasture. The grassland dominance is apparent in the overthickened A horizons seen in the backhoe trenching and test unit excavations. The presence of trees is associated with the slight elevational rise at 41GD113, although the geoarcheological investigations indicate there is no distinction between this higher area and other portions of the terrace.

\section{Geoarcheological Investigations}

As discussed in the previous chapter, five backhoe trenches and seven $1-\mathrm{x}-1-\mathrm{m}$ test units were excavated on this site (see Figure 3-1) to determine the nature of the subsurface deposits. The site is situated in alluvial terrace sediments overlying older Bk and Bt deposits. Artifacts were identified only from the overthickened A horizons and thin B horizons. These recent soils rest above a series of Bt soils. Several trench profiles indicated an unconformable contact between the $\mathrm{Bt}$ and $\mathrm{B}$ horizons. The lowest units exposed in these backhoe trenches are calcic horizons with significantly greater $\mathrm{CaCO}_{3}$ accumulations than any overlying sedimentary units. Soils were described for BHTs 1-4 on 41GD113 by professional geoarcheologists (see Appendix A). This work is supplemented by complete profiles drawn for BHTs 1-5. Additional descriptions of these soils and sediments by the project archeologist allowed more fine-grained resolution of the sedimentary and pedogenic history of these sites.

\section{Backhoe Trench 1}

Backhoe Trench 1 (BHT 1) was excavated on the western side of the site at the apparent margin of the slight topographic rise where the site is located (see Figure 3-1). This trench was approximately $11.85 \mathrm{~m}$ long and maximally $1.4 \mathrm{~m}$ deep. The trench was oriented north-south $\left(0^{\circ}-180^{\circ}\right.$ from magnetic north) and the eastern wall was drawn and the soils described (Figure 4-1). A magnetic susceptibility sample column also was collected from the eastern wall, approximately $3 \mathrm{~m}$ south of the northern end of the trench. Twenty-two samples were collected for MS analysis (see Appendix C).

The soils and sediments in BHT 1 are typical of most of the other trenches excavated on 41 GD113 (Table 4-1). There is an overthickened group of A horizons $60-70 \mathrm{~cm}$ thick. This is underlain by a Bt horizon, $25-40 \mathrm{~cm}$ thick, overlying two $\mathrm{Bk}$ horizons. The A horizons are fine, well-sorted loamy sands that are black (10YR2/1-10YR2/2) to very dark grayish brown (10YR3/1-10YR3/2) in color. MS values from the upper 50 to $55 \mathrm{~cm}$ of this profile are consistent with a series of organic enriched, poorly defined horizons, with the lower portions of the profile showing no enrichment (see Appendix C, Figure C-1). The Bt horizon is a fine, well-sorted sandy loam with a noticeable clay bulge. Both $\mathrm{Bk}$ horizons are fine, well-sorted sandy loams that are yellowish brown (10YR5/4-10YR6/4) to very pale brown (10YR7/4) in appearance. Unlike most of the profiles at 41GD113, calcium carbonate was identified in all horizons. BHT 2 was the only other trench containing $\mathrm{CaCO}_{3}$ throughout the entire soil profile above the Bk horizons. All of the soil units in BHT 1 are parallel sedimentary units with no apparent disturbances. TU 1 was excavated off the eastern side of the trench. Most of the artifacts in TU 1 were found in the $\mathrm{A} 3$ and uppermost $\mathrm{A} 4$ horizons. No artifacts were recovered in the $\mathrm{Bt}$ soil unit.

\section{Backhoe Trench 2}

This trench was located in the south-central portion of the site (see Figure 3-1). Backhoe Trench 2 was $11.55 \mathrm{~m}$ long and was excavated to a maximum depth of $1.6 \mathrm{~m}$. The northern end of the trench was directly west of the ST 4, the shovel test with the highest density of artifacts recovered during the Prewitt and Associates testing effort. BHT 2 was oriented north-south $\left(0^{\circ}-180^{\circ}\right.$ from magnetic north $)$ and the eastern wall was profiled, described and sampled (Figure 4-2). This trench provided the most robust evidence for the buried archeological deposit at 41GD113. An apparent concentration of fire-cracked rock (FCR) was identified in the eastern wall of this trench. This concentration was 


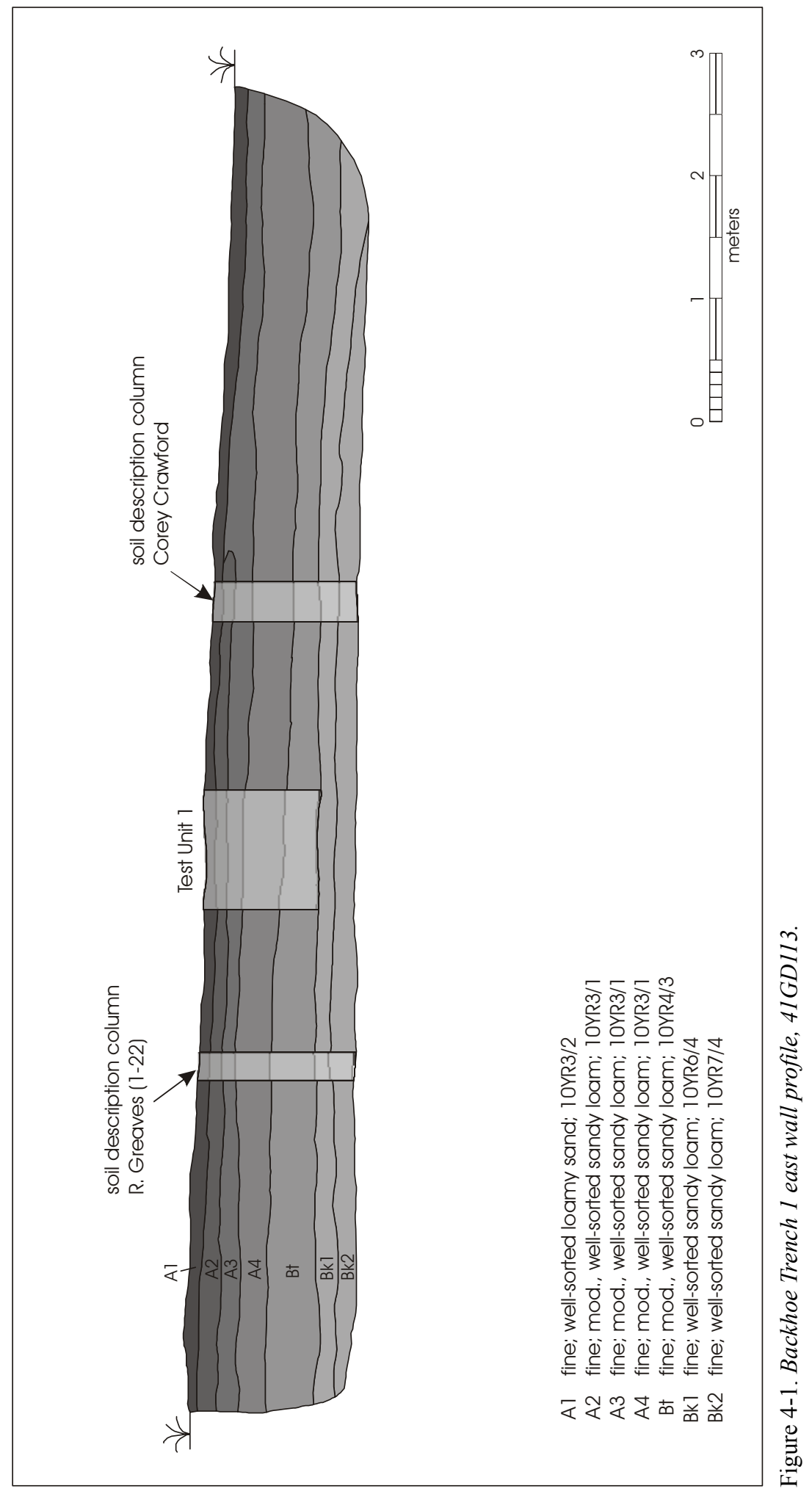




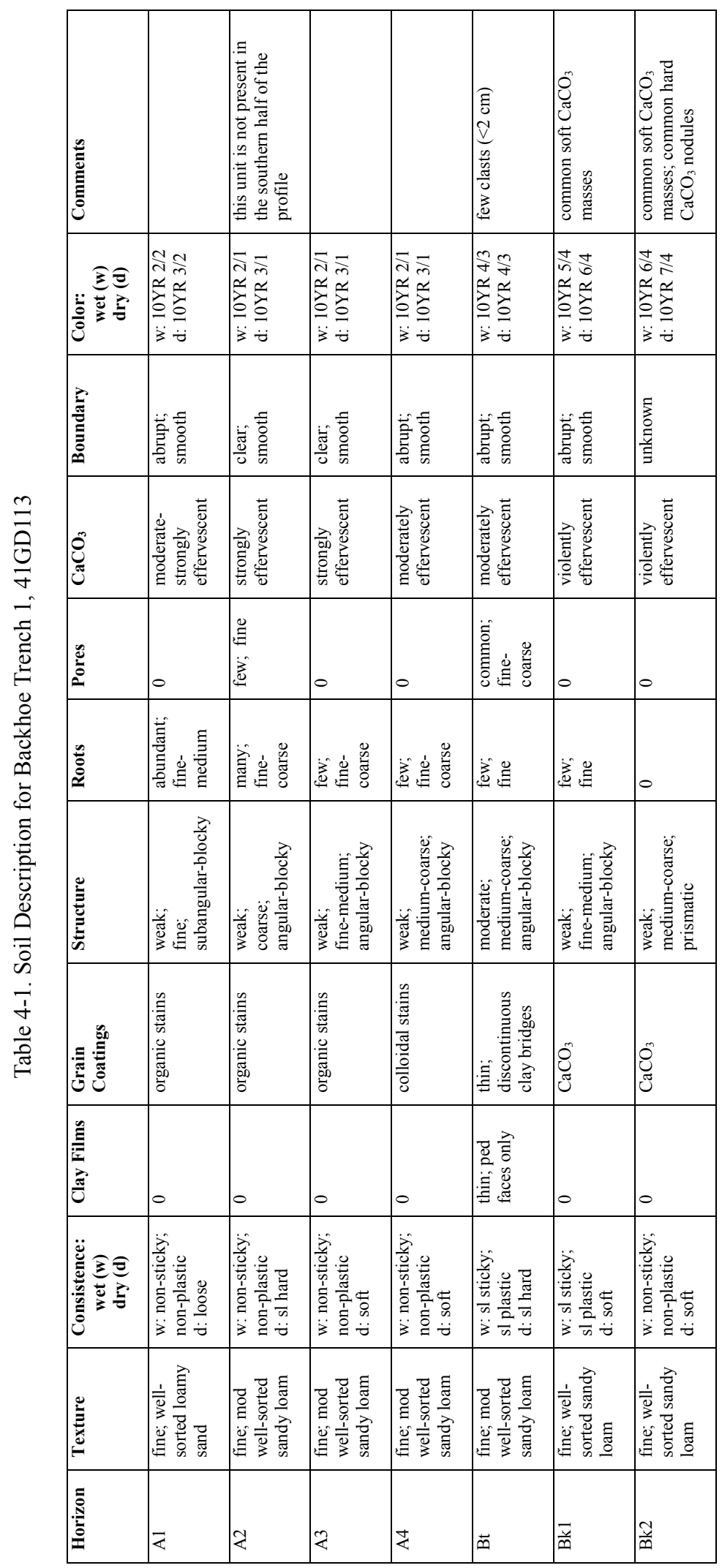


designated Feature 1. A detailed profile of this concentration is presented in Figure 4-3. This figure also represents the western walls of TU 2 and TU 6 as exposed in the backhoe trench profile. These two adjacent test units were excavated off the eastern side of this trench through this apparent feature to investigate whether the FCR concentration represented a possible buried intact feature. A magnetic susceptibility column of 28 samples was collected from the eastern wall, $3 \mathrm{~m}$ south of the northern end of the trench.

The soils in BHT 2 are similar to BHT 1 (Table 4-2). The A horizons in BHT 2 are $60-85 \mathrm{~cm}$ thick and are fine, wellsorted loamy sands. There is extensive bioturbation in the A2 horizon. Recent animal burrows and krotovina were common throughout the A horizon soils in both TU 2 and TU 6 . The accumulation of rock visible in the profile and identified during excavations rests on the approximate contact between the A4 and B horizons. The B horizon contains numerous gravel clasts. This is a poorly sorted sandy loam. The Bt horizon is a poorly sorted sandy clay loam that exhibits rubification at the northern end of the trench but appears more brown in the southern two-thirds of BHT 2. The clasts in the B and Bt horizons indicate a sedimentary difference between the B horizons and the A horizons depositional events. The higher energy B units contain a much greater volume of clasts than were encountered in the A horizons. The accumulation of FCR and natural clasts at the base of the A horizons appears to represent evidence of some surface stability at the top of the current $\mathrm{B}$ horizon prior to deposition of the sands that form the A1-A4 solum. The magnetic soil susceptibility values document two possible areas of enrichment, one at roughly $77 \mathrm{~cm}$ below surface (bs), and a second at about 90 cmbs (see Appendix C, Figure C-3). Either of these two peaks may be associated with the top of the B horizon, though reference to Figure 4-2 suggest that in the area of sampling, the upper peak is most likely this stable surface. Dating of three charcoal samples (discussed in detail in Chapter 5) indicates that the A4 and B horizons span approximately 200 years of the Late Archaic. The Bk horizon underlying the $\mathrm{Bt}$ is a fine, well-sorted silt loam that is visibly lightened from its $\mathrm{CaCO}_{3}$ content. All horizons showed strong-violent effervescence.

\section{Backhoe Trench 3}

Backhoe Trench 3 was excavated in the northeastern portion of the identified site area (see Figure 3-1). This trench was $10.55 \mathrm{~m}$ long and was maximally $1.5 \mathrm{~m}$ in the deepest portion. BHT 3 was oriented north-south $\left(0^{\circ}-180^{\circ}\right.$ from magnetic north). The eastern wall was profiled and described
(Figure 4-4). Twenty-seven soil susceptibility samples were collected from this exposed profile in a column approximately $2.4 \mathrm{~m}$ south of the northern end of the trench.

BHT 3 presents a relatively simple sequence of soils that reinforce the information seen in BHTs 1 and 2 (Table 4-3). The A horizons are shallower in this trench than in those farther south. A1-A4 occupy the uppermost $40-50 \mathrm{~cm}$ of the profile. Magnetic susceptibility values are consistent with this characterization of the A horizons, with an upper peak at roughly $37.5 \mathrm{cmbs}$ (see Appendix C, Figure C-4). Two B horizons extend from approximately $50-70 \mathrm{cmbs}$. The $\mathrm{Bt}$ horizons underlie those to a depth of approximately 115$120 \mathrm{cmbs}$. The calcic horizons were encountered under the $\mathrm{Bt}$ soils. The sequence of B and Bt horizons are associated with a dramatic increase in natural clasts. The largest clasts $(<5 \mathrm{~cm})$ were noted in the B1 horizon. The B2 contains a higher density of gravels that are slightly smaller $(\sim 5-20$ $\mathrm{mm})$. In the $\mathrm{Bt} 1$ and $\mathrm{Bt} 2$ horizons there are fewer clasts and none larger than $5 \mathrm{~mm}$ were identified. There is an erosional unconformity between the Bt2 and the underlying Bk1 horizon. Nordt and Crawford (Appendix A) do not comment on this feature. During a visit to the site, Wes Miller, from the USDA Natural Resources Conservation Service in Victoria, Texas, observed this feature and confirmed that it represented a very distinct erosional unconformity (Wes Miller, personal communication July 30, 2002). Given the alluvial context of these deposits, this probably represents erosion from a small channel. Both Bk units are fine and well-sorted with no apparent clasts. The B1 and B2 horizons are only $20-30 \mathrm{~cm}$ thick. The Bt horizons are much thicker, $35-75 \mathrm{~cm}$ thick. There is an interruption in the Bk1 unit in the approximate center of the trench. It is uncertain what caused this undulation in the Bk1 surface. There were no horizons above the $\mathrm{Bk} 1$ that produced any effervescence indicating $\mathrm{CaCO}_{3}$ presence in the sediments.

\section{Backhoe Trench 4}

BHT 4 was excavated on the southeastern side of the site (see Figure 3-1). With BHT 1 and BHT 2, it forms a sequence of three north-south trenches that examine the sediments and soils of the entire southern boundary of 41GD113. BHT 4 is directly south of BHT 3 and is perpendicular to BHT 5 . Backhoe Trenches 3, 4, and 5 form a detailed view of the eastern portion of this site. BHT 4 did not initially connect with BHT 5. When first exposed as a 10-m-long trench, the juncture of the $\mathrm{Bw}$ horizon and an erosional feature suggested that additional excavation at the northern end of the trench extending it to intersect BHT 5 would identify the relationship between the $\mathrm{Bw}$ and that erosional event. 


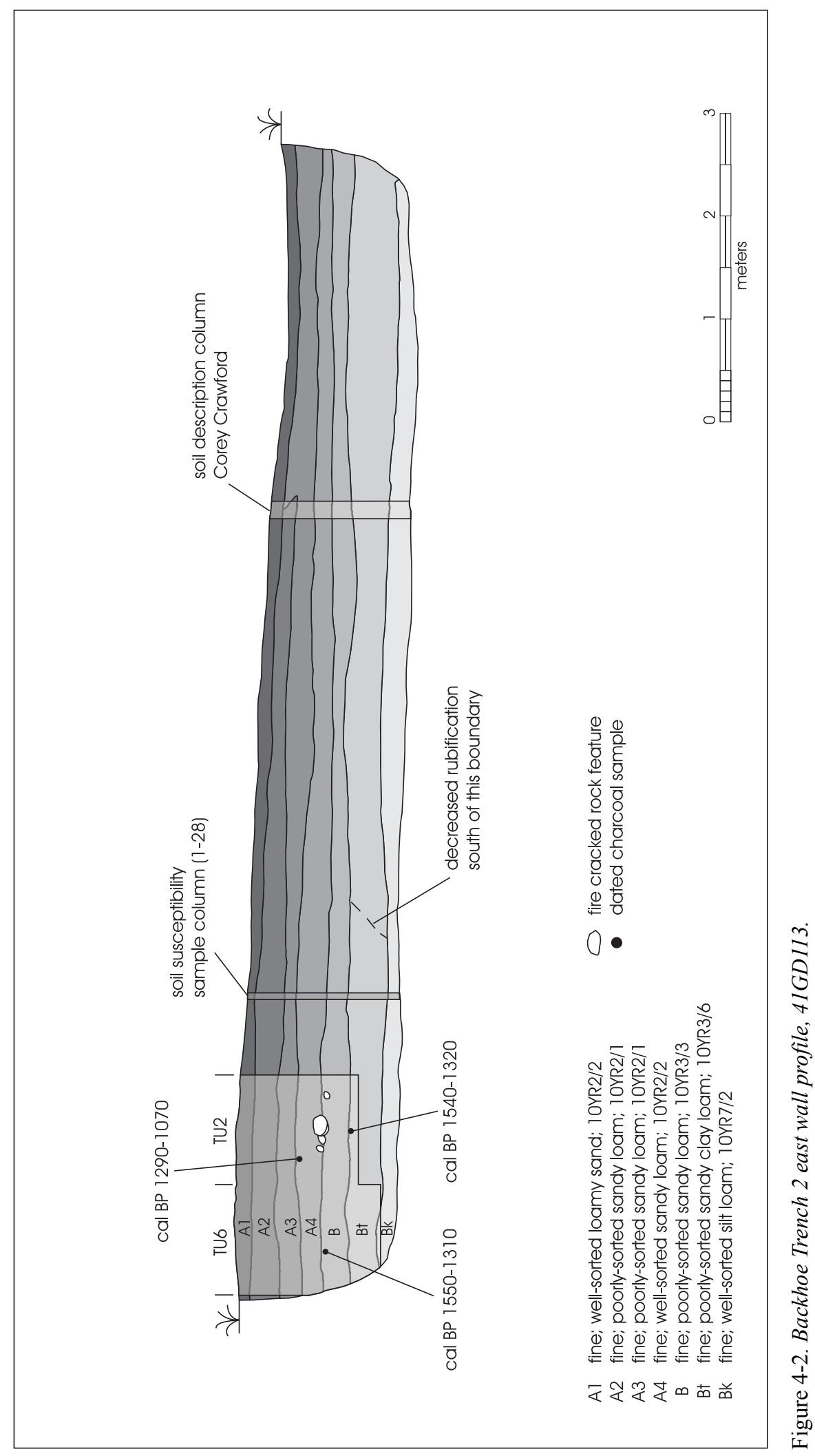




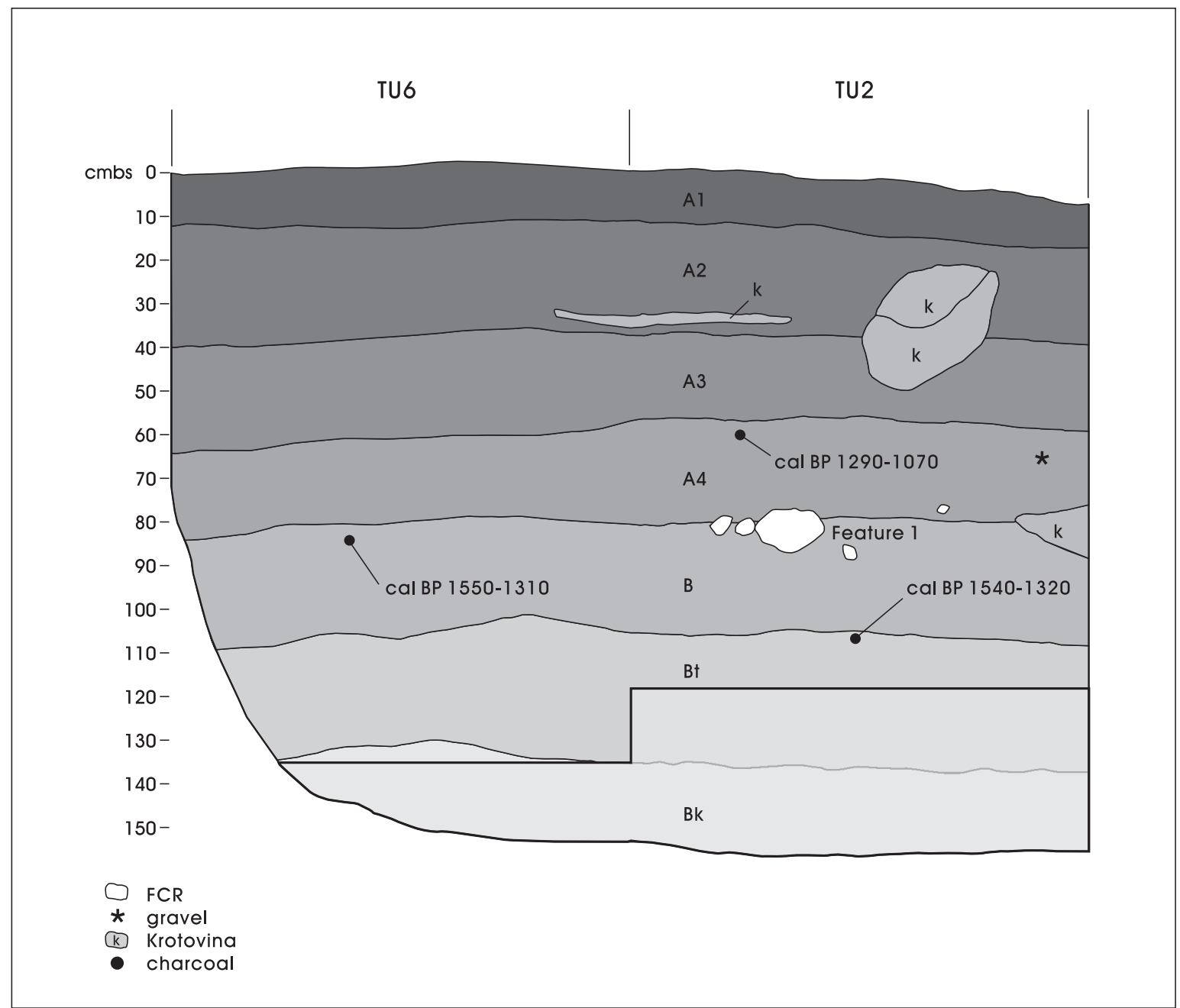

Figure 4-3. Detail of fire-cracked rock distribution in Backhoe Trench 2 representing the western walls of TU 2 and $T U 6,41 G D 113$.

The additional excavation permitted clarification of this soil and sediment change and connected this trench to a perpendicular view of the site in BHT 5. BHT 4 was $13.4 \mathrm{~m}$ long and extended to a maximum depth of $1.57 \mathrm{~m}$ below the modern ground surface. This trench connected with BHT 5 at its northern end. BHT 4 was oriented north-south $\left(2^{\circ}-182^{\circ}\right.$ from magnetic north). The eastern wall of this trench was profiled, described and sampled (Figure 4-5). Twenty-four magnetic susceptibility samples were collected from a column approximately $3.1 \mathrm{~m}$ north of the southern end of the trench.

BHT 4 provides important information about site formation and past landforms at 41GD113. This trench sampled a transitional location separating an older terrace margin from a more recent set of terrace deposits. From the current sample it cannot be determined if this represents ancient meanders of the modern Perdido Creek or some other drainage. The geoarcheological investigation (Appendix A) did not address this question. Several aspects of this profile indicate this change in geomorphology. Upper A horizons identifiable in the northern end of BHT 4 lose their distinction downslope to the south. This appears to simply be due to a timetransgressive migration of the floodplain southward (Figure 4-5). This trench provides a dynamic view of sedimentary units and soils that are analogous to those found in the other backhoe trenches (Table 4-4). Distinctions of A2 and A3 horizons present at the northern end of the trench are absent in the southern portion. As can be seen in the profile, the older A horizons (A5 and A6) are identifiable across the entire trench. The more recent soil formation of A2 and A3 at the northern end is apparently older than the uppermost 


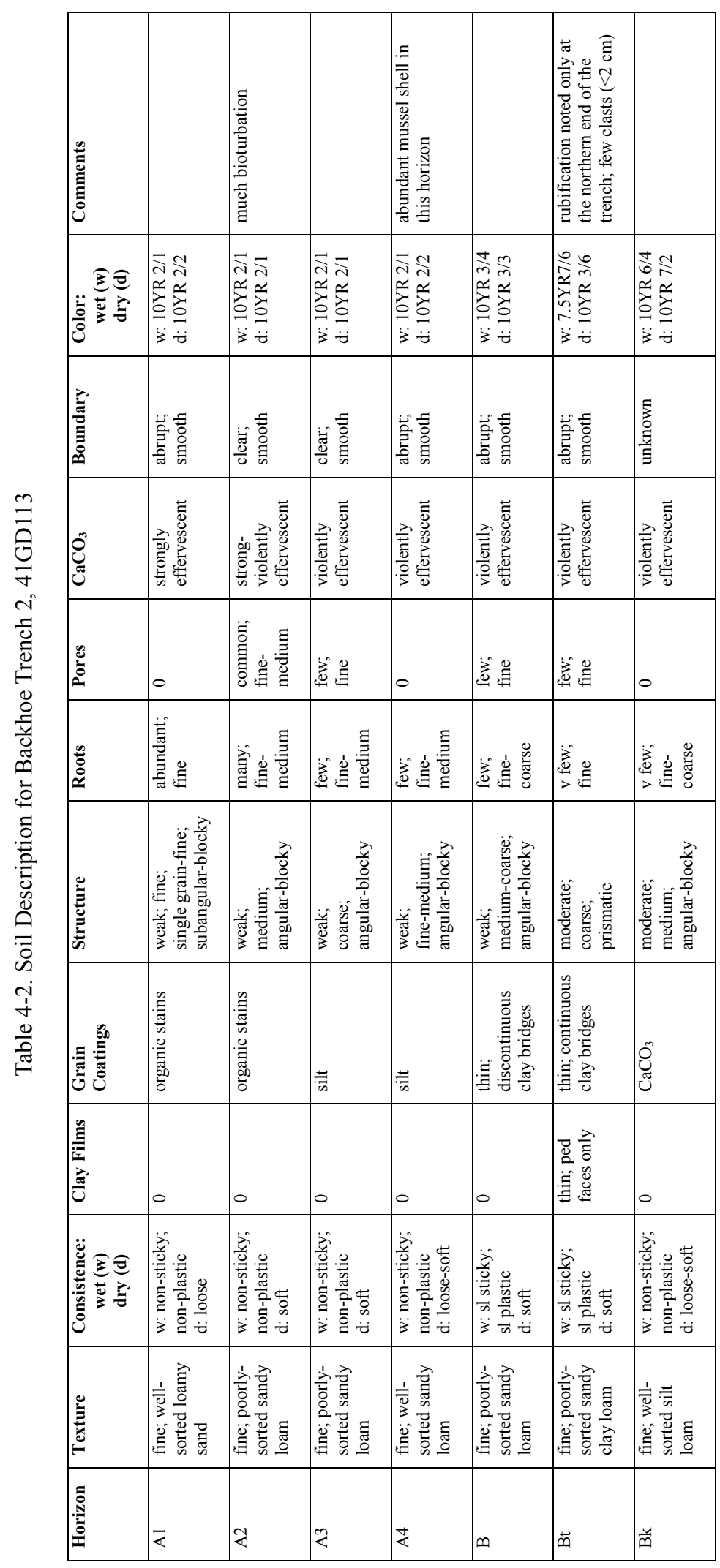




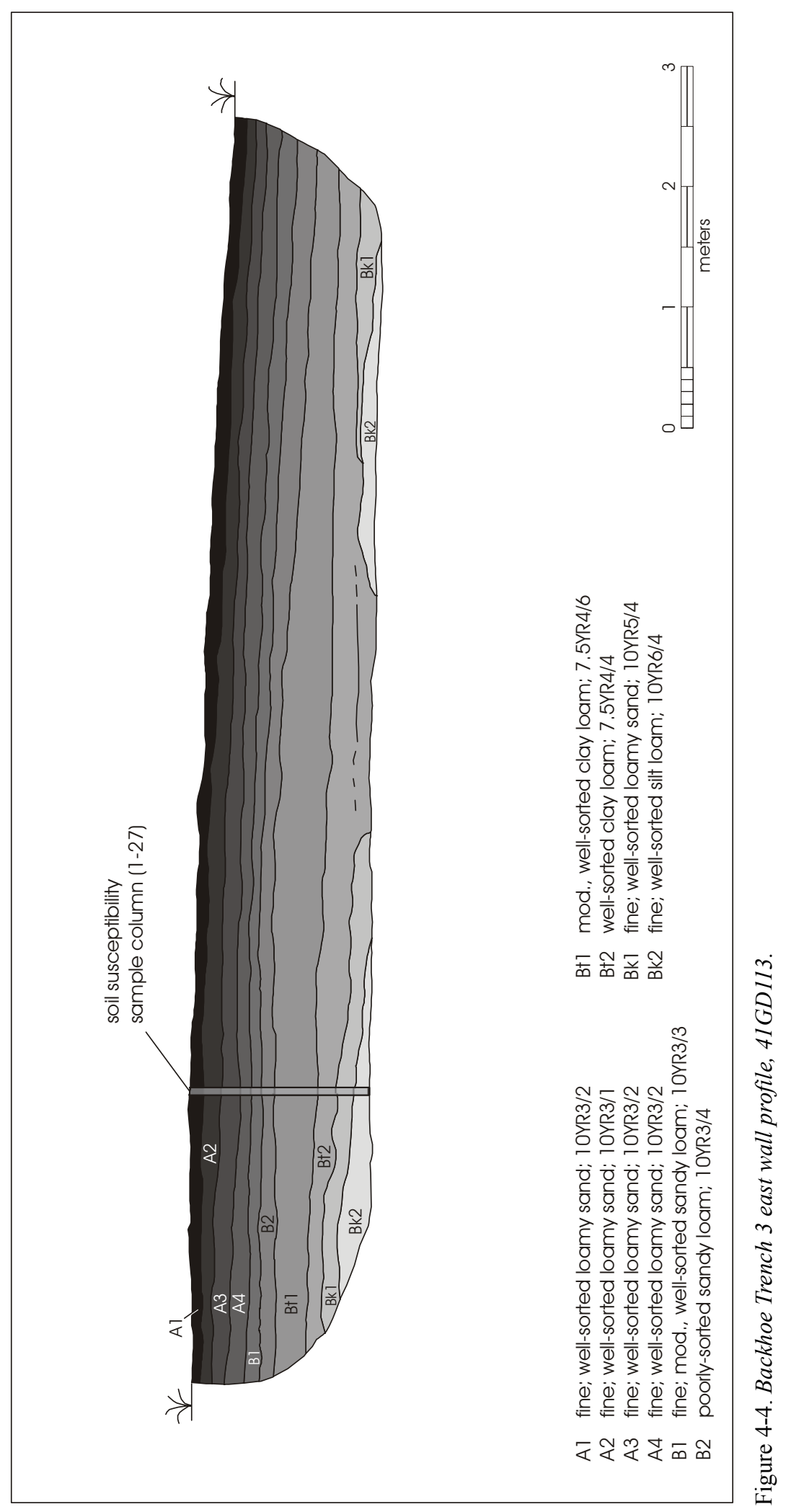




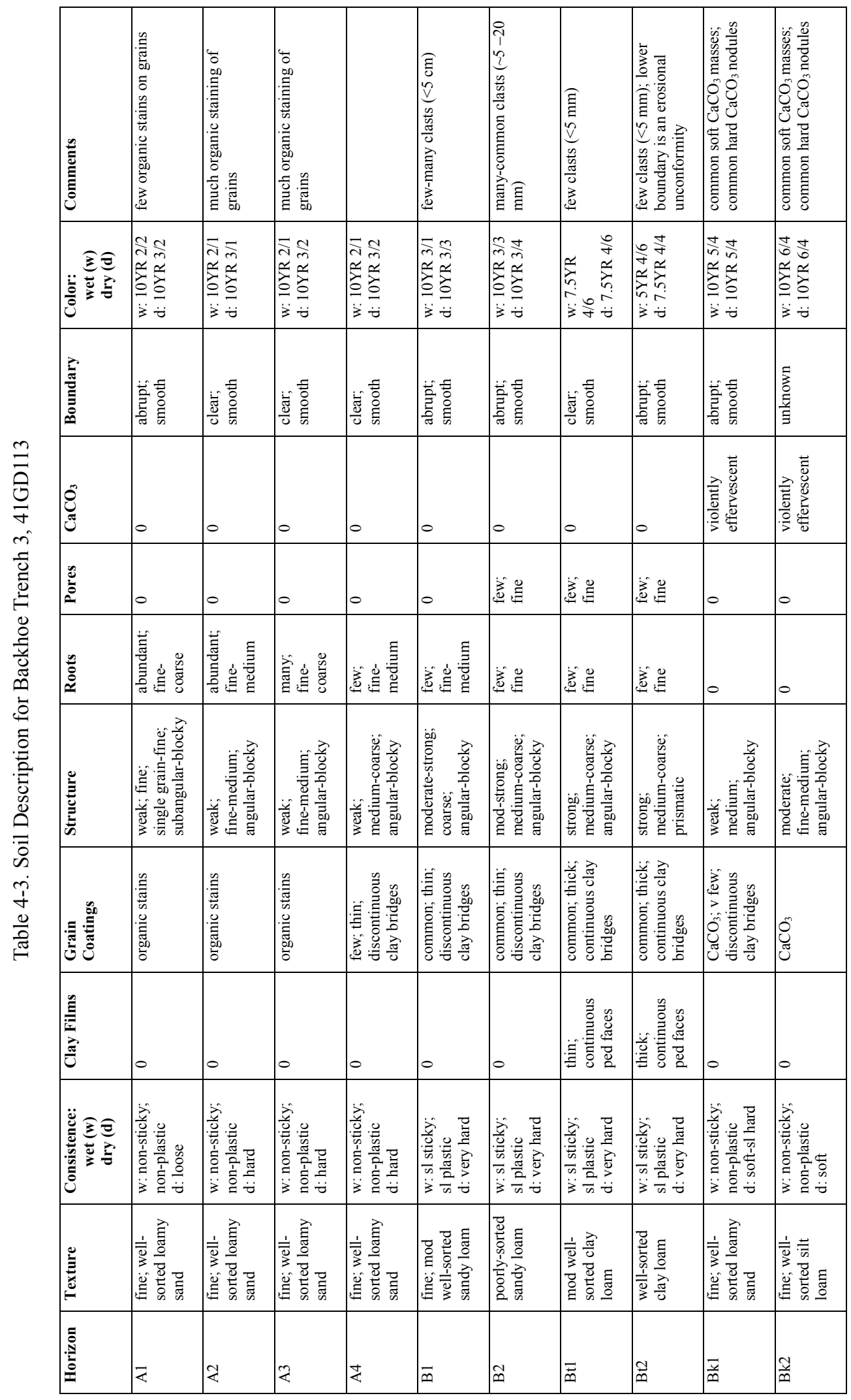


profile at the southern end. The A4 of the southern seven meters is the equivalent horizon to $\mathrm{A} 2, \mathrm{~A} 3$, and $\mathrm{A} 4$ at the northern end of BHT 4. The A horizons are maximally 100 $\mathrm{cm}$ thick at the northern end of the trench and thin from approximately 80 to $40 \mathrm{~cm}$ thick in the southern nine meters. A single redeposited flake was collected at a depth of 42 cmbs from the A6 horizon in the profile of BHT 4. This piece exhibited a clear platform, bulb of percussion, and multiple dorsal flake scars. It had been subject to abrasion and the entire flake had been smoothed, but this did not obscure the morphology of this piece as lithic debitage. It is almost certain that this polishing resulted from alluvial redeposition. No other lithics were recovered that indicated a secondary context as did this piece. The amount of polishing was unlike any other lithic recovered at 41GD113 and suggests that it had been introduced as a sedimentary clast from eroded materials derived from a different archeological site upstream. Unfortunately, this flake was inadvertently discarded during laboratory processing prior to any analysis. This piece is not included in any of the summary information on lithics at 41GD113.

There is a significant interruption in the sedimentary sequence from approximately $2.5-4 \mathrm{~m}$ south of the northernmost end of the trench. All of these events are recorded below the $\mathrm{A} 6$ horizon within the $\mathrm{Bt}$ and $\mathrm{Bk}$ sequences. The $\mathrm{Bk}$ horizons are only expressed deeply in the northern portion of the profile. Their upper boundary follows the contour of the upper boundary of the Bw. All of these deposits appear to be truncated by an event that partially scoured out the Bk deposits and then allowed formation of the rubified $\mathrm{Bw}$ soil. This unit is present only in the northern $3.5 \mathrm{~m}$ of BHT 4. Fluvial erosion may be responsible for removal of the older Bk deposits in the southern portion of BHT 4. Alternatively, this may be a remnant soil from a previous landform such as a channel bank that has been buried in subsequent overbank deposition. The sloping upper contour of the Bw follows the morphology of the Bk horizons. The discontinuance of this unit to the south indicates a changing depositional regime. The Bt1 horizon partly overlies the $\mathrm{Bw}$ near the southern terminus of the Bw. There are abundant gravels at the base of the $\mathrm{Bt}$, especially just south of where the Bw horizon has been eroded. The $\mathrm{Bt} 2$ and $\mathrm{Bt} 3$ may be analogous units to the $\mathrm{Bw}$. They may not be as rubified because of slight timetransgressive differences and the absence of overthickened A horizons above them influencing pedogenesis. Above the $\mathrm{Bt} 1$, the sequence of sedimentary episodes providing the parent materials for the A horizons appears to be a single depositional regime. As noted, the thinner A horizon thickness to the south appears to be related to timetransgressive movement of the stream channel to the south. There are more A horizon units (6) at the northern end than at the southern end (4). It appears that BHT 4 preserves evidence of at least four different sedimentary events at 41GD113, possibly five if $\mathrm{Bt} 2$ and $\mathrm{Bt} 3$ are not equivalent to $\mathrm{Bw}$. This sequence is shown graphically with false colors in Figure 4-5.

Sedimentary unit 1 in Figure 4-5 refers to the calcic horizons visible only in the northern end of the trench. Shown in green in Figure 4-5, this is the oldest unit encountered within the trenches on 41GD113. Sedimentary unit 2 , in red, is divided into group 1 and group 2 soils. Group 1 refers to the $\mathrm{Bw}$ horizon at the northern end of the trench. This rubified unit shows less development than the $\mathrm{Bt} 2$ and $\mathrm{Bt} 3$ that are in equivalent positions in the southern nine meters of BHT 4. All of sedimentary group 2 have much greater amounts of soil development and contain a large number of gravel clasts that indicate both a sedimentary and soil development difference from the overlying units. These probably represent Pleistocene age soils (Wes Miller, personal communication, July 30, 2002). An erosional unconformity evidences scouring of the upper portion of the $\mathrm{Bw}$ and the Bt2. There is deposition of a large number of gravel clasts at the northern end of the Bt2 and at the boundary with the Bt1. This suggests that higher energy deposits are associated with the deposition of sediments subsequent to the erosion of portions of the $\mathrm{Bw}$ and $\mathrm{Bt} 2$. The $\mathrm{Bt} 1$ horizon, shown in dark blue, is the lowest horizon in the recent sediments and soils identified as sedimentary unit 3 . The Bt1 horizon is much less welldeveloped than the Bt2 and this unit's morphology indicates it is a separate sedimentary event. The gravels at the base of the Bt1 are evident across the entire southern nine meters of BHT 4. That sedimentary separation, and its less-developed structure and clay films, indicates it is younger and not genetically related to the $\mathrm{Bt} 2$. Some of the clay content of this horizon and the gravels are probably derived from the Bw unit. Sedimentary unit 4 , shown in three shades of light blue, records recent alluvial deposits. This is the modern solum where archeological deposits are located. The color contrast shows the presence of greater amounts of sediment and greater evidence of soil formation at the northern end of the trench compared to the southern end. At the point of the soil susceptibility column, the distinction between sedimentary unit 3 and the more recent alluvial deposits (unit 4) is roughly 40 to $45 \mathrm{cmbs}$. This distinction is consistent with the enhancement of the upper portion of the profile relative to the lower portion of the profile (see Appendix C, Figure C-5). Figure 4-5 illustrates the dynamics 


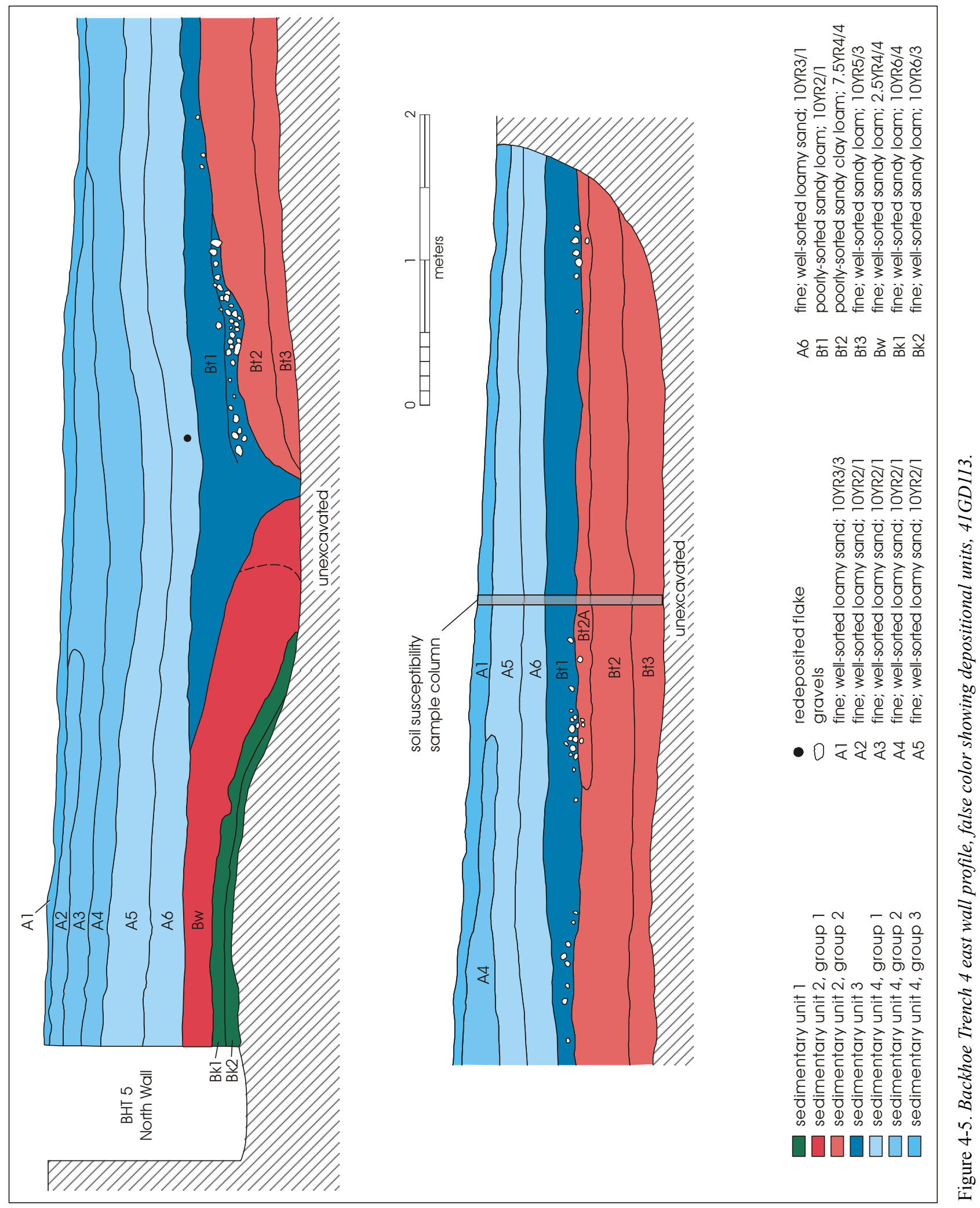




\begin{tabular}{|c|c|c|c|c|c|c|c|c|c|c|c|c|}
\hline نे & & 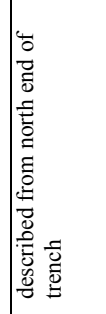 & 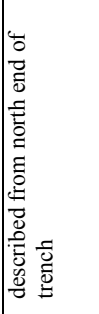 & 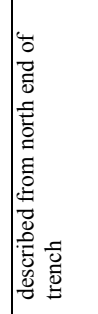 & & & 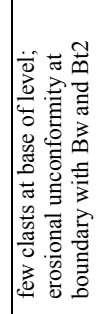 & 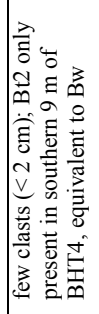 & 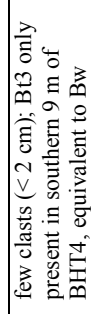 & 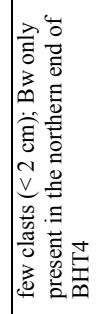 & 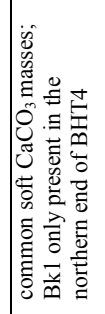 & 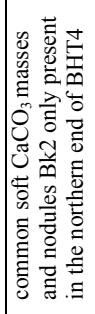 \\
\hline 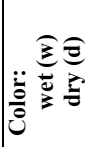 & 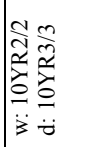 & 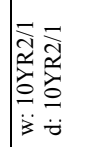 & 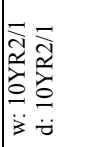 & 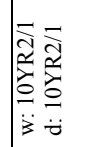 & 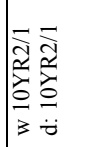 & 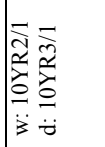 & 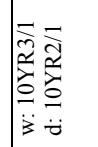 & 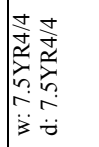 & 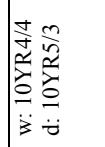 & 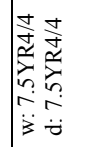 & 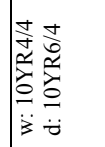 & 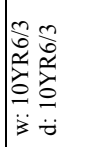 \\
\hline 焉 & 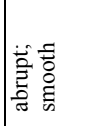 & 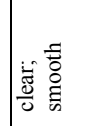 & 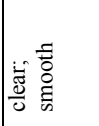 & 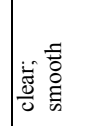 & 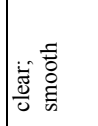 & 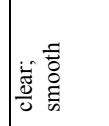 & 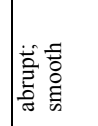 & 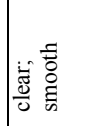 & 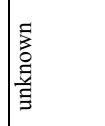 & 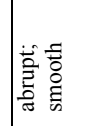 & 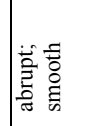 & 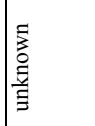 \\
\hline שֶ & 0 & 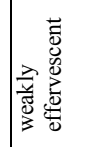 & 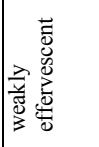 & 0 & 0 & 0 & 0 & 0 & 0 & 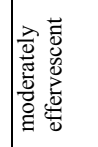 & 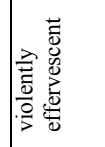 & 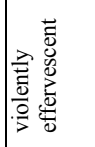 \\
\hline 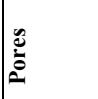 & 0 & 0 & 0 & 0 & 0 & 0 & 竞方焉 & 竞总焉 & 童爮总 & 0 & 茅号 & 0 \\
\hline 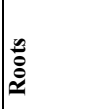 & 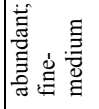 & 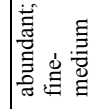 & 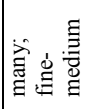 & 童员 & 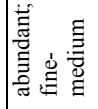 & 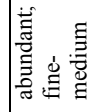 & 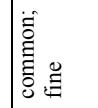 & 苞昌 & 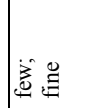 & 童邑 & 竧兽 & 竧兽 \\
\hline 章 & 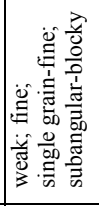 & 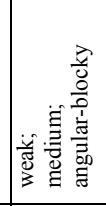 & 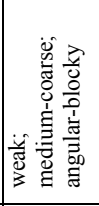 & 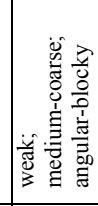 & 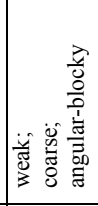 & 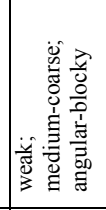 & 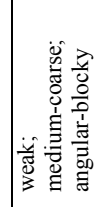 & 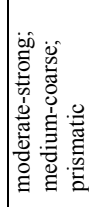 & 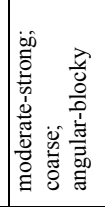 & 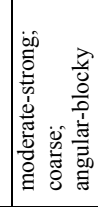 & 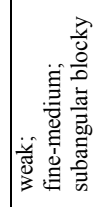 & 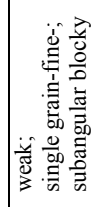 \\
\hline Uू & 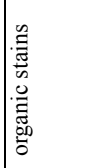 & 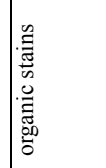 & 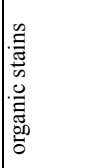 & 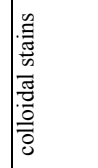 & 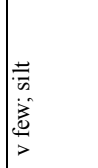 & 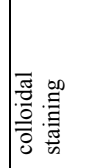 & 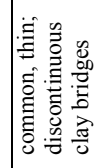 & 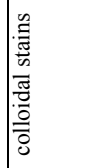 & 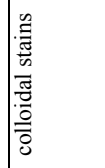 & 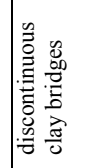 & $\begin{array}{l}0 \\
0 \\
\tilde{U}\end{array}$ & ठृ \\
\hline 童 & 0 & 0 & 0 & 0 & 0 & 0 & 0 & 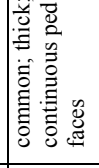 & 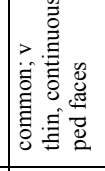 & 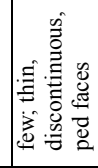 & 0 & 0 \\
\hline 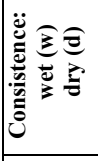 & 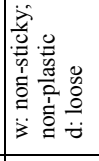 & 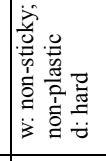 & 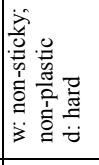 & 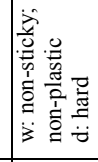 & 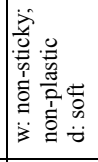 & 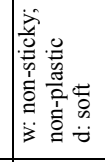 & 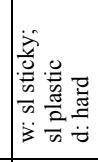 & 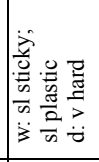 & 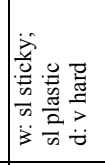 & 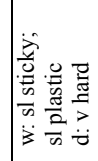 & 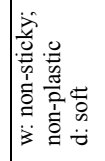 & 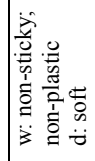 \\
\hline 竧 & 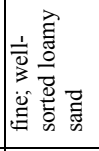 & 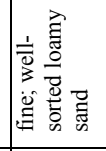 & 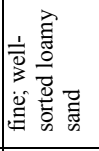 & 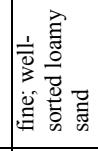 & 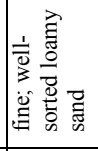 & 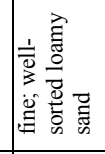 & 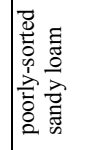 & 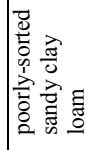 & 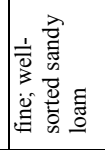 & 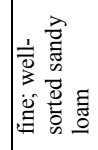 & 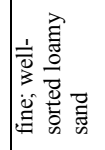 & 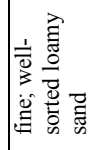 \\
\hline 产 & « & $\approx$ & \& & 专 & i & 4 & 俤 & लै & $\stackrel{9}{\oplus}$ & 芯 & $\frac{\vec{m}}{\underline{m}}$ & $\frac{\tilde{y}}{m}$ \\
\hline
\end{tabular}


of stream migration southward associated with decreased floodplain deposition as the stream abandons the older terrace.

\section{Backhoe Trench 5}

Backhoe Trench 5 was excavated perpendicular to BHT 4. BHT 5 was $11.5 \mathrm{~m}$ long and had a maximum depth of $1.4 \mathrm{~m}$ below surface. BHT 5 was oriented east-west $\left(6^{\circ}-276^{\circ}\right.$ from magnetic north) to provide a perpendicular view of soil profiles in relation to BHT 4 (see Figure 3-1). The northern wall of this trench was profiled, described, and sampled (Figure 4-6). Twenty-six soil susceptibility samples were collected from a column approximately two meters east of the western end of the trench.

BHT 5 provides an excellent view of the sedimentary history of 41 GD113 (Table 4-5). There is a clear set of three calcic horizons at the base of this trench ( $\sim 90-105 \mathrm{cmbs})$. The upper boundary of the $\mathrm{Bk} 1$ horizon is an erosional unconformity with the $\mathrm{Bt} 2$ horizon. The lowermost $4-5 \mathrm{~cm}$ of this argillic horizon (Bt2) are rubified (5YR4/6). The majority of the Bt1 horizon is brown to dark yellowish brown (10YR4/4-10YR4/4). The Bt horizons are approximately $40 \mathrm{~cm}$ thick and their upper boundary is $70 \mathrm{~cm}$ below the modern ground surface. The B horizon extends from approximately $50-70 \mathrm{~cm}$ below ground surface. There are abundant gravels associated with the $\mathrm{Bt}$ horizons and some localized pockets of gravels in the B horizon. The Bk1 horizon also contains some gravels. The abundance of these clasts strongly suggests that the $\mathrm{B}$ and $\mathrm{Bt}$ horizons are part of a separate sedimentary regime from the overlying A horizons. The A horizons are the only portion of this profile associated with artifacts. The fine, well-sorted loamy sands of the A horizons were noticeably thicker at the western end than eastern end of the trench. The A horizons are approximately $50 \mathrm{~cm}$ thick at the western end and only 20 $30 \mathrm{~cm}$ thick at the eastern end. The $\mathrm{B}$ horizon varies from $10-20 \mathrm{~cm}$ thick and is not well developed at the extreme eastern end of BHT 5. It is apparent that the artifact bearing soils are thickest in the identified site area and thin considerably east of this slight topographic rise. Magnetic susceptibility results (Appendix C, Figure C-6) from this trench suggest two locations of enhancement; the first is at about $35 \mathrm{cmbs}$, and may be associated with the top of the B horizon, and a second peak is present at about $105 \mathrm{cmbs}$.

TU 3 was excavated off the southern wall of BHT 5 and no artifacts were encountered between $40-80 \mathrm{~cm}$ below surface. The interruption of the $\mathrm{Bt}$ and $\mathrm{Bk}$ horizons noted in the profile (Figure 4-6) is associated with a concentration of gravels in the Bt1 and $\mathrm{B}$ horizons. There are no indications that would suggest this is a cultural feature. Previous tree root penetration of these horizons is likely responsible for this broken boundary of the lowermost horizons. There are several large roots within the A4 and B soils at this location that may be taking advantage of this perforation of the less permeable Bt horizons to access deeper vadose water.

\section{Discussion}

Deposits at 41GD113 have been well-sampled through the backhoe trenching of the site. Soils are similar to those noted in other investigations along Perdido and Coleto creeks (Brown 1986:12-17; Fox 1979:18-25). The series of five trenches provide a comprehensive catena downslope across the site and good views of the lateral extent of this site. $41 \mathrm{GD} 113$ is situated at the margin between an older upper alluvial terrace and a lower terrace setting. A horizon sediments that mantle this site are analogous and derive from floodplain deposits related to the lower and farther position of the stream channel of the Payton Branch of Perdido Creek. This epipedon is slightly thicker on the upslope area, consistent with the expectation that floodplain deposits are time-transgressive (Figure 4-5). A greater number of divisions of the A horizon were identified in the more northerly trenches sampling the upper terrace surface. BHT 3 shows this especially well. All of the recovered archeological material appears to be associated with these upper A horizon deposits or the lowest surface between the older Bt soils and the modern solum.

Underlying the modern soil is a series of older stratigraphic units. Some parts of the modern profile exhibit formation of a B horizon (BHT 2, BHT 3, and BHT 5). This appears to be genetically related to the A horizons. Underneath the B horizons or the lowest A horizons, one to three Bt soils are present. Several morphological attributes of these horizons suggest they represent an older sedimentary and perhaps soil formation regime. The Bt horizons generally contain a significantly greater number of siliceous gravel clasts than the overlying A horizon deposits. These poorly sorted sediments contrast with the fine, well-sorted loamy sands that characterize the A horizons. The Bt horizons contain significantly greater amounts of clay than exhibited in the B or lowest A horizons. Although no erosional unconformities between the $\mathrm{Bt}$ and $\mathrm{A}$ units were identified, there is an apparent disjuncture in the sedimentary relationship between these units. The more well-developed Bt horizons may also suggest that they were part of an older soil formation regime now obscured through A and B horizon development in the modern solum (Waters 1992:40-43). Nordt and Crawford (Appendix A) have indicated that the 


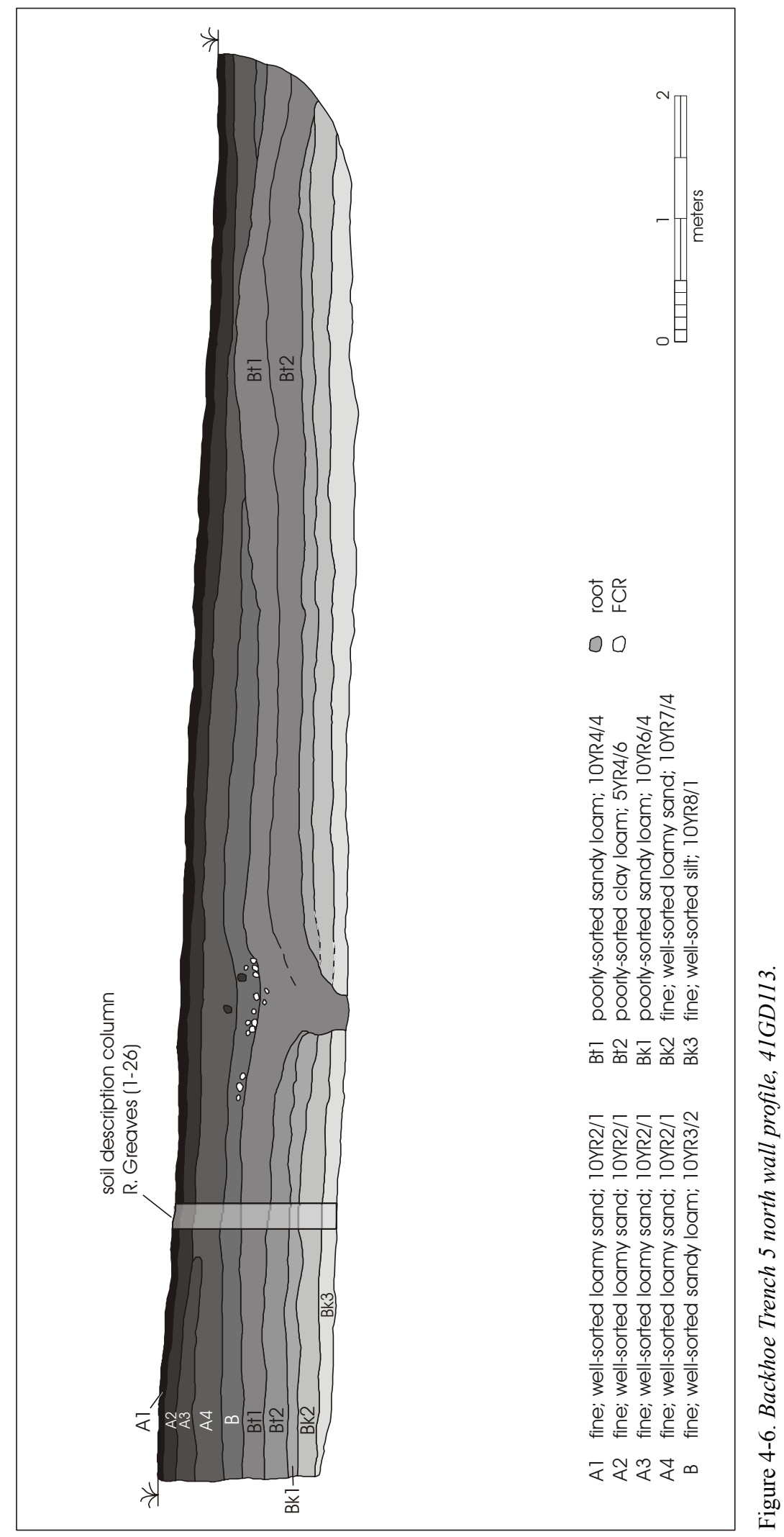




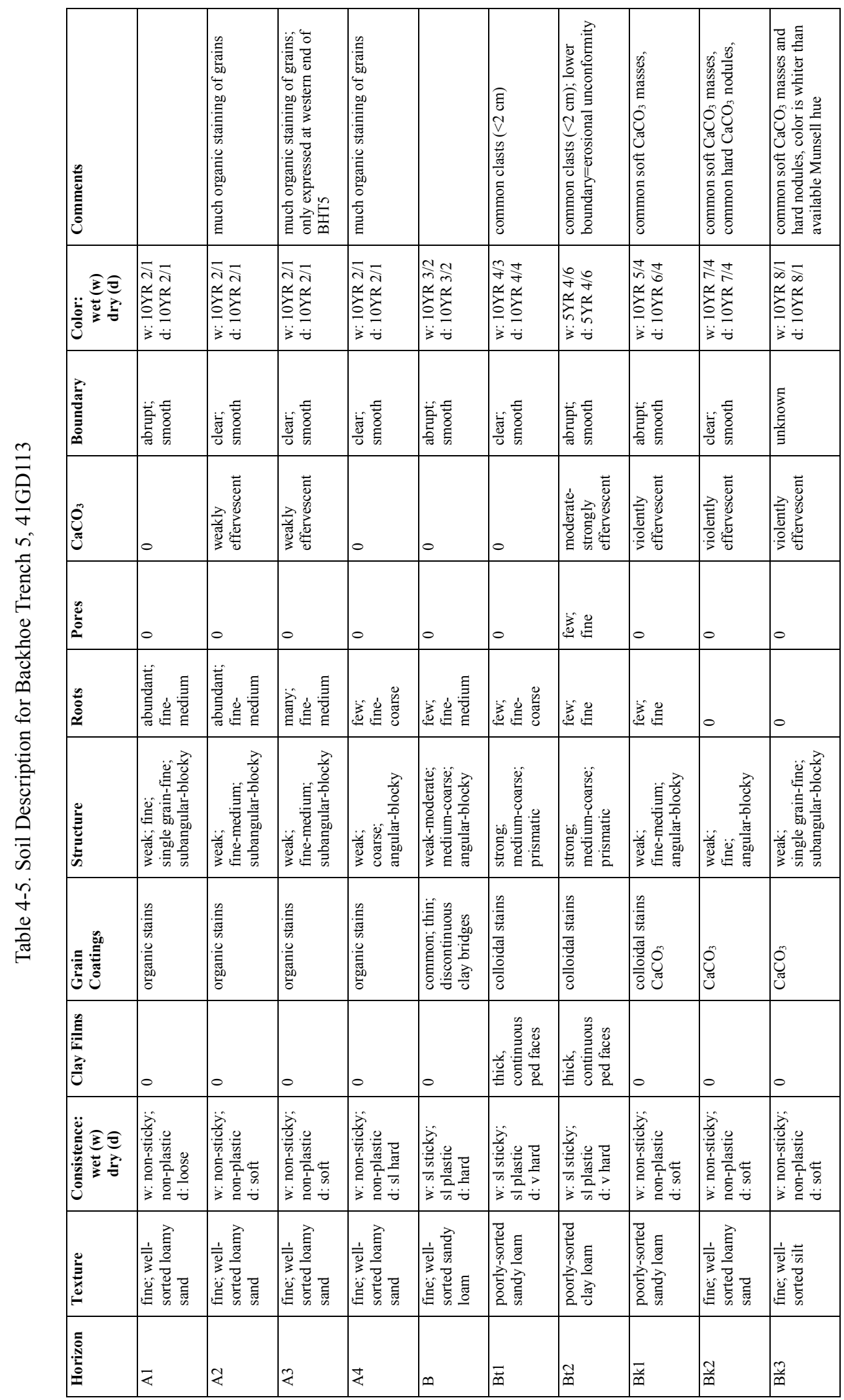


$\mathrm{Bt}$ is likely a Pleistocene soil overlain by Holocene deposits that represent the $\mathrm{A}$ and $\mathrm{B}$ horizons.

Underneath the Bt soils are one or more units of a calcic horizon that is quite extensive. This unit may be older than the Bt horizon and genetically unrelated to the Bt. However, decalcified Bt horizons overlying stage II/late stage II calcic horizons are not uncommon in intact Pleistocene soils in Texas (Jim Abbott personal communication February 27, 2004). The suggestion that the Bk soils are older is based on unconformities between the $\mathrm{Bk}$ and $\mathrm{Bt}$ soils and their greater content. Nordt and Crawford (Appendix A) do not report such unconformities. During his visit to the site, Wes Miller of the USDA Natural Resources Conservation Service in Victoria, was consulted about the possibility of unconformities in BHTs 3, 4, and 5. He examined the Bk$\mathrm{Bt}$ boundaries in these trenches and in his opinion, based on his expertise on local soils, unconformities were present (Wes Miller, personal communication July 30, 2002) In BHT 3 , BHT 4 , and BHT 5 there is an erosional unconformity between the $\mathrm{Bk}$ and $\mathrm{Bt}$ units so that the Bt soils cannot be genetically related and are younger than the Bk horizons. The amount of carbonate expressed in these calcic horizons is significant. They exhibit complete whitening of the sediments, massive soft carbonate, and abundant soft masses suggesting pedogenic carbonate development. The majority of the overlying deposits do not contain $\mathrm{CaCO}_{3}$ and the development of these $\mathrm{Bk}$ horizons is clearly not part of the modern soil formation. There is no gradual increase in carbonate in the overlying soils that would identify them as buried soil components of that formation regime. BHT 1 and BHT 2 exhibited moderate to strong effervescence throughout the entire soil profile. BHT 3 had no indication of carbonate above the Bk soils. BHT 4 and BHT 5 both had weak $\mathrm{HCl}$ effervescent reactions only within their A2 and $\mathrm{A} 3$ horizons. It is unclear why there should be carbonate diffused throughout BHT 1 and BHT 2 but not the other backhoe trenches. Although the bulldozer disturbance on 41 GD113 was only identified in TU 5 , it is possible that excavation into the calcic sediments may have resulted in colluvial and alluvial movement of carbonate rich sediments downslope to the BHT 1 and BHT 2 locations resulting in leaching of $\mathrm{CaCO}_{3}$ into upper portions of the profile very recently. The strong to violent effervescence noted in these two profiles suggests significant carbonate enrichment that is not evident in analogous soil units on other parts of the site. Recent inclusion of carbonates could be responsible for this differential distribution in the solum.
The perpendicular trenches, BHT 4 and BHT 5, provide the most critical information about site formation at 41GD113. The BHT 5 profile offers an excellent view of the depositional regime for the upper terrace. Its connection with BHT 4 offers insight into stream dynamics near this site. The occurrence of buried archeological material in both the upper and lower terrace settings indicates that the occupation occurred when the lower terrace was within the active floodplain. The drainage was moving to the south, abandoning the higher, older terrace that is situated on the northern side of the two-track road. This indicates that the floodplain of Payton Branch (to the south of these sites) is the channel responsible for these alluvial deposits. Perdido Creek to the north shows no evidence of downcutting through the higher terrace north of the two-track road on the northern side of the two sites. The paucity of gravels in the $\mathrm{A}$ and $\mathrm{B}$ horizons contrasts with their presence in the $\mathrm{Bt}$ horizons. These higher-energy stream deposits represent not only movement of the channel southward, but a very different relationship between floodplain and channel at this location. Both terrace settings show this change in sedimentation above the Bt units. The same A horizons mantle the upper and lower terraces, although they are thicker on the northern, upslope side. The thicker A horizons are due to greater amounts of deposition on the older surface. This also suggests that the distribution of artifacts indicates a high probability that $41 \mathrm{GD} 113$ is a multiple occupation site. Although these upper A horizons are analogous across the entire site, the overthickening on the higher terrace indicates that they are time-transgressive. Dating of a sequence of three charcoal samples from TU 2 and TU 6 identify them as Late Archaic in age. TU 5, on the upslope side of the site, does not offer any information about site formation because the deposits in this location were completely disturbed.

\section{Test Unit Excavations}

Seven 1-x-1-m test units were excavated on 41GD113 (see Figure 3-1). Six of the test units were placed directly adjacent to backhoe trenches. One additional unit (TU 5) sampled the north-central portion of the site. This unit encountered extreme disturbance of deposits to a depth of approximately $217 \mathrm{~cm}$ below the modern ground surface. These disturbances may be due to road construction or to the placement of one bulldozer cut in this site at the same time as the extensive impacts to $41 \mathrm{GD} 114$. Archeological recovery from the test units on $41 \mathrm{GD} 113$ is presented in Table 4-6. 


\section{Test Unit I}

TU 1 was excavated off the eastern wall of BHT 1 . The unit was located approximately $4.5 \mathrm{~m}$ south of the northern end of the trench. TU 1 was excavated in arbitrary $10-\mathrm{cm}$ levels to a maximum depth of $94 \mathrm{~cm}$ below datum (bd). At approximately 70-75 cmbd, the Bt horizon was encountered. The remaining two excavation levels were dug in arbitrary $10-\mathrm{cm}$ spits and the final level (Level 10) encountered a very irregular upper boundary of the Bk1 horizon at 86-94 cmbd. No excavation was made into the calcic soils. The excavation subdatum used for this unit was at the level of the highest ground surface corner in TU 1. Elevations below datum are identical with measurement of the depth below the modern ground surface.

TU 1 produced the third highest density of artifacts from test excavations (excluding TU 5 because of its extensive disturbance). Thirty-four pieces of debitage, two flake tools, three pieces of bone, and a total of 179.2 grams of mussel shell fragments was collected from TU 1 (Table 4-6). All encountered snail shell was reserved from this unit, although gravels were not saved or quantified. Lithics were recovered from Levels $2-3$ (10-30 cmbd) and 5-6 (40-60 cmbd). The highest density of debitage was from Levels $2(n=18$ and one flake tool) and $3(n=8)$. There were no lithics from Level 4. Four pieces of debitage and one flake tool were found in Level 5, and four flakes were recovered from Level 6 . The artifacts in Levels 5-6 are just above the contact with the Bt horizon. The vertical distribution of artifacts suggests a strong possibility that multiple occupational events are recorded in this test unit.

\section{Test Unit 2}

TU 2 was excavated off the eastern wall of BHT 2 (Figures 4-2 and 4-3). This unit was located approximately 1-2 m south of the northern end of BHT 2 (see Figure 3-1). This location was selected because of the presence of a large FCR concentration visible in the east wall profile of this trench. This rock was the only cluster of FCR that had a probability of representing a thermal feature. This rock concentration was designated Feature 1. A profile of the western wall of TU 2 (and of TU 6) as exposed within the profile of BHT 2 was drawn prior to their excavation (Figure 4-3). This profile shows the position of the FCR concentration and stratigraphic location of dates from charcoal samples piece-plotted in TU 2. The excavation subdatum for this unit was a minimum of $12 \mathrm{~cm}$ above the highest ground surface in the unit. All of the elevations presented are $12 \mathrm{~cm}$ higher than the distance below the modern ground surface of this unit. Because excavation was stopped at the Bt horizon, only $10-20 \mathrm{~cm}$ of controlled excavation sampled the Bt soil in TU 2. This unit was terminated at Level $12(120-130 \mathrm{cmbd})$. Evidence of extensive bioturbation in the uppermost portion of the $\mathrm{Bt}$ horizon of TU 2 suggests that artifacts were displaced and do not represent intact archeological deposits.

TU 2 contained the highest density of cultural artifacts and other materials of any unit excavated on 41GD113. Four hundred seven lithics, 171 bone fragments, 307 pieces of FCR, and 218.43 grams of mussel shell were recovered. All natural gravels and snail shells also were collected and returned to the laboratory at CAR. TU 2 produced cultural artifacts and other materials in every excavation level (Table 4-6). There are two identifiable zones of high-density artifacts. Level $2(20-30 \mathrm{cmbd})$ contained more lithics $(n=13)$ and bone $(n=3)$ than adjacent levels. Level $6(60$ $70 \mathrm{cmbd})$ produced 21 lithics and Level $7(70-80 \mathrm{cmbd})$ had more debitage $(n=55)$. The highest concentration of cultural and natural clasts was recovered in Levels 7-10. Level 7 ( $70-80 \mathrm{cmbd}$ ) had 55 pieces of debitage. Level 8 (80-90 cmbd) had 54 pieces of debitage and 14 bone fragments. Level 9 (90-100 cmbd) produced 112 lithics, 90 pieces of bone, and 205 pieces of FCR. Level 10 (100$110 \mathrm{cmbd}$ ) had 81 pieces of debitage, 38 pieces of bone, and 38 FCR. The density of lithics drops to 30 in Level 11 $(110-120 \mathrm{cmbd})$ and 17 in Level $12(120-130 \mathrm{cmbd})$. Bone and other material densities also decrease in Levels 11-12.

Excavation of TU 2 did identify additional FCR in the vicinity of those initially exposed in the eastern profile wall of BHT 2 (Feature 1). FCR was concentrated in Level 9 (90-100 cmbd) of TU 2. However, this dispersed concentration of rocks did not form any identifiable intact cultural feature and was not associated with any higher concentration of charcoal than was present throughout the adjacent soils. The rock may represent a dispersed ephemeral feature or redeposited cleanup of a feature elsewhere at the site. Although there was some bioturbation, it does not appear extensive enough to be the primary agent of accumulation for these clasts. Vertically, the frequency of FCR in Level $9(\mathrm{n}=205,1.72 \mathrm{~kg})$ is higher than in any other level. The non-cultural clasts collected from TU 2 provide quantified information on the differences in depositional regimes between the $\mathrm{A}$ and $\mathrm{B}$ horizons in this part of the site (see Chapter 5). 


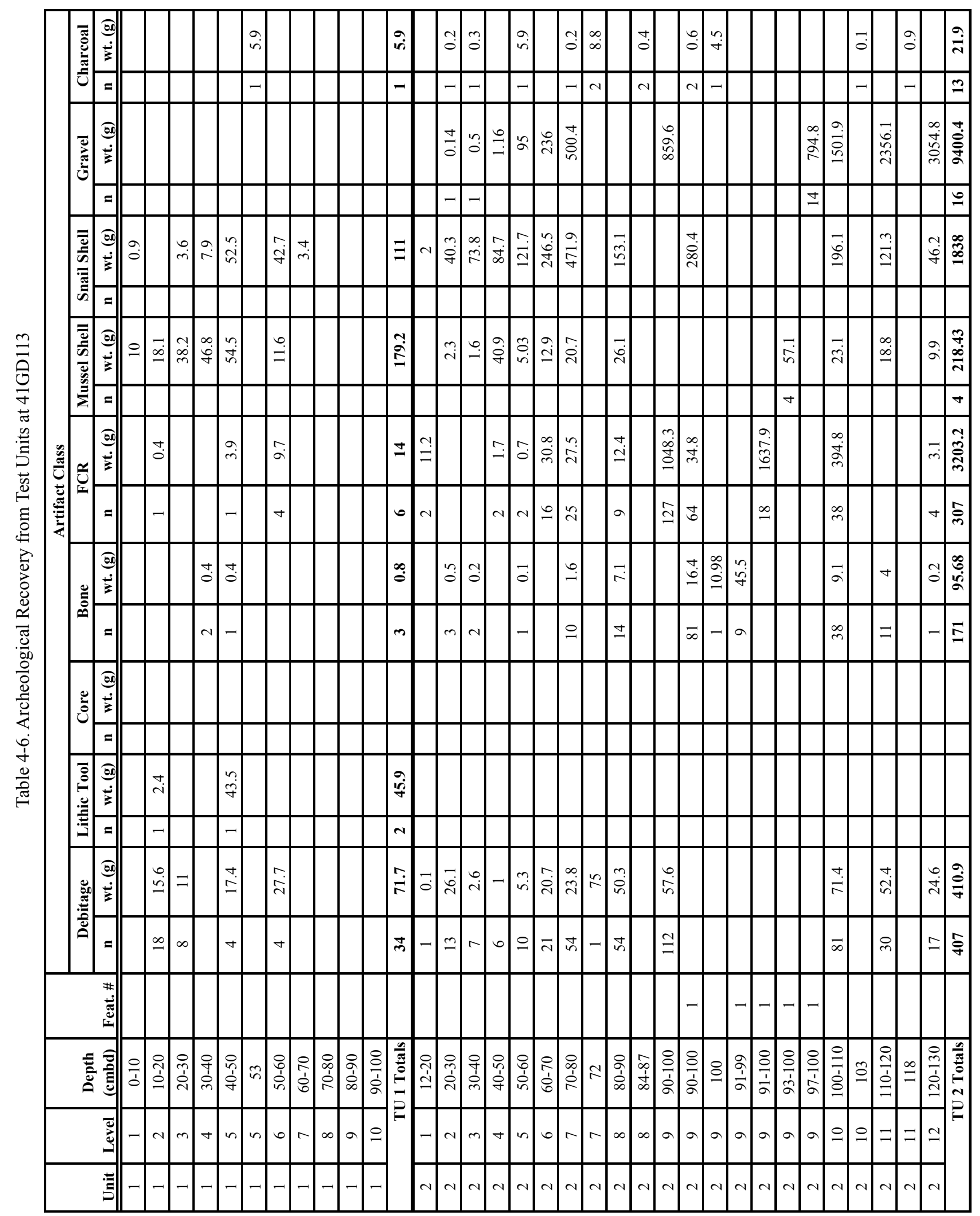




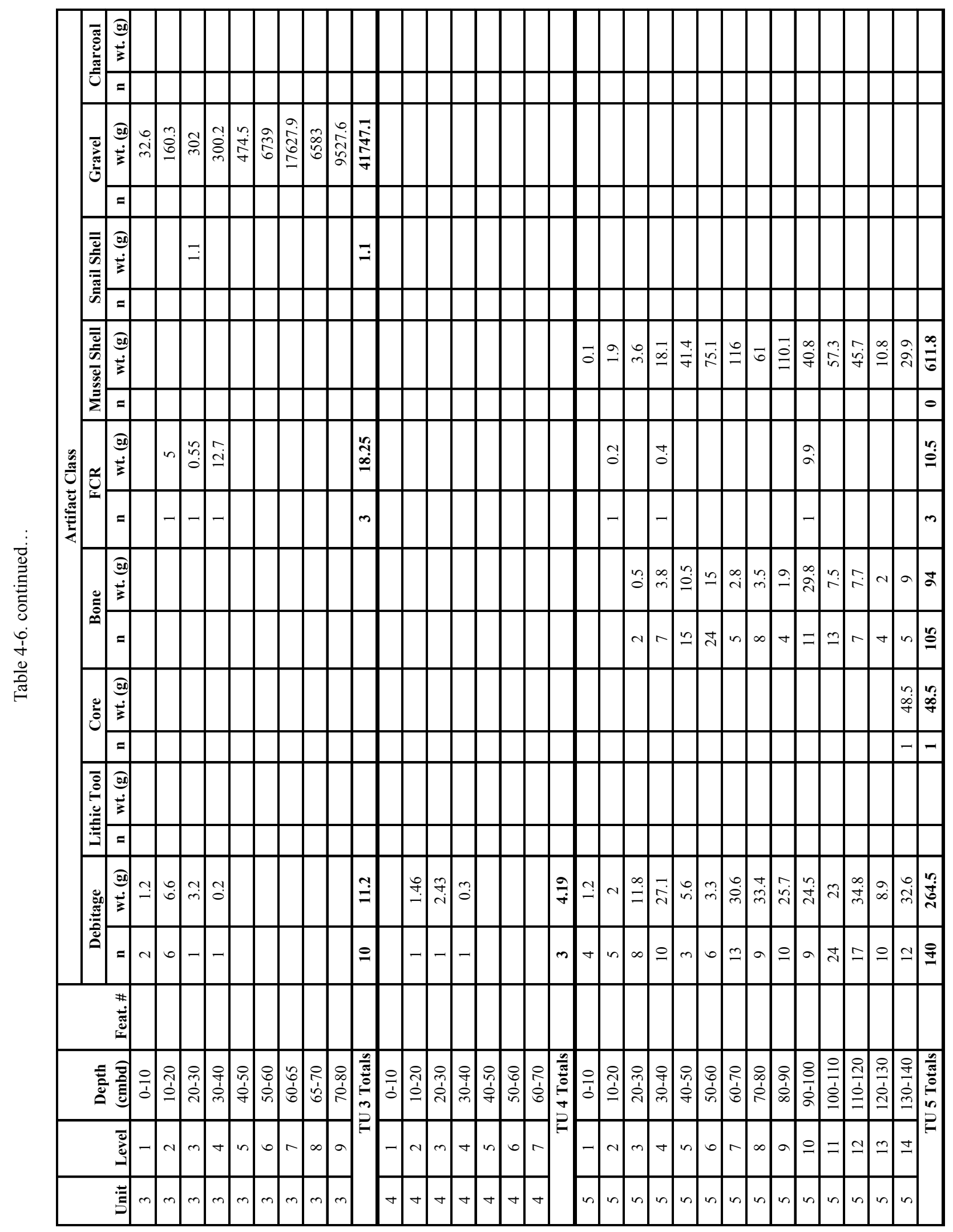




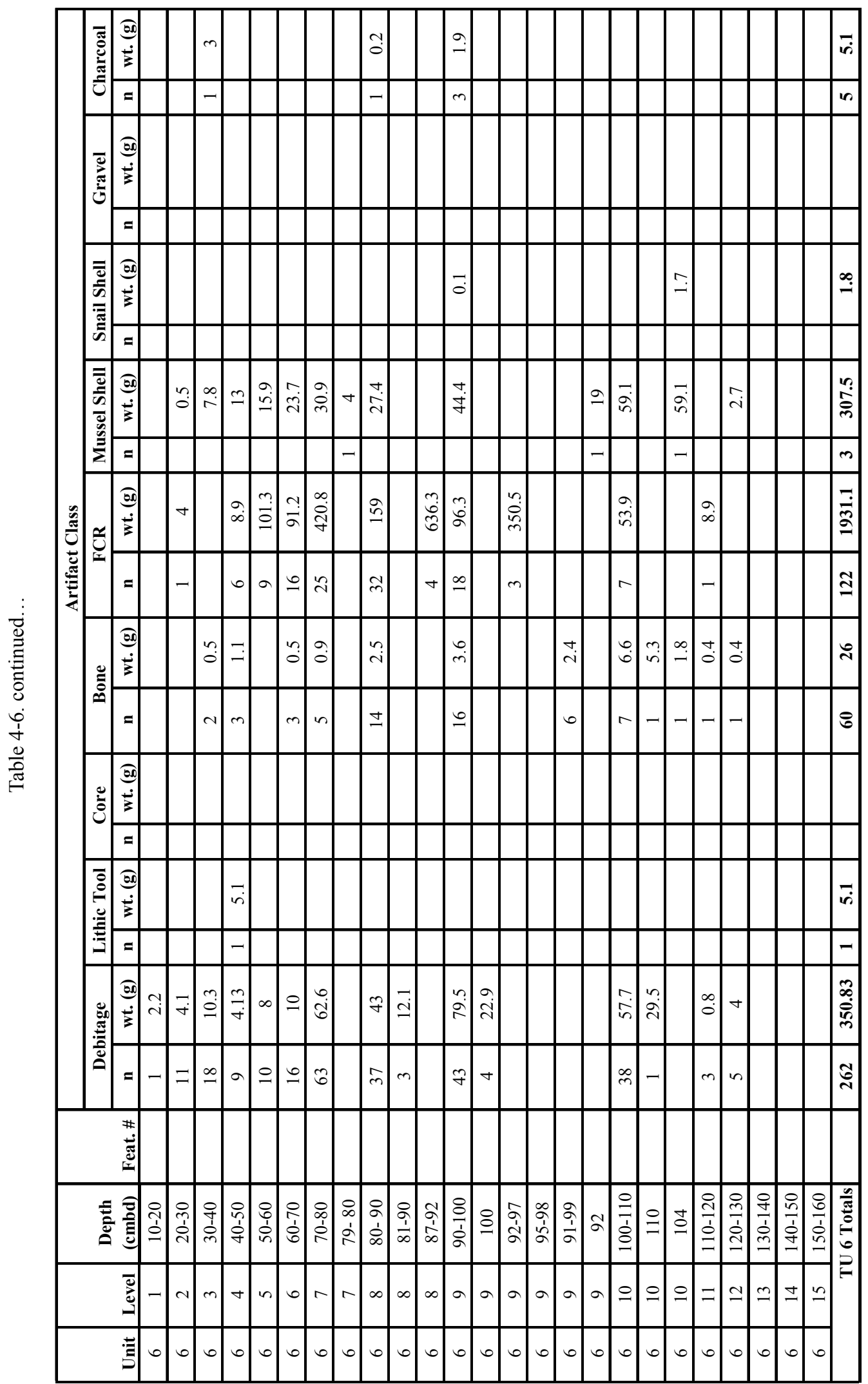




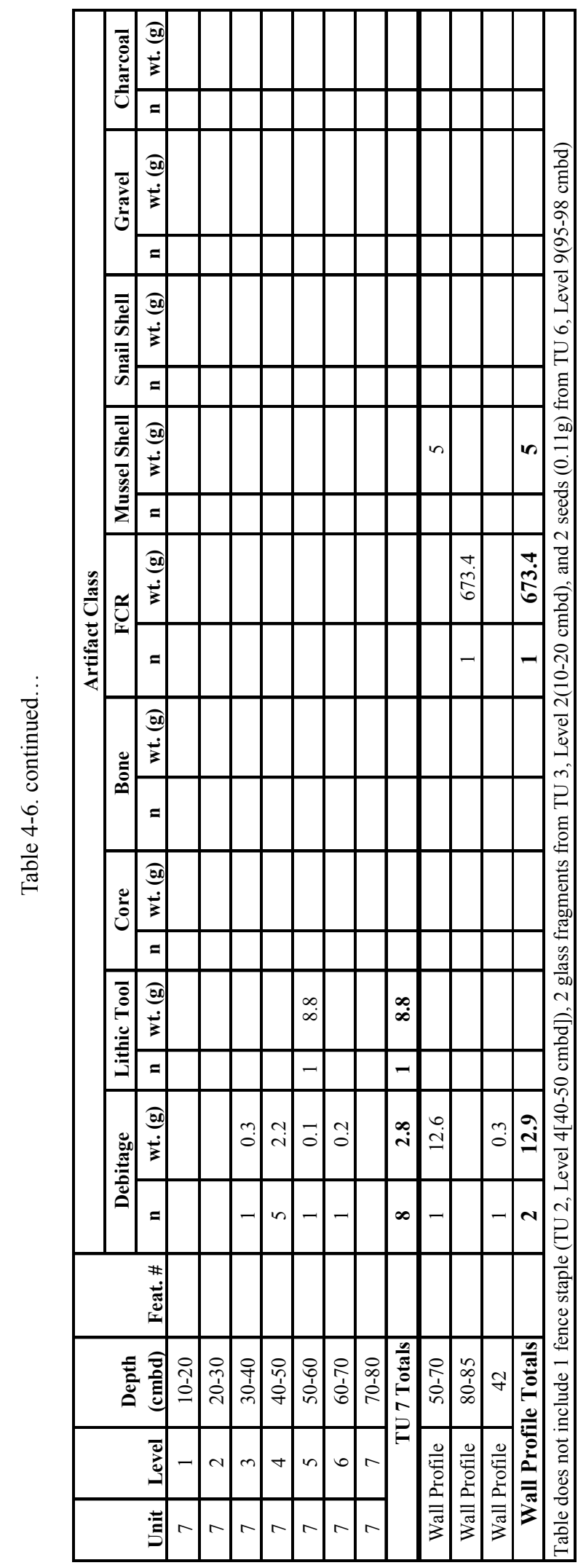

The highest density archeological zone is in the A4 and B horizons, bracketed by the three AMS dates on charcoal samples (Figure 4-3). It has been previously noted that bioturbation appears to be responsible for the presence of artifacts within the uppermost Bt soil in TU 2 and these cultural materials are derived from the overlying $\mathrm{B}$ horizon. The concentration of materials in Level 9 (90-100 cmbd) appears to represent an accumulation on a stable surface. Many more natural rocks and shell also were present in Level 9 than in other excavation levels. The largest rock clasts encountered were in this level. Partially articulated canid remains in Level 9, including the cranium, both mandibles, and one or two cervical vertebrae, suggests incorporation onto a surface that was relatively rapidly buried (Figure 4-7). There was no evidence that these remains were in any pit feature. The only slightly displaced anatomical position of the mandibles, lack of subaerial weathering, and separation of the cranial remains from all of the postcranial elements indicates these bones were exposed for a short period of time prior to burial. Few other bones in the assemblage show any evidence of subaerial weathering or significant exposure on the ground surface prior to burial. However, the amount of chemical etching of the outer bone table on most bone specimens may have obscured some indications of surface exposure (see Chapter 5). Rapid, probably alluvial, burial is likely, but cannot be unambiguously inferred because of the variable weathering of the faunal assemblage (Lyman 1994:359, 365-366). Note that the soil susceptibility values for BHT 2, located near TU 2 , suggest two areas of enhancement between 77 and $90 \mathrm{cmbs}$, or roughly 89 to $102 \mathrm{cmbd}$ (see Appendix C, Figure C-3). No upper peaks are present in these data. This is consistent with the rapid burial of a stable surface (see Appendix C).

\section{Test Unit 3}

TU 3 was excavated off the south wall of BHT 5, approximately $2.5 \mathrm{~m}$ east of the western end of the trench (see Figure 3-1). Profiling and description of the soils and sediments of BHT 5 were performed on the northern wall almost opposite the excavation of TU 3. The excavation subdatum was established at the highest corner of this unit $(0 \mathrm{cmbd})$ so that all elevations are below ground surface. The fine, well-sorted loamy sands of the A horizon were approximately $40 \mathrm{~cm}$ thick in TU 3 . The B horizon, visible only in the western two-thirds of BHT 5, is approximately $10 \mathrm{~cm}$ thick. TU 3 was excavated to a maximum depth of $81 \mathrm{cmbd}$, through most of the Bt1 horizon and terminating at the boundary with the Bt2. This unit was dug into the top of the Bt horizon to determine if cultural artifacts were associated with that soil and to sample the differences in gravels between the $\mathrm{A}, \mathrm{B}$, and $\mathrm{Bt}$ horizons. 


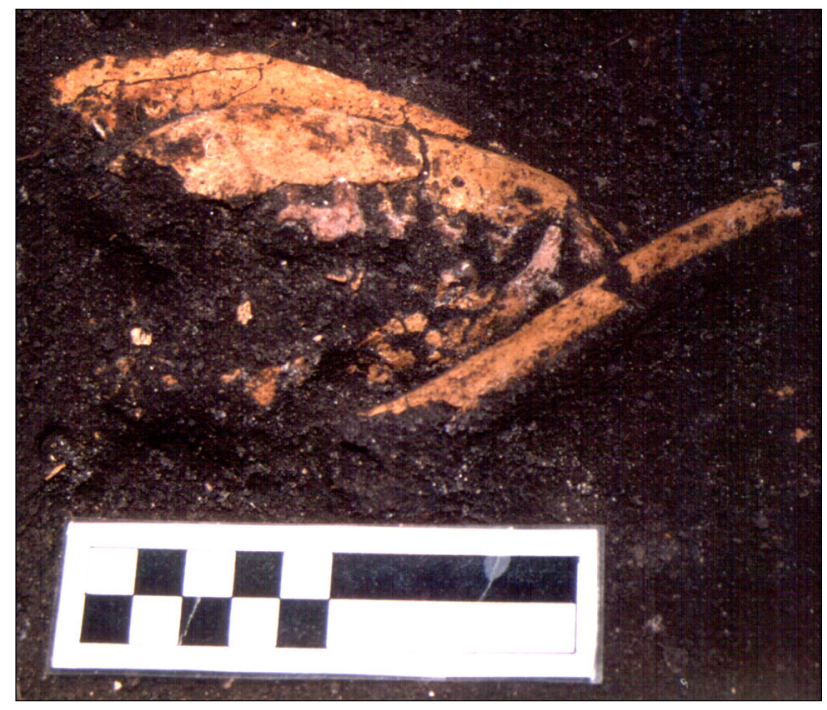

Figure 4-7. Canid remains recovered in Test Unit 2, 41 GD113.

TU 3 contained few artifacts (Table 4-6). Ten pieces of debitage, three fragments of FCR, and two pieces of modern glass were collected. All cultural material was recovered in Levels 1-4 $(0-40 \mathrm{cmbd})$. No artifacts were encountered in Levels 5-7 (40-80 cmbd). Level 2 contained the highest density of lithics. Six pieces of debitage and one FCR were recovered from this level. The two shards of glass also were recovered in Level 2. Clast density was quite high in the B and especially Bt horizons. As noted in the profile of BHT 5 (Table 4-5), this sedimentary texture difference demonstrates that the A horizons containing the archeological materials are a separate regime from the older $\mathrm{B}$ and $\mathrm{Bt}$ soils above the much older calcic horizons present at $41 \mathrm{GD} 113$.

\section{Test Unit 4}

TU 4 was excavated off the western wall at the southern end of BHT 4 (see Figure 3-1). TU 4 was placed three meters north of the southern end of BHT 4. This unit complemented the placement of TU 3 near the northern end of BHT 4, off the perpendicular BHT 5 trench. This unit also provided a sample of the southeastern portion of 41GD113. Excavation of this unit was terminated at approximately $70 \mathrm{cmbd}$. The excavation subdatum for this unit was $3-8 \mathrm{~cm}$ above the ground surface of TU 4 . The ground surface at the corner 3 $\mathrm{cm}$ below the subdatum was the reference for excavation level depths. In this part of BHT 4, the A horizons are 40$50 \mathrm{~cm}$ thick. The base of the final excavation level (Level 7, 60-70 cmbd) represents the contact of the Bt1 soil with the $\mathrm{Bt} 2$ horizon. There is a dramatic increase in clay content and number of gravel clasts at the upper boundary of the
Bt2 soil. In BHT 4, the Bt1 horizon was identified at approximately $40-60 \mathrm{cmbs}$.

TU 4 contained the lowest density of artifacts recovered in testing of 41GD113 (Table 4-6). Only three pieces of debitage were recovered, one each from Levels 2, 3, and 4. No artifacts were encountered in Levels 5-7. Excavation was terminated at $71-73 \mathrm{cmbd}$. It is probable that the low recovery from this unit is because this location represents the periphery of the site in a younger terrace deposit (see discussion of BHT 4).

\section{Test Unit 5}

TU 5 was placed in the north-central portion of the site (see Figure 3-1) to sample an area that could not be readily examined through backhoe trenching. It was located approximately $13.5 \mathrm{~m}$ north of the northern end of BHT 2 . As noted, the presence of abundant trees made trenching of the central portion of $41 \mathrm{GD} 113$ problematic. It was hoped that this test unit would provide information about the content of this part of the site. The excavation subdatum was established 5-9 $\mathrm{cm}$ above the modern ground surface. This unit was excavated to a maximum depth of $140 \mathrm{cmbd}$ to identify any remaining intact soils. No soils or sediments were encountered that match units identified in the other test units. All of the area examined in TU 5 has been disturbed.

Although TU 5 contained a significant amount of material (Table 4-6), the entire unit has been extensively disturbed. None of the dark A horizon soils that characterized the other test units and backhoe trench exposures were encountered. No evidence of the B and Bt soils was encountered. Excavation was terminated at $140 \mathrm{cmbd}$ and augering encountered the Bk soil at a depth of $218 \mathrm{cmbd}$. The deep disturbance of the sediments and soils in TU 5 suggests this area is the most likely area impacted by the landowner's investigation.

One hundred forty pieces of debitage, one core, 105 pieces of bone, and 611.8 grams of mussel shell were recovered from TU 5. Many of the bones are identifiable deer-sized fragmentary elements that show fresh bone breakage. All of these materials are in a mixed context and of limited analytic value.

\section{Test Unit 6}

TU 6 was excavated directly adjacent TU 2 to form a 1-x-2-m excavation block off the eastern wall of BHT 2 (see Figures 3-1, 4-2, and 4-3). This unit was approximately $5 \mathrm{~cm}$ south of the northern end of BHT 2. This location 
was selected because of the high density of artifacts encountered in TU 2 in Levels 8-10 ( $80-110 \mathrm{cmbd})$. The canid skull was at the northern wall of TU 2 and it appeared that the postcranial elements of this animal would be in TU 6. Complete excavation of the canid remains and obtaining an additional sample of this high-density portion of 41GD113 merited the excavation of this test unit. The same subdatum elevation was used for this unit as that employed in TU 2. Because of normal ground surface variability, there is a slight elevational difference between the ground surface of these two adjacent units. The subdatum elevation was $10-14 \mathrm{~cm}$ above the modern ground surface of TU 6 . The highest corner of TU 2 was $12 \mathrm{~cm}$ below the subdatum. Level 1 in TU 2 was 12-20 cmbd and in TU 6 was 10-20 cmbd. Use of the same reference subdatum assures that elevation measurements are equivalent within this 1-x-2-m block. None of the noncultural materials from this unit were reserved because of the sample available from TU 2.

The stratigraphy in TU 6 is essentially identical to that described for TU 2 (Figure 4-3). The A horizons extend to approximately $80 \mathrm{cmbs}$. The $\mathrm{B}$ horizon was visible between $80-110 \mathrm{cmbs}$, and the Bt was identified at $110-140 \mathrm{cmbs}$. This unit was excavated to the approximate upper boundary of calcic mottling and a very irregular contact between the $\mathrm{Bt}$ and Bk horizons. The excavation of this unit adjacent TU 2 provides an excellent sample of the artifacts and natural soil components accumulating on a series of surfaces in this portion of the site.

TU 6 contained numerous cultural and natural clasts with essentially the same vertical distribution as TU 2 (Table 4-6). TU 6 had the second highest number of debitage $(n=262)$ and the third largest bone assemblage $(n=60)$. If TU 5 is not considered, then the faunal density is second highest in this unit after TU 2, which produced 171 pieces of bone. A single flake tool was recovered from Level 4 $(30-40 \mathrm{cmbd})$ There also were 122 fragments of FCR, two hackberry seeds, and 307.5 grams of mussel shell (Table 4-6). One charcoal sample was collected from the screened matrix and three samples were piece-plotted. There were three excavation levels with high density of materials, matching the vertical distribution noted in TU 2. Each of these also is associated with high density in adjacent levels. Level 3 (30-40 cmbd) contained a relatively large amount of lithics $(\mathrm{n}=18)$. The density is comparable to that recorded for Level 2 in TU 2. In Level 7 (70-80 cmbd), 63 pieces of debitage provide similar stratigraphic evidence of a zone of accumulation to that noted in Level $6(60-70 \mathrm{~cm})$ in TU 2 (21 pieces of debitage). Similar to TU 2, there was a large accumulation of archeological materials in Level 9 (90-100 cmbd); 47 lithics were found in Level 9 of TU 6. There were fewer artifacts (though still a relatively high density) in Levels 8 and 10. Artifact density decreased dramatically in Levels 11 and 12 (three and five pieces of debitage, respectively). No artifacts were recovered from Levels 13$15(130-156 \mathrm{cmbd})$ in the Bt soil. Excavation was stopped at the contact with the $\mathrm{Bk}$ horizon. The vertical distribution of artifacts in TU 6 closely matches that seen in TU 2 .

The canid remains in TU 6 were not associated with a postcranial skeleton. Only two very fragmentary cervical vertebrae, in slightly displaced anatomical position, were encountered. The condition of the initial discovery suggested a strong likelihood that a dog interment might have been encountered. Care was taken to determine if any burial pit could be identified in association with the canid remains. No pit was apparent, and the lack of the postcranial skeleton below the cervicals indicates this was not a burial. The accumulation of artifacts, natural clasts, and the canid skull in Levels $8-10(80-110 \mathrm{cmbd})$ of TUs 2 and 6 strongly suggests accumulation on a stable surface. The close anatomical position of the cranium, mandibles, and cervical vertebrae, as well as the lack of subaerial weathering, indicates that it could not have been exposed at the surface for long or these bones would have become scattered.

\section{Test Unit 7}

TU 7 was excavated off the western profile wall of BHT 3, approximately $4.5 \mathrm{~m}$ south of the northern end of the trench (see Figure 3-1). This is the northeastern most test unit excavated on 41GD113. The subdatum used for excavation of TU 7 was $10-14 \mathrm{~cm}$ above the modern ground surface. Stratigraphic information about the soils in this unit are derived from comparison with the profile of BHT 3 (Figure 4-4, Table 4-3). The A horizons containing artifacts extend approximately $50 \mathrm{~cm}$ below ground surface. The $\mathrm{B}$ horizons were identified from $50-70 \mathrm{cmbs}$. Two Bt horizons overlying the calcic soils extend from $70-120 \mathrm{cmbs}$ in the backhoe trench profile. A significant increase in gravels was identified at the contact with the Bt horizon. Excavation of TU 7 was stopped at $80 \mathrm{cmbd}$ with a dramatic increase in gravels.

TU 7 was among the lowest density units from this test excavation (Table 4-6). Eight pieces of debitage and one biface fragment were recovered from four excavation levels. Artifacts were only encountered in Levels 3-6 (30-70 cmbd). Only Levels $4(40-50 \mathrm{cmbd})$ and $5(50-60 \mathrm{cmbd})$ contained more than a single lithic. Five pieces of debitage were collected from Level 4 and one flake and a broken, 
late stage biface came from Level 5. No FCR, bone, or mussel shell was found in TU 7. The recovery of few artifacts from TU 7, TU 3, and TU 4 suggest that these eastern test units sampled the periphery of $41 \mathrm{GD} 113$.

\section{Archeological Recovery}

Materials collected are briefly discussed below. A more detailed discussion is presented in Chapter 5 for all classes of recovered remains.

\section{Lithics}

Eight hundred seventy-one lithics were recovered from the controlled 1-x-1-m excavations at 41GD113. No diagnostic artifacts were encountered and only four tools have been identified from this assemblage. A single biface fragment was identified from TU 7. Two flake tools were collected from TU 1. One other flake tool was recovered from TU 6. One core was collected from the disturbed context of TU 5. All of the other 866 lithics from 41GD113 are debitage. The highest densities of lithic debitage were encountered in TU $2(n=407)$, TU $6(n=262)$, TU $5(n=141)$, and TU 1 $(n=34)$. Unfortunately, the assemblage from TU 5 is from a completely disturbed context.

\section{Fire-cracked Rock}

Four hundred forty-two pieces of fire-cracked rock was recovered from 41GD113. Almost all the identified FCR was collected in TU 2 and TU 6. Only six pieces of FCR were collected from TU 1, three from TU 3 , and three from TU 5. No FCR was found in TUs 4 and 7. No intact features were identified. The large number of fire-cracked rock in TU 2 and TU 6, identified as Feature 1 in the profile of BHT 2, suggests that a feature was located near these units.

\section{Feature 1}

Feature 1 was a loose association of FCR within TU 2 and TU 6. The concentration was first noted in the profile wall of BHT 2 and was the reason for selection of the TU 2 location. Feature 1 was defined from the exposure in BHT 2 and the relatively high density of cultural materials associated with this location during excavation of TU 2 and TU 6. The majority of the mapped FCR was recovered from the southern half of TU 2 in Level $9(90-100 \mathrm{cmbd})$, especially the southwestern quadrant of this unit. Eighteen mapped pieces of FCR (1,638 g) and 64 other pieces (35 g) were identified by excavators as closely associated and part of Feature 1. An additional 127 pieces of FCR (1,048 g) were recovered from this level. Although not specifically designated as part of Feature 1 during excavation, this additional amount of fire-cracked rock is certainly related to the feature concentration. Fewer and more dispersed FCR and artifacts were encountered in TU 6 . The highest density of mapped items in TU 6 was recovered from the southcentral portion of Levels 8 and $9(80-100 \mathrm{cmbd})$. Four pieces of FCR $(636 \mathrm{~g})$ were piece-plotted in Level 8 and 32 additional pieces $(159 \mathrm{~g})$ recovered. In Level 9 , three pieces of FCR were mapped ( $351 \mathrm{~g}$ ) and 18 pieces $(96 \mathrm{~g}$ ) recovered from screening. The area of FCR concentration in TU 2 is approximately $70 \mathrm{~cm}$ east-west by $60 \mathrm{~cm}$ north-south. These dimensions are almost certainly smaller than the distribution of FCR at this location. The FCR concentration in the southwestern quadrant of TU 2 is adjacent to the unexcavated deposits on the south side of this unit and the BHT 2 excavation on the western side of the unit. No FCR was seen on the western wall of BHT 2. This elevation in TU 2 and TU 6 is associated with high densities of other cultural and non-cultural materials (Table 4-6).

There is no higher density of charcoal associated with the FCR in the other portions of TUs 2 and 6 . This group of FCR does not represent an intact feature, but is the highest concentration of FCR recovered at 41GD113. Feature 1 is likely to represent either the remains of a thermal feature that was disassembled prior to site abandonment, a small hearth that has been dispersed from natural agents following abandonment, or part of an accumulation of trash. As noted previously, the preservation of the canid remains suggests rapid burial has affected at least some of the recovered material in this location. It is unclear how the physical association of those bones may relate behaviorally to the FCR. The high number of FCR, lithics, and bone may suggest that this area was a dump rather than an area of primary activities.

The canid burial was not designated as a separate feature. The partially articulated cranial remains were not associated with any definable spatial separation from adjacent materials and no evidence of a pit could be identified. There is no indication that the skull, cervical vertebrae, and other fragments were deposited as a unique event, they simply appear to be part of the same accumulation events affecting FCR and lithics at this location. The canid bones represent a component of the debris associated with the FCR concentration designated as Feature 1.

\section{Bone}

Three hundred thirty-nine fragments of bone were recovered during excavation of 41GD113. Bone fragments were not 
common in most of 41GD113. Significant amounts of bone were identified in TU 2 and TU 6, and from the disturbed context of TU 5. The majority of the bone assemblage is represented by fragments of unidentified elements of unknown species, small mammals, medium-sized mammals, and deer-sized ungulates. Identified remains include deer (Odocoileus virginianus), tortoise (family Testudinidae), canid (Canis sp.), and recent remains of armadillo (Dasypus novemcinctus). There is no unambiguous evidence suggesting significant prehistoric cultural origin for this bone.

\section{Charcoal}

Eleven pieces of charcoal were piece-plotted at 41GD113 and another 10 pieces were saved from screening. Eight pieces of charcoal were piece-plotted in TU 2 and three were piece-plotted in TU 6. In TU 2, one sample was pieceplotted in Level 5 (50-60 cmbd), two in Level 7 (70-80 cmbd), two in Level 8 (80-90 cmbd), one in Level 9 (90-100 cmbd), one in Level $10(100-110 \mathrm{cmbd})$, and one in Level $11(110-120 \mathrm{cmbd})$. The three piece-plotted charcoal samples from TU 6 all came from Level 9 (90$100 \mathrm{cmbd}$ ). Sufficient charcoal samples were recovered to date the apparent archeological concentration of artifacts in Level 9 and the overlying soils in Levels $7-8$. Two hackberry (Celtis sp.) endocarps also were piece-plotted and collected from Level 9 (90-100 cmbd) in TU 2. They were reserved for potential dating or paleoenvironmental analysis. Although the hackberry endocarps were not dated or submitted for additional analyses, they have been retained as part of the curated assemblage from 41GD113. In addition to their dating potential, isotopic analysis can identify past rainfall patterns (Cowen et al. 1997; Jahren et al. 2001). An additional seven pieces of charcoal were reserved from screening of Levels 2 (20-30 cmbd), $3(30-40 \mathrm{cmbd}), 7$ ( $70-80 \mathrm{cmbd})$, and $9(90-100 \mathrm{cmbd})$ in TU 2 at $41 \mathrm{GD} 113$ for potential species identification or other analyses. One piece of charcoal was saved from screening of Level 3 (30$40 \mathrm{cmbd})$ of TU 6 and one from Level $8(80-90 \mathrm{cmbd})$ of that unit. Although the context of these samples is not adequate for investment in dating, charcoal recovered from screening can be useful for reconstruction of past climate, vegetation, natural fire regimes, and for implications about firewood use.

\section{Shell and Gravels}

All materials retained in the screens from TUs 2 and 3 were collected. In addition to cultural material, this also included all mussel shells, snail shells, and natural lithic clasts. These two test units offer controlled, systematic information about the non-cultural components of these sedimentary units. This is important in addressing archeological site formation.
TU 2 produced 218.43 grams of mussel shell, $1.84 \mathrm{~kg}$ of snail shell, and $9.4 \mathrm{~kg}$ of gravels. Natural clasts collected from TU 3 included 1.1 grams of snail shells and $41.7 \mathrm{~kg}$ of gravel. No mussel shell was recovered from TU 3. Mussel shell was systematically collected from all other units. TU 1 produced 179.2 grams of mussel shell. Snail shells also were systematically saved during excavation of TU 1 and there were 111 grams recovered. The disturbed deposits of TU 5 contained 612 grams of mussel shell, and 307.5 grams were collected from TU 6. No mussel shell was found in TU 4 or TU 7.

\section{Modern Artifacts}

Few recent artifacts were recovered during excavation. All of the recent artifacts pertain to the middle to late-twentiethcentury activities associated with the adjacent roadway and cattle pasture. None of the artifacts suggest historic period use of this location. Only one fence staple from Level 4 $(40-50 \mathrm{cmbd})$ in TU 2 and two pieces of modern glass from Level 2 (10-20 cmbd) in TU 3 were found. Although TU 5 was completely disturbed, no recent artifacts were recovered in this unit. This paucity of historic debris indicates that 41GD113 does not have any evidence for deposits prior to mid-twentieth-century use. No artifacts were found suggesting any Spanish Colonial, eighteenth-century, or early-twentieth-century events in the vicinity of the site.

\section{Discussion}

There are at least two vertical concentrations of artifacts in the upper A horizons of TU 2 (Levels 2 and 6) and TU 6 (Levels 3 and 7). It is unclear how these may be equivalent to the artifact concentrations in TUs 1,3 , and 4 where there is only a low density of artifacts between $20-40 \mathrm{~cm}$ below ground surface. TU 7 had artifacts only between $30-70 \mathrm{~cm}$, with the highest density between $40-60 \mathrm{~cm}$. The two test units off BHT 2 (TU 2 and TU 6) were the only excavations to contain artifacts at the contact between the Bt and upper horizons. Minimally, these data suggest that three stable surfaces associated with significant accumulations of artifacts are represented at $41 \mathrm{GD} 113$. It is unclear if this can be inferred to identify at least three cultural occupation events. All units have a nearly identical sequence of alluvial deposits above the Bt soil. The BHT 4 profile suggests that the Bt soil of the southern terrace may be younger than that in the northern end of BHT 4, or in BHT 3 and BHT 5. Nordt and Crawford's description (Appendix A) of BHT 4 was done only in the younger sediments and soils of that trench. They also note that BHT 3 contains what is probably an older Bt soil from that in BHT 1, BHT 2, and the southern two-thirds of BHT 4. 
The densest artifact recovery was from the southwestern portion of the site in TU 1, TU 2, and TU 6 (Table 4-6). Dating of three charcoal samples from TU 2 and TU 6 suggest gradual aggradation associated with the zones of highest artifact density. Dates from the top of the Bt horizon, top of the B horizon, and top of the A4 soil indicate 30-50 $\mathrm{cm}$ of sedimentary accumulation over a period of about 200 years. These dated soils situated at approximately $60-110$ $\mathrm{cm}$ below the current ground surface do not indicate more rapid burial events than noted for other drainages in the well-documented Houston district (Abbott 2001:Figure 24). The accumulations in TU 2 and TU 6 indicate that some non-cultural materials are most common at the same elevations as cultural artifacts. The frequencies of bone, mussel shell, and snail shell are similar to the vertical distribution of cultural lithics. There are no indications that the mussel or snail shells are unambiguously cultural debris. There is no dense accumulation or breakage of the pelecypod valves that would suggest these shells have been deposited as discarded subsistence or technological waste. They are considered sedimentary particles informative about natural processes of site formation (Claassen 1998:53, 70-73). Gravel frequencies are not associated with the highest density of artifacts and indicate a higher energy stream context prior to human use of this location.

The multiple zones of peak artifact frequencies noted in TUs 2 and 6 and the presence of materials in the upper horizons of TUs 1, 3, 4, and 7, indicate that 41GD113 has experienced multiple human occupations. These are associated with a series of periodically stable soil surfaces in an aggrading floodplain environment. The presence of mussel shell that is not cultural in origin indicates that these surfaces associated with the highest archeological densities were temporally available for a range of depositional events. The depositional pulses incorporating natural and cultural materials demonstrate a depositional relationship, not a behaviorally related association (see Chapter 5). The three dated charcoal samples suggest that sedimentation episodes were closely spaced, but that the overall amount of sediment containing archeological materials did not aggrade rapidly at 41GD113. Although three zones of artifact accumulation are present, many individual occupation events could have occurred during periods when these surfaces were stable.

Site 41GD113 contains a relatively low-density archeological assemblage, few tools, potentially mixed deposits, and evidence of multiple occupational events. The single concentration of fire-cracked rock (Feature 1) identified is not an intact feature and likely represents an area of trash accumulation rather than primary activity space.

\section{$41 G D 114$}

The setting of 41 GD114 is nearly identical to that of 41GD113. This site is located on a slight rise that is much more heavily vegetated than the surrounding grassland. Tree cover is identical to that noted on 41GD113. There is a predominance of mesquite, with acacias, oaks, and prickly pear in decreasing order of frequency. 41GD114 is located about 86-120 m east of the eastern margin of 41GD113.

Three backhoe trenches and two 1-x-1-m test units were excavated on this site to examine the integrity and content of subsurface remains (see Figure 3-2). BHTs 1 and 2 indicated extreme disturbance of the sediments of 41GD114 to a depth of $1.5 \mathrm{~m}$ and greater by activities before TXDOT initiated survey and testing of these sites. BHT 3 contained some intact sediments and soils, but also demonstrated some destruction of intact site deposits from the landowner's mechanical excavation of this site. Test unit excavation identified very shallow soils ( $\sim 50 \mathrm{~cm}$ deep) overlying weathered Goliad formation coarse sandstone or siliceous gravel deposits of fluvial origin. The proximity of rock that holds ground water is associated with significant evidence of tree root bioturbation and krotovina. Unlike 41GD113, this site exhibits extensive destruction of many of the archeological deposits and poor subsurface integrity of the remaining portions within the proposed Noble Cemetery relief route right-of-way.

\section{Geoarcheological Investigations}

\section{Backhoe Trench 1}

This trench was excavated on the western side of the site (see Figure 3-2). It was approximately $11.2 \mathrm{~m}$ long and maximally $1.6 \mathrm{~m}$ deep. BHT 1 was oriented north-south $\left(0^{\circ}-180^{\circ}\right.$ from magnetic north). This trench exhibited extensive mechanical disturbance of the soils and sediments that exceeds the maximum depth exposed in the trench. There was almost no intact soil visible in this excavation. No profile of this trench was drawn nor was it described. Nordt and Crawford (Appendix A) also did not describe this trench.

\section{Backhoe Trench 2}

BHT 2 sampled the northern portion of 41GD114 (see Figure $3-2$ ). BHT 2 was excavated perpendicular to BHT 1 and BHT 3. This trench was oriented east-west $\left(271^{\circ}-91^{\circ}\right.$ from magnetic north). BHT 2 was $9.6 \mathrm{~m}$ long and maximally 1.5 $\mathrm{m}$ deep. This backhoe trench also exposed sediments and soils that were significantly disturbed from the landowner's 
excavations of this site. Mechanical excavation extended at least $1.5 \mathrm{~m}$ below the current ground surface. A very small portion of the eastern end of this trench was relatively undisturbed. No drawing or soil description was performed for this backhoe trench. Because the soil and sedimentary sequence visible in this portion of BHT 2 was identical to the less disturbed BHT 3, recording of the more intact trench offered more valuable geoarcheological information about 41GD114. Nordt and Crawford did describe this trench profile (Appendix A).

\section{Backhoe Trench 3}

BHT 3 was situated on the eastern side of site $41 \mathrm{GD} 114$ (see Figure 3-2) oriented north-south $\left(0^{\circ}-180^{\circ}\right.$ from magnetic north). This trench was excavated $9.7 \mathrm{~m}$ long and extended to a maximum depth of $1.45 \mathrm{~m}$ below the current ground surface. This was the only trench of the three excavated on this site that contained some undisturbed sediments and soils. The western wall of BHT 3 was profiled, described, and sampled for magnetic susceptibility (Figure 4-8, Table 4-7). Twenty-two soil susceptibility samples were collected from a column approximately $80 \mathrm{~cm}$ north of the southern end of the trench.

There is significant mechanical disturbance of the entire middle of this backhoe trench. Only the southern $1.5 \mathrm{~m}$ and northern $3.5 \mathrm{~m}$ of this trench contain original stratigraphy that has not been impacted by the landowner's mechanical investigations. Soils in this trench are similar to those described for 41GD113. Three A horizons extend to a depth of $50 \mathrm{cmbs}$. A Bt soil extends to approximately $80-85 \mathrm{cmbs}$. This soil was noticeably rubified (dry color $=2.5 \mathrm{YR} 4 / 2$ ). Two Bk soils were identified at the base of the profile. Only these last two horizons had any effervescent reaction. There are insignificant amounts of carbonate in the solum and $\mathrm{Bt}$ horizons. As noted in Appendix C, the magnetic soil susceptibility profile shows three areas of enhancement, though the values are low. The first is at roughly $22 \mathrm{cmbs}$, a second occurs at about $57 \mathrm{cmbs}$, and a third is present at around $75 \mathrm{cmbs}$ (see Appendix C, Figure C-1). None of these appear to be related to the breaks noted above.

\section{Discussion}

Although the trenches on 41GD114 sampled significantly disturbed sediments, site formation is nearly identical to that noted at 41GD113. The deepest exposed units are soils with massive soft carbonate and evidence of extensive pedogenic carbonate formation. These units appear to be much older than any other component of the ancient and modern solum. Overlying sediments exhibit no carbonate above the Bk (although BHT 1 and BHT 2 on 41 GD113 both produced moderate to strong effervescent reactions of the $\mathrm{B}$ and $\mathrm{A}$ horizons). In BHT 3 and BHT 5 on 41GD113, there is an erosional unconformity between the $\mathrm{Bk}$ and the lowermost Bt boundary. The Bt soil in BHT 3 on 41 GD114 also appears to be much older than the overlying A horizons. The amount of clay accumulation and occurrence of many more clasts than in the A horizons suggests that the strong development indicated is not pedogenically related to the modern soil, but is considerably older.

\section{Test Unit Excavations}

\section{Test Unit I}

Because of the significant amount of disturbance in the area where the backhoe trenches were placed, test units were excavated away from those locations. TU 1 was placed close to the right-of-way to sample what was identified as the approximate middle of the site (see Figure 3-2). TU 1 is approximately $7.6 \mathrm{~m}$ south of the southern end of BHT 3 . The excavation subdatum was located $5 \mathrm{~cm}$ above the ground surface of TU 1.

This unit was only excavated to $61 \mathrm{cmbd}$. At that level, highly weathered limestone bedrock was encountered across almost the entire excavation floor of TU 1 . There was significant root disturbance of the upper $40 \mathrm{cmbd}$ in this unit. Large amounts of recent charcoal also were encountered in the upper $20 \mathrm{cmbd}$. Many siliceous gravels were present from Levels 3-4 (20-40 cmbd) in the AB and B horizons. These directly overlie what appears to be an $\mathrm{R}$ horizon of weathered Goliad formation sandstone bedrock. The bedrock does not resemble the soft calcic horizons noted in the backhoe trenches. The $\mathrm{R}$ horizon consists of abundant fractured pieces of calcareous conglomerate sandstone that get larger with depth. This was not seen in any of the backhoe trenches on $41 \mathrm{GD} 114$ or $41 \mathrm{GD} 113$. This rock is identical to the material present as fire-cracked rock on 41GD113. The clear stratigraphy and lack of siliceous gravels in the lowest portion of the excavation suggests that this is not a gravel deposit indicative of channel deposits.

Artifact density in TU 1 was relatively high compared with 41GD113. Thirty-one pieces of debitage, one piece of bone, eight pieces of FCR, and 11.77 grams of mussel shell were recovered from TU 1 (Table 4-8). Most of these artifacts were recovered from Levels 2 (13 lithics) and 3 (10 lithics) at $10-30 \mathrm{cmbd}$. A single fence staple was recovered from Level 4. Bioturbation from tree roots was abundant throughout Levels 1-4. Recent charcoal was abundant within 


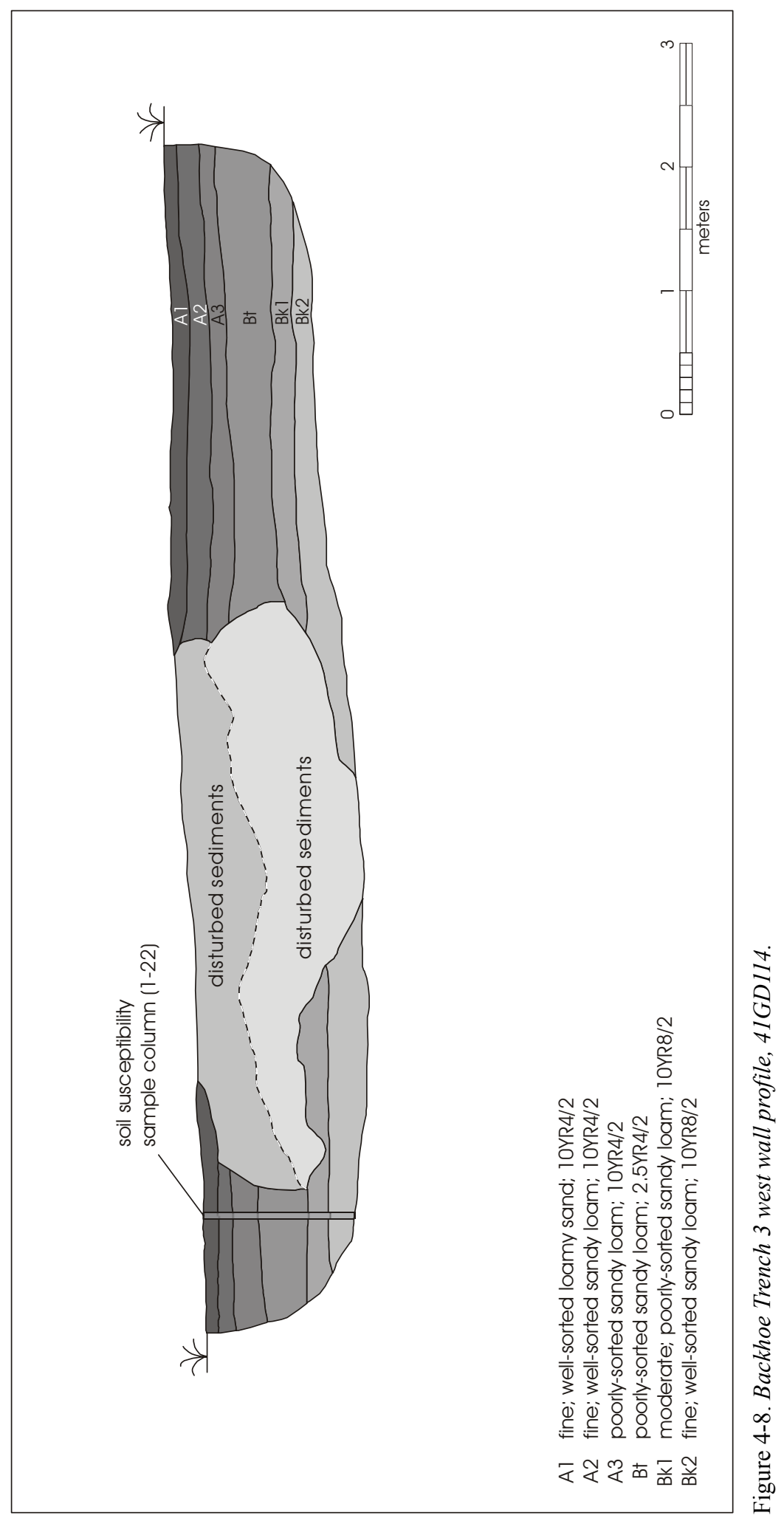


bioturbated areas of Levels 1-2. Only one piece of bone was recovered and snail shell was not as common as on 41GD113. Artifact density decreased in Level 4 (five lithics) and more dramatically in Level 5 (three lithics). No artifacts were recovered from Level 6. Siliceous gravels were common throughout Levels 3-6. Fractured sandstone bedrock was encountered from the lower half of Level 2 through Level 6, and increased in abundance with depth. Weathered in situ sandstone bedrock was encountered within the lowest $5 \mathrm{~cm}$ of Level 6 .

\section{Test Unit 2}

TU 2 was excavated north of TU 1 (see Figure 3-2) to determine if the bedrock encountered in the lowest portions of TU 1 extended farther and to link the soils of TU 1 with the results of profiling BHT 3 . TU 2 was placed approximately $2.3 \mathrm{~m}$ west of the southern end of BHT 3 . The subdatum for TU 2 was $11 \mathrm{~cm}$ above the modern ground surface. Excavation terminated at $60 \mathrm{cmbd}$ in a zone of abundant siliceous gravels. The uppermost three levels all contained significant amounts of bioturbation. Krotovina were common and some recent charcoal associated with evidence of bioturbation by tree roots was evident in Levels 1-3 (11-40 cmbd). Gravels were common throughout the excavation of TU 2 , and became more abundant and larger in Levels 3-5. Clasts were $<3 \mathrm{~cm}$ in Level 3, increasing to a maximum dimension of $5 \mathrm{~cm}$ in Level 5 . Gravel clast frequency was very high in Level 5.

Artifact recovery was comparable to that in TU 1 (Table 4-8). Thirty-four lithics were collected from TU 2. A single piece of FCR was recovered in Level 3. No other classes of prehistoric or historic materials were encountered. All excavation levels in TU 2 contained lithics. The highest density of debitage was in Level $3(n=14)$. Excavation was terminated at the base of Level $5(60 \mathrm{cmbd})$ because it was apparent that the sediments below $35-40 \mathrm{cmbd}$ represented channel deposit of abundant gravels with extremely low probability to contain archeological deposits that were not extensively disturbed through stream processes. No indications of bedrock were seen in TU 2. Most gravels were siliceous and appeared to represent high-energy sediments.

\section{Archeological Recovery}

Sixty-five lithics, one bone fragment, one FCR, and 11.77 grams of mussel shell fragments were recovered from TU 1 and TU 2. Both units showed a peak concentration in the upper portion of the soil profile. Artifact densities were highest between 10-40 cmbd in both TU 1 and TU 2. Both

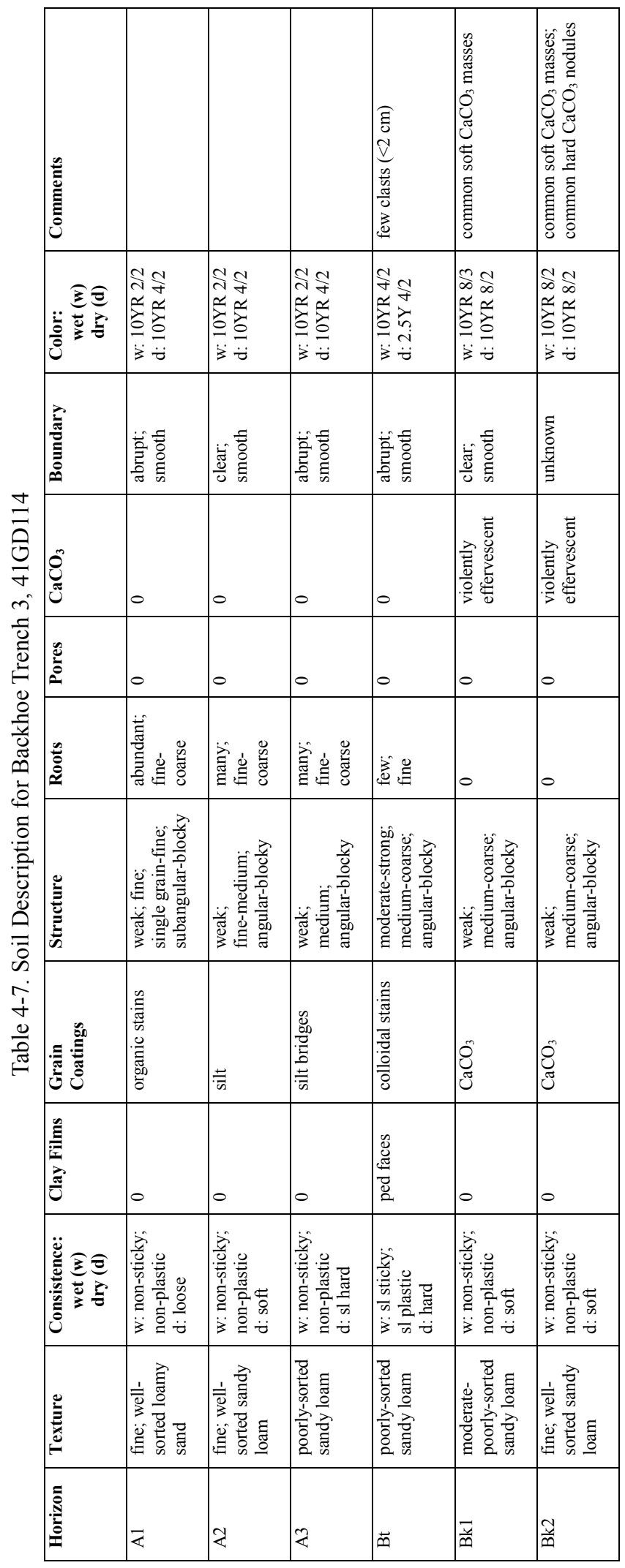


Table 4-8. Archeological Recovery from Test Units at 41GD114

\begin{tabular}{|c|c|c|c|c|c|c|c|c|c|c|c|c|}
\hline \multirow[b]{3}{*}{ Unit } & \multirow[b]{3}{*}{ Level } & \multirow{3}{*}{$\begin{array}{c}\text { Depth } \\
\text { (cmbd) }\end{array}$} & \multicolumn{10}{|c|}{ Artifact Class } \\
\hline & & & \multicolumn{2}{|c|}{ Debitage } & \multicolumn{2}{|c|}{ Bone } & \multicolumn{2}{|c|}{ FCR } & \multicolumn{2}{|c|}{ Mussel Shell } & \multicolumn{2}{|c|}{ Gravel } \\
\hline & & & $\mathbf{n}$ & wt. (g) & $\mathbf{n}$ & wt. (g) & $\mathbf{n}$ & wt. (g) & n & wt. (g) & $\mathbf{n}$ & wt. (g) \\
\hline 1 & 1 & $0-10$ & & & & & & & & & & \\
\hline 1 & 2 & $10-20$ & 13 & 6 & & & 1 & 26.2 & 1 & 0.2 & & \\
\hline 1 & 3 & $20-30$ & 10 & 19.6 & & & 1 & 1.45 & 2 & 5.03 & 2 & 1.1 \\
\hline 1 & 4 & $30-40$ & 5 & 10.1 & & & 1 & 0.43 & 1 & 4.6 & & \\
\hline 1 & 5 & $40-50$ & 3 & 13.6 & 1 & 0.2 & 5 & 13.7 & 1 & 1.74 & & \\
\hline 1 & 6 & $50-60$ & & & & & & & 1 & 0.2 & & \\
\hline \multicolumn{3}{|r|}{ TU 1 Totals } & 31 & 49.3 & 1 & 0.2 & 8 & 41.78 & 6 & 11.77 & 2 & 1.1 \\
\hline 2 & 1 & $11-20$ & 2 & 6.4 & & & & & & & & \\
\hline 2 & 2 & $20-30$ & 6 & 2.1 & & & & & & & & \\
\hline 2 & 3 & $30-40$ & 14 & 17.1 & & & 1 & 0.7 & & & & \\
\hline 2 & 4 & $40-50$ & 7 & 17.7 & & & & & & & & \\
\hline 2 & 5 & $50-60$ & 5 & 63 & & & & & & & & \\
\hline \multicolumn{3}{|r|}{ TU 2 Totals } & 34 & 106.3 & & & 1 & 0.7 & & & & \\
\hline
\end{tabular}

test units were terminated at $60 \mathrm{cmbd}$ because of dramatic increases in natural clasts (TU 2) or the presence of weathered bedrock (TU 1). Artifacts are probably mixed into this lowest portion of the A horizons because of the significant amount of bioturbation from burrowing animals and large roots noted in both test units. TU 1 contained common fluvial gravels from $30-55 \mathrm{cmbd}$ and weathered bedrock was encountered at approximately $55-60 \mathrm{cmbd}$. TU 2 contained abundant evidence of stream gravel deposits from $\sim 35 \mathrm{cmbd}$ to the base of the excavation at $60 \mathrm{cmbd}$. This portion of the site produced low densities of artifacts during the initial testing as well. ST 2 and ST 4 were the only shovel tests from Prewitt and Associates' work that fall within the right-of-way. ST 2 contained no artifacts and ST 4 contained six items. ST 4 was near to BHT 1, and no additional testing was performed on the western side of the site because of the extensive disturbance found in BHT 1. Because the majority of the site is outside of the road construction right-of-way, only this northernmost area could be examined.

\section{Discussion}

Fields et al. (2002:54) report deep soils for the southern and eastern portions of the site and note the shallow A horizon underlain by gravels in the northern and western shovel tests. Fields et al. (2002:54) also note that gastropod and pelecypod shells are scarce at 41GD114 and suggest the few encountered probably do not have a cultural origin.
CAR's testing investigation did not identify any significant, buried archeological deposits. Examination of the portion of $41 \mathrm{GD} 114$ within the right-of-way indicates that only shallow archeological deposits are present over stream deposits of gravels and weathered bedrock. There is much bioturbation of these deposits, primarily by root activity. ST 2 and ST 4 excavated by Prewitt and Associates also encountered gravels at the base of excavations. Gravels were encountered at 40 cmbs in ST 4 and at $60 \mathrm{cmbs}$ in ST 2. The northern one-third of $41 \mathrm{GD} 114$ has been extensively disturbed by mechanical excavation to a depth of at least $1.5 \mathrm{~m}$. CAR's testing excavations targeted what was presumed to have been the most apparent surface indications of mounding and artifacts during the landowners' investigation of this site. This area has been so extensively disturbed through uncontrolled bulldozer impact that it contains no intact archeological deposits and cannot contribute to archeological research.

Much of Prewitt and Associates' testing of 41GD114 occurred outside of the area identified as the current project right-ofway. Although these areas contained deeper sediments, recovery of archeological material was quite low (Fields 2002:3). There is no evidence that the portion of 41GD114 outside of the TxDOT right-of-way contains significant archeological deposits. Examinations of the portion of 41 GD114 within the right-of-way demonstrated the presence of shallow soils with very low densities of artifacts and the landowner's extensive mechanical destruction of the northern portion of the site. 


\section{Chapter 5: Laboratory Analyses of Recovered Archeological Material}

Site 41GD113 produced a moderately large assemblage of lithics, bone, and fire-cracked rock. Eight hundred seventyone lithics, 339 pieces of bone, and 442 pieces of FCR (5.85 $\mathrm{kg}$ ) were recovered from controlled 1-x-1-m test excavation units. Eleven charcoal samples were piece-plotted and collected. Two pieces of recent glass, and one recent fence staple also were recovered from 41GD113. A sample of natural clasts included $1.32 \mathrm{~kg}$ of mussel shell, $1.95 \mathrm{~kg}$ of snail shells, and $51.2 \mathrm{~kg}$ of gravels that were quantified for comparison with archeological artifact frequencies. Additional samples include two mapped hackberry seeds and magnetic susceptibility samples collected from each backhoe trench. These can provide information about past environments and cultural activities at 41GD113. Additionally, data on site formation are available from the profiling and magnetic susceptibility samples collected from one profile in each backhoe trench, and from retention of gravels and shell clasts from two test units.

Site 41GD114 produced only 65 lithics, one piece of bone, and nine pieces of FCR ( $43 \mathrm{~g}$ ) from shallow contexts that do not appear to demonstrate significant integrity. One recent fence staple and 11.77 grams of mussel shell also were collected. The small size of the lithic assemblage from 41GD114 does not appear to offer any significant opportunities for improved understanding of prehistoric use of this site or the area. Other than the lithic debitage assemblage from 41GD114, the other remains from this site are not presented in any greater detail than previously discussed in the site description.

\section{Charcoal}

Chronometric dating of archeological deposits is valuable even when artifacts considered to be temporally diagnostic are recovered from excavations. In the absence of any diagnostic artifacts from 41GD113, radiocarbon dating of the archeological horizons is even more critical. Three charcoal samples were submitted to Beta Analytic for AMS dating. Samples were selected on the basis of their contextual integrity as recorded by excavators and the size of each sample. A series of three specimens were chosen to provide vertically bracketed dating on the densest portion of the deposit. The results of those analyses are presented in Table 5-1 and in Appendix B. The dates provided in Table 5-1 represent both the measure of their uncorrected radiocarbon age and the 2-sigma calibrated results. Beta sample 174046 was piece plotted in TU 2 at $72 \mathrm{~cm}$ below datum (Level 7) at the top of the A4 horizon. This sample dated to cal BP 1290-1070. Beta sample 174047 was mapped at $118 \mathrm{cmbd}$ (Level 11) in TU 2 within the uppermost portion of the Bt horizon. This sample dated to cal BP 1540-1320. One charcoal sample (Beta sample 174045) from the top of the B horizon plotted in TU 6 at $100 \mathrm{cmbd}$ (Level 9) produced a date of cal BP 1550-1310. The stratigraphic positions of these samples are shown in Figure 4-3.

The two older dates suggest relatively rapid formation of thin sedimentary deposits within what is now the B horizon. All of the dates are in approximately expected stratigraphic position and suggest that they are good indicators of the ages of the Bt, B, A4, and A3 depositional sequence. The slightly younger date from the sample in the uppermost $\mathrm{Bt}$ horizon of TU 2 (Beta sample 174047) compared with that from the B horizon in TU 6 (Beta sample 174045) does not necessarily indicate a disturbed context. All of the boundaries of these horizons are abrupt (within $\sim 2 \mathrm{~cm}$ ), but there is horizontal variation in expression of those boundaries that were not detectable by the excavation crew. These are soil boundaries that are not completely equivalent to sedimentary stratigraphy. The proximity of the transition from the B to Bt horizons may suggest that the sample from the uppermost portion of the Bt horizon (Beta sample 174047) was deposited within a nearly equivalent time period to the sediments within the modern B horizon of this

Table 5-1. AMS Radiocarbon Dates from TU 2 and TU 6 at 41 GD113

\begin{tabular}{|c|c|l|c|c|c|c|c|}
\hline Unit & Level & $\begin{array}{c}\text { Depth below } \\
\text { Subdatum }\end{array}$ & Feature \# & Beta Sample \# & $\begin{array}{c}\text { Radiocarbon Years } \\
\text { Before Present }\end{array}$ & Calibrated Date & 13C/14C Ratio \\
\hline TU 6 & 9 & $100 \mathrm{~cm}$ & 1 & 174045 & $1550 \pm 60 \mathrm{BP}$ & cal BP $1550-1310$ & $-26.5 \%$ \\
\hline TU 2 & 7 & $72 \mathrm{~cm}$ & 1 & 174046 & $1270 \pm 50 \mathrm{BP}$ & cal BP $1290-1070$ & $-26.7 \%$ \\
\hline TU 2 & 11 & $118 \mathrm{~cm}$ & 1 & 174047 & $1550 \pm 50 \mathrm{BP}$ & cal BP $1540-1320$ & $-26.9 \% 0$ \\
\hline
\end{tabular}


profile that produced a statistically identical date (Beta sample 174045). Additionally, although care was taken to note krotovina and avoid taking samples from disturbed contexts, slight displacement of charcoal particles could have occurred through invertebrate bioturbation. However, such minor potential displacements do not cast suspicions that the dates are not associated with their sedimentary events associated with the highest density concentration of artifacts in TU 2 and TU 6.

All three dates indicate a Late Archaic occupation associated with the densest archeological deposits at 41GD113. No diagnostic artifacts were recovered from this site during CAR's testing or the previous examination by Prewitt and Associates. No diagnostic implements were reported by Schmiedlin or Birmingham. It is unknown if the artifacts in the upper portions of the solum may come from more recent time periods. They could be materials that are contemporaneous or only slightly younger than the charcoal dates. The relatively large amount of bioturbation may indicate that at least some of the artifacts above the dated soils are likely contemporaneous with those in the highest density deposits in Levels 7 through 11 in TUs 2 and 6. Although some artifacts were encountered at elevations deeper than the dated samples, these represent only a small portion of the total artifact assemblage.

Because no clearly definable features, bone assemblages, robust sample of identifiable tools, or other interpretive anchoring points can be identified with the dates, it is uncertain how 41 GD113 could be used to improve culture historical understanding of this location. From the excavated sample, it cannot be unambiguously determined if the 40 $\mathrm{cm}$ bulge in artifact density that has been dated represents a single occupation or the remains of several alternative multiple visitation dynamics (i.e., few or many, closely spaced temporally or highly episodic). However, dating and the evidence from natural clasts that the same portions of the profile were subject to background environmental incorporation of mussel shells and snail shells all suggest that multiple occupation events are most probable. The very closely matched dates from Beta samples 174047 (cal BP 1540-1320) from $118 \mathrm{cmbd}$ and 174045 (cal BP 1550-1310) at $100 \mathrm{cmbd}$ do indicate that the sediments of the B horizon likely formed in a relatively rapid set of fine alluvial depositional events. Beta sample 174046 (cal BP 12901070) at $72 \mathrm{cmbd}$ does not indicate any different rates of sedimentation affecting the upper portion of the high-density artifact zone.

\section{Lithics}

The small size of the $41 \mathrm{GD} 113$ assemblage makes relatively complete descriptive analyses of these materials possible to document this location and fully report the contents of this site for other comparative studies of this region. The recovered materials do not represent a unique or significant collection of materials, but descriptive analyses can provide useful additional data on prehistoric activities along this minor tributary of Coleto Creek. The assemblage contained only one biface fragment, three flake tools, one core and 866 pieces of debitage. Only a small sample of debitage was recovered from the two test units excavated at 41GD114.

\section{Lithic Tools}

Only four tools have been identified during the fieldwork and laboratory processing, all came from 41GD113 (Figure 5-1). A single biface fragment was recovered from Level 5 (50-60 cmbd) of TU 7 adjacent to BHT 3. This implement is made on good-quality translucent brown chert and represents late stage reduction (Figure 5-1a). It is broken by a snap fracture and not a manufacturing break. This fragment is $38 \mathrm{~mm}$ in maximum length, $25 \mathrm{~mm}$ wide, and 9 $\mathrm{mm}$ thick. The majority of the flake scars are from hard hammer percussion, but there are a few pressure flake scars. The edges are still somewhat sinuous and there has been some bifacial thinning of one end resulting in a beveled cross-section. It is not apparent whether this piece was intended to be a projectile point or knife implement. Except for three flake tools and one core, no other formal tools, preforms, or flake tools were identified during analysis of the lithic assemblage.

One unifacial flake tool was recovered from Level 5 $(40-50 \mathrm{cmbd})$ in TU 1 . This is a fragment of a large brown chert flake with two very steep, reworked edges that occupy two-thirds of the flake perimeter (Figure 5-1b). This piece is $42 \mathrm{~mm}$ long, measured from the proximal to distal margin. A significant amount of the proximal portion of this flake is missing. Figure 5-1b shows this tool in normal orientation with the proximal end to the bottom of the page. The maximum width of this tool is $45 \mathrm{~mm}$. There is no modification of the ventral face. The dorsal surface is very convex (thickness is $20 \mathrm{~mm}$ ) with several large hard hammer flake scars. There are two separate edges that have steep hard hammer retouch and use scars. A convex portion of the dexter edge has abundant step fracturing from rejuvenation of apparently hard use of this edge. Many fine step fractures 
suggest use damage from a relatively hard surface. There is a concave retouched edge with heavy wear that is the sinister (or broken proximal) portion of this fragment. The entire edge has small step fractures and few larger removals suggesting this portion of the tool was less reworked than the convex portion. Both edges suggest a significant amount of use and some resharpening. Use on hard materials is suggested by the abundant step fracturing of the tool edges. The variability in the adjacent used edge morphologies suggests that wood (or possibly bone) working may have been the use role of this flake tool.

A flake tool recovered from the Level 2 $(10-20 \mathrm{cmbd})$ of TU 1 is made on a coarse-grained pink chert. The flake is $32 \mathrm{~mm}$ long and is maximally $16 \mathrm{~mm}$ wide. It is blade-like in its morphology (two main dorsal scars with a central ridge) and is missing an unknown amount of the distal portion (Figure 5-1c). The flake is slightly curved, the dexter edge is concave and the sinister is convex. There are numerous platform step fractures from pre-removal preparation. There are fine, overlapping scalar flakes indicating use wear along $24 \mathrm{~mm}$ of the distal portion of the sinister edge. This is the convex edge of this piece. All of the modification is on the dorsal face of this flake. The damage to the edge appears to be use wear and not intentional shaping of the worked edge. There is slight polish over the flake scars and no evidence of step fracturing or other damage indicating use on hard materials.

The final flake tool is made on a gray-brown piece of Edwards chert and was collected in Level $4(40-50 \mathrm{cmbd})$ of TU 6. This is a complete flake that is $34 \mathrm{~mm}$ long and 23 $\mathrm{mm}$ in maximum width (Figure 5-1d). Most of the platform broke off during removal, but a small portion of the most distal platform retains several step fractures from edge preparation prior to removal from the nucleus. The distal portion of the flake has a pronounced curve in the ventral face and there is a step termination. It appears this flake

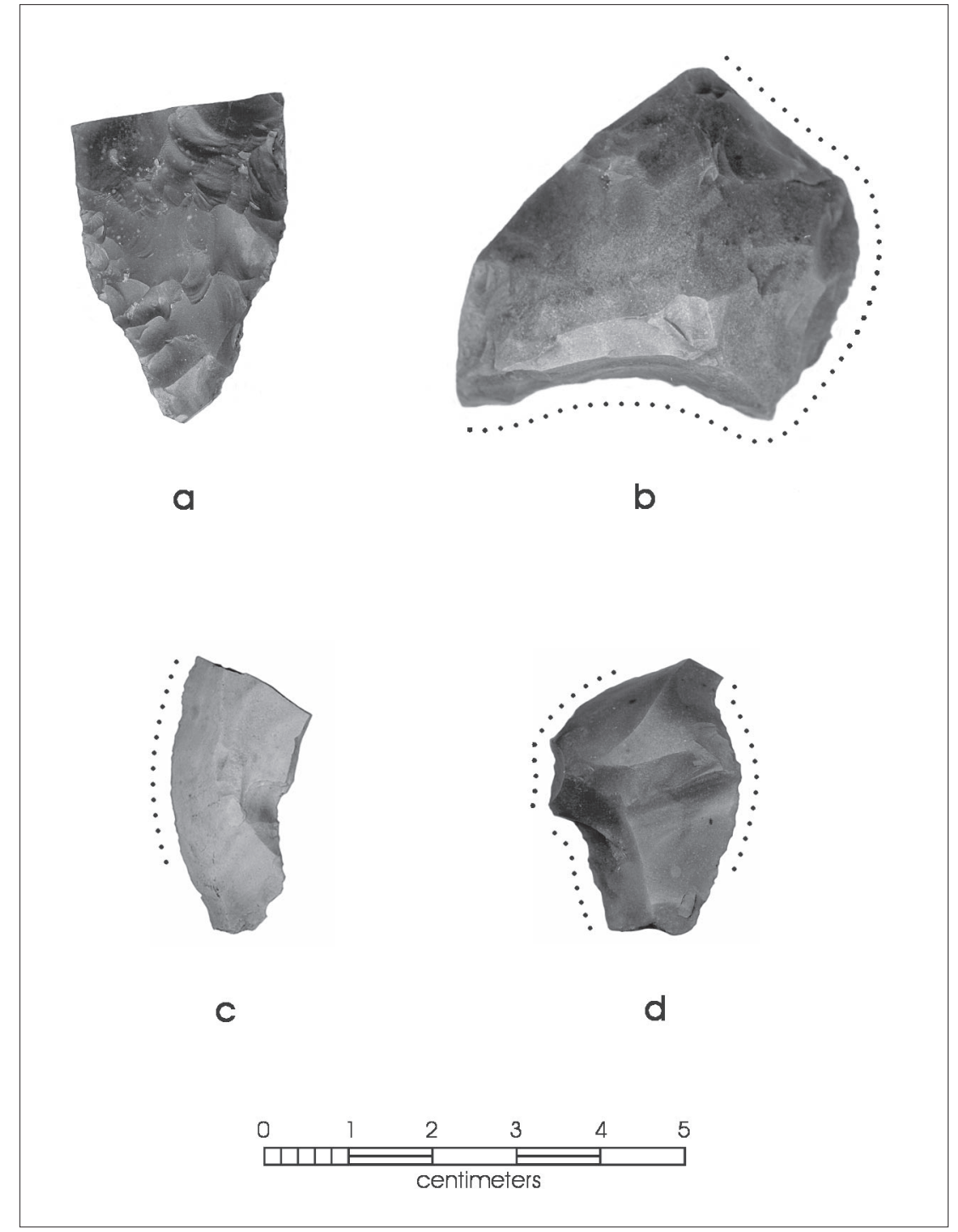

Figure 5-1. Lithic tools recovered from 41GD113. a) biface fragment; b) retouched flake tool; c) utilized flake tool; d) utilized flake tool. (Dots indicate areas of edges with retouch or use wear.)

removed a thick portion of the piece from which it was struck. Both the dexter and sinister margins show evidence of edge wear but not intentional modification. Both of these edges are sinuous in outline, and overlapping fine scalar flakes on the dorsal face are present in both the concave and convex sections. Edge damage is present on $22 \mathrm{~mm}$ of the dexter edge and $31 \mathrm{~mm}$ of the sinister margin. A few, isolated segments of each edge (more on the sinister than dexter) exhibit step fractures. The majority of the damage suggests use on softer materials with minimal employment against harder mediums. 
A single core was identified within the assemblage. This is a piece of gray-brown chert that is $56 \mathrm{~mm}$ in maximum length. This core exhibits five flake scars showing multidirectional removals and has a significant amount of cortex. The exterior morphology suggests that this was a projecting portion of a small gravel. This piece is technically defined as a core because it exhibits only negative flake scars, but there is minimal evidence of reduction or planned removals. This piece was recovered from Level $14(130-140 \mathrm{cmbd})$ of TU 5. All of the sediments in this unit indicated significant disturbance from the landowner's backhoe activities. The multiple flake scars from differing directions suggest that this piece is cultural and was not produced during mechanical excavation.

No other formal tools, flake tools, or cores were identified during analysis of the lithics from 41GD113. During the initial examination by Prewitt and Associates (Fields et al. 2002:54), one biface fragment was noted in disturbed surface context adjacent the ranch road on the north side of 41GD113. The raw materials represented in the assemblage are primarily a variety of translucent brown cherts with occasional inclusions. Most of the debitage appear to be made on very similar chert that is likely from a limited source.

\section{Lithic Debitage Analysis by Jason D. Weston and Russell D. Greaves}

\section{The 4IGDI 13 Sample}

Excavations at 41GD113 recovered 866 pieces of unmodified chipped stone debris from seven 1-x-1-m test units. The majority of the debitage came from TU 2, TU 5, and TU 6 (Figure 5-2), located in the central portion of the identified site boundaries. TU 5 contains sediments that have been completely disturbed by backhoe excavations to a depth of $>140 \mathrm{cmbd}$. TU 1 is on the western margin of the site and TUs 3 and 7 are on the eastern side (see Figure 3-1). Except for TU 5, data analysis shows that the pattern of debitage types, amount of dorsal cortex, heating frequencies, material types or debitage condition is similar across all of the test units. Horizontally, the debitage appears to represent a homogenous sample, and the aggregate assemblage can be used to describe the lithic activities at 41GD113.

\section{Vertical Distribution of Lithics}

There are differences between the vertical densities of lithics among the different test units. Debitage densities are based on the counts and weights of lithics in each 10 -cm excavation

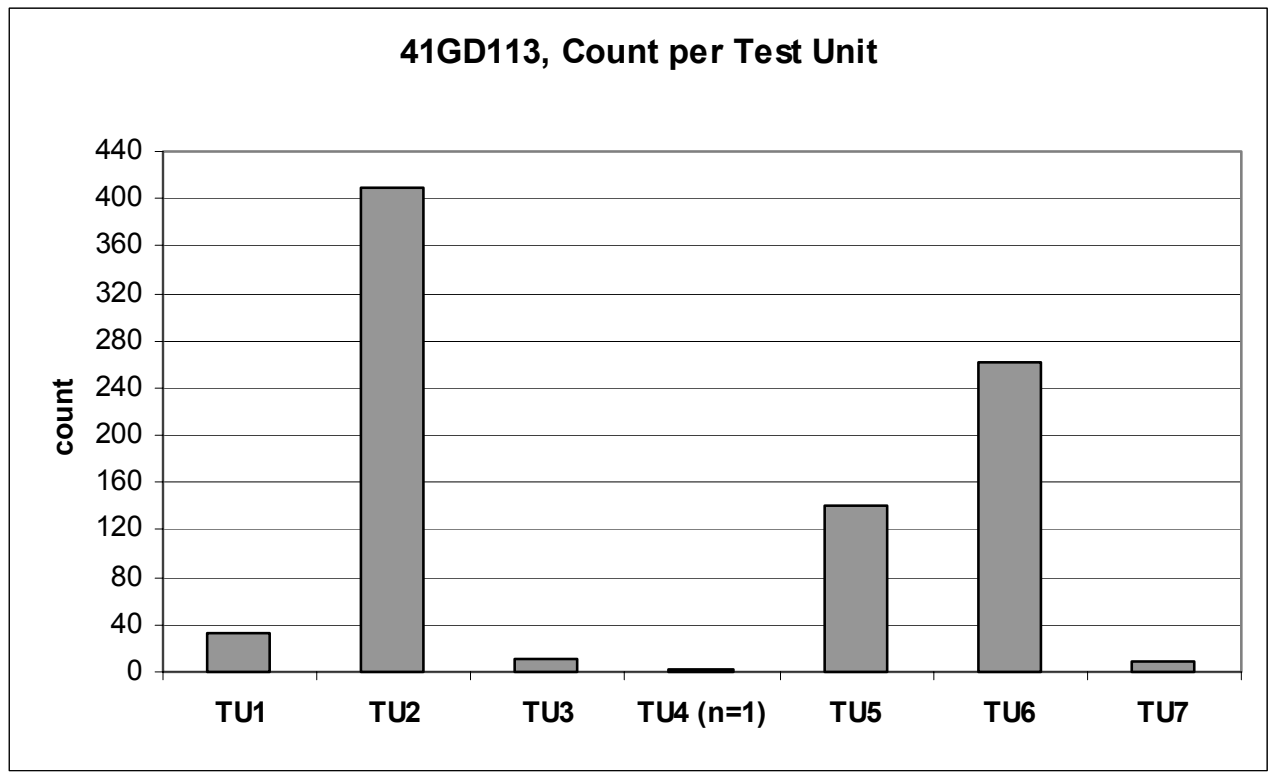

Figure 5-2. Debitage frequencies from test units at 41GD113. Note that bar column height increased to make Test Unit 4 column visible. 
level. These have been adjusted in relation to ground surface elevations so that the following discussions present elevations in equivalent comparable vertical relationships. The frequencies and weights of lithics are examined individually and as blocks (for the adjacent units TU 2 and TU 6).

TUs 1, 3, 4, and 7 have samples sizes too small to be reliable indicators of variability in vertical distribution of lithics. TUs 2, 5, and 6 have sample sizes large enough to be useful in this analysis. However, TU 5 shows clear evidence of significant mechanical disturbance and total destruction of the original stratigraphy. The assemblages from the two adjacent 1-x-1-m units, TU 2 and TU 6, are large enough to examine patterns of vertical distribution and variability.

TUs 2 and 6 are adjacent units forming a 1-x-2-m block excavated with the same vertical datum reference so that their distributions can be examined and compared as a single sample. TUs 2 and 6 yielded 669 pieces of debitage from 12 of the 15 levels excavated in these units. There is a dramatic increase in lithic frequency and weight at 70-80 cmbs. There is a consistently high number of debitage present from 70 to $110 \mathrm{cmbs}$ in both these excavation units (Figures 5-3 and 5-4). The vertical distribution exhibits a bimodal distribution with peaks of lithic frequency at 70$80 \mathrm{cmbs}$ and at $90-100 \mathrm{cmbs}$ (Figures 5-3 and 5-4). Both the numbers of individual flakes and their mass (weight) have identical bimodal patterns in TU 2 and TU 6. The distribution of faunal remains also shows peak accumulations at approximately $70-90 \mathrm{cmbs}$. The highest relative values from the soil magnetic susceptibility samples are from 77.5-90 cmbs (Appendix C). These similarities suggests either that these frequency peaks indicate periods of higher occupational intensity or that those elevations represent relatively more stable soil surfaces that were available for longer periods of time to receive cultural and natural accumulation of materials. While the co-occurrence of peaks in both lithic debitage and culturally modified bone is likely an indicator of occupation intensity, the peak in soil magnetic susceptibility values may simply be auto-correlated with the presence of faunal remains.

Although TU 5 had the third largest sample of lithics, the count and weight distributions of TU 5 lack any clear peak in debitage density as can be seen in Figures 5-3 and 5-4. This flat vertical distribution is typical of disturbed deposits where artifacts are mixed in the soils resulting in diffuse, even deposits. Due to this disturbance, no vertical distribution data from TU 5 can be used to address site formation and prehistoric activities at the site.

\section{Raw Material Types}

There were three identified classes of lithic raw materials found at 41GD113. All of the material was classed either as chert, quartzite, or petrified wood. No attempts were made to distinguish finer divisions of chert or quartzite. Chert accounts for $97 \%(n=840)$ of the debitage assemblage. Petrified wood was represented by 18 pieces $(2.1 \%)$ and only eight examples of quartzite were recovered $(0.9 \%)$.

\section{Heating and Material Type}

Examination of the debitage from 41GD113 indicates that heat treatment was not a common or systematic practice. The majority $76.6 \%(n=663)$ of the debitage was not exposed to heat. Heat-treated flakes represent only on $4.5 \%(n=39)$ of the debitage. An additional $18.9 \%$ of the heated flakes were thermally damaged. Thermal damage is defined as the presence of heat spalls or crazing of lithics. Heat spalling results from rapid, uncontrolled heating to high temperatures (Cooper 1975:189). The presence of heat spalls on the ventral surface indicates that a flake was exposed to rapid heating after it was struck from the core or tool. Such heating is unintentional and occurs outside of the lithic reduction and tool production process. Unintended heating is caused by natural surface fires, the incidental incorporation of flaking debris into thermal features, or cultural fires intended to clear vegetation or accumulated dry fuel. Overall, the assemblage indicates a predominance of incidental heating and not systematic controlled thermal treatment of chert that might suggest attempts to improve knapping quality. There is no relationship between the material types or the frequency of thermal modification and damage to debitage.

\section{Debitage Types and Flake Condition}

Analysis of debitage classes indicates that $15.1 \%(n=131)$ of the assemblage is consistent with biface manufacturing (Figure 5-5). Platform preparation flakes account for $22.1 \%$ $(\mathrm{n}=191)$ of the total debitage recovered. Platform preparation flakes are derived both from core reduction or biface production (Weston and Mauldin 2003:36). Angular debris, blades, core reduction and uniface manufacture and/or rejuvenation flakes accounted for a much smaller proportion of the total assemblage (Figure 5-5). The majority of the debitage, $57.7 \%(\mathrm{n}=500)$, could not be classified into particular production trajectories and was designated as indeterminate. The inability to securely classify much of the assemblage is due to the high proportion of incomplete flakes in the sample. Only $24.7 \%(\mathrm{n}=214)$ of the debitage are complete flakes, and $19.7 \%(\mathrm{n}=171)$ are proximal flake fragments (Figure 5-6). Diagnostic identification relies 


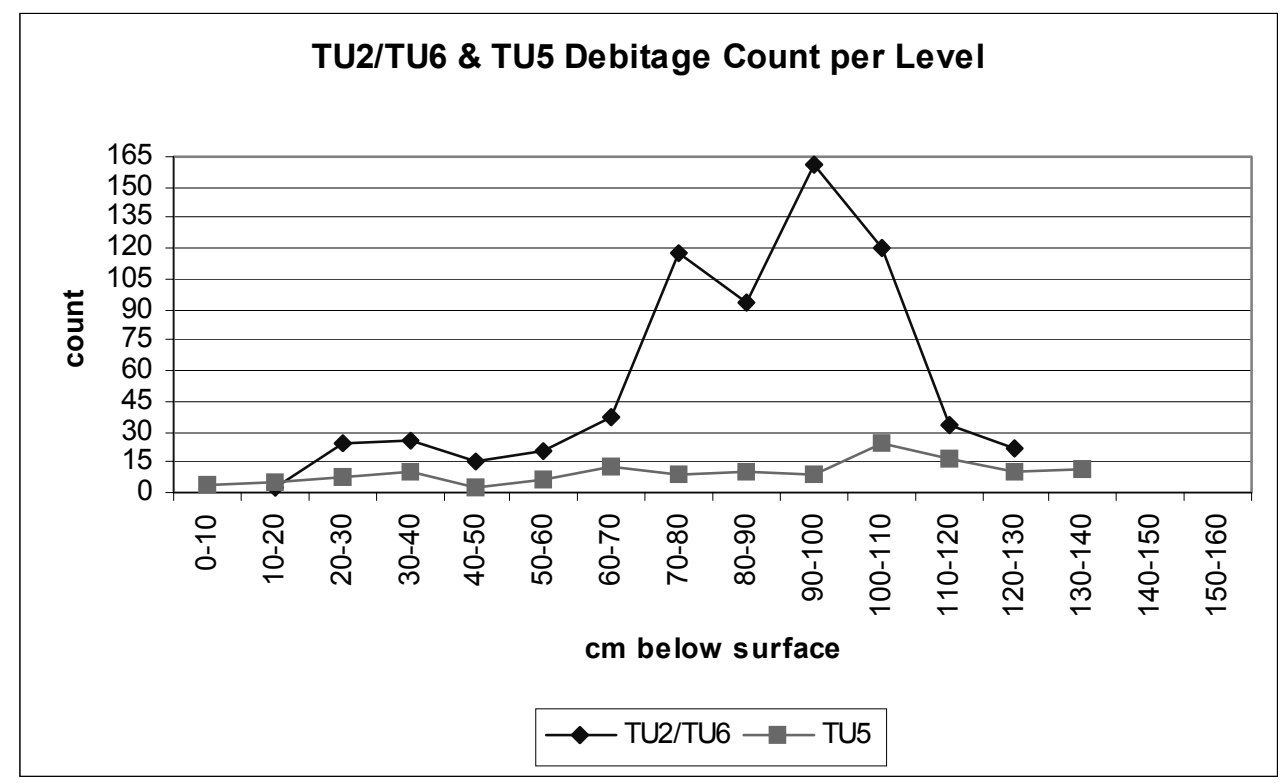

Figure 5-3. Vertical debitage frequencies for Test Units 2, 5, and 6 at 41GD113.

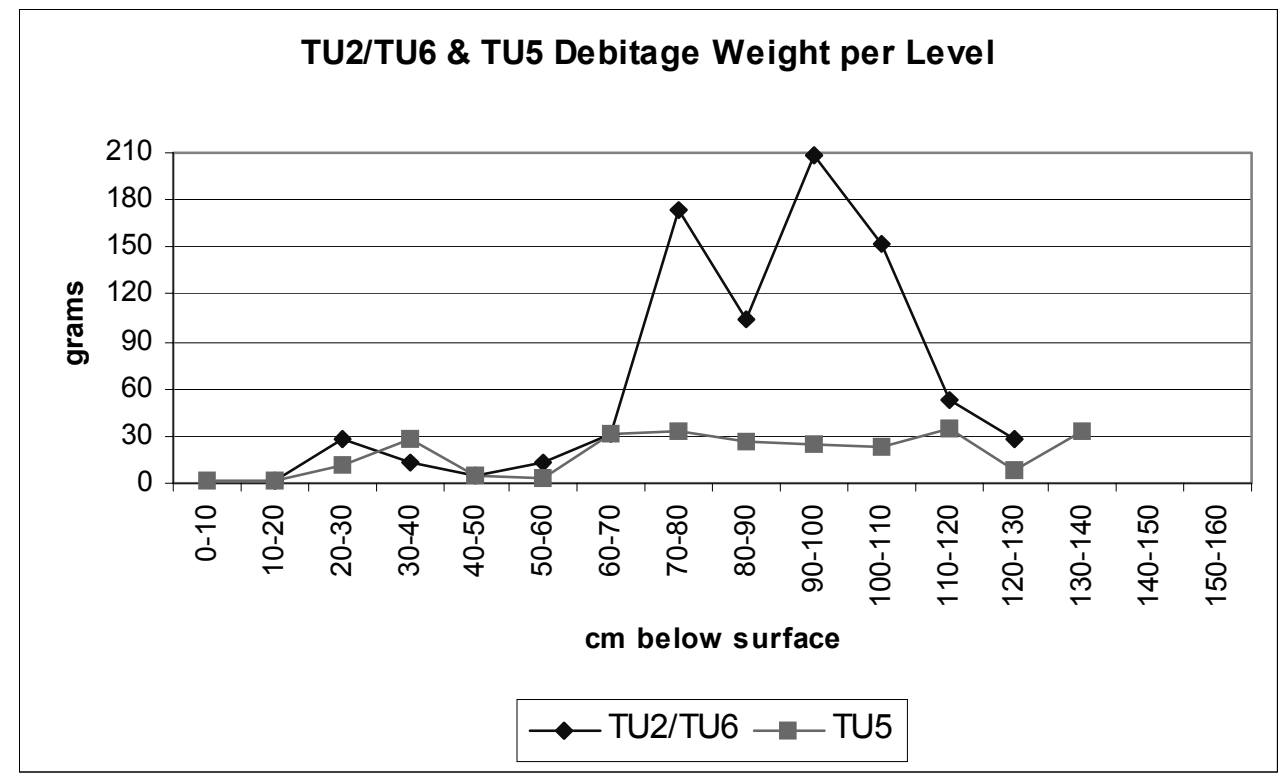

Figure 5-4. Vertical debitage weights for Test Units 2, 5, and 6 at 41GD113. 


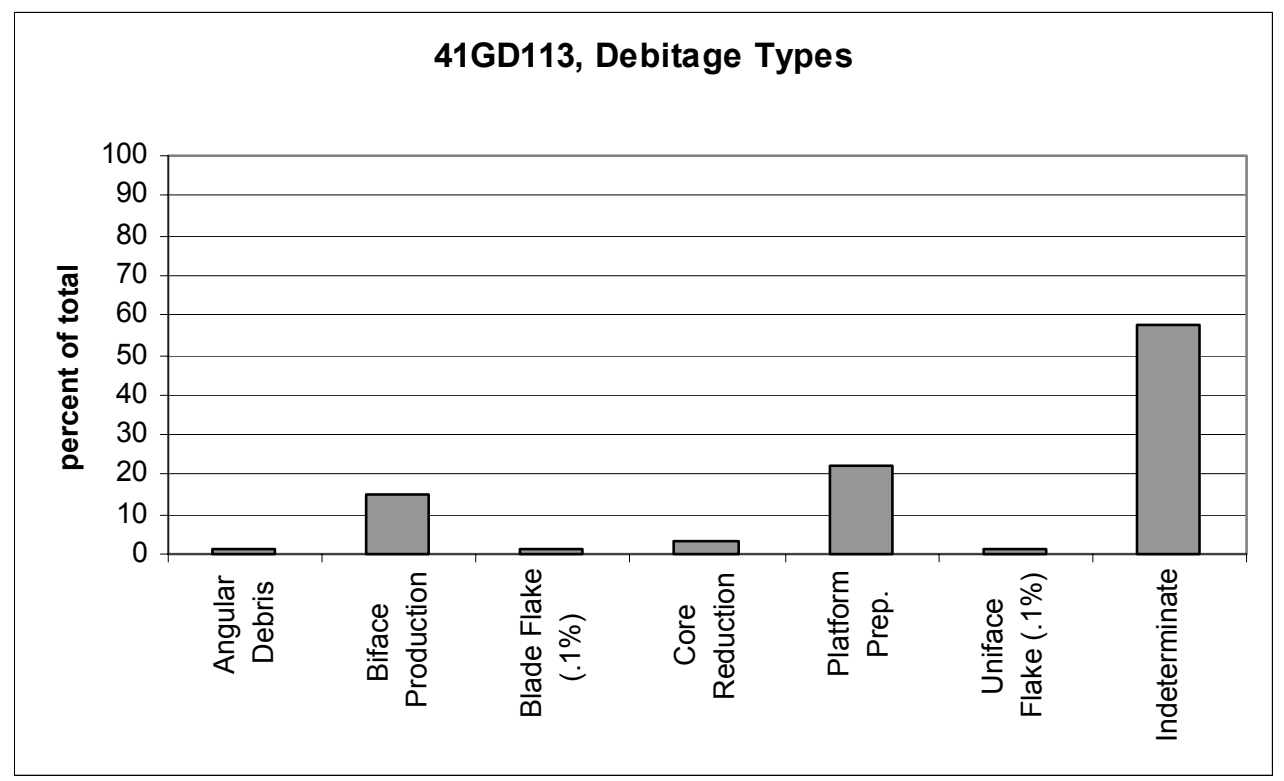

Figure 5-5. Debitage types at 41GD113. Note that bar column height increased for blade and uniface to make columns visible.

primarily on the characteristics of the striking platform attributes of flakes.

\section{Cortex and Flake Size}

The majority of the debitage assemblage exhibited no cortex and suggests minimal primary reduction at 41GD113. Six hundred five flakes $(69.9 \%)$ lack cortex. Debitage with $1-50 \%$ cortex on the dorsal surface accounts for only $19.7 \%$ $(\mathrm{n}=171)$ of the total assemblage and pieces with $51-99 \%$ cortex or $100 \%$ cortex are uncommon (Figure $5-7$ ). Flake size was examined using length and weight of only the complete flakes ( $\mathrm{n}=214,24.7 \%$ of the total sample). Not surprisingly, decorticate $(0 \%$ cortex) flakes and those with $1-50 \%$ cortex represent smaller mass removals (mean flake weight $=0.56 \mathrm{~g})$ than the corticate $(100 \%$ cortex $)$ flakes and those with $51-99 \%$ cortex (mean flake weight $=6.62 \mathrm{~g}$ ). As weight and length have been found to be auto-correlated (Andrefsky 1998:96), a heavier average weight also indicates longer average flake length. The average maximum length of the corticate and $51-99 \%$ cortex debitage is 21.78 $\mathrm{mm}$. Decorticate flakes and those with $1-50 \%$ cortex debitage have an average length of $18.01 \mathrm{~mm}$. The assemblage from 41GD113 is dominated by small flakes. This may indicate a predominance of later stage reduction of raw materials that were brought to the site in a partially decorticate condition and probably the reduction of small, primarily locally available raw materials.

\section{The 4IGDI14 Sample}

The excavation of two 1-x-1-m test units in relatively undisturbed deposits at $41 \mathrm{GD} 114$ yielded 65 lithics. TU 1 produced 31 pieces of debitage and in TU 2 a sample of 34 pieces of debitage was recovered (Table 4-8). All lithics represent unmodified debitage and no formal or situational tools were recovered from this site. Such a small sample size makes secure inferences from this sample problematic. The data on debitage types, cortex presence, heating frequencies, material types and debitage condition vary little between the two units. There are no indicators of significant differences in the materials recovered from these two 1-x-1-m excavation units. Therefore, the aggregate assemblage from both test units is discussed as a single sample.

\section{Vertical Distribution of Lithics}

There is only slight variability in debitage counts and weights in the sample from $41 \mathrm{GD} 114$ related to vertical distribution. TU 1 produced 31 pieces of unmodified chipped stone debris from four levels (Levels $2-5,10-50 \mathrm{cmbs}$ ). No lithics were encountered in Level $6(50-60 \mathrm{cmbs})$. This final level was terminated on encounter with weathered bedrock. The highest individual flake frequency was recovered from $10-20 \mathrm{cmbs}$ but the greatest artifact weight was from lithics between 20-30 cmbs (Figures 5-8 and 5-9). Because of the small sample size, this pattern is not considered particularly meaningful. It is not surprising that most lithics were 


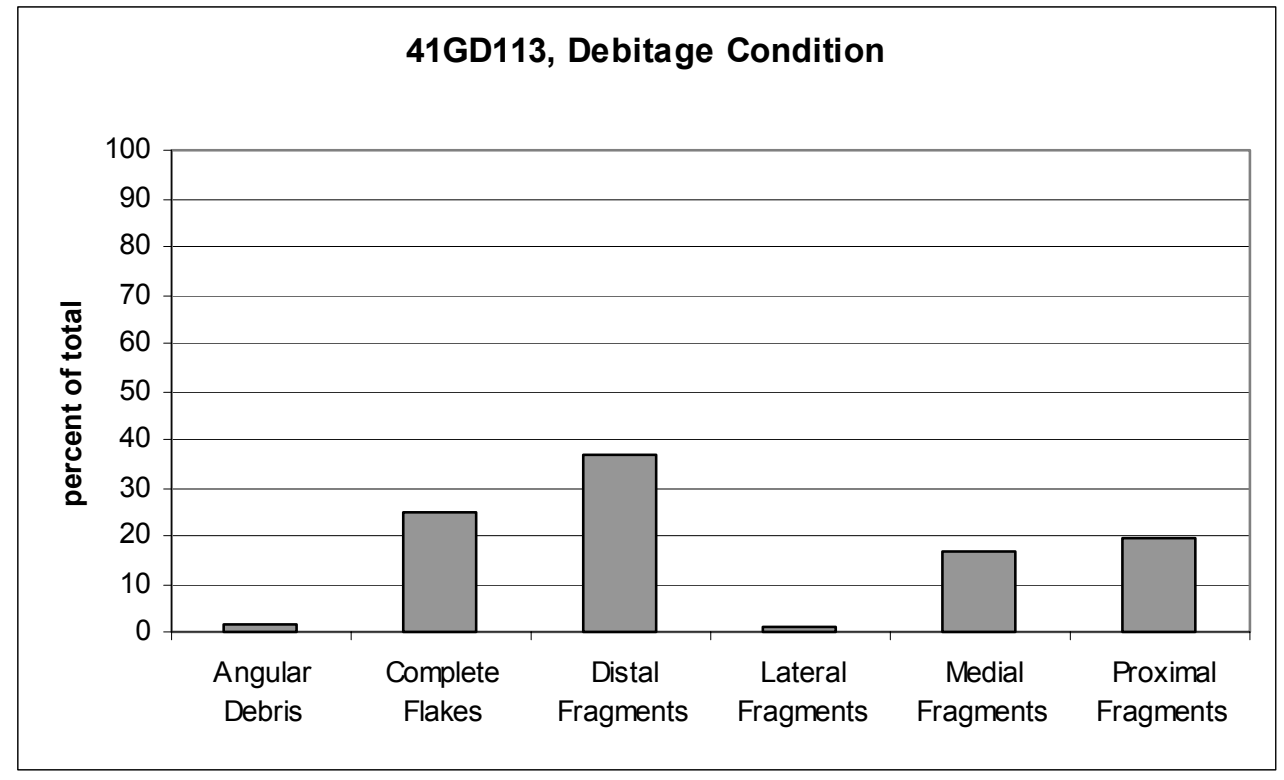

Figure 5-6. Debitage condition at 41GD113.

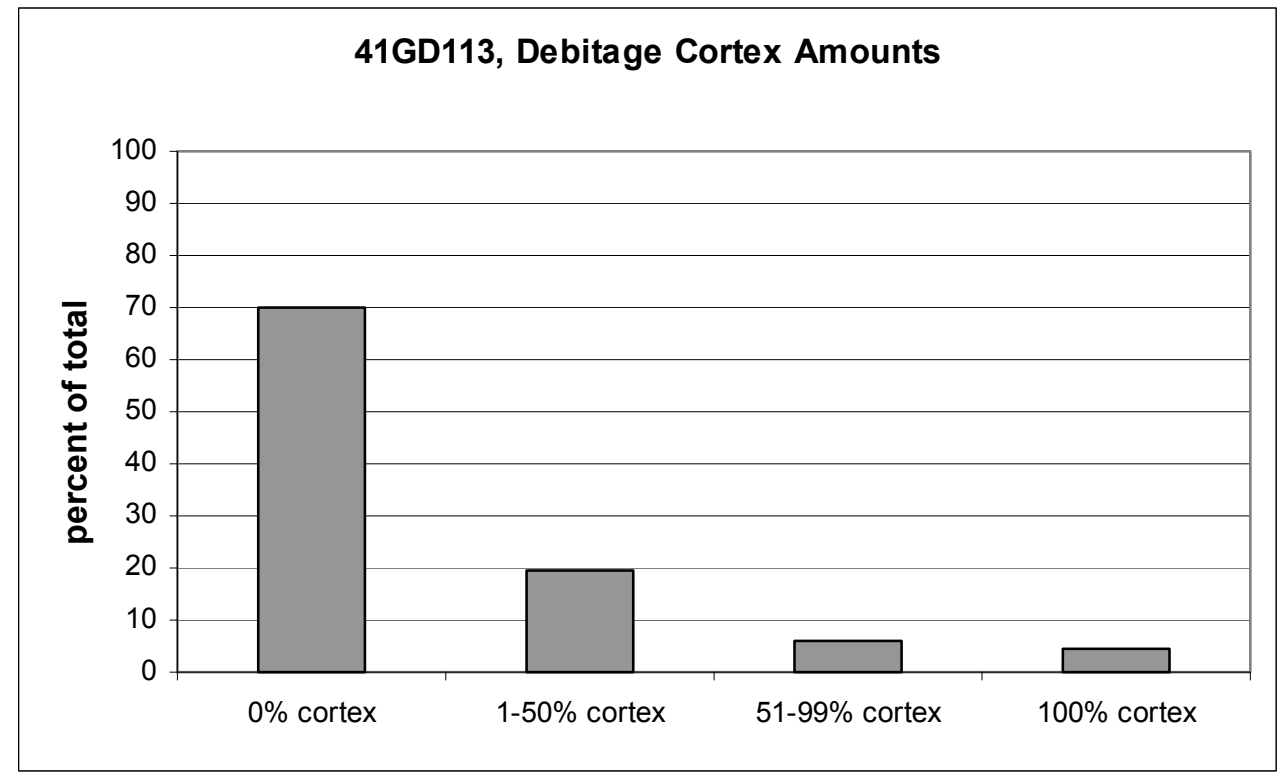

Figure 5-7. Debitage cortex frequency at 41GD113. 
encountered in the uppermost $30 \mathrm{~cm}$ of the deposit in TU 1 . There is an increased density of gravels from $20 \mathrm{cmbs}$ to the base of the excavation at the top of the bedrock. Significant tree root turbation was present in the uppermost $20 \mathrm{~cm}$ of this excavation unit.

TU 2 yielded 34 pieces of unmodified chipped stone debris found in all five levels $(10-60 \mathrm{cmbs})$. The lithic frequency is highest at $30-40 \mathrm{cmbs}$ with 14 pieces of debitage but the weight peaks at 50-60 cmbs with 63.03 grams (Figures 5-8 and 5-9). Although lithics were encountered in the final excavation level, the density of alluvial gravels was very high and the context indicates redeposition or vertical displacement of artifacts into the lower sediments. Excavation was terminated at approximately $50 \mathrm{cmbs}(60$ cmbd) because the deposits were entirely alluvial gravel. As with TU 1, the highest density was in the upper portions of this unit (approximately $30-40 \mathrm{cmbs}$ ). As noted for TU 1 , there were significant amounts of animal and tree root bioturbation in the upper horizons. Both TU 1 and TU 2 appear to represent much more bioturbated archeological deposits than encountered at 41GD113.

\section{Raw Material Types}

The lithic raw materials present at 41GD114 are chert and petrified wood. Chert accounts for $89.2 \%(\mathrm{n}=58)$ of the recovered debitage and petrified wood for the remaining $10.8 \%(\mathrm{n}=7)$.

\section{Heating and Material Type}

Evidence of heat treatment of chert was uncommon at 41GD114. The majority $(86.2 \%, \mathrm{n}=56)$ of the debitage sample contained no evidence of any thermal exposure. Only six flakes $(9.2 \%)$ exhibited any evidence of thermal damage. Only three pieces $(4.6 \%)$ of the debitage represent heattreated specimens. The other three flakes exhibited potlid heat spalls that suggest inadvertent heating of debris. As noted for $41 \mathrm{GD} 113$, the low incidence of heat damage does not indicate systematic heat treatment of raw materials. The overwhelming evidence is that the majority of the heat alteration represents postdepositional effects from inclusion in natural or cultural fires. There is no correlation between heating, thermal damage, and material type at this site.

\section{Debitage Types and Flake Condition}

Of the identifiable debitage, platform preparation flakes are the most common flake types $(n=12,18.5 \%)$. Only six $(9.2 \%)$ biface production flakes were identified (Figure 5-10). This pattern probably reflects the fact that complete flakes account for only $24.6 \%(\mathrm{n}=16)$ of the total debitage sample (Figure 5-11). There are nine (13.9\%) proximal fragments retaining diagnostic striking platforms. The remainder of the debitage $(63.1 \%, \mathrm{n}=41)$ is fragmentary and most of the assemblage and could only be identified as indeterminate.

\section{Cortex and Flake Size}

Decorticate flakes ( $0 \%$ cortex) compose $47.7 \%(n=31)$ of the debitage. Flakes with $1-50 \%$ cortex make up $21.5 \%$ $(\mathrm{n}=14)$ of the sample and $51-99 \%$ cortex is present on $10.8 \%$ $(n=7)$ of the debitage. Primary ( $100 \%$ dorsal cortex) flakes represent a relatively high amount $(20 \%, \mathrm{n}=13)$ of the total debitage (Figure 5-12). Average flake size patterns are derived from a very small sample of complete flakes from the site $(n=16)$. The mean length of complete decorticate flakes and those with $1-50 \%$ cortex is $22.42 \mathrm{~mm}$ and the average weight of such flakes is 0.39 grams. For the complete flakes that have $51-99 \%$ cortex and the corticate flakes, the mean flake length is $25.47 \mathrm{~mm}$. The average weight of these pieces of debitage is 1.93 grams.

\section{Natural Clasts: Gravels, Mussel Shell, and Snail Shell}

Gravel and shell clasts that are non-cultural were collected from two test units on 41GD113. Collection and quantification of these materials from TU 2 and TU 3 was designed to address site formation dynamics. Comparisons of artifact densities with non-cultural materials offer opportunities to determine whether assemblage variability reflects behavioral or site formation differences. If gravels, lithics, and shell are all found in highest proportion in the same deposits, this would suggest high-energy alluvial sedimentation and low probability of any site integrity. If the lithic materials are not associated with gravel, but are positively correlated with shell densities, this indicates lower-energy sedimentation and there is a greater probability that some of the archeological materials may retain some integrity. High numbers of archeological materials associated with a high proportion of natural shell clasts may suggest surface stability and accumulation of a variety of items over a relatively long period of time. This can make the separation of cultural occupation events quite complicated. Determination of the duration and intensity of the cultural occupation must use other analytic tools beyond assemblage size to make archeological inferences. Low densities of cultural artifacts and natural clasts might indicate short-term surface stability. Conversely, large cultural assemblages associated with few 


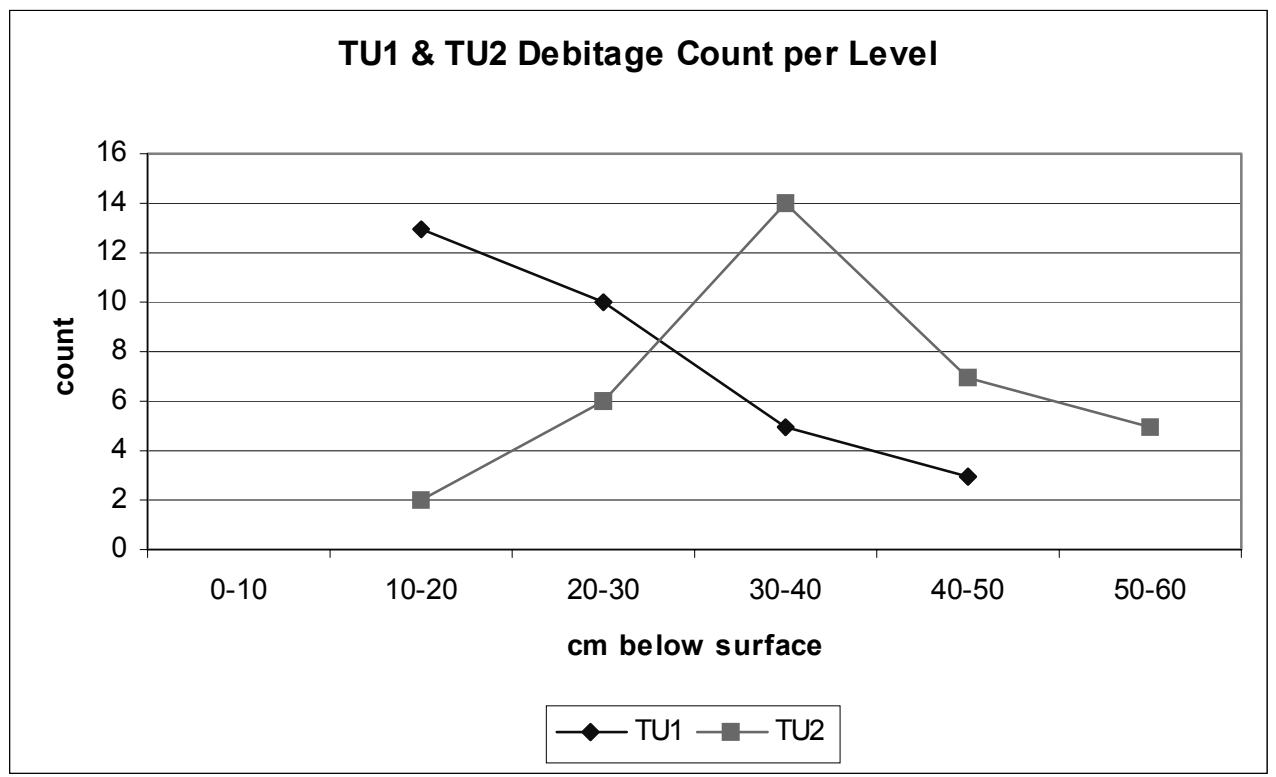

Figure 5-8. Vertical debitage frequencies for Test Units 1 and 2 at 41 GD114.

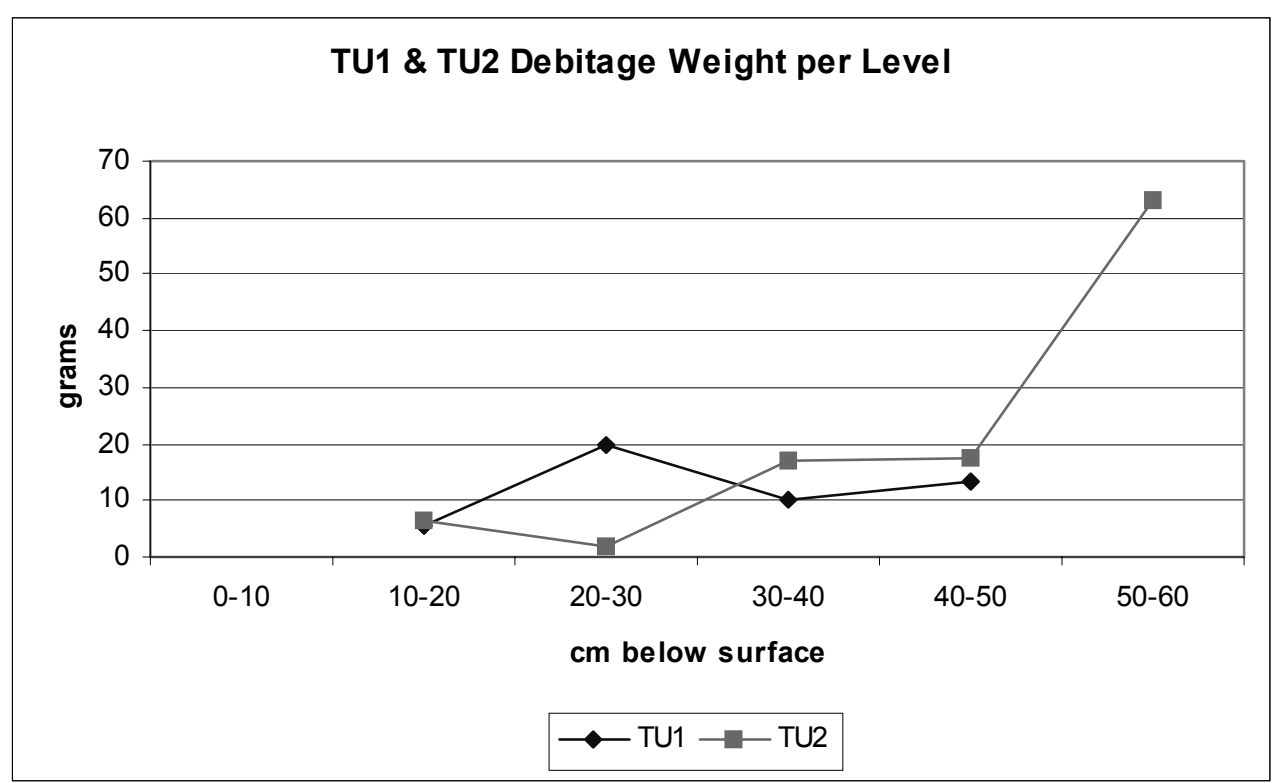

Figure 5-9. Vertical debitage weights for Test Units 1 and 2 at 41GD114. 


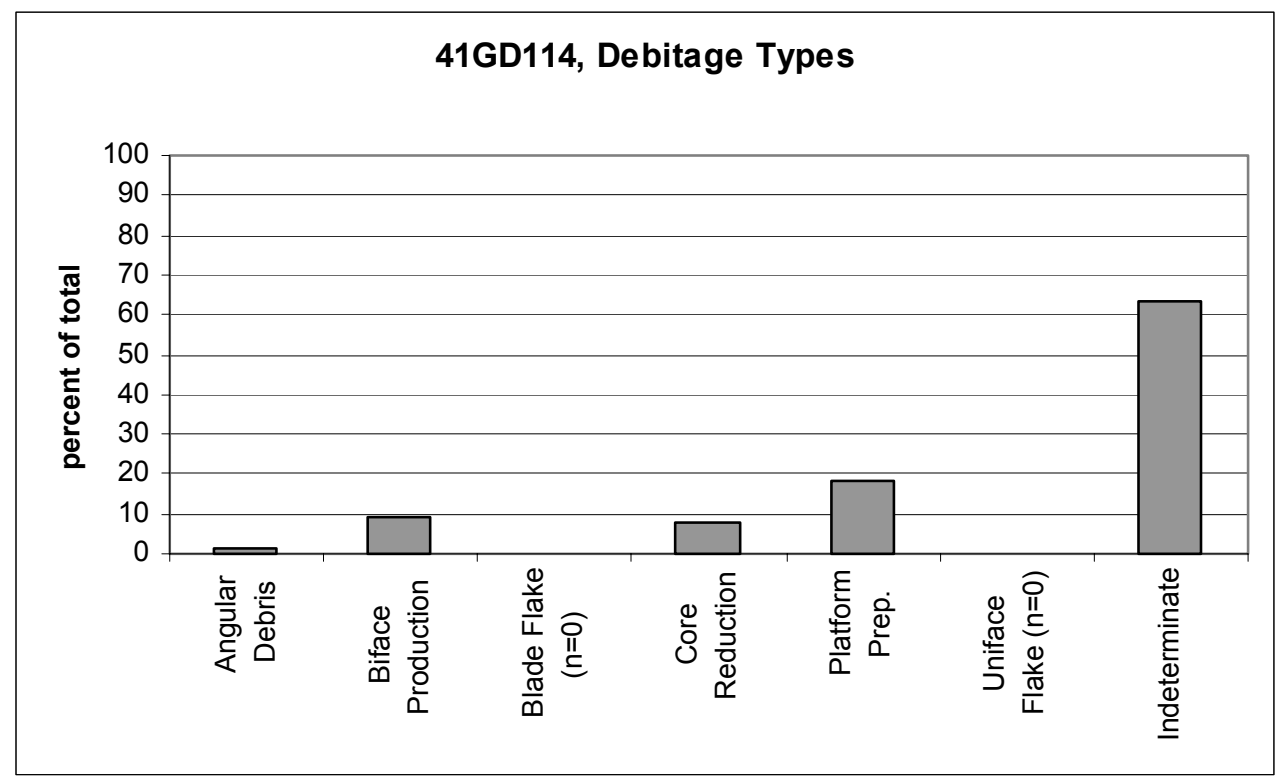

Figure 5-10. Debitage types at 41GD114.

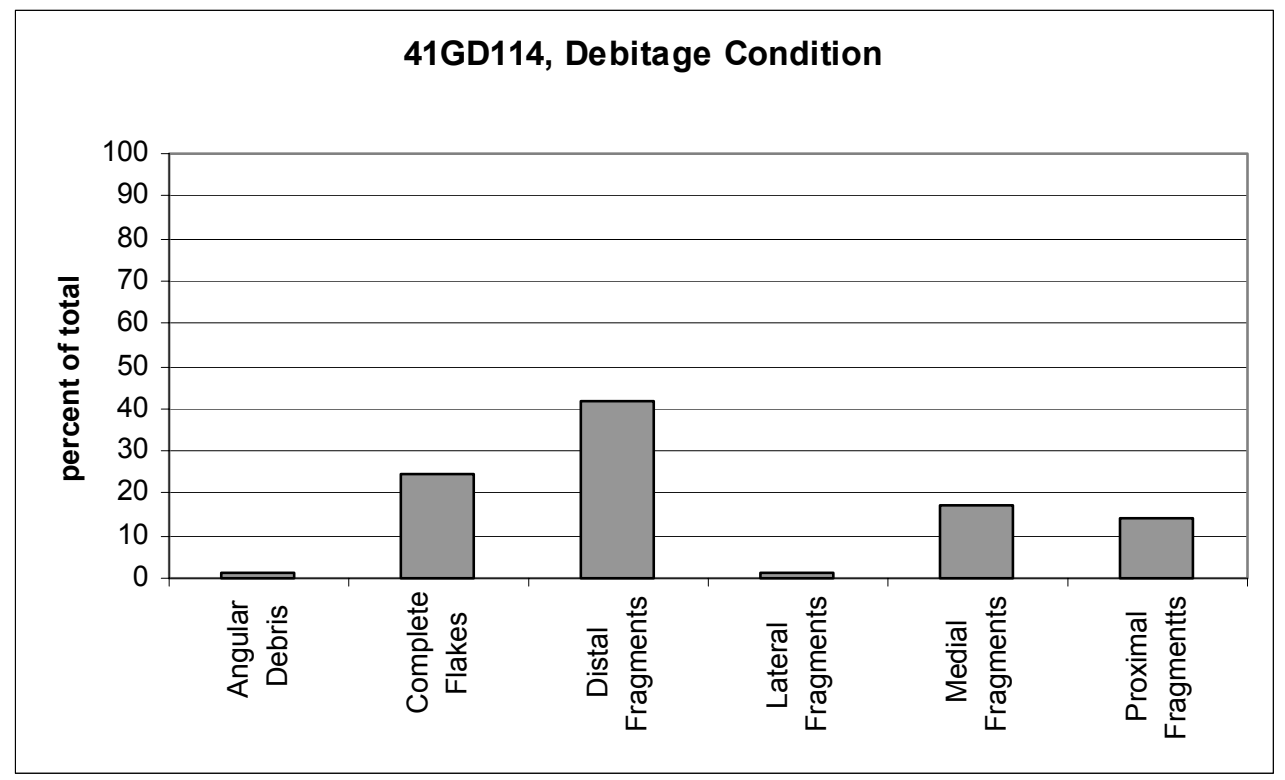

Figure 5-11. Debitage condition at 41GD114. 


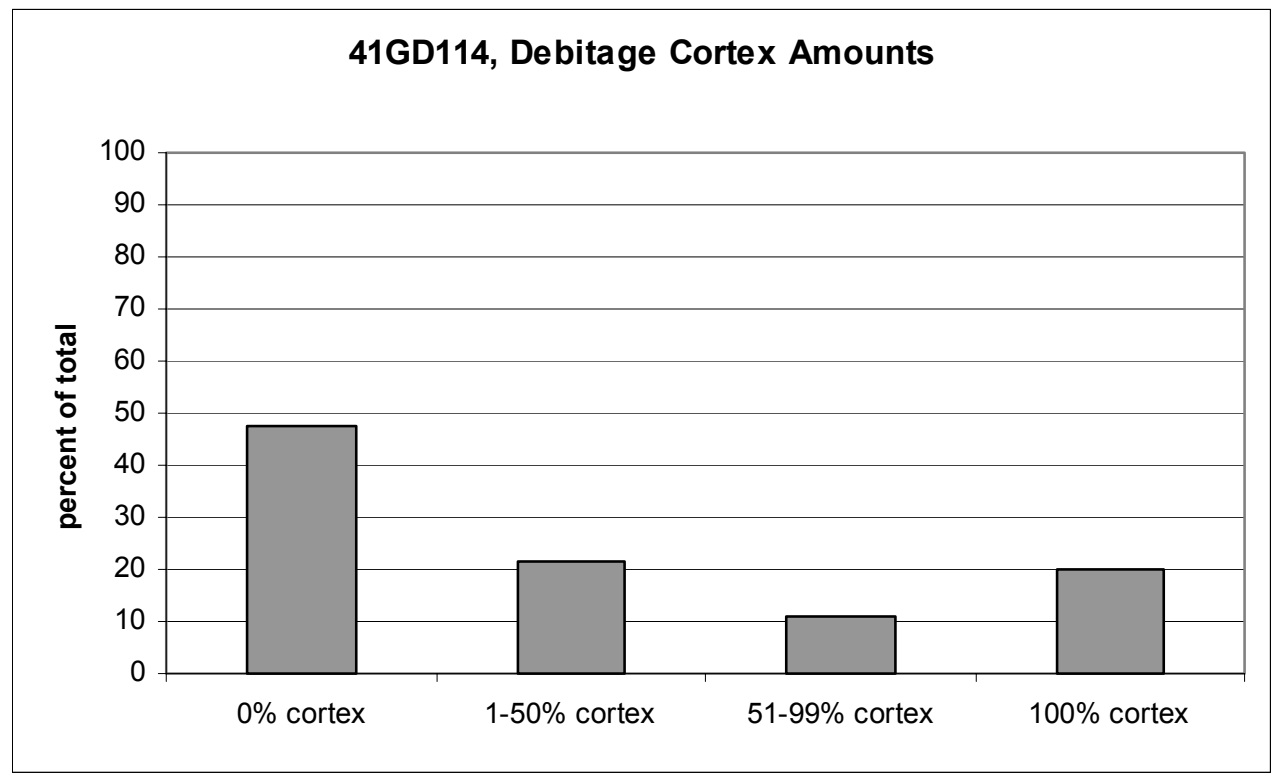

Figure 5-12. Debitage cortex frequency at 41GD114.

natural clasts might indicate a larger or longer occupation (if there is evidence that greater amounts of stone, bone, or shell may have accumulated in other parts of a site simply due to surface stability). Small numbers of artifacts in association with high densities of natural clasts would strongly suggest a short-term human site use. These independent means of evaluating assemblage size in relation to site formation are important (Waters 1992:159). Lowdensity artifact assemblages are not necessarily shorter or smaller occupations than those represented in denser deposits. Site formation can create a stable surface that receives greater absolute numbers of artifact discards, but from individual occupation episodes of identical duration to those represented by fewer items.

Gravels were collected from TU 2 and TU 3 to address site formation at 41GD113. Gravels were most common in the lower portion of the profiles that contained fewer lithics and least common in the upper deposits associated with higher densities of artifacts. The fining upward sequence indicates stream migration away from the site location and decreasing energy levels of the floodplain deposits at 41GD113. Gravel density in TU 2 (see Table 4-6) reflects a higher frequency of gravels in Level $6(60-70 \mathrm{cmbd})$ and increasing steadily towards the bottom of the excavation. These natural clasts are unlikely to have been deposited through cultural activities and reflect higher-energy alluvial deposits in the lower portion of the profile of the area of TU 2 and TU 6. This increase is associated with decreasing lithic frequency from Level 10 to the base of the excavation. Gravel density in TU 3 (see Table 4-6) shows a dramatic increase in frequency in Levels 3-9 $(20-80 \mathrm{cmbd})$. This trend is similar to that noted in TU 2 deposits. TU 3 is situated at a lower elevation than TU 2 and it is therefore not surprising that gravels are represented higher in the profile of TU 3.

Mussel shells and snail shells were sampled from TU 2 and TU 3 at 41GD113. Most of the mussel shell was highly fragmentary and identification to genera or species has not been systematically attempted. Much of the shell appears to be from threeridge mussels (Amblema plicata), but no secure identifications have been performed. No evidence of shell breakage or the accumulation of midden deposits was identified that would indicate a high probability of human agencies of accumulation. The snail shells also do not exhibit any evidence of human manipulation and certainly represent natural death assemblages.

Even if not cultural, both gastropod and pelecypod shell can provide significant information about site formation (Claassen 1998:12-13; Howells et al. 1996:14-23). Many non-human agencies of shell accumulation have been documented, including avian fauna (Claassen 1998:47, 71-73), terrestrial 
animals (Claassen 1998:71), invertebrates (Claassen 1998:71; Stein 1983), and flood or other soil events (Claassen 1998:53, 70, 85; Ford 1992; Stein 1983, 1992).

The low density of mussel valves, their dispersed presence, and lack of unambiguous association with cultural features or human modification makes natural inclusion into these sediments the most parsimonious interpretation for their presence in 41GD113. Mussel shell is associated with approximately the same elevations that contain the densest archeological remains (see Table 4-6). In TU 1, it is apparent that the highest frequencies of mussel shell (by weight) were found in Levels 3, 4, and 5. The highest lithic densities in this unit were in Levels 2-6 (10-60 cmbd). In TU 2, the greatest mussel shell recovery was from Levels 4 and 9-10 (40-50 $\mathrm{cmbd}$ and $90-110 \mathrm{cmbd}$ ). The highest lithic frequencies were in Levels 7-10. In TU 6 mussel shell frequency was highest in Levels 6-10 $(60-110 \mathrm{~cm})$ and the peak lithic densities were in Levels 7-10. The large amount of mussel shell in TU 5 is not of use in this comparison because of the disturbed context of that unit. No mussel shell was recovered from TUs 3, 4, or 7 .

It is apparent from these comparisons that a strong association exists between cultural material densities and mussel shell. The associated higher density of mussel shell and cultural materials indicate that the surfaces where archeological materials were deposited also were available for other non-cultural depositional events. Given this indicator of at least periodic surface stability, there is a high probability that multiple events may also be responsible for each of the vertical peaks in cultural artifact frequency. This is consistent with the AMS dating that indicated relatively slow amounts of sedimentation occurred at 41GD113. Artifact frequencies identify two portions of the profile with higher densities that suggest multiple visitation events. Mussel shell data indicate that the number of likely reoccupation events is greater than only these two subsurface concentrations. The complexity of potential re-occupation dynamics at $41 \mathrm{GD} 113$ makes characterization of normative activities at this site difficult.

Snail shells also were systematically collected from TU 2 and TU 3 at 41GD113. Almost all of the snail shells represent Rabdotus sp. Gastropod remains became extremely fragmentary because the excavation methods, screening, and laboratory processing were not designed for their recovery. The number of these remains reflects primarily the amount of fragmentation, and so weight is used for comparisons.
Snail shell weight appears to exhibit similar maximum accumulations to the frequency of lithics in TU 2 (see Table 4-6). Snail shells increase in frequency in Level $6(60-70$ cmbd), peak in Level 7, are high in Levels 8-10 (80-110 $\mathrm{cmbd}$ ), and decrease in Levels 11 and 12. They do not show accumulations that are similar to the gravel densities but are most similar to lithic frequency distributions in the profile columns. Gastropods may be auto-correlated with cultural remains because they feed off of organic materials in human trash. They also may exhibit similar distributions because they accumulate in proportion to the temporal stability of ground surfaces where they are incorporated as natural death assemblages. It is unclear why gastropods were less common in TU 3. The high proportion of gravels in this unit may have resulted in significant destruction from screening and subsequent processing. Unlike TU 2, gastropods and gravels were not separated in the field and preliminary counts of these materials were not performed because of the very high frequency of gravels in TU 3. The gravels may indicate a microhabitat lower in organic residues that discouraged gastropod aggregation in the vicinity of TU 3 .

\section{Discussion}

The association of mussel and snail shells with the elevations containing high proportions of lithic artifacts is interesting. None of these materials appear to be evidence of human food residues. The mussel and snail shells are apparently natural clasts in these deposits. It is interpreted as most likely indicating that the archeological materials are densest in particular portions of the soil profile because those are relatively stable surfaces that were available for accumulation of cultural and natural debris. Unlike the shell that does accumulate on stable ground surfaces, gravels exhibit a pattern that does not mirror the density of archeological material. Gravels increase in density towards the base of the deposits in TU 2 and TU 3. This indicates a changing sedimentary regime. Older, higher-energy sediments are demonstrated by high gravel frequency and low recovery of lithics and shell. The only evidence of alluvial erosional unconformities (from high-energy flood events) also is confined to the lowermost horizons seen in the profiles of BHTs 3,4 , and 5 . The more recent sediments are not associated with high-energy deposition. Given this indicator of at least periodic surface stability, there is a high probability that multiple cultural occupation events may also be responsible for each of the vertical peaks in artifact frequency. The localized concentration near TU 2 and TU 6 is unlike other portions of 41GD113 and indicates 
that small-scale events are represented at this site. The potential taphonomic complexity of these low-density mixed archeological deposits suggests that 41GD113 is unlikely to provide unambiguous data on regional patterns of Late Archaic adaptations.

\section{Faunal Remains}

Developments in zooarcheological research are among the most common forms of archeological inquiry about site formation and cultural behavior (Lyman 1994:7-8). Identification of possible food animals, seasonality of occupation, paleoenvironmental reconstruction, and site formation all can be significantly addressed through faunal analyses. These studies have important implications for the interpretation of all other classes of materials recovered from archeological sites. Unfortunately, none of the bone from 41GD113 indicates human manipulation and most bone has experienced significant diagenic destruction.

Three hundred thirty-nine pieces of bone were recovered from 41GD113. The majority of the bone from 41GD113 was recovered in TU $2(n=171)$ and TU $6(n=60$; Table 5-2). TU 5 had 105 bones. Unfortunately, this unit contains mechanically disturbed deposits in all levels. The specimens from this unit do augment the potential list of remains present at the site, but there is no contextual information about these faunal remains. Three unidentifiable bone fragments were recovered in Levels 4 and 5 of TU 1. Only a single unidentified bone fragment was collected at 41GD114.

Most of the bone recovered from 41GD113 has been damaged by diagenesis and archeological recovery. Most bones exhibited minor to extreme chemical etching of most bone surfaces. Few of the larger bones exhibited portions of either their interior or exterior surfaces that did not have any chemical dissolution. Root etching was visible on some bone fragments, but the generally eroded condition of the bone often obscured the potential to identify root etching. Few bone fragments exhibited weathering cracks that indicated prolonged periods of surface exposure. This negative evidence does not indicate that significant subaerial weathering from long surface exposure did not affect much of the assemblage. Given the large amount of chemical dissolution, bone that had experienced surface deterioration would likely be under-represented subsequent to preferential diagenesis of this already structurally compromised bone. Even some of the demonstrably recent armadillo bone has experienced chemical destruction of portions of the outer bone table.
Only the burned bone fragments exhibit very little surface damage from diagenesis. A total of 69 bone fragments exhibited some burning. Thirty-two of those show only some discoloration, 27 have blackening or a small amount of calcining, and ten pieces are fully calcined. A single burned flat bone fragment was recovered from Level 5 of TU 1. The four burned mammal bones and 10 Testudine carapace scutes from TU 5 are excluded from this discussion because of their disturbed context. The sample of burned bones suggests accidental inclusion in fires. There is no spatial segregation of burned bone that would indicate the excavations had encountered discrete areas of natural burning or cultural thermal features. The association of the highest amounts of bone, FCR, and recovered charcoal in TUs 2 and 6 may indicate proximity to locations of natural or cultural fire. The majority of the burned bone was recovered in TU 2. Burned bone was recovered in Levels 7 $(\mathrm{n}=3), 8(\mathrm{n}=1), 9(\mathrm{n}=17), 10(\mathrm{n}=11)$, and $11(\mathrm{n}=7)$ of TU 2 . Burned bone was found in Levels $3(n=2), 7(n=2), 8(n=4)$, $9(\mathrm{n}=4), 10(\mathrm{n}=2)$, and $12(\mathrm{n}=1)$ in TU 6. The variable amount of burning present, relatively infrequent occurrence, and disaggregated horizontal distribution suggests inadvertent scattering from adjacent thermal features. Although there is no unambiguous evidence linking any of the faunal remains to human processing, if some of the faunal sample is referent to cultural activities, then the dispersed evidence of burning could suggest trash deposition from multiple event contexts.

The best information on zooarcheological remains comes from TU 2 and TU 6 that had both high numbers of recovered fauna and good contextual excavation (Table 5-2). These units also produced the highest densities of lithics and FCR. Investigation of mussel and snail shells indicate that there are high frequencies of molluscan remains associated with the same excavation levels as those high numbers of lithics. There is a strong probability that this co-association is due to natural accumulation on stable soil surfaces. Unlike the co-association of the highest lithic and faunal densities in TU 2 and TU 6, the disturbed deposits in TU 5 show no correlations between the levels with the highest density of fauna $(40-60 \mathrm{cmbs})$ and the vertical frequencies of lithics (highest 110-120 cmbs).

At least some of the vertebrate faunal remains may be associated with these same portions of the deposit through natural death taphonomy. TU 2 produced faunal remains from all but three of the excavation levels $(1,4$, and 6$)$. The great majority of this assemblage is from Levels 8-11 (80$120 \mathrm{cmbd}$ ). There are significant amounts of modern armadillo (Dasypus novemcinctus) in the assemblage from TU 2, especially in Level 9 (Table 5-3). A recent burrow 
Table 5-2. Faunal Remains Recovered from 41GD113, Sorted by Unit

\begin{tabular}{|c|c|c|c|c|c|c|c|}
\hline Prov/Unit & Level & Count & Species/Class & Element & Comments & Side & Burn \\
\hline TU 1 & 4 & 1 & unidentified & unspecified fragment & & $\mathrm{n}$ & 0 \\
\hline $\mathrm{TU} 1$ & 4 & 1 & unidentified & unspecified fragment & sediment abrasion & $\mathrm{n}$ & 0 \\
\hline \begin{tabular}{|l|}
$\mathrm{TU} 1$ \\
\end{tabular} & 5 & 1 & unidentified & flat bone fragment & & $\mathrm{n}$ & 3 \\
\hline Totals & & 3 & & & & & \\
\hline TU 2 & 2 & 1 & medium mammal & long bone fragment & rodent gnawing & $\mathrm{n}$ & 0 \\
\hline TU 2 & 2 & 1 & Dasypus novemcinctus & scute & & $\mathrm{n}$ & 0 \\
\hline TU 2 & 2 & 1 & unidentified & long bone fragment & & $\mathrm{n}$ & 0 \\
\hline TU 2 & 3 & 1 & Dasypus novemcinctus & scute & & $\mathrm{n}$ & 0 \\
\hline TU 2 & 3 & 1 & unidentified & flat bone fragment & & $\mathrm{n}$ & 0 \\
\hline TU 2 & 5 & 1 & unidentified & flat bone fragment & & $\mathrm{n}$ & 0 \\
\hline TU 2 & 7 & 5 & Dasypus novemcinctus & scute & & $\mathrm{n}$ & 0 \\
\hline TU 2 & 7 & 1 & small mammal & long bone fragment & fresh break & $\mathrm{n}$ & 0 \\
\hline TU 2 & 7 & 1 & unidentified & unspecified fragment & & $\mathrm{n}$ & 0 \\
\hline TU 2 & 7 & 1 & unidentified & unspecified fragment & & $\mathrm{n}$ & 2 \\
\hline TU 2 & 7 & 2 & unidentified & unspecified fragment & & $\mathrm{n}$ & 3 \\
\hline TU 2 & 8 & 1 & canid & maxillary pm4 & & $\mathrm{R}$ & 0 \\
\hline TU 2 & 8 & 1 & medium mammal & long bone fragment & & $\mathrm{n}$ & 0 \\
\hline TU 2 & 8 & 1 & medium mammal & long bone fragment & & $\mathrm{n}$ & 0 \\
\hline TU 2 & 8 & 1 & Dasypus novemcinctus & 3rd phalanx & & $\mathrm{n}$ & 0 \\
\hline TU 2 & 8 & 7 & Dasypus novemcinctus & scute & & $\mathrm{n}$ & 0 \\
\hline TU 2 & 8 & 1 & small mammal & cervical vertebra & & $\mathrm{n}$ & 0 \\
\hline TU 2 & 8 & 1 & unidentified & flat bone fragment & & $\mathrm{n}$ & 2 \\
\hline TU 2 & 8 & 1 & unidentified & unspecified fragment & & $\mathrm{n}$ & 0 \\
\hline TU 2 & 9 & 1 & deer sized & flat bone fragment & & $\mathrm{n}$ & 0 \\
\hline TU 2 & 9 & 1 & deer sized & long bone fragment & & $\mathrm{n}$ & 2 \\
\hline TU 2 & 9 & 1 & deer sized & metapodial fragment & & $\mathrm{n}$ & 1 \\
\hline TU 2 & 9 & 1 & deer sized & vertebra fragment & & $\mathrm{n}$ & 3 \\
\hline TU 2 & 9 & 1 & deer sized & thoracic vertebra fragment & & $\mathrm{n}$ & 1 \\
\hline TU 2 & 9 & 1 & canid & cranium & & $\mathrm{n}$ & 0 \\
\hline TU 2 & 9 & 1 & canid & mandible & & $\mathrm{L}$ & 0 \\
\hline TU 2 & 9 & 1 & canid & mandible & & $\mathrm{R}$ & 0 \\
\hline TU 2 & 9 & 1 & canid & tibia fragment & & $\mathrm{n}$ & 0 \\
\hline TU 2 & 9 & 1 & canid & mandibular $\mathrm{m} 2$ & & $\mathrm{R}$ & 0 \\
\hline TU 2 & 9 & 2 & canid & incisor & & $\mathrm{n}$ & 0 \\
\hline TU 2 & 9 & 1 & canid & mandibular pm & & $\mathrm{R}$ & 0 \\
\hline TU 2 & 9 & 3 & canid & incisor & & $\mathrm{n}$ & 0 \\
\hline TU 2 & 9 & 1 & canid & incisor & & $\mathrm{n}$ & 0 \\
\hline TU 2 & 9 & 1 & medium mammal & carpal & & $\mathrm{n}$ & 0 \\
\hline TU 2 & 9 & 1 & medium mammal & long bone fragment & & $\mathrm{n}$ & 0 \\
\hline TU 2 & 9 & 1 & medium mammal & long bone fragment & & $\mathrm{n}$ & 0 \\
\hline TU 2 & 9 & 1 & medium mammal & long bone fragment & & $\mathrm{n}$ & 2 \\
\hline TU 2 & 9 & 1 & medium mammal & unspecified fragment & & $\mathrm{n}$ & 0 \\
\hline TU 2 & 9 & 2 & medium mammal & unspecified fragment & & $\mathrm{n}$ & 0 \\
\hline TU 2 & 9 & 1 & Dasypus novemcinctus & flat bone fragment & & $\mathrm{n}$ & 0 \\
\hline TU 2 & 9 & 1 & Dasypus novemcinctus & 1 st phalanx & & $\mathrm{n}$ & 0 \\
\hline TU 2 & 9 & 1 & Dasypus novemcinctus & 2nd phalanx & & $\mathrm{n}$ & 0 \\
\hline TU 2 & 9 & 1 & Dasypus novemcinctus & 3rd phalanx & & $\mathrm{n}$ & 0 \\
\hline TU 2 & 9 & 1 & Dasypus novemcinctus & rib & & $\mathrm{n}$ & 0 \\
\hline TU 2 & 9 & 2 & Dasypus novemcinctus & scute & & $\mathrm{n}$ & 0 \\
\hline TU 2 & 9 & 5 & Dasypus novemcinctus & scute & & $\mathrm{n}$ & 0 \\
\hline TU 2 & 9 & 24 & Dasypus novemcinctus & scute & & $\mathrm{n}$ & 0 \\
\hline TU 2 & 9 & 1 & Dasypus novemcinctus & scute & & $\mathrm{n}$ & 0 \\
\hline TU 2 & 9 & 1 & Dasypus novemcinctus & scute & & $\mathrm{n}$ & 0 \\
\hline
\end{tabular}


Table 5-2. continued...

\begin{tabular}{|c|c|c|c|c|c|c|c|}
\hline Prov/Unit & Level & Count & Species/Class & Element & Comments & Side & Burn \\
\hline TU 2 & 9 & 1 & Dasypus novemcinctus & vertebra fragment & & $\mathrm{n}$ & 0 \\
\hline TU 2 & 9 & 1 & Dasypus novemcinctus & vertebra fragment & & $\mathrm{n}$ & 0 \\
\hline TU 2 & 9 & 1 & Dasypus novemcinctus & vertebra fragment & & $\mathrm{n}$ & 0 \\
\hline TU 2 & 9 & 1 & small mammal & long bone fragment & & $\mathrm{n}$ & 0 \\
\hline TU 2 & 9 & 1 & small mammal & long bone fragment & & $\mathrm{n}$ & 1 \\
\hline TU 2 & 9 & 1 & small mammal & long bone fragment & fresh break & $\mathrm{n}$ & 1 \\
\hline TU 2 & 9 & 1 & small mammal & long bone fragment & & $\mathrm{n}$ & 1 \\
\hline TU 2 & 9 & 1 & unidentified & cancellous bone & weathering cracks & $\mathrm{n}$ & 0 \\
\hline TU 2 & 9 & 1 & unidentified & cancellous bone & & $\bar{n}$ & 1 \\
\hline TU 2 & 9 & 1 & unidentified & cancellous bone & & $\mathrm{n}$ & 0 \\
\hline TU 2 & 9 & 1 & unidentified & flat bone fragment & & $\mathrm{n}$ & 0 \\
\hline TU 2 & 9 & 6 & unidentified & flat bone fragment & & $\bar{n}$ & 0 \\
\hline TU 2 & 9 & 1 & unidentified & flat bone fragment & & $\mathrm{n}$ & 1 \\
\hline TU 2 & 9 & 2 & unidentified & flat bone fragment & & $\mathrm{n}$ & 2 \\
\hline TU 2 & 9 & 1 & unidentified & flat bone fragment & & $\mathrm{n}$ & 3 \\
\hline TU 2 & 9 & 1 & unidentified & unspecified fragment & weathering cracks & $\mathrm{n}$ & 0 \\
\hline TU 2 & 9 & 1 & unidentified & unspecified fragment & & $\mathrm{n}$ & 0 \\
\hline TU 2 & 9 & 1 & unidentified & unspecified fragment & & $\mathrm{n}$ & 0 \\
\hline TU 2 & 9 & 2 & unidentified & unspecified fragment & & $\mathrm{n}$ & 2 \\
\hline TU 2 & 9 & 2 & unidentified & unspecified fragment & & $\bar{n}$ & 3 \\
\hline TU 2 & 10 & 1 & deer sized & long bone fragment & & $\mathrm{n}$ & 2 \\
\hline TU 2 & 10 & 1 & deer sized & unspeicified fragment & & $\bar{n}$ & 1 \\
\hline TU 2 & 10 & 1 & medium mammal & long bone fragment & & $\mathrm{n}$ & 2 \\
\hline TU 2 & 10 & 1 & medium mammal & unspecified fragment & & $\mathrm{n}$ & 0 \\
\hline TU 2 & 10 & 1 & medium mammal & cervical vertebra fragment & & $\mathrm{n}$ & 0 \\
\hline TU 2 & 10 & 1 & Dasypus novemcinctus & inominate fragment & & $\mathrm{L}$ & 0 \\
\hline TU 2 & 10 & 1 & Dasypus novemcinctus & metapodial & & $\mathrm{n}$ & 0 \\
\hline TU 2 & 10 & 18 & Dasypus novemcinctus & scute & & $\mathrm{n}$ & 0 \\
\hline TU 2 & 10 & 1 & Dasypus novemcinctus & vertebra fragment & & $\mathrm{n}$ & 0 \\
\hline TU 2 & 10 & 1 & small mammal & inominate fragment & & $\mathrm{R}$ & 1 \\
\hline TU 2 & 10 & 1 & small mammal & long bone fragment & & $\mathrm{n}$ & 0 \\
\hline TU 2 & 10 & 1 & small mammal & long bone fragment & & $\mathrm{n}$ & 1 \\
\hline TU 2 & 10 & 1 & small mammal & long bone fragment & & $\mathrm{n}$ & 2 \\
\hline TU 2 & 10 & 1 & small mammal & long bone fragment & & $\mathrm{n}$ & 2 \\
\hline TU 2 & 10 & 1 & unidentified & flat bone fragment & & $\mathrm{n}$ & 0 \\
\hline TU 2 & 10 & 3 & unidentified & flat bone fragment & & $\mathrm{n}$ & 1 \\
\hline TU 2 & 10 & 2 & unidentified & unspecified fragment & & $\mathrm{n}$ & 0 \\
\hline TU 2 & 10 & 1 & unidentified & unspecified fragment & & $\mathrm{n}$ & 3 \\
\hline TU 2 & 11 & 1 & large ungulate & flat bone fragment & & $\mathrm{n}$ & 0 \\
\hline TU 2 & 11 & 1 & deer sized & long bone fragment & & $\mathrm{n}$ & 2 \\
\hline TU 2 & 11 & 1 & deer sized & vertebra fragment & & $\mathrm{n}$ & 2 \\
\hline TU 2 & 11 & 1 & medium mammal & cervical vertebra fragment & & $\mathrm{n}$ & 0 \\
\hline TU 2 & 11 & 1 & Dasypus novemcinctus & scute & & $\mathrm{n}$ & 0 \\
\hline TU 2 & 11 & 1 & small mammal & long bone fragment & & $\mathrm{n}$ & 2 \\
\hline TU 2 & 11 & 2 & unidentified & flat bone fragment & & $\mathrm{n}$ & 1 \\
\hline TU 2 & 11 & 1 & unidentified & unspecified fragment & & $\mathrm{n}$ & 0 \\
\hline TU 2 & 11 & 1 & unidentified & unspecified fragment & & $\mathrm{n}$ & 1 \\
\hline TU 2 & 11 & 1 & unidentified & unspecified fragment & & $\mathrm{n}$ & 2 \\
\hline TU 2 & 12 & 1 & canid & maxillary $\mathrm{m} 1$ & & $\bar{L}$ & 0 \\
\hline TU 2 & 12 & 1 & unidentified & unspecified fragment & & $\mathrm{n}$ & 0 \\
\hline Totals & & 171 & & & & & \\
\hline
\end{tabular}


Table 5-2. continued...

\begin{tabular}{|c|c|c|c|c|c|c|c|}
\hline Prov/Unit & Level & Count & Species/Class & Element & Comments & Side & Burn \\
\hline TU 5 & 3 & 1 & medium mammal & long bone fragment & & $\bar{n}$ & 2 \\
\hline$\overline{T U} 5$ & 3 & 1 & unidentified & flat bone fragment & & $\bar{n}$ & 0 \\
\hline TU 5 & 4 & 1 & deer sized & diatal radius fragment & & $\bar{n}$ & 0 \\
\hline TU 5 & 4 & 1 & medium mammal & long bone fragment & & $\bar{n}$ & 2 \\
\hline TU 5 & 4 & 1 & small mammal & distal tibia fragment & & $\bar{n}$ & 0 \\
\hline TU 5 & 4 & 1 & unidentified & flat bone fragment & & $\mathrm{n}$ & 0 \\
\hline TU 5 & 4 & 1 & unidentified & flat bone fragment & & $\bar{n}$ & 1 \\
\hline TU 5 & 4 & 2 & unidentified & unspecified fragment & & $\mathrm{n}$ & 0 \\
\hline TU 5 & 5 & 11 & tortoise & carapace scutes & & $\mathrm{n}$ & 0 \\
\hline TU 5 & 5 & 1 & unidentified & vertebra fragment & & $\mathrm{n}$ & 0 \\
\hline TU 5 & 5 & 3 & unidentified & unspecified fragment & 1 fresh break & $\mathrm{n}$ & 0 \\
\hline TU 5 & 6 & 1 & Odocoileus virginianus & 2nd \& 3rd carpal & & $\bar{R}$ & 0 \\
\hline TU 5 & 6 & 2 & Odocoileus virginianus & metatarsal fragment & & $\mathrm{n}$ & 0 \\
\hline TU 5 & 6 & 1 & Odocoileus virginianus & proximal rib fragmenty & & $\mathrm{n}$ & 0 \\
\hline TU 5 & 6 & 4 & medium mammal & long bone fragment & & $\mathrm{n}$ & 0 \\
\hline TU 5 & 6 & 1 & rodent & long bone fragment & & $\mathrm{n}$ & 0 \\
\hline TU 5 & 6 & 4 & tortoise & carapace scutes & 1 dermestid burrow & $\bar{n}$ & 0 \\
\hline TU 5 & 6 & 3 & tortoise & carapace scutes & & $\mathrm{n}$ & 1 \\
\hline TU 5 & 6 & 4 & unidentified & flat bone fragment & & $\mathrm{n}$ & 0 \\
\hline TU 5 & 6 & 4 & unidentified & flat bone fragment & & $\mathrm{n}$ & 0 \\
\hline TU 5 & 7 & 1 & Odocoileus virginianus & inominate-acetablulum \& pubis fragment & & $\bar{n}$ & 0 \\
\hline TU 5 & 7 & 4 & tortoise & carapace scutes & & $\mathrm{n}$ & 1 \\
\hline TU 5 & 8 & 1 & small mammal & distal humerus & & $\bar{n}$ & 0 \\
\hline TU 5 & 8 & 7 & tortoise & carapace scutes & & $\mathrm{n}$ & 0 \\
\hline TU 5 & 9 & 4 & tortoise & plastron scutes & & $\bar{n}$ & 0 \\
\hline TU 5 & 10 & 4 & Odocoileus virginianus & long bone fragment & 3 fresh breaks & $\bar{n}$ & 0 \\
\hline TU 5 & 10 & 1 & Odocoileus virginianus & metapodial fragment & 1 fresh break & $\mathrm{n}$ & 0 \\
\hline TU 5 & 10 & 1 & Odocoileus virginianus & proximal metatarsal fragment & 1 fresh break & $\mathrm{L}$ & 0 \\
\hline TU 5 & 10 & 1 & deer sized & long bone fragment & & $\mathrm{n}$ & 0 \\
\hline TU 5 & 10 & 1 & deer sized & long bone fragment & & $\mathrm{n}$ & 2 \\
\hline TU 5 & 10 & 1 & tortoise & carapace scute & & $\mathrm{n}$ & 0 \\
\hline TU 5 & 10 & 2 & turtle & carapace scutes & & $\bar{n}$ & 1 \\
\hline TU 5 & 10 & 1 & unidentified & unspecified fragment & & $\mathrm{n}$ & 0 \\
\hline TU 5 & 11 & 1 & Odocoileus virginianus & acetabulum \& pubis fragment & & $\bar{n}$ & 0 \\
\hline TU 5 & 11 & 1 & Odocoileus virginianus & nasals fragment & & $\mathrm{R}$ & 0 \\
\hline TU 5 & 11 & 3 & small mammal & long bone fragment & & $\bar{n}$ & 0 \\
\hline TU 5 & 11 & 6 & tortoise & carapace scutes & & $\mathrm{n}$ & 0 \\
\hline TU 5 & 11 & 1 & unidentified & flat bone fragment & & $\bar{n}$ & 0 \\
\hline TU 5 & 12 & 1 & Odocoileus virginianus & distal radius fragment & & $\mathrm{R}$ & 0 \\
\hline TU 5 & 12 & 1 & small mammal & long bone fragment & fresh breaks & $\mathrm{n}$ & 0 \\
\hline TU 5 & 12 & 1 & tortoise & bridge scute & & $\mathrm{n}$ & 2 \\
\hline TU 5 & 12 & 2 & tortoise & carapace scutes & & $\bar{n}$ & 0 \\
\hline TU 5 & 12 & 1 & unidentified & unspecified fragment & & $\mathrm{n}$ & 0 \\
\hline TU 5 & 12 & 1 & unidentified & unspecified fragment & & $\bar{n}$ & 0 \\
\hline TU 5 & 13 & 1 & deer sized & cervical verebra fragment & & $\mathrm{n}$ & 0 \\
\hline TU 5 & 13 & 1 & tortoise & carapace scute & & $\mathrm{n}$ & 0 \\
\hline TU 5 & 13 & 2 & unidentified & flat bone fragment & & $\mathrm{n}$ & 0 \\
\hline TU 5 & 14 & 1 & Odocoileus virginianus & tibial crest fragment & & $\mathrm{L}$ & 0 \\
\hline TU 5 & 14 & 1 & rodent & mandible fragment & & $\mathrm{R}$ & 0 \\
\hline TU 5 & 14 & 2 & tortoise & carapace scutes & & $\mathrm{n}$ & 0 \\
\hline TU 5 & 14 & 1 & unidentified & flat bone fragment & & $\mathrm{n}$ & 0 \\
\hline Totals & & 105 & & & & & \\
\hline
\end{tabular}


Table 5-2. continued...

\begin{tabular}{|c|c|c|c|c|c|c|c|}
\hline Prov/Unit & Level & Count & Species/Class & Element & Comments & Side & Burn \\
\hline TU 6 & 3 & 1 & medium mammal & long bone fragment & & $\mathrm{n}$ & 1 \\
\hline TU 6 & 3 & 1 & unidentified & flat bone fragment & & $\mathrm{n}$ & 2 \\
\hline TU 6 & 4 & 1 & small mammal & long bone fragment & & $\mathrm{n}$ & 0 \\
\hline TU 6 & 4 & 1 & small mammal & long bone fragment & & $\mathrm{n}$ & 0 \\
\hline TU 6 & 4 & 1 & unidentified & unspecified fragment & & $\mathrm{n}$ & 0 \\
\hline TU 6 & 6 & 3 & unidentified & unspecified fragment & & $\mathrm{n}$ & 0 \\
\hline TU 6 & 7 & 1 & unidentified & flat bone fragment & & $\mathrm{n}$ & 2 \\
\hline TU 6 & 7 & 1 & unidentified & flat bone fragment & & $\mathrm{n}$ & 3 \\
\hline TU 6 & 7 & 1 & unidentified & long bone fragment & & $\mathrm{n}$ & 0 \\
\hline TU 6 & 7 & 2 & unidentified & unspecified fragment & & $\mathrm{n}$ & 0 \\
\hline TU 6 & 8 & 1 & deer sized & proximal rib fragment & & $\mathrm{L}$ & 0 \\
\hline TU 6 & 8 & 1 & medium mammal & long bone fragment & & $\mathrm{n}$ & 0 \\
\hline TU 6 & 8 & 1 & medium mammal & rib fragment & & $\mathrm{n}$ & 3 \\
\hline TU 6 & 8 & 1 & small mammal & long bone fragment & & $\mathrm{n}$ & 1 \\
\hline TU 6 & 8 & 1 & unidentified & flat bone fragment & & $\mathrm{n}$ & 2 \\
\hline TU 6 & 8 & 8 & unidentified & unspecified fragment & & $\mathrm{n}$ & 0 \\
\hline TU 6 & 8 & 1 & unidentified & unspecified fragment & & $\mathrm{n}$ & 1 \\
\hline TU 6 & 9 & 1 & deer sized & phalanx anterior epiphyseal plate & & $\mathrm{n}$ & 0 \\
\hline TU 6 & 9 & 1 & medium mammal & cranial fragment & & $\mathrm{n}$ & 0 \\
\hline TU 6 & 9 & 1 & medium mammal & cranial fragment & & $\mathrm{n}$ & 0 \\
\hline $\mathrm{TU} 6$ & 9 & 2 & medium mammal & cranial fragment & & $\mathrm{n}$ & 1 \\
\hline TU 6 & 9 & 1 & medium mammal & 1st phalanx & & $\mathrm{n}$ & 2 \\
\hline TU 6 & 9 & 1 & medium mammal & lumbar vertebra fragment & & $\mathrm{n}$ & 0 \\
\hline TU 6 & 9 & 1 & Dasypus novemcinctus & occipital & & $\mathrm{n}$ & 0 \\
\hline TU 6 & 9 & 1 & small mammal & long bone fragment & & $\mathrm{n}$ & 0 \\
\hline TU 6 & 9 & 1 & unidentified & cancellous bone & & $\mathrm{n}$ & 2 \\
\hline TU 6 & 9 & 1 & unidentified & flat bone fragment & & $\mathrm{n}$ & 0 \\
\hline TU 6 & 9 & 1 & unidentified & flat bone fragment & & $\mathrm{n}$ & 0 \\
\hline $\mathrm{TU} 6$ & 9 & 6 & unidentified & unspecified fragment & & $\mathrm{n}$ & 0 \\
\hline TU 6 & 9 & 1 & unidentified & unspecified fragment & & $\mathrm{n}$ & 0 \\
\hline TU 6 & 9 & 1 & unidentified & unspecified fragment & & $\mathrm{n}$ & 0 \\
\hline TU 6 & 9 & 1 & unidentified & unspecified fragment & & $\mathrm{n}$ & 0 \\
\hline TU 6 & 9 & 1 & unidentified & unspecified fragment & & $\mathrm{n}$ & 0 \\
\hline TU 6 & 10 & 1 & Odocoileus virginianus & 1st phalanx & & $\mathrm{n}$ & 0 \\
\hline TU 6 & 10 & 1 & small mammal & long bone fragment & & $\mathrm{n}$ & 1 \\
\hline TU 6 & 10 & 1 & small mammal & long bone fragment & & $\mathrm{n}$ & 2 \\
\hline TU 6 & 10 & 1 & small mammal & scapula fragment & & $\mathrm{n}$ & 0 \\
\hline TU 6 & 10 & 1 & small mammal & proximal tibia fragment & & $\mathrm{n}$ & 0 \\
\hline TU 6 & 10 & 1 & unidentified & unspecified fragment & & $\mathrm{n}$ & 0 \\
\hline TU 6 & 10 & 2 & unidentified & unspecified fragment & & $\mathrm{n}$ & 0 \\
\hline TU 6 & 11 & 1 & medium mammal & long bone fragment & & $\mathrm{n}$ & 0 \\
\hline TU 6 & 11 & 1 & medium mammal & long bone fragment & & $\mathrm{n}$ & 0 \\
\hline TU 6 & 12 & 1 & medium mammal & flat bone fragment & & $\mathrm{n}$ & 2 \\
\hline Totals & & 60 & & & & & \\
\hline
\end{tabular}

Key: R=right; $\mathrm{L}=$ left; $\mathrm{n}=$ not sided or not applicable

$0=$ no burning; 1 =some discoloration from burning; $1=$ =blackening; $2=$ partially calcined; $3=$ fully calcined 
containing the complete skeleton of one recent individual was recovered in Level 10 (100-110 cmbd) of TU 2 . Minimally, the remains of two individuals are represented in the TU 2 and TU 6 excavations (based on two occipitals). The highest density of faunal material was from Level 9 $(n=81)$ and Level $10(n=38)$ of TU 2. Forty percent of the recovered bones from Level 9 of TU $2(n=32)$ represent a recent natural armadillo death. TU 6 did not have any faunal material from Levels 1, 2, 4, 5, and 13. The highest density of fauna was from Level $8(n=14)$ and Level $9(n=16)$.

Sixteen bones could be identified as deer (Odocoileus virginianus; Table 5-3). All but one of these bones was recovered from the completely disturbed deposits of TU 5 . Three of the bones from TU 5 had breaks that occurred when the bone was still in a fresh condition. In the absence of any contextual information, it is unclear whether these are prehistoric, cultural, natural, of if they might be intrusive recent remains. The single identified deer phalanx from TU 6 was recovered from sediments associated with a krotovina. None of the identified deer bone exhibited thermal modification. If the deer bone is prehistoric, it represents the only evidence of animal remains that could suggest human butchery. However, the mechanically disturbed context of TU 5 makes such interpretation purely speculative. No other faunal remains indicate any pattern that suggests cultural origins for any of the bone in this deposit. Fifteen bones were identified as coming from deersized animals. The majority of these are very likely deer, but lack distinctive architecture making secure identification impossible. Five of the deer-sized bones are diaphyses fragments from long bones. Two of those bones are from TU 5. Four vertebral fragments are the next most common bones assigned to this body size class. One of those was recovered in TU 5. Nine of the deer-sized fragments from TU 2 and TU 6 exhibit heat damage. None of the deer-sized bones had any evidence of fresh breakage, cut marks, or other indications of human manipulation. A single flat bone fragment is from a larger body sized ungulate.

Smaller-sized animals dominate the recovered faunal assemblage. Much of this is the recent remains of at least two armadillos in TU 2 and TU 6. Recovery of recent $D$. novemcinctus is even more common than represented in the tables. A complete skeleton of one individual from a partially infilled modern burrow was obviously recent and has not been tallied with the more dispersed armadillo remains in the other portions of the two adjacent test units.

It was noted that canid remains in Level $9(90-100 \mathrm{cmbd})$ of TU 2 were responsible for excavation of TU 6 directly north of TU 2. The canid skull found in TU 2 (Level 9) consisted of a fragmentary cranium, both mandibles, and one or two very degraded cervical vertebrae. In the absence of appropriate casting materials, it was impossible to recover the skull intact. The cranium had apparently been partly crushed by the overlying sediment load and weakened by root infiltration. Both mandibles were removed without significant destruction. The condition of the cranium precludes secure examination to determine if the individual recovered from TU 2 may represent a domestic or wild animal. The nasals and prenasals were present, and appeared short enough to indicate a domestic dog. However, these bones fragmented during transportation to the laboratory. All of the associated bones $(n=14)$ have been identified only as Canis sp. The canid remains appear to be from a small individual. The skull exhibited slight displacement of the mandibles, destruction of the entire brain case, and very severely decomposed cervical vertebrae fragments. A single diaphysis of a long bone was associated with the skull. This shaft was situated proximal and cranial of the nasals lying over the left lateral upward side of the maxillary dentition. Small unidentifiable fragments of bone and loose teeth were recovered near to this diaphysis. During removal, the long bone shaft shattered and secure anatomical identification is now problematic. It is unknown if this may represent a portion of the forelimb of this canid. Excavation of the adjacent 1-x-1-m unit (TU 6) was undertaken in part to recover the remaining portion of this animal and help identify its context. Only fragments of the cervical vertebrae were recovered and there was no evidence of any other postcranial elements in association or dispersed within this unit. Careful excavation and inspection failed to detect evidence of additional postcranial elements or a burial pit associated with these remains. The retention of these bones in conjoinable but not anatomical position indicates minimal exposure and relatively rapid burial. The skull with associated vertebrae suggest moderately rapid burial, but the missing postcranial skeleton indicates a high probability that scavenging separated the remainder of the carcass prior to burial. The canid remains would suggest that they represent some of the penultimate accumulations on this surface, exposed long enough to be partially scavenged but buried rapidly enough to preserve the association of the cranium, mandibles, and cervical vertebrae. If the canid represents a domestic dog, its position in an area of relatively high debitage presence may indicate its disposal in an area that functioned as a trash deposit, at least during the final prehistoric human events recorded on this surface. None of the canid bones exhibit any evidence of human butchery or processing. 
Table 5-3. Faunal Remains Recovered from 41GD113, Sorted by Taxon

\begin{tabular}{|c|c|c|c|c|c|c|c|}
\hline Prov/Unit & Level & Count & Species/Class & Element & Comments & Side & Burn \\
\hline TU 5 & 11 & 1 & Odocoileus virginianus & acetabulum $\&$ pubis fragment & & $\mathrm{n}$ & 0 \\
\hline TU 5 & 6 & 1 & Odocoileus virginianus & 2nd \& 3rd carpal & & $\mathrm{R}$ & 0 \\
\hline TU 5 & 7 & 1 & Odocoileus virginianus & inominate-acetablulum \& pubis fragment & & $\bar{n}$ & 0 \\
\hline TU 5 & 10 & 4 & Odocoileus virginianus & long bone fragment & 3 fresh breaks & $\mathrm{n}$ & 0 \\
\hline TU 5 & 10 & 1 & Odocoileus virginianus & metapodial fragment & 1 fresh break & $\mathrm{n}$ & 0 \\
\hline TU 5 & 6 & 2 & Odocoileus virginianus & metatarsal fragment & & $\mathrm{n}$ & 0 \\
\hline TU 5 & 10 & 1 & Odocoileus virginianus & proximal metatarsal fragment & 1 fresh break & $\mathrm{L}$ & 0 \\
\hline TU 5 & 11 & 1 & Odocoileus virginianus & nasals fragment & & $\mathrm{R}$ & 0 \\
\hline TU 6 & 10 & 1 & Odocoileus virginianus & 1st phalanx & & $\mathrm{n}$ & 0 \\
\hline TU 5 & 12 & 1 & Odocoileus virginianus & distal radius fragment & & $\mathrm{R}$ & 0 \\
\hline TU 5 & 6 & 1 & Odocoileus virginianus & proximal rib fragmenty & & $\mathrm{n}$ & 0 \\
\hline TU 5 & 14 & 1 & Odocoileus virginianus & tibial crest fragment & & $\bar{L}$ & 0 \\
\hline Totals & & 16 & & & & & \\
\hline TU 2 & 9 & 1 & deer sized & flat bone fragment & & $\mathrm{n}$ & 0 \\
\hline TU 5 & 10 & 1 & deer sized & long bone fragment & & $\mathrm{n}$ & 0 \\
\hline TU 2 & 9 & 1 & deer sized & long bone fragment & & $\mathrm{n}$ & 2 \\
\hline TU 2 & 10 & 1 & deer sized & long bone fragment & & $\mathrm{n}$ & 2 \\
\hline TU 2 & 11 & 1 & deer sized & long bone fragment & & $\mathrm{n}$ & 2 \\
\hline TU 5 & 10 & 1 & deer sized & long bone fragment & & $\mathrm{n}$ & 2 \\
\hline TU 2 & 9 & 1 & deer sized & metapodial fragment & & $\mathrm{n}$ & 1 \\
\hline TU 6 & 9 & 1 & deer sized & phalanx anterior epiphyseal plate & & $\mathrm{n}$ & 0 \\
\hline TU 5 & 4 & 1 & deer sized & diatal radius fragment & & $\mathrm{n}$ & 0 \\
\hline TU 6 & 8 & 1 & deer sized & proximal rib fragment & & $\mathrm{L}$ & 0 \\
\hline TU 2 & 10 & 1 & deer sized & unspeicified fragment & & $\mathrm{n}$ & 1 \\
\hline TU 5 & 13 & 1 & deer sized & cervical verebra fragment & & $\mathrm{n}$ & 0 \\
\hline TU 2 & 11 & 1 & deer sized & vertebra fragment & & $\mathrm{n}$ & 2 \\
\hline TU 2 & 9 & 1 & deer sized & vertebra fragment & & $\mathrm{n}$ & 3 \\
\hline TU 2 & 9 & 1 & deer sized & thoracic vertebra fragment & & $\mathrm{n}$ & 1 \\
\hline TU 2 & 11 & 1 & large ungulate & flat bone fragment & & $\mathrm{n}$ & 0 \\
\hline Totals & & 16 & & & & & \\
\hline TU 2 & 9 & 1 & canid & cranium & & $\mathrm{n}$ & 0 \\
\hline TU 2 & 9 & 1 & canid & mandible & & $\mathrm{L}$ & 0 \\
\hline TU 2 & 9 & 1 & canid & mandible & & $\mathrm{R}$ & 0 \\
\hline TU 2 & 9 & 1 & canid & tibia fragment & & $\mathrm{n}$ & 0 \\
\hline TU 2 & 8 & 1 & canid & maxillary pm4 & & $\mathrm{R}$ & 0 \\
\hline TU 2 & 9 & 1 & canid & mandibular $\mathrm{m} 2$ & & $\mathrm{R}$ & 0 \\
\hline TU 2 & 9 & 2 & canid & incisor & & $\mathrm{n}$ & 0 \\
\hline TU 2 & 9 & 1 & canid & mandibular pm & & $\mathrm{R}$ & 0 \\
\hline TU 2 & 9 & 3 & canid & incisor & & $\mathrm{n}$ & 0 \\
\hline TU 2 & 9 & 1 & canid & incisor & & $\mathrm{n}$ & 0 \\
\hline TU 2 & 12 & 1 & canid & maxillary $\mathrm{m} 1$ & & $\mathrm{~L}$ & 0 \\
\hline Totals & & 14 & & & & & \\
\hline \begin{tabular}{l|l} 
TU 2 \\
\end{tabular} & 9 & 1 & medium mammal & carpal & & $\bar{n}$ & 0 \\
\hline TU 6 & 9 & 1 & medium mammal & cranial fragment & & $\mathrm{n}$ & 0 \\
\hline TU 6 & 9 & 1 & medium mammal & cranial fragment & & $\mathrm{n}$ & 0 \\
\hline TU 6 & 9 & 2 & medium mammal & cranial fragment & & $\mathrm{n}$ & 1 \\
\hline TU 6 & 12 & 1 & medium mammal & flat bone fragment & & $\mathrm{n}$ & 2 \\
\hline TU 2 & 2 & 1 & medium mammal & long bone fragment & rodent gnawing & $\mathrm{n}$ & 0 \\
\hline TU 2 & 8 & 1 & medium mammal & long bone fragment & & $\mathrm{n}$ & 0 \\
\hline TU 2 & 8 & 1 & medium mammal & long bone fragment & & $\mathrm{n}$ & 0 \\
\hline TU 2 & 9 & 1 & medium mammal & long bone fragment & & $\mathrm{n}$ & 0 \\
\hline TU 2 & 9 & 1 & medium mammal & long bone fragment & & $\mathrm{n}$ & 0 \\
\hline TU 5 & 6 & 4 & medium mammal & long bone fragment & & $\mathrm{n}$ & 0 \\
\hline
\end{tabular}


Table 5-3. continued...

\begin{tabular}{|c|c|c|c|c|c|c|c|}
\hline Prov/Unit & Level & Count & Species/Class & Element & Comments & Side & Burn \\
\hline TU 6 & 10 & 1 & medium mammal & long bone fragment & & $\mathrm{n}$ & 0 \\
\hline TU 6 & 8 & 1 & medium mammal & long bone fragment & & $\mathrm{n}$ & 0 \\
\hline TU 6 & 11 & 1 & medium mammal & long bone fragment & & $\mathrm{n}$ & 0 \\
\hline TU 6 & 3 & 1 & medium mammal & long bone fragment & & $\mathrm{n}$ & 1 \\
\hline TU 2 & 9 & 1 & medium mammal & long bone fragment & & $\mathrm{n}$ & 2 \\
\hline TU 2 & 10 & 1 & medium mammal & long bone fragment & & $\mathrm{n}$ & 2 \\
\hline TU 5 & 3 & 1 & medium mammal & long bone fragment & & $\mathrm{n}$ & 2 \\
\hline TU 5 & 4 & 1 & medium mammal & long bone fragment & & $\mathrm{n}$ & 2 \\
\hline TU 6 & 9 & 1 & medium mammal & 1st phalanx & & $\mathrm{n}$ & 2 \\
\hline TU 6 & 8 & 1 & medium mammal & rib fragment & & $\mathrm{n}$ & 3 \\
\hline TU 2 & 9 & 1 & medium mammal & unspecified fragment & & $\mathrm{n}$ & 0 \\
\hline TU 2 & 10 & 1 & medium mammal & unspecified fragment & & $\mathrm{n}$ & 0 \\
\hline TU 2 & 9 & 2 & medium mammal & unspecified fragment & & $\mathrm{n}$ & 0 \\
\hline TU 2 & 10 & 1 & medium mammal & cervical vertebra fragment & & $\mathrm{n}$ & 0 \\
\hline TU 2 & 11 & 1 & medium mammal & cervical vertebra fragment & & $\mathrm{n}$ & 0 \\
\hline TU 6 & 9 & 1 & medium mammal & lumbar vertebra fragment & & $\mathrm{n}$ & 0 \\
\hline Totals & & 32 & & & & & \\
\hline \begin{tabular}{l|l} 
TU 6 \\
\end{tabular} & 9 & 1 & Dasypus novemcinctus & occipital & & $\bar{n}$ & 0 \\
\hline TU 2 & 9 & 1 & Dasypus novemcinctus & flat bone fragment & & $\mathrm{n}$ & 0 \\
\hline TU 2 & 10 & 1 & Dasypus novemcinctus & inominate fragment & & $\mathrm{L}$ & 0 \\
\hline TU 2 & 10 & 1 & Dasypus novemcinctus & metapodial & & $\mathrm{n}$ & 0 \\
\hline TU 2 & 9 & 1 & Dasypus novemcinctus & 1st phalanx & & $\mathrm{n}$ & 0 \\
\hline TU 2 & 9 & 1 & Dasypus novemcinctus & 2nd phalanx & & $\mathrm{n}$ & 0 \\
\hline TU 2 & 8 & 1 & Dasypus novemcinctus & 3rd phalanx & & $\mathrm{n}$ & 0 \\
\hline TU 2 & 9 & 1 & Dasypus novemcinctus & 3rd phalanx & & $\mathrm{n}$ & 0 \\
\hline TU 2 & 9 & 1 & Dasypus novemcinctus & rib & & $\mathrm{n}$ & 0 \\
\hline TU 2 & 2 & 1 & Dasypus novemcinctus & scute & & $\mathrm{n}$ & 0 \\
\hline TU 2 & 3 & 1 & Dasypus novemcinctus & scute & & $\mathrm{n}$ & 0 \\
\hline TU 2 & 7 & 5 & Dasypus novemcinctus & scute & & $\mathrm{n}$ & 0 \\
\hline TU 2 & 8 & 7 & Dasypus novemcinctus & scute & & $\mathrm{n}$ & 0 \\
\hline TU 2 & 9 & 2 & Dasypus novemcinctus & scute & & $\mathrm{n}$ & 0 \\
\hline TU 2 & 9 & 5 & Dasypus novemcinctus & scute & & $\mathrm{n}$ & 0 \\
\hline TU 2 & 9 & 24 & Dasypus novemcinctus & scute & & $\mathrm{n}$ & 0 \\
\hline TU 2 & 9 & 1 & Dasypus novemcinctus & scute & & $\mathrm{n}$ & 0 \\
\hline TU 2 & 9 & 1 & Dasypus novemcinctus & scute & & $\mathrm{n}$ & 0 \\
\hline TU 2 & 10 & 18 & Dasypus novemcinctus & scute & & $\mathrm{n}$ & 0 \\
\hline TU 2 & 11 & 1 & Dasypus novemcinctus & scute & & $\mathrm{n}$ & 0 \\
\hline TU 2 & 9 & 1 & Dasypus novemcinctus & vertebra fragment & & $\mathrm{n}$ & 0 \\
\hline TU 2 & 9 & 1 & Dasypus novemcinctus & vertebra fragment & & $\mathrm{n}$ & 0 \\
\hline TU 2 & 9 & 1 & Dasypus novemcinctus & vertebra fragment & & $\mathrm{n}$ & 0 \\
\hline TU 2 & 10 & 1 & Dasypus novemcinctus & vertebra fragment & & $\bar{n}$ & 0 \\
\hline Totals & & 79 & & & & & \\
\hline \begin{tabular}{l|l} 
TU 5 \\
\end{tabular} & 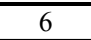 & 1 & rodent & long bone fragment & & $\bar{n}$ & 0 \\
\hline TU 5 & 14 & 1 & rodent & mandible fragment & & $\mathrm{R}$ & 0 \\
\hline Totals & & 2 & & & & 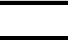 & \\
\hline \begin{tabular}{l|l} 
TU 5 \\
\end{tabular} & 8 & 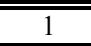 & small mammal & distal humerus & & $\overline{\mathrm{n}}$ & 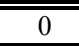 \\
\hline TU 2 & 10 & 1 & small mammal & inominate fragment & & $\bar{R}$ & 1 \\
\hline TU 2 & 7 & 1 & small mammal & long bone fragment & fresh break & $\mathrm{n}$ & 0 \\
\hline TU 2 & 9 & 1 & small mammal & long bone fragment & & $\mathrm{n}$ & 0 \\
\hline TU 2 & 10 & 1 & small mammal & long bone fragment & & $\mathrm{n}$ & 0 \\
\hline TU 5 & 11 & 3 & small mammal & long bone fragment & & $\mathrm{n}$ & 0 \\
\hline TU 5 & 12 & 1 & small mammal & long bone fragment & fresh breaks & $\mathrm{n}$ & 0 \\
\hline TU 6 & 9 & 1 & small mammal & long bone fragment & & $\bar{n}$ & 0 \\
\hline
\end{tabular}


Table 5-3. continued...

\begin{tabular}{|c|c|c|c|c|c|c|c|}
\hline Prov/Unit & Level & Count & Species/Class & Element & Comments & Side & Burn \\
\hline TU 6 & 4 & 1 & small mammal & long bone fragment & & $\mathrm{n}$ & 0 \\
\hline TU 6 & 4 & 1 & small mammal & long bone fragment & & $\mathrm{n}$ & 0 \\
\hline TU 2 & 9 & 1 & small mammal & long bone fragment & & $\mathrm{n}$ & 1 \\
\hline TU 2 & 9 & 1 & small mammal & long bone fragment & fresh break & $\mathrm{n}$ & 1 \\
\hline TU 2 & 9 & 1 & small mammal & long bone fragment & & $\mathrm{n}$ & 1 \\
\hline TU 2 & 10 & 1 & small mammal & long bone fragment & & $\mathrm{n}$ & 1 \\
\hline TU 6 & 8 & 1 & small mammal & long bone fragment & & $\mathrm{n}$ & 1 \\
\hline TU 6 & 10 & 1 & small mammal & long bone fragment & & $\mathrm{n}$ & 1 \\
\hline TU 2 & 10 & 1 & small mammal & long bone fragment & & $\mathrm{n}$ & 2 \\
\hline TU 2 & 10 & 1 & small mammal & long bone fragment & & $\mathrm{n}$ & 2 \\
\hline TU 2 & 11 & 1 & small mammal & long bone fragment & & $\mathrm{n}$ & 2 \\
\hline TU 6 & 10 & 1 & small mammal & long bone fragment & & $\mathrm{n}$ & 2 \\
\hline TU 6 & 10 & 1 & small mammal & scapula fragment & & $\mathrm{n}$ & 0 \\
\hline TU 5 & 4 & 1 & small mammal & distal tibia fragment & & $\mathrm{n}$ & 0 \\
\hline TU 6 & 10 & 1 & small mammal & proximal tibia fragment & & $\mathrm{n}$ & 0 \\
\hline TU 2 & 8 & 1 & small mammal & cervical vertebra & & $\mathrm{n}$ & 0 \\
\hline Totals & & 26 & & & & & \\
\hline \begin{tabular}{|l|l|} 
TU 5 \\
\end{tabular} & 12 & 1 & tortoise & bridge scute & & $\mathrm{n}$ & 2 \\
\hline TU 5 & 10 & 1 & tortoise & carapace scute & & $\mathrm{n}$ & 0 \\
\hline TU 5 & 5 & 11 & tortoise & carapace scutes & & $\mathrm{n}$ & 0 \\
\hline TU 5 & 6 & 4 & tortoise & carapace scutes & 1 dermestid burrow & $\mathrm{n}$ & 0 \\
\hline TU 5 & 8 & 7 & tortoise & carapace scutes & & $\mathrm{n}$ & 0 \\
\hline TU 5 & 9 & 4 & tortoise & plastron scutes & & $\mathrm{n}$ & 0 \\
\hline TU 5 & 11 & 6 & tortoise & carapace scutes & & $\mathrm{n}$ & 0 \\
\hline TU 5 & 12 & 2 & tortoise & carapace scutes & & $\mathrm{n}$ & 0 \\
\hline TU 5 & 13 & 1 & tortoise & carapace scute & & $\mathrm{n}$ & 0 \\
\hline TU 5 & 14 & 2 & tortoise & carapace scutes & & $\mathrm{n}$ & 0 \\
\hline TU 5 & 6 & 3 & tortoise & carapace scutes & & $\mathrm{n}$ & 1 \\
\hline TU 5 & 7 & 4 & tortoise & carapace scutes & & $\mathrm{n}$ & 1 \\
\hline Totals & & 46 & & & & & \\
\hline \begin{tabular}{l|l} 
TU 5 \\
\end{tabular} & 10 & 2 & turtle & carapace scutes & & $\mathrm{n}$ & 1 \\
\hline Totals & & 2 & & & & 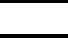 & \\
\hline \begin{tabular}{l|l} 
TU 2 \\
\end{tabular} & 9 & 1 & unidentified & cancellous bone & weathering cracks & $\mathrm{n}$ & 0 \\
\hline TU 2 & 9 & 1 & unidentified & cancellous bone & & $\mathrm{n}$ & 1 \\
\hline TU 2 & 9 & 1 & unidentified & cancellous bone & & $\mathrm{n}$ & 0 \\
\hline TU 6 & 9 & 1 & unidentified & cancellous bone & & $\mathrm{n}$ & 2 \\
\hline $\mathrm{TU} 1$ & 5 & 1 & unidentified & flat bone fragment & & $\mathrm{n}$ & 3 \\
\hline TU 2 & 3 & 1 & unidentified & flat bone fragment & & $\mathrm{n}$ & 0 \\
\hline TU 2 & 5 & 1 & unidentified & flat bone fragment & & $\mathrm{n}$ & 0 \\
\hline TU 2 & 8 & 1 & unidentified & flat bone fragment & & $\mathrm{n}$ & 2 \\
\hline TU 2 & 9 & 1 & unidentified & flat bone fragment & & $\mathrm{n}$ & 0 \\
\hline TU 2 & 9 & 6 & unidentified & flat bone fragment & & $\mathrm{n}$ & 0 \\
\hline TU 2 & 9 & 1 & unidentified & flat bone fragment & & $\mathrm{n}$ & 1 \\
\hline TU 2 & 9 & 2 & unidentified & flat bone fragment & & $\mathrm{n}$ & 2 \\
\hline TU 2 & 9 & 1 & unidentified & flat bone fragment & & $\mathrm{n}$ & 3 \\
\hline TU 2 & 10 & 1 & unidentified & flat bone fragment & & $\mathrm{n}$ & 0 \\
\hline TU 2 & 10 & 3 & unidentified & flat bone fragment & & $\mathrm{n}$ & 1 \\
\hline TU 2 & 11 & 2 & unidentified & flat bone fragment & & $\mathrm{n}$ & 1 \\
\hline TU 5 & 3 & 1 & unidentified & flat bone fragment & & $\mathrm{n}$ & 0 \\
\hline TU 5 & 4 & 1 & unidentified & flat bone fragment & & $\mathrm{n}$ & 0 \\
\hline TU 5 & 4 & 1 & unidentified & flat bone fragment & & $\mathrm{n}$ & 1 \\
\hline $\mathrm{TU} 5$ & 6 & 4 & unidentified & flat bone fragment & & $\mathrm{n}$ & 0 \\
\hline TU 5 & 6 & 4 & unidentified & flat bone fragment & & $\mathrm{n}$ & 0 \\
\hline
\end{tabular}


Table 5-3. continued...

\begin{tabular}{|c|c|c|c|c|c|c|c|}
\hline Prov/Unit & Level & Count & Species/Class & Element & Comments & Side & Burn \\
\hline TU 5 & 11 & 1 & unidentified & flat bone fragment & & $\mathrm{n}$ & 0 \\
\hline TU 5 & 13 & 2 & unidentified & flat bone fragment & & $\mathrm{n}$ & 0 \\
\hline TU 5 & 14 & 1 & unidentified & flat bone fragment & & $\mathrm{n}$ & 0 \\
\hline TU 6 & 3 & 1 & unidentified & flat bone fragment & & $\mathrm{n}$ & 2 \\
\hline TU 6 & 7 & 1 & unidentified & flat bone fragment & & $\mathrm{n}$ & 2 \\
\hline TU 6 & 7 & 1 & unidentified & flat bone fragment & & $\mathrm{n}$ & 3 \\
\hline TU 6 & 8 & 1 & unidentified & flat bone fragment & & $\bar{n}$ & 2 \\
\hline TU 6 & 9 & 1 & unidentified & flat bone fragment & & $\mathrm{n}$ & 0 \\
\hline TU 6 & 9 & 1 & unidentified & flat bone fragment & & $\bar{n}$ & 0 \\
\hline TU 2 & 2 & 1 & unidentified & long bone fragment & & $\mathrm{n}$ & 0 \\
\hline TU 6 & 7 & 1 & unidentified & long bone fragment & & $\mathrm{n}$ & 0 \\
\hline TU 5 & 5 & 1 & unidentified & vertebra fragment & & $\mathrm{n}$ & 0 \\
\hline TU 1 & 4 & 1 & unidentified & unspecified fragment & & $\mathrm{n}$ & 0 \\
\hline TU 1 & 4 & 1 & unidentified & unspecified fragment & sediment abrasion & $\mathrm{n}$ & 0 \\
\hline TU 2 & 7 & 1 & unidentified & unspecified fragment & & $\mathrm{n}$ & 0 \\
\hline TU 2 & 7 & 1 & unidentified & unspecified fragment & & $\mathrm{n}$ & 2 \\
\hline TU 2 & 7 & 2 & unidentified & unspecified fragment & & $\mathrm{n}$ & 3 \\
\hline TU 2 & 8 & 1 & unidentified & unspecified fragment & & $\mathrm{n}$ & 0 \\
\hline TU 2 & 9 & 1 & unidentified & unspecified fragment & weathering cracks & $\mathrm{n}$ & 0 \\
\hline TU 2 & 9 & 1 & unidentified & unspecified fragment & & $\mathrm{n}$ & 0 \\
\hline TU 2 & 9 & 1 & unidentified & unspecified fragment & & $\mathrm{n}$ & 0 \\
\hline TU 2 & 9 & 2 & unidentified & unspecified fragment & & $\mathrm{n}$ & 2 \\
\hline TU 2 & 9 & 2 & unidentified & unspecified fragment & & $\mathrm{n}$ & 3 \\
\hline TU 2 & 10 & 2 & unidentified & unspecified fragment & & $\bar{n}$ & 0 \\
\hline TU 2 & 10 & 1 & unidentified & unspecified fragment & & $\mathrm{n}$ & 3 \\
\hline TU 2 & 11 & 1 & unidentified & unspecified fragment & & $\mathrm{n}$ & 0 \\
\hline TU 2 & 11 & 1 & unidentified & unspecified fragment & & $\mathrm{n}$ & 1 \\
\hline TU 2 & 11 & 1 & unidentified & unspecified fragment & & $\mathrm{n}$ & 2 \\
\hline TU 2 & 12 & 1 & unidentified & unspecified fragment & & $\mathrm{n}$ & 0 \\
\hline TU 5 & 4 & 2 & unidentified & unspecified fragment & & $\mathrm{n}$ & 0 \\
\hline TU 5 & 5 & 3 & unidentified & unspecified fragment & 1 fresh break & $\mathrm{n}$ & 0 \\
\hline TU 5 & 10 & 1 & unidentified & unspecified fragment & & $\mathrm{n}$ & 0 \\
\hline TU 5 & 12 & 1 & unidentified & unspecified fragment & & $\mathrm{n}$ & 0 \\
\hline TU 5 & 12 & 1 & unidentified & unspecified fragment & & $\mathrm{n}$ & 0 \\
\hline TU 6 & 6 & 3 & unidentified & unspecified fragment & & $\mathrm{n}$ & 0 \\
\hline TU 6 & 7 & 2 & unidentified & unspecified fragment & & $\mathrm{n}$ & 0 \\
\hline TU 6 & 8 & 8 & unidentified & unspecified fragment & & $\mathrm{n}$ & 0 \\
\hline TU 6 & 8 & 1 & unidentified & unspecified fragment & & $\mathrm{n}$ & 1 \\
\hline TU 6 & 9 & 6 & unidentified & unspecified fragment & & $\mathrm{n}$ & 0 \\
\hline TU 6 & 9 & 1 & unidentified & unspecified fragment & & $\mathrm{n}$ & 0 \\
\hline TU 6 & 9 & 1 & unidentified & unspecified fragment & & $\mathrm{n}$ & 0 \\
\hline TU 6 & 9 & 1 & unidentified & unspecified fragment & & $\mathrm{n}$ & 0 \\
\hline TU 6 & 9 & 1 & unidentified & unspecified fragment & & $\mathrm{n}$ & 0 \\
\hline TU 6 & 10 & 2 & unidentified & unspecified fragment & & $\mathrm{n}$ & 0 \\
\hline TU 6 & 10 & 1 & unidentified & unspecified fragment & & $\mathrm{n}$ & 0 \\
\hline TU 6 & 4 & 1 & unidentified & unspecified fragment & & $\mathrm{n}$ & 0 \\
\hline Totals & & 106 & & & & & \\
\hline
\end{tabular}

Key: $\mathrm{R}=$ right; $\mathrm{L}=\mathrm{left}$; $\mathrm{n}=$ not sided or not applicable

$0=$ no burning; $1=$ some discoloration from burning; $1=$ =blackening; $2=$ partially calcined; $3=$ fully calcined 
An additional 32 bone fragments were identifiable only as coming from medium-sized mammals. Seven of these bones were from TU 5 and the remainder came from TU 2 and TU 6 . Many of these may represent additional canid remains. The majority of these are unspecified long bone diaphyseal fragments. There also were four cranial and three vertebral fragments. Seven of the medium-sized mammal bones from TU 2 and TU 6 have been exposed to heating. None of these bones exhibited any fresh bone breaks or other indications of human modification.

Two recovered rodent bones are almost certainly very recent inclusions due to natural death. Twenty-six other bones indicate small mammals, approximately rabbit-sized. Several of the small mammal remains may be additional fragments of the recent armadillo in TUs 2 and 6. Six of these are long bone fragments from TU 5. Eighteen other long bone diaphyses fragments, one proximal tibia, and a single portion of a vertebra were also collected from TUs 2 and 6. Three of the small mammal long bone fragments exhibited fresh breaks, one of those came from TU 5. In addition to the three fresh breaks on deer bone from TU 5 , this is the only evidence of postmortem damage to bone that has not experienced significant postdepositional weathering. This does not offer any strong suggestion of human involvement.

Forty-six tortoise and two turtle scute fragments were found in TU 5. A single plastron scute and one bridge scute are represented in this sample of carapace scutes. Because only TU 2, 5, and 6 produced bones (TU 1 contained only three small fragments), it cannot be considered anomalous that the only Testudines were recovered from one test unit. TU 5 also contained all of the identified deer. The canid remains and localized artifact concentration in TUs 2 and 6 also demonstrate very individual characters of these deposits that also support interpretation as a palimpsest of unrelated multiple occupation events. None of the faunal remains have any evidence of human disarticulation.

\section{Fire-cracked Rock}

All identified or suspect fire-cracked rock was collected during fieldwork and returned to the laboratory for inspection and quantification. Four hundred forty-two pieces of FCR were recovered at 41GD113 from screening and pieceplotting $(\mathrm{n}=29)$, representing $5.85 \mathrm{~kg}$ of material (see Table 4-6). Most of the FCR came from TU $2(\mathrm{n}=307,3203.2 \mathrm{~g})$ and TU $6(\mathrm{n}=122,1931.1 \mathrm{~g})$. TU 3 contained three pieces of FCR $(18.3 \mathrm{~g})$. Six fragments of FCR $(14.0 \mathrm{~g})$ were collected from TU 1. Three pieces of FCR $(10.5 \mathrm{~g})$ were recovered from the disturbed context of TU 5. TUs 4, and 7 contained no FCR. One large FCR (673.4 g) was dislodged during excavation of BHT 2, but came from the area excavated as TU 2.

Even in the absence of identifiable features, these samples provided the only evidence that some cultural thermal activities occurred in a portion of 41GD113, although it cannot be used to unambiguously distinguish what activities occurred in the vicinity of TU 2 and TU 6 . The lack of associated charcoal may indicate that these FCR are not in proximity to the location of prehistoric features, that minimal use of heated rock occurred, or that post-use exposure resulted in dispersal of the feature and its associated fuel residues. Data from this portion of the site cannot currently determine whether the FCR represents a post-use dispersed feature, cleanup of another portion of the site, or an actual midden deposit from short-term use events. The proximity of the partially conjoined canid remains and the debitage concentration to the very dispersed Feature 1 rocks may suggest trash disposal activities from other portions of the site. This is important negative information that could indicate that the high density of lithics, FCR, and bone is an artifact of disposal behavior and does not identify a prehistoric locus of maintained activities.

All of the material identified as fire-cracked rock represents course, calcareous sandstones that are derived from the Goliad Formation (Barnes 1975). This bedrock is expressed at least $6 \mathrm{~km}$ northwest of $41 \mathrm{GD} 113$ but there may be shallowly buried outcrops closer to the site. Weathered Goliad sandstone bedrock was identified at a depth of approximately $55 \mathrm{cmbs}$ in the excavations of TU 1 at 41GD114. Numerous fragments of this bedrock were encountered from at least $15 \mathrm{cmbs}$ to the solid layer in TU 1. Gravels encountered within the deposits at 41GD113 (and identified as a fluvial deposits on 41GD114) are almost exclusively siliceous rocks. Excavations at 41GD113 did not identify any area where Goliad sandstone outcrops were near the surface. The channel deposits investigated through backhoe trench profiling and test unit excavation were associated only with siliceous gravels. The FCR in 41 GD113 was derived from conglomerate sandstone that was selectively brought to the location by prehistoric human inhabitants and indicates intentional use in thermal features. 


\section{Chapter 6: Summary and Recommendations}

Site Summaries

\section{$41 G D 113$}

Site 41GD113 contained evidence of multiple occupations that may be very short term. The site is located on terrace deposits that experienced primarily low-energy overbank flooding that is responsible for preservation of this site. The highest density of artifacts was associated with three dates that indicate Late Archaic use of this location. A concentration of FCR in TU 2 and TU 6 suggests that a thermal feature was located in this vicinity. This dispersed rock did not represent an intact feature that could usefully provide references for site structural inferences. The association of burned rock, lithics, and bone may represent a trash accumulation from episodes in one or several other areas of the site. Lithics recovered from the site are dominated by late stage reduction debris. Biface manufacturing events are likely. Given the dearth of tools, production does not appear to be for local use at this site. Situational flake tools were recovered in greater frequency $(n=3)$ than either implements abandoned during manufacturing $(\mathrm{n}=1)$ or exhausted tools $(\mathrm{n}=0)$. Natural clast data indicate that the site is not the product of alluvial redeposition. However, moderately slow burial has resulted in the incorporation of non-cultural materials in proportion to artifact frequency. None of the faunal remains unambiguously indicate that they are human food residues. In combination with the very localized horizontal concentration of lithics and dispersed evidence of FCR, 41GD113 appears to be a palimpsest of numerous small and short-term occupation events.

\section{$41 G D 114$}

Very little can be inferred about prehistoric activities at this site. This is partially because testing only examined two 1-x-1-m units; however, the shallow nature of the deposit, significant amount of bioturbation, and the recent mechanical destruction of much of the site within the TxDOT right-ofway indicate this is not a location that contains an artifact assemblage or context that offers significant interpretive opportunities. Lithic data are similar to those from $41 \mathrm{GD} 113$. No tools were recovered and most of the debitage indicates late stage reduction events. Slightly more early stage flakes were present on 41GD113 than 41GD114, but the small sample size makes it impossible to infer differences in activities. No features or datable charcoal were encountered during the investigation of 41GD114.

\section{Recommendations}

The research potential of $41 \mathrm{GD} 113$ and 41GD114 will be briefly compared with other local Late Archaic archeological sites. Given that prehistoric occupation of this area is not as well understood as other portions of Texas (Black 1989:39), it is important to evaluate what potential research contribution these sites could make. Following this comparison, a summary is presented outlining the reasons each site is not considered to be eligible for NRHP listing nor warrant designation as a SAL.

\section{Regional Significance}

Archeological investigations have identified numerous local sites that are primarily concentrated along Coleto Creek. Limited recent investigations of theses sites have been performed. Several sites examined following the Coleto Creek Reservoir survey do exhibit qualities of preservation and content that contribute information about prehistoric adaptations in this area. Because the dates at 41GD113 indicate a Late Archaic occupation, the potential of sites $41 \mathrm{GD} 113$ and 41GD114 is evaluated only in relation to other local Late Archaic sites. The Berger Bluff site (41GD30) represents a stratified archeological site that includes mostly Late Archaic and Late Prehistoric artifacts. Concentrations of burned rock and charcoal stained soil were considered associated with the Late Prehistoric Toyah Phase occupation, with other deposits identified as representing a Late Archaic occupation floor (Brown 1983:21-26, 74-88). It is unclear if there is a Middle Archaic occupation at 41GD30 and the dated charcoal of Paleoindian age is not associated with any artifacts. The Berger Bluff site (41GD30) is considered to possess an excellent stratified deposit that offers significant environmental information about this region (Brown 1986:3). Site 41GD21 possessed a record of Early Archaic through Late Prehistoric remains identified through diagnostic artifacts and three charcoal dates (Fox 1979:3942, 62-65). Deposits containing artifacts were encountered in excess of $180 \mathrm{~cm}$ below surface. Excellent geoarcheological investigations were undertaken and landscape 
formation at 41GD21 is well understood (Fox 1979:66). Paleoenvironmental reconstruction included analyses of geomorphology, gastropod remains, and phytoliths.

In comparison with other sites known from the local vicinity, 41GD113 and 41GD114 possess limited research potential. Only one area of 41GD113 contained a dense artifact distribution (TUs 2 and 6). This distribution was associated with higher frequencies of FCR than at other locations at the site, but it did not represent an intact feature. Within this artifact concentration, no diagnostic implements were recovered. This area also had been subject to much bioturbation. 41GD114 contained only shallow deposits and no dense artifact concentrations, diagnostic tools, or features were identified. Much of the site within the TxDOT right-of-way has been heavily disturbed. Neither site is considered to possess qualities that make them likely to contribute an improved understanding of local or regional prehistoric lifeways.

\section{$41 G D 113$}

Site 41GD113 is not considered to be eligible for NRHP listing nor warrant designation as a SAL. No additional archeological investigations are considered necessary at this site. Although buried deposits were identified at 41GD113, no unambiguous features were encountered during this testing effort. The single loose association of fire-cracked rock (Feature 1) cannot be unambiguously identified as in primary context or as secondary disposal of FCR from another location. Lithics were abundant in two units (TU 2 and TU 6) but only one biface fragment and three flake tools were recovered from this examination. The relatively low density of material at 41GD113 suggests that the area examined in TU 2 and TU 6 is unique in the amount of cultural materials encountered. A portion of the site that may have contained an abundant faunal record (TU 5) had been destroyed prior to this investigation. It is recommended that road construction be allowed to proceed in this area.

\section{$41 \mathrm{GD} 114$}

Site 41GD114 is not considered eligible for NRHP listing nor warrant designation as a SAL. Based on CAR's test excavations, the portion of this site within the TxDOT rightof-way contains primarily shallow, sparse and disturbed archeological deposits. Results of shovel test investigations of a portion of the site outside of the current right-of-way by Prewitt and Associates, Inc. also does not demonstrate that significant archeological remains with good integrity are present outside of the area tested by CAR. The northern portion of this site has been significantly disturbed through uncontrolled mechanical investigation of the archeological deposits by the landowner prior to any scheduled or permitted work by TxDOT. Bulldozer destruction is extensive. An area at least $25 \mathrm{~m}$ east-west and $15 \mathrm{~m}$ north-south in the northernmost portion of the site has been excavated to a depth of $1.5 \mathrm{~m}$ and deeper. Test units within the less disturbed portion of the site indicated the presence of very shallow deposits $(60 \mathrm{~cm}$ deep) overlying weathered bedrock and fluvial gravel deposits. There is much animal and root bioturbation of the shallow soils containing the very lowdensity archeological record of 41GD114. The sample of artifacts does not provide any evidence that a dense, diverse, or unique archeological record with adequate integrity is present in this site to possess significant research potential. The area within the right-of-way contains some of the shallowest deposits identified during initial survey. This testing effort confirmed that this portion of 41GD114 has shallow A horizon soils containing very low-density archeological deposits. These soils are underlain by a very gravelly B horizon and weathered Goliad sandstone bedrock that indicate no archeological materials are likely present below $50 \mathrm{cmbs}$ in the area of the site examined. No traces of thermal features, middens, or potential habitation locations were identified. No additional archeological investigations are considered necessary at this site. It is recommended that the proposed road construction activities be allowed to proceed. 


\section{References Cited}

Abbott, J. T.

2001 Houston Area Geoarcheology: A Framework for Archeological Investigation, Interpretation, and Cultural Resource Management in the Houston Highway District. Texas Department of Transportation, Environmental Affairs Division, Archeological Studies Program Report No. 27. Morgan Printing, Austin.

Andrefsky, W.

1998 Lithics, Macroscopic Approaches to Analysis. Cambridge Manuals In Archaeology, Cambridge University Press, New York.

Arnold, J. B.

1996 The Texas Historical Commission's underwater archaeological survey of 1995 and the preliminary report on the Belle, LaSalle's shipwreck of 1686. Historical Archaeology 30(4):66-87.

Aten, L. E.

1983 Indians of the Upper Texas Coast. New World Archaeological Record. Academic Press, New York.

Bamforth, D. B.

1986 Technological Efficiency and Stone Tool Curation. American Antiquity 51:38-50.

Barnes, V. E.

1975 Geologic Atlas of Texas: Beeville-Bay City Sheet. Bureau of Economic Geology, The University of Texas at Austin.

Birmingham, W. W.

2001 Site visitation notes. Unpublished document on file, Center for Archaeological Research, The University of Texas at San Antonio.

Black, S. L.

1989 South Texas Plain. In From the Gulf to the Rio Grande: Human Adaptation in Central, South and Lower Pecos, Texas, by T. R. Hester, S. L. Black, D. G. Steele, B. W. Olive, A. A. Fox, K. J. Reinhard, and L. C. Bement, pp. 3962. Research Series No. 33. Arkansas Archeological Survey, Fayettville.

Blair, W. F.

1950 The Biotic Provinces of Texas. The Texas Journal of Science 2(1):93-117.

Bleed, P.

1986 The Optimal Design of Hunting Weapons. American Antiquity 51:737-747.

Bomar, G. W.

1995 Texas Weather. Second Edition. University of Texas Press, Austin.

Bradley, B. A.

1975 Lithic Reduction Sequences: A Glossary and Discussion. In Lithic Technology: Making and Using Stone Tools, edited by E. Swanson, pp. 5-13. The Hague, Mouton. 
Brown, D. O.

1983 The Berger Bluff Site (41GD30A): Excavations in the Upper Deposits, 1979. Archaeological Survey Report, No. 115. Center for Archaeological Research, The University of Texas at San Antonio.

Brown, K. M.

1986 Archaeological Survey and Backhoe Testing for Flume No. 3 Right-of-Way at Coleto Creek Reservoir, Goliad County, Texas. Archaeological Survey Report, No. 128. Center for Archaeological Research, The University of Texas at San Antonio.

Campbell, T. N.

1976 Archaeological Investigations at the Morhiss Site, Victoria County, Texas. In An Archaeological Survey of Coleto Creek, Victoria and Goliad Counties, Texas, by A. A. Fox and T. R. Hester, pp. 81-85. Archaeological Survey Report, No. 18. Center for Archaeological Research, The University of Texas at San Antonio.

Claassen, C.

1998 Shells. Cambridge Manuals in Archaeology. Cambridge University Press, Cambridge.

Collins, M. B.

1975 Lithic Technology as a Means of Processual Inference. In Lithic Technology: Making and Using Stone Tools, edited by E. Swanson, pp. 5-13. The Hague, Mouton.

1995 Forty Years of Archeology in Central Texas. Bulletin of the Texas Archeological Society 66:361-400.

Collins M. B., W. A. Gose, and S. Shaw

1994 Preliminary Geomorphological Findings from Dust and Nearby Caves. Journal of Alabama Archaeology 40:35-56.

Cooper, L. M.

1975 A Study of Kay County Flint. The Bulletin of the Oklahoma Anthropological Society 23:189.

Cowan, M. R., M. L. Gabel, A. H. Jahren, and L. L. Tieszen

1997 Growth and Biomineralization of Celtis occidantalis (Ulmaceae) Pericarps. American Midland Naturalist 137:266-273.

Crowther, J.

2003 Potential Magnetic Susceptibility and Fractional Conversion Studies of Archaeological Soils and Sediments. Archaeometry 45:685-701.

deFrance, S. D.

1999 Zooarcheological Evidence of Colonial Culture Change: A Comparison of Two Locations of Mission Espíritu Santo de Nuestra Señora de Zuñiga and Mission Nuestra Señora del Rosario, Texas. Bulletin of the Texas Archeological Society 70:169-195.

Dibble, $\mathrm{H}$.

1988 Typological Aspects of Reduction and Intensity of Utilization of Lithic Resources in the French Mousterian. In Upper Pleistocene Prehistory of Western Europe, edited by H. Dibble, pp. 181-198. The University Museum, Philadelphia.

Fields, R.

2002 Archaeological Survey of the Noble Cemetery Relief Route, U.S. Highway 59, Goliad County, Texas. Letter Report No. 506. Prewitt and Associates, Inc., Austin. 
Fields, R., K. Kibler, E. F. Gadus, and A. M. Holmes

2002 Archeological Impact Evaluations and Surveys in the Texas Department of Transportation's Bryan, Corpus Christi, San Antonio, and Yoakum Districts. Reports of Investigations, No 133. Texas Department of Transportation, Austin.

Ford, P.

1992 Interpreting the grain size distribution of archaeological shell. In Deciphering a Shell Midden, edited by J. Stein, pp. 283-325. Academic Press, San Diego.

Fox, A. A.

1977 The Archaeology and History of the Spanish Governor's Palace Park. Archaeological Survey Report, No. 31. Center for Archaeological Research, The University of Texas at San Antonio.

1989 Historic Anglo-European exploration and colonization. In From the Gulf to the Rio Grande: Human Adaptation in Central, South, and Lower Pecos, Texas, by T. R. Hester, S. L. Black, D. G. Steele, B. W. Olive, A. A. Fox, K. J. Reinhard, and L. C. Bement, pp. 85-92. Research Series No. 33. Arkansas Archeological Survey, Fayettville.

Fox, A. A., S. L. Black, and S. R. James

1979 Intensive Survey and Testing of Archaeological Sites on Coleto Creek, Victoria and Goliad Counties, Texas. Archaeological Survey Report, No. 67. Center for Archaeological Research, The University of Texas at San Antonio.

Fox, A. A., and T. R. Hester

1976 An Archaeological Survey of Coleto Creek, Victoria and Goliad Counties, Texas. Archaeological Survey Report, No. 18. Center for Archaeological Research, The University of Texas at San Antonio.

Fox, D. E.

1979 Archaeological Investigations of Two Prehistoric Sites on the Coleto Creek Drainage, Goliad County, Texas. Archaeological Survey Report, No. 69. Center for Archaeological Research, The University of Texas at San Antonio.

Fox, D. E., R. J. Mallouf, N. O’Malley, and W. M. Sorrow

1974 Archaeological Resources of the Proposed Cuero I Reservoir, Dewitt and Gonzales Counties, Texas. Archaeological Survey Report, No. 12. Texas Historical Commission and Texas Water Development Board, Austin.

Gilmore, K.

1974 Mission Rosario: Archeological Investigations 1973. Archeological Report 14, Part 1. Texas Parks and Wildlife Department, Historic Sites and Restoration Branch, Austin.

1975 Mission Rosario: Archeological Investigations 1974. Archeological Report 14, Part 2. Texas Parks and Wildlife Department, Historic Sites and Restoration Branch, Austin.

Hall, G. D, T. R. Hester, and S. L. Black

1986 The Prehistoric sites at Choke Canyon Reservoir, Southern Texas: Results of Phase II Archaeological Investigations. Choke Canyon Series, Vol. 10. Center for Archaeological Research, The University of Texas at San Antonio.

Hester, T. R.

1975 Archaeological and Historical Resources in the San Antonio-Guadalupe River Basins: A Preliminary Statement. Regional Studies, No. 1. Center for Archaeological Research, The University of Texas at San Antonio. 
1995 The Prehistory of South Texas. Bulletin of the Texas Archeological Society 66:427-459.

1999 Artifacts, Archeology, and Cabeza de Vaca in Southern Texas and Northeastern Mexico. Bulletin of the Texas Archeological Society 70:17-28.

Hester, T. R., and R. C. Parker

1970 The Berclair Site: A Late Prehistoric Component in Goliad County, Southern Texas. Bulletin of the Texas Archeological Society 44:1-23.

Howells, R. G., R. W. Neck, and H. D. Murray

1996 Freshwater Mussels of Texas. Texas Parks and Wildlife Department, Inland Fisheries Division, Austin.

Hunziker, J. M., and A. A. Fox

1998 Archaeological Testing at Goliad State Park, Goliad County, Texas. Archaeological Survey Report, No. 260. Center for Archaeological Research, The University of Texas at San Antonio.

Jahren, A. H., R. Amundson, C. Kendall, and P. Wigand

2001 Paleoclimatic Reconstruction Using Correlation in $\mathrm{O}^{18}$ of Hackberry Carbonate and Environmental Water, North America. Quaternary Research 56:252-263.

Keeley, L. H.

1980 Experimental Determination of Stone Tool Use: A Microwear Analysis. University of Chicago Press, Chicago.

Kuhn, S. L.

1991 "Unpacking" Reduction: Lithic Raw Material Economy in the Mousterian of West-central Italy. Journal of Anthropological Archaeology 10:76-106.

1994 A Formal Approach to the Design and Assembly of Modern Toolkits. American Antiquity 59:426-442.

Kvamme, K. L.

2001 Current Practice in Archaeogeophysics: Magnetic Resistivity, Conductivity, and Ground Penetrating Radar. In Earth Sciences and Archaeology, edited by P. Goldberg, V. T. Holliday, and C. R. Ferring, pp. 353-384. Kluwer Academic/Plenum Publishers, New York.

Leigh, D. S.

2001 Buried Artifacts in Sandy Soils: Techniques for Evaluating Pedoturbation Versus Sedimentation. In Earth Sciences and Archaeology, edited by P. Goldberg, V. T. Holliday, and C. R. Ferring, pp. 269-293. Kluwer Academic/ Plenum Publishers, New York.

Lyman, R. L.

1994 Vertebrate Taphonomy. Cambridge Manuals in Archaeology. Cambridge University Press, Cambridge.

McClean, R. G., and W. F. Kean

1993 Contributions of Wood Ash Magnetism to Archaeomagnetic Properties of Fire Pits and Hearths. Earth and Planetary Science Letters 119:387-394.

Macphail, R. I., and J. Cruise

2001 The Soil Micromorphologist as Team Player: A Multianalytical Approach to the Study of European Microstratigraphy. In Earth Sciences and Archaeology, edited by P. Goldberg, V. T. Holliday, and C. R. Ferring, pp. 241-267. Kluwer Academic/Plenum Publishers, New York. 
Mauldin, R. P.

2001 Magnetic Sediment Susceptibility Testing. In Camp Maxey II: Archaeological Testing of 23 Prehistoric Sites, Lamar County, Texas, by R. Mahoney, pp. 116-121. Archaeological Survey Report, No. 314. Center for Archaeological Research, The University of Texas at San Antonio.

Mauldin, R. P., and C. J. Broehm

2001 An Archaeological Survey of 90 Acres at Camp Bowie, Brown County, Texas. Archaeological Survey Report, No. 319. Center for Archaeological Research, The University of Texas at San Antonio.

Morinaga, H., H. Inokuchi, H. Yamashita, A. Ono, and T. Inada

1999 Magnetic Detection of Heated Soils at Paleolithic Sites in Japan. Geoarchaeology 14(5):377-399.

Mounger, M. A.

1959 Mission Espíritu Santo of Coastal Texas: An Example of Historic Site Archaeology. Unpublished M.A. thesis, The University of Texas at Austin.

Newcomb, W. W., Jr.

1961 The Indians of Texas: From Prehistory to Modern Times. University of Texas Press, Austin.

Nickels, D. L.

20001999 Excavation at Mission Rosario. Archaeological Survey Report, No. 298. Center for Archaeological Research, The University of Texas at San Antonio.

2001 Setting. In Test Excavations at the Culebra Creek Site, 41BX126, Bexar County, Texas, by D. L. Nickels, C. B. Bousman, J. D. Leach, and D. A. Cargill, pp. 4-18. Archeological Studies Program, Report 3, Environmental Division, Texas Department of Transportation, Austin. Archaeological Survey Report, No. 265, Center for Archaeological Research, The University of Texas at San Antonio.

Rapp, G., Jr., and C. L. Hill

1998 Geoarchaeology: The Earth Science Approach to Archaeological Interpretation. Yale University Press, New Haven.

Rasmussen, K. L.

2001 FOCUS: Provenance of Ceramics Revealed by Magnetic Susceptibility and Thermoluminescence. Journal of Archaeological Science 28:451-456.

Reynolds, R. L., and J. W. King

1995 Magnetic Records of Climate Change. U.S. National Report to I.U.G.G., 1991-1994. American Geophysical Union. <http://www.agu.ong/revgeophys/reyno100/reyno100.html> Accessed April 2001.

Ricklis, R. A.

1996 The Karankawa Indians of Texas: An Ecological Study of Cultural Tradition and Change. University of Texas Press, Austin.

1999 The Spanish Colonial Missions of Espíritu Santo (41GD1) and Nuestra Señora del Rosario (41GD2), Goliad, Texas: exploring patterns of ethnicity, interaction, and acculturation. Bulletin of the Texas Archeological Society 70:133-168.

Schmiedlin, E. H.

2001 Letter to Mike Davis at the Texas Historical Commission regarding sites in Highway 59 right-of-way, February 21. Unpublished document on file, Center for Archaeological Research, The University of Texas at San Antonio. 
Scott, R. F.

1982 Part I: Prehistoric investigations. In Excavations at Sites 41LK31/32 and 41LK202 in the Choke Canyon Reservoir, South Texas, pp. 5-90. Choke Canyon Series, Vol. 8. Center for Archaeological Research, The University of Texas at San Antonio.

Sellards, E. H.

1940 Pleistocene Artifacts and Associated Fossils from Bee County, Texas. Bulletin of the Geological Society of America $51: 1627-1658$.

Singer, M. J., and P. Fine

1989 Pedogenic Factors Affecting Magnetic Susceptibility of Northern California Soils. Soil Science of America Journal 53:1119-1127.

\section{Soil Survey Staff}

1975 Soil Taxonomy: A Basic System of Classification for Making and Interpreting Soil Surveys. Agricultural Handbook No. 436. Soil Conservation Service, U.S. Department of Agriculture. U.S. Government Printing Office, Washington, D.C.

1993 Soil Survey Manual. U.S. Department of Agriculture Handbook No. 18. U.S. Department of Agriculture. U.S. Government Printing Office, Washington, D.C.

Steele, D. G.

1986 Analysis of Vertebrate Faunal Remains from 41LK201, Live Oak County, Texas. In Archaeological Investigations at 41LK201, Choke Canyon Reservoir, Southern Texas, by C. L. Highley, pp. 200-249. Choke Canyon Series, No. 11. Center for Archaeological Research, The University of Texas at San Antonio.

Steele, D. G., and C. A. Hunter

1986 Analysis of Vertebrate Remains from 41MC222 and 41MC296, McMullen County, Texas. In The Prehistoric Sites at Choke Canyon Reservoir, Southern Texas: Results of Phase II Archaeological Investigations, by G. D. Hall, T. R. Hester, and S. L. Black, pp. 452-502. Choke Canyon Series, Vol. 10. Center for Archaeological Research, The University of Texas at San Antonio.

Stein, J.

1983 Earthworm Activity: A Source of Potential Disturbance of Archaeological Sediments. American Antiquity 48:277289.

1992 Interpreting Stratification of a Shell Midden. In Deciphering a Shell Midden, edited by J. Stein, pp. 71-94. Academic Press, San Diego.

Texas Historical Commission (THC)

2003 Texas Archeological Sites Atlas. <http://www.pedernales.thc.state.tx.us/> Accessed December.

Vines, R. A.

1960 Trees, Shrubs, and Woody Plants of the Southwest: A Guide for the States of Arkansas, Louisiana, New Mexico, Oklahoma, and Texas. University of Texas Press, Austin.

Waters, M. R.

1992 Principles of Geoarchaeology: A North American Perspective. University of Arizona Press, Tucson. 
Weston, J. D., and R. P. Mauldin

2003 Archaeological Testing of Four Sites on Camp Bowie, Brown County, Texas. Archaeological Survey Report, No. 335. Center for Archaeological Research, The University of Texas at San Antonio.

Wiant, M., and H. Hassan

1985 The Role of Lithic Resource Accessibility in the Organization of Lithic Technology. In Lithic Resource Procurement: Proceedings from the Second Conference on Prehistoric Chert Exploitation, edited by S. Vehicle, pp. 101-114. Center for Archaeological Investigations Occasional Paper 2. Southern Illinois University, Carbondale. 



\section{Appendix A: Geomorphology and Geoarcheology}

Lee C. Nordt and Corey A. Crawford 


\title{
Appendix A: Geomorphology and Geoarcheology
}

\author{
by Lee C. Nordt and Corey A. Crawford
}

\section{Introduction}

A geomorphological assessment of sites $41 \mathrm{GD} 113$ and 41GD114 was conducted on July 26, 2002 to determine prehistoric preservation potentials of the late Quaternary alluvial sediments of the Gulf Coast in which the sites were formed. The project area occurs within the Texas coastal plain and is underlain by the Pleistocene-age Lissie Formation (Barnes 1975). The Lissie Formation is comprised of sand, silt and clay with iron oxides and iron manganese nodules occurring within the weathering zone. Localized zones of massive calcium carbonate and carbonate nodules are also present within the upper facies of the Lissie Formation. Sites 41GD113 and 41GD114 occur on the terrace of Perdido Creek, a Holocene-age ephemeral stream. The soils in this area are mapped as Alfisols.

Soil-stratigraphic profile descriptions of seven previously excavated backhoe trenches were written following the standards and procedures set forth by the Soil Survey Division Staff (1998:Appendix A). When applicable, profile descriptions were recorded adjacent to test units to enhance the correlation between excavated cultural materials and alluvial-stratigraphic units.

\section{Soil-Stratigraphic Results}

Site 41GD113 occurs within the transition between a Pleistocene and Holocene terrace (Figure A-1). The Pleistocene terrace (BHT 3) occurs above the Holocene terrace by only a few centimeters to $2 \mathrm{~m}$. It is comprised of an A-Bt-Bk profile sequence within the upper $130 \mathrm{~cm}$. The soil is characterized by a $60 \mathrm{~cm}$ thick sandy loam A horizon underlain by a $40 \mathrm{~cm}$ thick sandy clay Bt horizon containing many clay films on ped faces. The Bt horizon is underlain by a sandy clay loam $\mathrm{Bk}$ horizon at least $30 \mathrm{~cm}$ thick. The $\mathrm{Bk}$ horizon is characterized by common soft carbonate masses and nodules. No depositional or erosional unconformities are present within the upper $130 \mathrm{~cm}$ of the Pleistocene terrace soil.

The Holocene terrace at site 41GD113 occurs between $0 \mathrm{~cm}$ and $200 \mathrm{~cm}$ lower than the Pleistocene terrace, and is typically comprised of an A-Bt-Bk profile sequence within the upper $150 \mathrm{~cm}$ of BHTs 1, 2, and 4 (Figure A-1). The dark sandy loam A horizon ranges from 50 to $80 \mathrm{~cm}$ in thickness, and is underlain by a 30 to $70 \mathrm{~cm}$ thick sandy clay loam to sandy clay Bt horizon. The Bt horizon is underlain by a $\mathrm{Bk}$ horizon similar to that observed within the Pleistocene terrace. Redoximorphic features are common within the lower part of the Holocene terrace soil, in localized, poorly drained topographic settings in BHTs 2 and 4. Although deposition of the Holocene terrace most likely occurred in a continual, slowly aggrading environment, no unconformities were observed within the upper $150 \mathrm{~cm}$.

Site 41GD114 occurs within a Holocene terrace that is severely disturbed (Figure A-1). Intact soils within the site are typified by a shallow $(80 \mathrm{~cm}) \mathrm{A}-\mathrm{Btg}$ profile sequence immediately underlain by the Lissie Formation. The dark sandy loam A horizon extends to a depth of approximately $25 \mathrm{~cm}$ and is underlain by a $55 \mathrm{~cm}$ thick sandy clay Btg horizon with common soft iron masses and siliceous pebbles. No paleosols were observed within the vicinity of site $41 \mathrm{GD} 114$.

\section{Geoarcheology}

The alluvial stratigraphic framework of site 41GD113 suggests sites within the Holocene terrace (seen in BHTs 1 and 4) may represent short-term encampments when the modern flood terrace was still an actively aggrading floodplain. No depositional or erosional unconformities were observed within the upper $130 \mathrm{~cm}$ of this soil. Therefore, the possibility of recovering cultural materials in a primary context within the Holocene terrace soil at site 41 GD113 remains high. Based on the relative age of the Pleistocene terrace soil observed in BHT 3, it is likely a palimpsest of cultural materials spanning all of Texas history and prehistory may occur on the surface of this soil.

Due to the severe anthropogenic disturbance at site $41 \mathrm{GD} 114$, the potential for recovering cultural materials within a primary context is low. However, in undisturbed areas, the probability of finding cultural materials within a primary context remains moderately high, due to the relative age of the soil. 


\section{Conclusions}

The soil-stratigraphic framework established at site $41 \mathrm{GD} 113$ demonstrates a high potential for recovering cultural materials, especially within the Holocene terrace soil. However, due to the severe anthropogenic disturbance in the vicinity of $41 \mathrm{GD} 114$, the probability of recovering cultural materials within a primary context is low. Additional backhoe trenching coupled with radiocarbon assays within the project area may lend further insight into site formation, and clarify the archeological significance of sites 41GD113 and $41 \mathrm{GD} 114$.

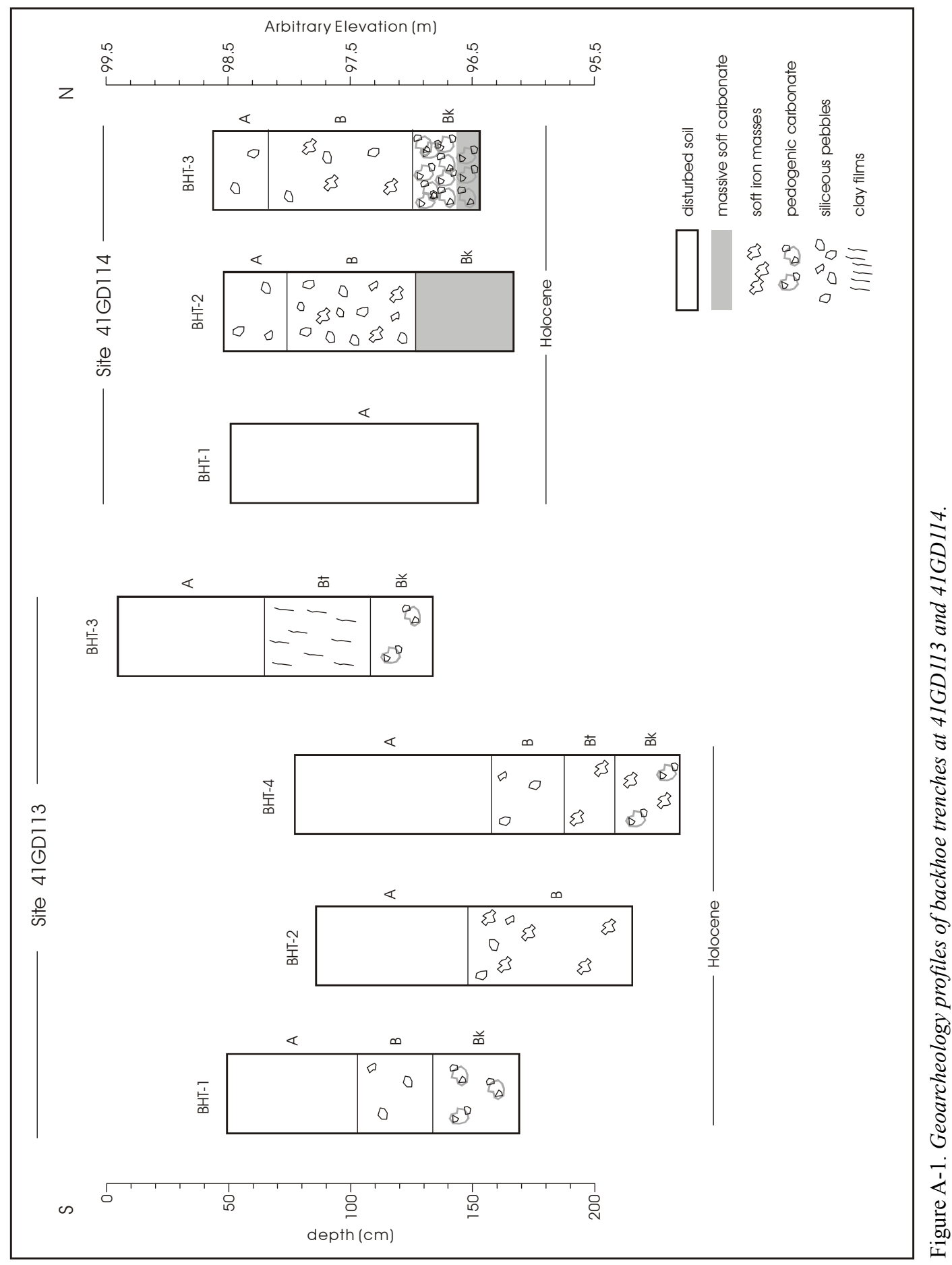




\section{Soil Profile Descriptions}

\section{GD 1 13; BHT 1; Unit 1; east wall; Holocene flood terrace.}

A1 0-23 cm; very dark gray (10YR 3/1) sandy loam; moderate medium subangular blocky; very friable; common fine roots; few fine to medium charcoal fragments; noncalcareous; gradual smooth.

A2 23-52 cm; very dark grayish brown (10YR 3/2) sandy loam; moderate medium subangular blocky; very friable; few fine roots; noncalcareous; gradual smooth.

Bt $\quad 52-84 \mathrm{~cm}$; dark grayish brown (10YR 4/2) sandy clay loam; weak coarse prismatic parting to weak medium angular blocky; friable; $1 \%$ shell fragments; 2\% 1-2 cm diameter angular siliceous pebbles; noncalcareous; clear smooth.

Bk 84-120 cm; pale brown (10YR 6/3) sandy clay loam; weak coarse prismatic parting to weak medium angular blocky; friable; common medium to coarse soft carbonate masses; common medium carbonate hard nodules.

41GD1 13; BHT 2; Unit 2; east wall; Holocene flood terrace; noncalcareous throughout.

A1 0-17 cm; very dark gray (10YR 3/1) sandy loam; moderate medium subangular blocky; very friable; common fine roots; gradual smooth.

A2 17-62 cm; very dark grayish brown (10YR 3/2) sandy loam; moderate medium subangular blocky; very friable; few fine roots; gradual smooth.

Btg1 62-92 cm; dark grayish brown (10YR 4/2) sandy clay loam; weak coarse prismatic parting to weak medium angular blocky; friable; common fine to medium distinct strong brown (7.5YR 5/6) soft iron masses; $1 \%$ shell fragments; 2\% 1-2 cm diameter angular siliceous pebbles; clear smooth.

Btg2 92-130 cm; gray (10YR 6/1) sandy clay loam; weak coarse prismatic to moderate medium angular blocky; firm; common medium distinct strong brown (7.5YR 5/8) soft iron masses.

41GD1 13; BHT 3; Unit 3; east wall; Pleistocene terrace.

A1 0-22 cm; very dark gray (10YR 3/1) sandy loam; moderate medium subangular blocky; very friable; common fine roots; noncalcareous; gradual smooth.

A2 22-60 cm; very dark grayish brown (10YR 3/2) sandy loam; moderate medium subangular blocky; very friable; few fine roots; noncalcareous; clear smooth.

Bt $\quad 60-105 \mathrm{~cm}$; strong brown (7.5YR 5/6) sandy clay; moderate medium prismatic parting to moderate medium angular blocky; firm; many medium to coarse brown (7.5YR 4/3) clay films on ped faces; calcareous; clear smooth.

Bk 105-130 cm; brown (7.5YR 5/3) sandy clay loam; weak coarse prismatic parting to moderate medium angular blocky; firm; moderate medium to coarse soft carbonate masses; common medium hard carbonate nodules. 


\section{GD1 13; BHT 4; Unit 4; east wall; Holocene flood terrace.}

A1 0-20 cm; very dark gray (10YR 3/1) sandy loam; moderate medium subangular blocky; very friable; common fine roots; few fine to medium charcoal fragments; noncalcareous; gradual smooth.

A2 20-81 cm; very dark grayish brown (10YR 3/2) sandy loam; moderate medium subangular blocky; very friable; few fine roots; noncalcareous; gradual smooth.

Bt $\quad 81-112 \mathrm{~cm}$; dark grayish brown (10YR 4/2) sandy clay loam; weak coarse prismatic parting to weak medium angular blocky; friable; $1 \%$ shell fragments; $2 \% 1-2 \mathrm{~cm}$ diameter angular siliceous pebbles; noncalcareous; clear smooth.

Btg 112-133 cm; light brownish gray (10YR 6/2) sandy clay; weak medium prismatic parting to moderate medium angular blocky; firm; $10 \% 0.1-1 \mathrm{~cm}$ diameter subangular to subrounded siliceous pebbles; common fine to medium distinct strong brown (7.5YR 5/8) soft iron masses; noncalcareous; clear smooth.

Bkg 133-160 cm; light brownish gray (2.5Y 6/2) sandy clay; weak coarse prismatic parting to moderate medium angular blocky; firm; $10 \%$ medium calcium carbonate nodules; many fine to medium distinct strong brown (7.5YR 5/8) soft iron masses.

\section{GD1 14; BHT 1; Unit 1; disturbed fill.}

Severely disturbed soil to at least $1 \mathrm{~m}$.

41GD114; BHT 2; Unit 2; disturbed surface.

Ap $\quad 0-26 \mathrm{~cm}$; dark grayish brown (10YR 4/2) sandy loam; moderate medium subangular blocky; very friable; common fine roots; $2 \% 0.1-2 \mathrm{~cm}$ diameter subangular to subrounded siliceous pebbles; noncalcareous; clear irregular.

Btg 26-79 cm; light brownish gray (10YR 6/2) sandy clay; weak medium prismatic; firm; 20\% 0.1-3 cm diameter subangular to subrounded siliceous pebbles; common medium distinct strong brown (7.5YR 5/8) and yellowish red (5YR 4/6) soft iron masses; calcareous; clear irregular.

C $\quad 79-120 \mathrm{~cm}$; massive carbonate.

\section{GD1 14; BHT 3; Unit 3.}

Ap $\quad 0-23 \mathrm{~cm}$; very dark grayish brown (10YR 3/2) sandy loam; moderate medium subangular blocky; very friable; common fine roots; $2 \% 1-2 \mathrm{~cm}$ diameter subangular to subrounded pebbles; noncalcareous; clear smooth.

Btg 23-82 cm; dark grayish brown (10YR 4/2) sandy clay; weak coarse prismatic parting to moderate medium angular blocky; firm; few fine roots; $2 \% 1-2 \mathrm{~cm}$ diameter subangular to subrounded pebbles; common medium distinct yellowish red (5YR 4/6) soft iron masses; noncalcareous; clear smooth.

BC $\quad 82-110 \mathrm{~cm}$; yellowish brown (10YR 5/4) clay loam; massive; firm; many massive carbonate soft masses and nodules. 


\section{References Cited}

Barnes, V. E.

1975 Geologic Atlas of Texas, Beeville-Bay City Sheet. Bureau of Economic Geology, University of Texas at Austin.

\section{Soil Survey Staff}

1998 Keys to Soil Taxonomy, $8^{\text {th }}$ edition. U.S. Department of Agriculture, Soil Conservation Service. U.S. Government Printing Office, Washington D.C. 
Appendix B: Radiocarbon Dating Results 
Dr. James Abbott

Report Date: 1/20/03

Texas Department of Transportation

Material Received: 12/18/02

\begin{tabular}{|c|c|c|c|}
\hline Sample Data & $\begin{array}{l}\text { Measured } \\
\text { Radiocarbon Age }\end{array}$ & $\begin{array}{c}13 C / 12 C \\
\text { Ratio }\end{array}$ & $\begin{array}{c}\text { Conventional } \\
\text { Radiocarbon Age }\left(^{*}\right)\end{array}$ \\
\hline $\begin{array}{l}\text { Beta - 174045 } \\
\text { SAMPLE : GD113-LOT151 } \\
\text { ANALYSIS : AMS-Standard delivery } \\
\text { MATERIAL/PRETREATMENT : (c } \\
\text { 2 SIGMA CALIBRATION : }\end{array}$ & $\begin{array}{l}\qquad 1570+/-60 \text { BP } \\
\text { ry } \\
\text { (charred material): acid/alkali/acid } \\
\text { Cal AD } 400 \text { to } 640(\text { Cal BP } 1550 \text { to } 1310)\end{array}$ & $-26.5 \mathrm{o} / 00$ & $1550+/-60 \mathrm{BP}$ \\
\hline $\begin{array}{l}\text { Beta - 174046 } \\
\text { SAMPLE : GD113-LOT155 } \\
\text { ANALYSIS : AMS-Standard delivery } \\
\text { MATERIAL/PRETREATMENT : (c } \\
\text { 2 SIGMA CALIBRATION : }\end{array}$ & $\begin{array}{l}\qquad 1300+/-50 \text { BP } \\
\text { ry } \\
\text { (charred material): acid/alkali/acid } \\
\text { Cal } 660 \text { to } 880(\text { Cal BP } 1290 \text { to } 1070)\end{array}$ & $-26.7 \mathrm{o} / \mathrm{oo}$ & $1270+/-50 \mathrm{BP}$ \\
\hline $\begin{array}{l}\text { Beta - 174047 } \\
\text { SAMPLE : GD113-LOT161-001 } \\
\text { ANALYSIS : AMS-Standard delivery } \\
\text { MATERIAL/PRETREATMENT : (c } \\
\text { 2 SIGMA CALIBRATION : }\end{array}$ & $\begin{array}{l}\qquad 1580+/-50 \text { BP } \\
\text { ry } \\
\text { (charred material): acid/alkali/acid } \\
\text { Cal AD } 410 \text { to } 620(\text { Cal BP } 1540 \text { to } 1320)\end{array}$ & $-26.9 \mathrm{o} / 00$ & $1550+/-50 \mathrm{BP}$ \\
\hline
\end{tabular}




\section{CALIBRATION OF RADIOCARBON AGE TO CALENDAR YEARS}

(V ariab les: $\mathrm{C} 13 / \mathrm{C} 12=-26.5: 1 \mathrm{ab} . \mathrm{mult}=1)$

Laboratory number: Beta-174045

Conventional radiocarbon age: $1550 \pm 60 \mathrm{BP}$

2 Sigma calibrated result: Cal AD 400 to 640 (Cal BP 1550 to 1310 )

(95\% probability)

Intercept data

Intercept of radiocarbon age

with calibration curve: Cal AD 530 (Cal BP 1420)

1 Sigma calibrated result: Cal A D 430 to 580 (Cal B P 1520 to 1360 ) (68\% probability)

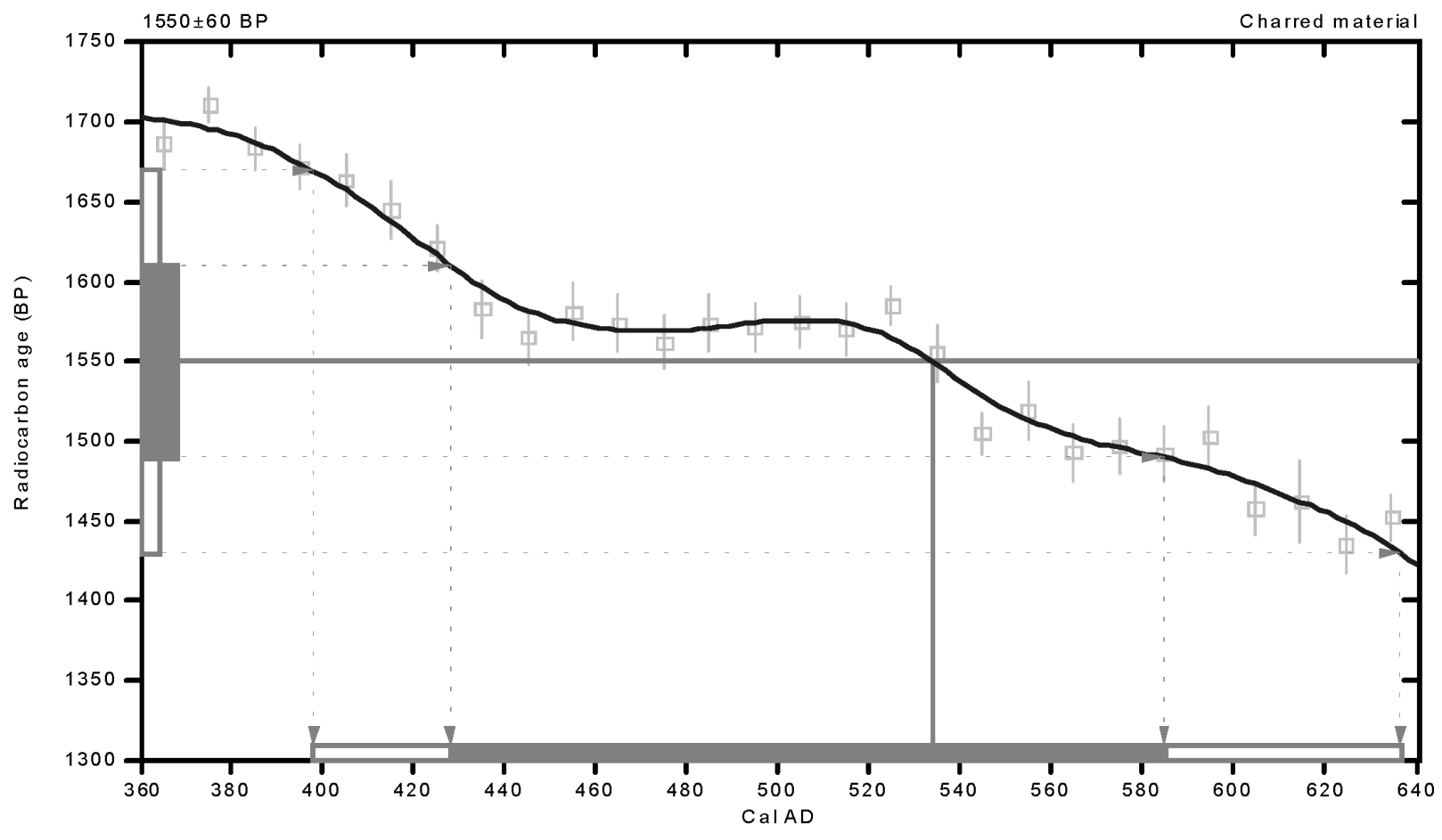

References:

Database used

Calibration Database

Editorial Com ment

Stuiver, M., van der Plicht, H., 1998, Radiocarbon 40(3), pxii-xii

INTCA L98 Radiocarbon Age Calibration

Stuiver, M., et. al., 1998, Radiocarbon 40(3), p1041-1083

M ath em atics

A Simplified Approach to Calibrating C14 Dates

Talma, A. S., Vogel, J. C., 1993, Radiocarbon 35(2), p317-322

\section{Beta Analytic Inc.}

4985SW74 Court, Miami, Florida33155USA -Tel: (305)6675167•Fax: (305)6630964・E-Mail: beta@radiocarbon.com 


\section{CALIBRATION OF RADIOCARBON AGE TO CALENDAR YEARS}

(V a riab les: C 13/C 12=-26.7: lab. $\mathrm{mult}=1$ )

Laboratory number:

Beta-174046

Conventional radiocarbon age:

$1270 \pm 50$ B P

2 Sigm a calibrated result: (95\% probability)

Cal AD 660 to 880 (Cal BP 1290 to 1070 )

Intercept data

Intercepts of radiocarbon age with calibration curve:

Cal AD 720 (Cal BP 1230) and

Cal AD 740 (Cal BP 1210) and

Cal AD 760 (Cal BP 1190$)$

1 Sigma calibrated result: Cal AD 680 to 790 (Cal B P 1270 to 1160 ) (68\% probability)

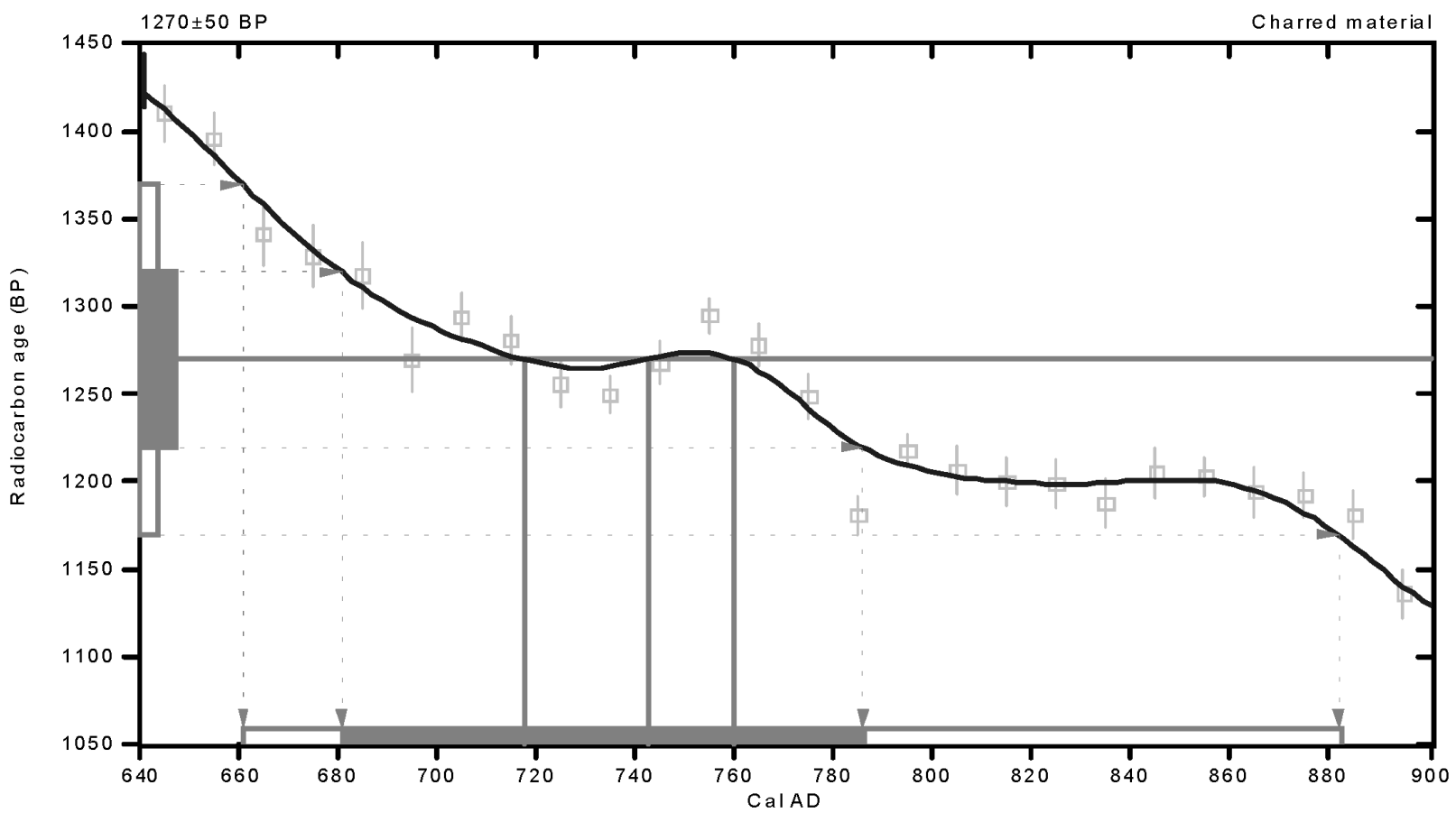

References:

Database used

Calibration Database

Editorial Com ment

Stuiver, M., van der Plicht, H., 1998, Radiocarbon 40(3), pxii-xiti

INTCAL98 Radiocarbon Age Calibration

Stuiver, M., et. al., 1998, Radiocarbon 40(3),p1041-1083

$M$ ath em atics

A Simplified Approach to Calibrating C14 Dates

Talma, A. S., Vogel, J. C., 1993, Radiocarbon 35(2), p317-322

Beta Analytic Inc.

4985SW74 Court, Miami, Florida 33155 USA - Tel: (305) 6675167 • Fax: (305) $6630964 \cdot$ E-Mail: beta@radiocarbon.com 


\section{CALIBRATION OF RADIOCARBON AGE TO CALENDAR YEARS}

(V a riab les: C $13 / \mathrm{C} 12=-26.9: \mathrm{lab} . \mathrm{mult}=1)$

Laboratory number: Beta-174047

Conventional radiocarbon age: $1550 \pm 50 \mathrm{BP}$

2 Sigma calibrated result: Cal AD 410 to 620 (Cal BP 1540 to 1320)

(95\% probability)

Intercept data

Intercept of radiocarbon age

with calibration curve: Cal A D 530 (Cal B P 1420)

1 Sigm a calibrated result: Cal AD 430 to 570 (Cal B P 1520 to 1380 ) (68\% probability)

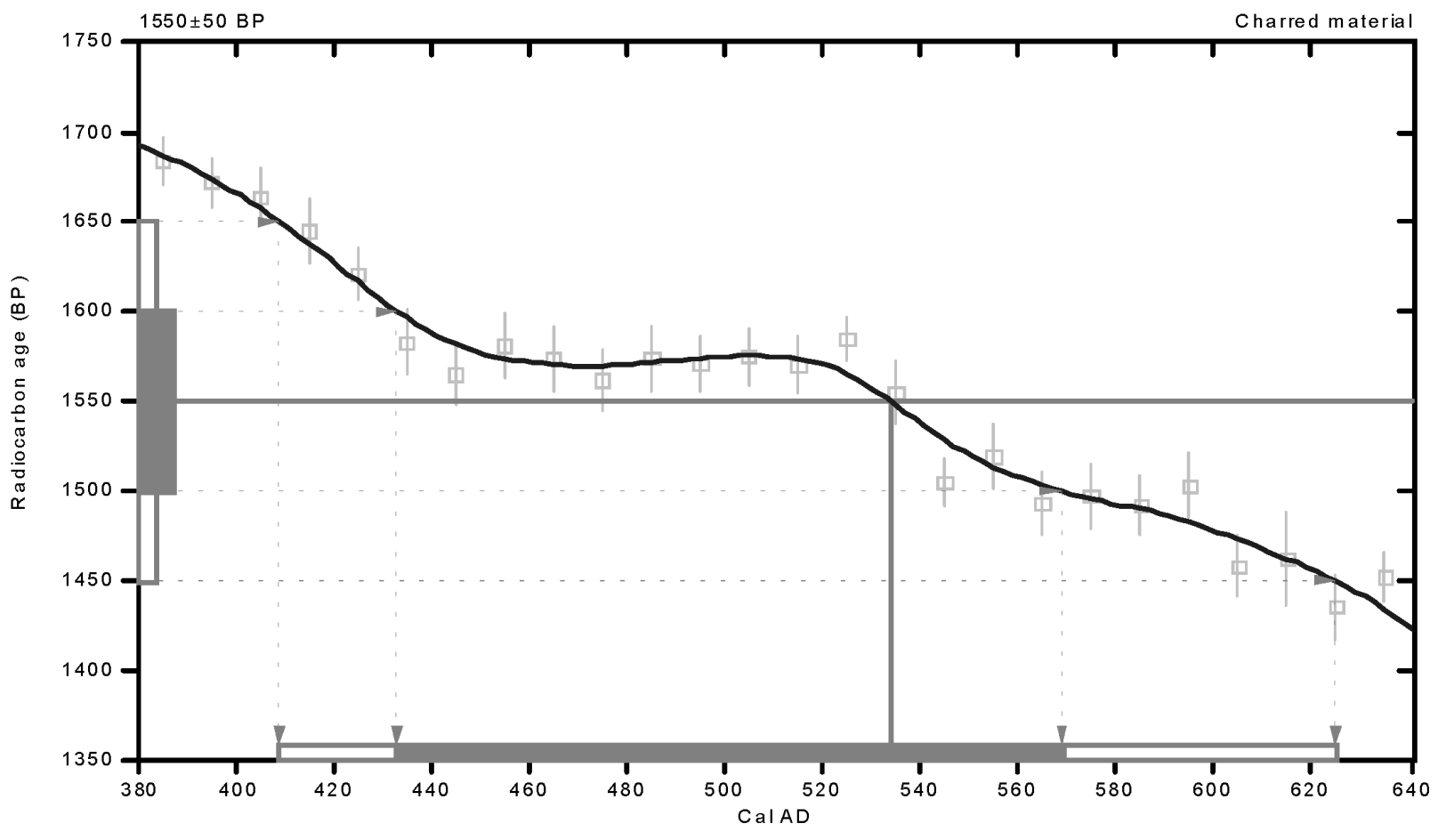

References:

Database used

Calibration Database

Editorial Com ment

Stuiver, M., van der Plicht, H., 1998, Radiocarbon 40(3), pxii-xiii

IN TCA L98 Radiocarbon Age Calibration

Stuiver, M., et. al., 1998, Radiocarbon 40(3), p1041-1083

$M$ ath em atics

A Simplified Approach to Calibrating C14 Dates

Talma, A. S., Vogel, J. C., 1993, Radiocarbon 35(2), p317-322

\section{Beta A nalytic Inc.}

4985SW74 Court, Miami, Florida 33155 USA Tel:(305)6675167•Fax: (305) $6630964 \cdot$ E-Mail: beta@ radiocarbon.com 

Appendix C: Magnetic Sediment Susceptibility Testing

Raymond P. Mauldin 


\title{
Appendix C: Magnetic Sediment Susceptibility Testing
}

\author{
by Raymond P. Mauldin
}

The magnetic susceptibility (MSS) of a given sediment sample can be thought of as a measure of how easily that sample can be magnetized (Dearing 1999; Gose and Nickels 2001). At low magnetic field strengths, this measure is primarily related to the concentration and grain size of ferriand ferromagnetic minerals in the sample (Gose and Nickels 2001). A number of processes can result in an increase in MSS values in a sediment sample. Of these processes, those that are of concern here are related to an increase in the organic constitutes, changes in the mineralogy of sediments in a given sample, and changes in susceptibility brought about by heating of sediments (see Collins et al. 1994; McClean and Kean 1993; Morinaga et al. 1999; Rasmussen 2001; Singer and Fine 1989). Sediments with higher organic content tend to have higher magnetic susceptibility values, probably as a result of the production of maghemite, an iron oxide, during organic decay (Reynolds and King 1995). Pedogenic processes, such as soil formation and weathering, can result in the concentration of organic material, as well as alterations in the mineralogy of a given zone. These processes can significantly impact susceptibility readings. Cultural processes, such as the concentration of ash, charcoal, and refuse, would also produce higher MSS readings. In addition, heating of sediments can dramatically increase susceptibility values, especially at temperatures consistent with open hearths (Morinaga et al. 1999; Jordanova et al. 2001). A measure of the magnetic susceptibility of a sediment sample, then, may provide information on both the presence of surfaces, as well as a measure of the concentration of cultural activity upon those surfaces.

\section{Collection Procedures and Laboratory Methods}

One hundred twenty-seven samples representing five backhoe trenches (BHTs 1, 2, 3, 4, and 5) were analyzed for magnetic sediment susceptibility from 41GD113. Twenty-two samples were analyzed from a single backhoe trench (BHT 3) on 41GD114. The samples were collected at $5-\mathrm{cm}$ intervals from the trenches, and placed in plastic vials. No metal tools or metal containers were used.
At the CAR laboratory, each sediment sample was air dried on a non-metal surface. After drying, it was sometimes necessary to grind the samples into a uniform grain size using a ceramic mortar and pestle. This was done to standardize particle size and make the material both easier to handle and pack into sample containers. After each sample was prepared, the mortar and pestle were washed with tap water and wiped dry with a paper towel to avoid cross-sample contamination. The ground sample was then poured into a sample container consisting of a plastic cube with external dimensions of 2.54 x $2.54 \times 1.94 \mathrm{~cm}$. The cubes have an average weight of 4.83 grams. The sediment filled cube was then weighed, and the weight of the sample calculated by subtracting the empty cube weight. This was done to correct for differences in mass. Assuming that sample volume and material is constant, larger samples should have higher susceptibility values simply as a function of greater mass.

The cube was then placed into a MS2B Dual Frequency Sensor that, in conjunction with a MS2 Magnetic Susceptibility Meter, provided a measure of the magnetic susceptibility of the sample (see Dearing 1999). For each cube, two independent readings were taken using the SI (standard international) scale. These were averaged to arrive at a single value. The value, referred to as volume specific susceptibility and noted with the symbol $K_{0}$ (Kappa), is recorded on a scale of $10^{-5}$, though there are no units associated with the value. That is, the value is dimensionless (Dearing 1999).

In order to correct for differences in sample weight, and provide units to the value $K_{\text {, }}$, the mass specific susceptibility value (X) was calculated using the formula

$$
\mathrm{X}=\left(\mathrm{K}_{\mathrm{o}} / \mathrm{p}\right)
$$

where $\mathrm{p}$ is the sample bulk density expressed in $\mathrm{kg} \mathrm{m}^{-3}$. The bulk density is determined by dividing the sample mass by volume. However, as all samples were measured in identical cubes, and all cubes were full, the sample volume is assumed to be constant. Only the mass of the sample varied. Mass specific susceptibility can be determined by 
$\mathrm{X}=\mathrm{K} *$ calibrated mass/ sample mass

where sample mass is determined by subtracting the cube weight from the total sample weight (Dearing 1999). Calibrated mass is assumed to be 10 grams.

While the resulting values now have both a scale and associated units, the critical element for the current discussion is related to relative differences between X $\mathrm{X}$ sample values within a given profile or site, rather than absolute differences. That is, the principal interest is in rapid changes in the mass specific susceptibility values along a profile. This change may signal either a buried surface and/or cultural activity at that location. Comparisons of absolute values between samples from different areas, especially when the parent material of the soils is different, are of limited utility given our current goals.

This can be seen in Table C-1, which lists a variety of examples of mass specific susceptibility values for several different materials. In all cases, the analysis was performed following the procedures outlined previously. Note that the values differ widely, from a low of -1.47 for tap water, to a high of 97.62 for sediments collected from a burned rock midden. Samples 5 and 6 are on two different clays from the same general setting, far northern Lamar County in north Texas. The mass specific susceptibility is different for these samples, probably as a function of different frequencies of trace elements that, though small in absolute quantity, can dramatically impact the susceptibility values.

The potential impacts of cultural processes on susceptibility values can be seen by considering a data set collected from an archeological site located in Brown County, Texas (41BR473). Two hundred seventy-nine sediment susceptibility samples were collected from each level of over 50 shovel tests placed at this site. In all cases, the analytical procedures followed those outlined previously. Table C-2 presents summary data on all 279 cases, along with susceptibility scores for those settings that had FCR or chipped stone present. If cultural inputs result in higher susceptibility values, probably as a result of both heating of sediments as well as the addition of organic materials, then it should be the case that significantly higher susceptibility values will be present in levels that have cultural material.

An examination of Table C-2 will demonstrate that this is indeed the case. Levels that have FCR present do have higher scores relative to those that lack FCR. Similarly, those levels that have chipped stone present have a higher average mass specific susceptibility score relative to those that lack chipped stone. As the distribution is approximately normal, a t-test was used to test the overall significance of these differences. In both the FCR and chipped stone comparisons,

Table C-1. Magnetic Sediment Susceptibility Data for a Variety of Substances

\begin{tabular}{|l|c|c|c|c|c|c|c|}
\hline Sample Type & $\begin{array}{c}\text { Total } \\
\text { Wt. (gr.) }\end{array}$ & $\begin{array}{c}\text { Sample } \\
\text { Wt. (gr.) }\end{array}$ & $\begin{array}{c}\text { Reading } \\
\mathbf{1}(\mathbf{k})\end{array}$ & $\begin{array}{c}\text { Reading } \\
\mathbf{2}(\mathbf{k})\end{array}$ & $\begin{array}{c}\text { Reading } \\
\mathbf{3} \text { (k) }\end{array}$ & $\begin{array}{c}\text { Average } \\
\text { K }\end{array}$ & $\begin{array}{c}\text { Corrected } \\
\text { Mass (X) }\end{array}$ \\
\hline $\begin{array}{l}\text { 1) Sandy sediment } \\
\text { with organics }\end{array}$ & 13.7 & 8.85 & 27.9 & 28 & 28.1 & 28.00 & 31.64 \\
\hline $\begin{array}{l}\text { 2) Modern } \\
\text { mesquite charcoal } \\
\text { and sediment }\end{array}$ & 9.4 & 4.55 & 10.7 & 10.8 & 10.7 & 10.73 & 23.59 \\
\hline $\begin{array}{l}\text { 3) Modern oak } \\
\text { wood ash }\end{array}$ & 7.5 & 2.65 & 16.1 & 16.2 & 16.2 & 16.17 & 61.01 \\
\hline $\begin{array}{l}\text { 4) Sediment from } \\
\text { burned rock } \\
\text { midden }\end{array}$ & 11.3 & 6.45 & 62.9 & 63 & 63 & 62.97 & 97.62 \\
\hline $\begin{array}{l}\text { 5) Grey clay- no } \\
\text { human occupation }\end{array}$ & 12.6 & 7.75 & 10.4 & 10.3 & 10.4 & 10.37 & 13.38 \\
\hline $\begin{array}{l}\text { 6) Red clay-no } \\
\text { human occupation }\end{array}$ & 10.8 & 5.95 & 11.9 & 12 & 12 & 11.97 & 20.11 \\
\hline 7) Sandstone & 14.7 & 9.85 & 6.9 & 7 & 7.1 & 7.00 & 7.11 \\
\hline 8) Limestone & 12.7 & 7.85 & -0.5 & -0.5 & -0.5 & -0.50 & -0.64 \\
\hline 9) Tap water & 10.5 & 5.65 & -0.8 & -0.8 & -0.9 & -0.83 & -1.47 \\
\hline
\end{tabular}


Table C-2. Presence/absence of Cultural Material and Mass Specific Sediment Susceptibility Scores for Shovel Tests at 41BR473

\begin{tabular}{|l|c|c|c|c|c|}
\hline & All Cases & $\begin{array}{c}\text { FCR } \\
\text { Present }\end{array}$ & $\begin{array}{c}\text { FCR } \\
\text { Absent }\end{array}$ & $\begin{array}{c}\text { Chipped Stone } \\
\text { Present }\end{array}$ & $\begin{array}{c}\text { Chipped Stone } \\
\text { Absent }\end{array}$ \\
\hline $\begin{array}{l}\text { Number } \\
\text { of Samples }\end{array}$ & 279 & 84 & 195 & 38 & 241 \\
\hline Mean Value & 48.3 & 56.9 & 44.6 & 55.2 & 47.2 \\
\hline $\begin{array}{l}\text { Standard } \\
\text { Deviation }\end{array}$ & 17.2 & 17.7 & 15.6 & 16.1 & 17.1 \\
\hline
\end{tabular}

the test confirms that those levels with cultural material have significantly higher scores than those without cultural material (FCR t-statistic $=5.804, \mathrm{df}=277, \mathrm{p}<.001$; chipped stone t-statistic $=2.674, \mathrm{df}=277, \mathrm{p}=.008$ ). Our preliminary investigations, then, coupled with the previous work, clearly suggest that an analysis of the magnetic susceptibility of sediment can provide additional information on both the presence of buried surfaces, as well as the impact of cultural material on those surfaces.

\section{Results}

Table C-3 presents the results of the susceptibility analysis of the 149 samples from the six trenches on 41GD113 and 41GD114. An examination of the data for site 41GD113 shows that the susceptibility values range from a low of 1.3 to a high of 27.1, with a mean score of 11.02 and a median value of 10.2. As a group, these values are substantially higher than those from 41 GD114, which has a mean of only 5.9 , a median of 6.05 , and a range of 1.2 to 10.7 .

Figure C-1 presents the values for 41GD114, all of which are from BHT 3. Note that in spite of the low overall scores, the plot of the values suggests that two, and perhaps three, surfaces may be present. These are suggested at around 22 $\mathrm{cmbs}$ and $72 \mathrm{cmbs}$, with the possible third buried surface at 57 cmbs.
Figures C-2 through C-6 present plots for the five backhoe trenches on 41GD113. Examinations of the plots suggest that several of these curves are quite similar. As a group, they also seem to suggest that two buried surfaces may be present at this location. These are clearly shown in Figures C-4 and C-6, with upper peaks at around $35 \mathrm{cmbs}$, and a lower peak at about $1 \mathrm{~m}$ below surface. This upper peak is also suggested in both Figure C-2 and Figure C-5. These peaks are probably reflecting natural surfaces, and may be related to the $41 \mathrm{GD} 114$ peaks discussed above. Examination of Figure C-3, the profile for BHT 2 near TUs 2 and 6 at 41GD113, suggests that this profile is unique. The upper and lower peaks are not present, probably suggesting fairly rapid accumulation of sediment in this area. Two spikes, one at about $77 \mathrm{cmbs}$, and a second at about $90 \mathrm{cmbs}$, are clearly visible. 
Table C-3. Magnetic Susceptibility Results from 41GD113 and 41GD114

\begin{tabular}{|c|c|c|c|c|}
\hline Site & Provenience & $\begin{array}{c}\text { cm below } \\
\text { surface }\end{array}$ & Weight & MS Values \\
\hline $41 \mathrm{GD} 113$ & BHT1 & 2.5 & 13.3 & 27.1 \\
\hline $41 \mathrm{GD} 113$ & BHT1 & 7.5 & 13.5 & 18.86 \\
\hline $41 \mathrm{GD} 113$ & BHT1 & 12.5 & 13.3 & 20.72 \\
\hline $41 \mathrm{GD} 113$ & BHT1 & 17.5 & 13.3 & 21.43 \\
\hline $41 \mathrm{GD} 113$ & BHT1 & 22.5 & 13.3 & 22.43 \\
\hline $41 \mathrm{GD} 113$ & BHT1 & 27.5 & 13.4 & 23.69 \\
\hline $41 \mathrm{GD} 113$ & BHT1 & 32.5 & 13.2 & 23.89 \\
\hline $41 \mathrm{GD} 113$ & BHT1 & 37.5 & 13.3 & 23.2 \\
\hline $41 \mathrm{GD} 113$ & BHT1 & 42.5 & 13.5 & 21.28 \\
\hline $41 \mathrm{GD} 113$ & BHT1 & 47.5 & 13.2 & 21.33 \\
\hline $41 \mathrm{GD} 113$ & BHT1 & 52.5 & 13.2 & 20.91 \\
\hline $41 \mathrm{GD} 113$ & BHT1 & 57.5 & 13.4 & 17.62 \\
\hline $41 \mathrm{GD} 113$ & BHT1 & 62.5 & 13.2 & 14.99 \\
\hline $41 \mathrm{GD} 113$ & BHT1 & 67.5 & 13.2 & 13.2 \\
\hline $41 \mathrm{GD} 113$ & BHT1 & 72.5 & 13.5 & 11.65 \\
\hline $41 \mathrm{GD} 113$ & BHT1 & 77.5 & 13.3 & 10.74 \\
\hline $41 \mathrm{GD} 113$ & BHT1 & 82.5 & 13.4 & 9.16 \\
\hline $41 \mathrm{GD} 113$ & BHT1 & 87.5 & 13.5 & 6.52 \\
\hline $41 \mathrm{GD} 113$ & BHT1 & 92.5 & 12.3 & 6.69 \\
\hline $41 \mathrm{GD} 113$ & BHT1 & 97.5 & 13.4 & 5.02 \\
\hline $41 \mathrm{GD} 113$ & BHT1 & 102.5 & 13.4 & 5.25 \\
\hline $41 \mathrm{GD} 113$ & BHT1 & 107.5 & 13.4 & 5.13 \\
\hline $41 \mathrm{GD} 113$ & BHT2 & 2.5 & 13.3 & 10.04 \\
\hline $41 \mathrm{GD} 113$ & BHT2 & 7.5 & 13.3 & 9.56 \\
\hline $41 \mathrm{GD} 113$ & BHT2 & 12.5 & 13.3 & 9.62 \\
\hline $41 \mathrm{GD} 113$ & BHT2 & 17.5 & 13.3 & 9.98 \\
\hline $41 \mathrm{GD} 113$ & BHT2 & 22.5 & 13.3 & 11.16 \\
\hline $41 \mathrm{GD} 113$ & BHT2 & 27.5 & 13.4 & 12.19 \\
\hline $41 \mathrm{GD} 113$ & BHT2 & 32.5 & 13.3 & 12.34 \\
\hline $41 \mathrm{GD} 113$ & BHT2 & 37.5 & 13.4 & 12.19 \\
\hline $41 \mathrm{GD} 113$ & BHT2 & 42.5 & 13.2 & 13.02 \\
\hline $41 \mathrm{GD} 113$ & BHT2 & 47.5 & 13.4 & 12.43 \\
\hline $41 \mathrm{GD} 113$ & BHT2 & 52.5 & 13.4 & 13.07 \\
\hline $41 \mathrm{GD} 113$ & BHT2 & 57.5 & 13.2 & 14.87 \\
\hline $41 \mathrm{GD} 113$ & BHT2 & 62.5 & 13.4 & 14.06 \\
\hline $41 \mathrm{GD} 113$ & BHT2 & 67.5 & 13.5 & 14.59 \\
\hline $41 \mathrm{GD} 113$ & BHT2 & 72.5 & 13.2 & 14.93 \\
\hline $41 \mathrm{GD} 113$ & BHT2 & 77.5 & 13.4 & 17.09 \\
\hline $41 \mathrm{GD} 113$ & BHT2 & 82.5 & 13.2 & 13.92 \\
\hline $41 \mathrm{GD} 113$ & BHT2 & 87.5 & 13.3 & 15.82 \\
\hline $41 \mathrm{GD} 113$ & BHT2 & 92.5 & 13.3 & 15.7 \\
\hline $41 \mathrm{GD} 113$ & BHT2 & 97.5 & 13.2 & 14.16 \\
\hline $41 \mathrm{GD} 113$ & BHT2 & 102.5 & 13.2 & 12.54 \\
\hline $41 \mathrm{GD} 113$ & BHT2 & 107.5 & 13.5 & 9.92 \\
\hline $41 \mathrm{GD} 113$ & BHT2 & 112.5 & 13.3 & 8.26 \\
\hline $41 \mathrm{GD} 113$ & BHT2 & 117.5 & 13.2 & 8.36 \\
\hline $41 \mathrm{GD} 113$ & BHT2 & 122.5 & 13.5 & 7.44 \\
\hline $41 \mathrm{GD} 113$ & BHT2 & 127.5 & 13.3 & 7.32 \\
\hline $41 \mathrm{GD} 113$ & BHT2 & 132.5 & 13.3 & 7.5 \\
\hline $41 \mathrm{GD} 113$ & BHT2 & 137.5 & 13.2 & 7.65 \\
\hline
\end{tabular}

\begin{tabular}{|c|c|c|c|c|}
\hline Site & Provenience & $\begin{array}{c}\text { cm below } \\
\text { surface }\end{array}$ & Weight & MS Values \\
\hline $41 \mathrm{GD} 113$ & BHT3 & 2.5 & 13.2 & 11.71 \\
\hline $41 \mathrm{GD} 113$ & BHT3 & 7.5 & 13.3 & 13.52 \\
\hline $41 \mathrm{GD} 113$ & BHT3 & 12.5 & 13.4 & 14.88 \\
\hline $41 \mathrm{GD} 113$ & BHT3 & 17.5 & 13.2 & 14.52 \\
\hline $41 \mathrm{GD} 113$ & BHT3 & 22.5 & 13.3 & 16.29 \\
\hline $41 \mathrm{GD} 113$ & BHT3 & 27.5 & 13.4 & 16.28 \\
\hline $41 \mathrm{GD} 113$ & BHT3 & 32.5 & 13.2 & 16.97 \\
\hline $41 \mathrm{GD} 113$ & BHT3 & 37.5 & 13.4 & 17.09 \\
\hline $41 \mathrm{GD} 113$ & BHT3 & 42.5 & 13.2 & 15.65 \\
\hline $41 G D 113$ & BHT3 & 47.5 & 13.5 & 13.96 \\
\hline $41 \mathrm{GD} 113$ & BHT3 & 52.5 & 13.2 & 12.25 \\
\hline $41 \mathrm{GD} 113$ & BHT3 & 57.5 & 13.5 & 11.94 \\
\hline $41 \mathrm{GD} 113$ & BHT3 & 62.5 & 13.5 & 9.98 \\
\hline $41 \mathrm{GD} 113$ & BHT3 & 67.5 & 13.3 & 7.79 \\
\hline $41 \mathrm{GD} 113$ & BHT3 & 72.5 & 13.3 & 7.97 \\
\hline $41 G D 113$ & BHT3 & 77.5 & 13.4 & 7.35 \\
\hline $41 \mathrm{GD} 113$ & BHT3 & 82.5 & 13.5 & 7.04 \\
\hline $41 G D 113$ & BHT3 & 87.5 & 13.4 & 7.53 \\
\hline $41 \mathrm{GD} 113$ & BHT3 & 92.5 & 13.4 & 8.28 \\
\hline $41 G D 113$ & BHT3 & 97.5 & 13.5 & 8.42 \\
\hline $41 \mathrm{GD} 113$ & BHT3 & 102.5 & 13.5 & 9.98 \\
\hline $41 \mathrm{GD} 113$ & BHT3 & 107.5 & 13.5 & 8.36 \\
\hline $41 \mathrm{GD} 113$ & BHT3 & 112.5 & 13.5 & 7.61 \\
\hline $41 G D 113$ & BHT3 & 117.5 & 13.2 & 7.35 \\
\hline $41 \mathrm{GD} 113$ & BHT3 & 122.5 & 13.4 & 7.06 \\
\hline $41 G D 113$ & BHT3 & 127.5 & 13.5 & 2.54 \\
\hline $41 \mathrm{GD} 113$ & BHT3 & 132.5 & 13.2 & 2.69 \\
\hline $41 G D 113$ & BHT4 & 2.5 & 11.3 & 9.58 \\
\hline $41 \mathrm{GD} 113$ & BHT4 & 7.5 & 13.5 & 10.21 \\
\hline $41 \mathrm{GD} 113$ & BHT4 & 12.5 & 13.2 & 11.05 \\
\hline $41 G D 113$ & BHT4 & 17.5 & 13.3 & 11.98 \\
\hline $41 G D 113$ & BHT4 & 22.5 & 13.6 & 12.6 \\
\hline $41 G D 113$ & BHT4 & 27.5 & 13.4 & 11.73 \\
\hline $41 \mathrm{GD} 113$ & \begin{tabular}{|l|} 
BHT4 \\
\end{tabular} & 32.5 & 13.2 & 11.77 \\
\hline $41 \mathrm{GD} 113$ & BHT4 & 37.5 & 13.3 & 10.57 \\
\hline $41 G D 113$ & BHT4 & 42.5 & 13.3 & 7.32 \\
\hline $41 \mathrm{GD} 113$ & BHT4 & 47.5 & 13.5 & 6.98 \\
\hline $41 \mathrm{GD} 113$ & BHT4 & 52.5 & 13.5 & 7.09 \\
\hline $41 G D 113$ & BHT4 & 57.5 & 13.2 & 6.57 \\
\hline $41 \mathrm{GD} 113$ & BHT4 & 62.5 & 13.6 & 6.5 \\
\hline $41 G D 113$ & BHT4 & 67.5 & 13.4 & 6.07 \\
\hline $41 \mathrm{GD} 113$ & BHT4 & 72.5 & 13.2 & 5.73 \\
\hline $41 \mathrm{GD} 113$ & BHT4 & 77.5 & 13.2 & 5.44 \\
\hline $41 G D 113$ & BHT4 & 82.5 & 13.3 & 6.14 \\
\hline $41 \mathrm{GD} 113$ & BHT4 & 87.5 & 13.2 & 5.02 \\
\hline $41 \mathrm{GD} 113$ & BHT4 & 92.5 & 13.4 & 4.43 \\
\hline $41 G D 113$ & BHT4 & 97.5 & 13.5 & 4.5 \\
\hline $41 \mathrm{GD} 113$ & BHT4 & 102.5 & 13.4 & 4.9 \\
\hline $41 \mathrm{GD} 113$ & BHT4 & 107.5 & 13.5 & 3.81 \\
\hline $41 \mathrm{GD} 113$ & BHT4 & 112.5 & 13.5 & 4.67 \\
\hline
\end{tabular}


Table C-3. continued...

\begin{tabular}{|c|c|c|c|c|}
\hline Site & Provenience & $\begin{array}{c}\text { cm below } \\
\text { surface }\end{array}$ & Weight & MS Values \\
\hline $41 \mathrm{GD} 113$ & BHT4 & 117.5 & 13.5 & 4.21 \\
\hline $41 \mathrm{GD} 113$ & BHT5 & 2.5 & 13.3 & 12.34 \\
\hline $41 \mathrm{GD} 113$ & BHT5 & 7.5 & 13.5 & 13.55 \\
\hline $41 \mathrm{GD} 113$ & BHT5 & 12.5 & 13.3 & 13.7 \\
\hline $41 \mathrm{GD} 113$ & BHT5 & 17.5 & 13.5 & 13.96 \\
\hline $41 \mathrm{GD} 113$ & BHT5 & 22.5 & 13.5 & 13.84 \\
\hline $41 \mathrm{GD} 113$ & BHT5 & 27.5 & 13.2 & 13.68 \\
\hline $41 \mathrm{GD} 113$ & BHT5 & 32.5 & 13.5 & 15.69 \\
\hline $41 \mathrm{GD} 113$ & BHT5 & 37.5 & 13.4 & 15.23 \\
\hline $41 \mathrm{GD} 113$ & BHT5 & 42.5 & 13.5 & 14.24 \\
\hline $41 \mathrm{GD} 113$ & BHT5 & 47.5 & 13.3 & 12.4 \\
\hline $41 \mathrm{GD} 113$ & BHT5 & 52.5 & 13.3 & 12.22 \\
\hline $41 \mathrm{GD} 113$ & BHT5 & 57.5 & 13.4 & 10.62 \\
\hline $41 \mathrm{GD} 113$ & BHT5 & 62.5 & 13.4 & 9.28 \\
\hline $41 \mathrm{GD} 113$ & BHT5 & 67.5 & 13.2 & 8.12 \\
\hline $41 \mathrm{GD} 113$ & BHT5 & 72.5 & 13.5 & 7.9 \\
\hline $41 \mathrm{GD} 113$ & BHT5 & 77.5 & 13.2 & 7.47 \\
\hline $41 \mathrm{GD} 113$ & BHT5 & 82.5 & 13.5 & 7.84 \\
\hline $41 \mathrm{GD} 113$ & BHT5 & 87.5 & 13.5 & 6.98 \\
\hline $41 \mathrm{GD} 113$ & BHT5 & 92.5 & 13.2 & 7.89 \\
\hline 41GD113 & BHT5 & 97.5 & 13.5 & 8.77 \\
\hline $41 G D 113$ & BHT5 & 102.5 & 13.3 & 9.15 \\
\hline $41 \mathrm{GD} 113$ & BHT5 & 107.5 & 13.5 & 7.96 \\
\hline $41 \mathrm{GD} 113$ & BHT5 & 112.5 & 13.4 & 5.83 \\
\hline $41 \mathrm{GD} 113$ & BHT5 & 117.5 & 13.4 & 3.27 \\
\hline $41 \mathrm{GD} 113$ & BHT5 & 122.5 & 12 & 1.26 \\
\hline $41 \mathrm{GD} 113$ & BHT5 & 127.5 & 13.2 & 1.85 \\
\hline $41 \mathrm{GD} 114$ & BHT3 & 2.5 & 13.2 & 9.44 \\
\hline $41 \mathrm{GD} 114$ & BHT3 & 7.5 & 13.4 & 8.69 \\
\hline $41 \mathrm{GD} 114$ & BHT3 & 12.5 & 13.4 & 8.98 \\
\hline $41 \mathrm{GD} 114$ & BHT3 & 17.5 & 13.4 & 10.04 \\
\hline $41 \mathrm{GD} 114$ & BHT3 & 22.5 & 13.3 & 10.68 \\
\hline $41 \mathrm{GD} 114$ & BHT3 & 27.5 & 12.8 & 8.97 \\
\hline 41GD114 & BHT3 & 32.5 & 13.5 & 8.71 \\
\hline $41 \mathrm{GD} 114$ & BHT3 & 37.5 & 13.5 & 6.06 \\
\hline $41 \mathrm{GD} 114$ & BHT3 & 42.5 & 13.2 & 6.51 \\
\hline $41 \mathrm{GD} 114$ & BHT3 & 47.5 & 13.3 & 4.6 \\
\hline 41GD114 & BHT3 & 52.5 & 13.5 & 4.67 \\
\hline $41 \mathrm{GD} 114$ & BHT3 & 57.5 & 13.4 & 5.95 \\
\hline $41 \mathrm{GD} 114$ & BHT3 & 62.5 & 13.4 & 4.26 \\
\hline $41 \mathrm{GD} 114$ & BHT3 & 67.5 & 13.2 & 5.62 \\
\hline $41 \mathrm{GD} 114$ & BHT3 & 72.5 & 13.3 & 7.85 \\
\hline $41 \mathrm{GD} 114$ & BHT3 & 77.5 & 13.5 & 6.69 \\
\hline $41 \mathrm{GD} 114$ & BHT3 & 82.5 & 13.3 & 4.01 \\
\hline $41 \mathrm{GD} 114$ & BHT3 & 87.5 & 13.3 & 2.77 \\
\hline $41 \mathrm{GD} 114$ & BHT3 & 92.5 & 13.4 & 1.34 \\
\hline $41 \mathrm{GD} 114$ & BHT3 & 97.5 & 13.2 & 1.43 \\
\hline $41 \mathrm{GD} 114$ & BHT3 & 102.5 & 13.5 & 2.13 \\
\hline $41 \mathrm{GD} 114$ & BHT3 & 107.5 & 13.4 & 1.23 \\
\hline
\end{tabular}




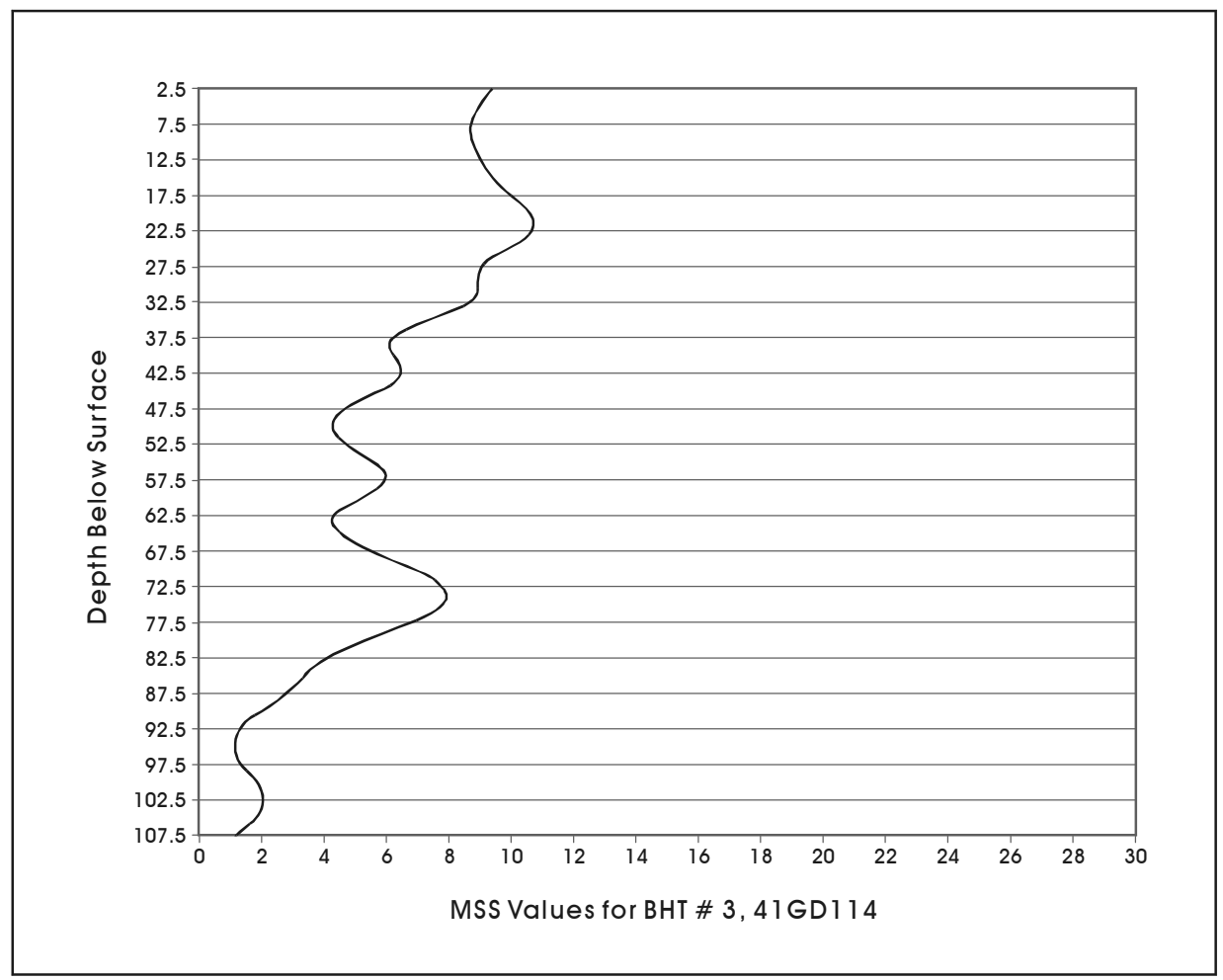

Figure C-1. Magnetic susceptibility values for BHT 3 at 41 GD114.

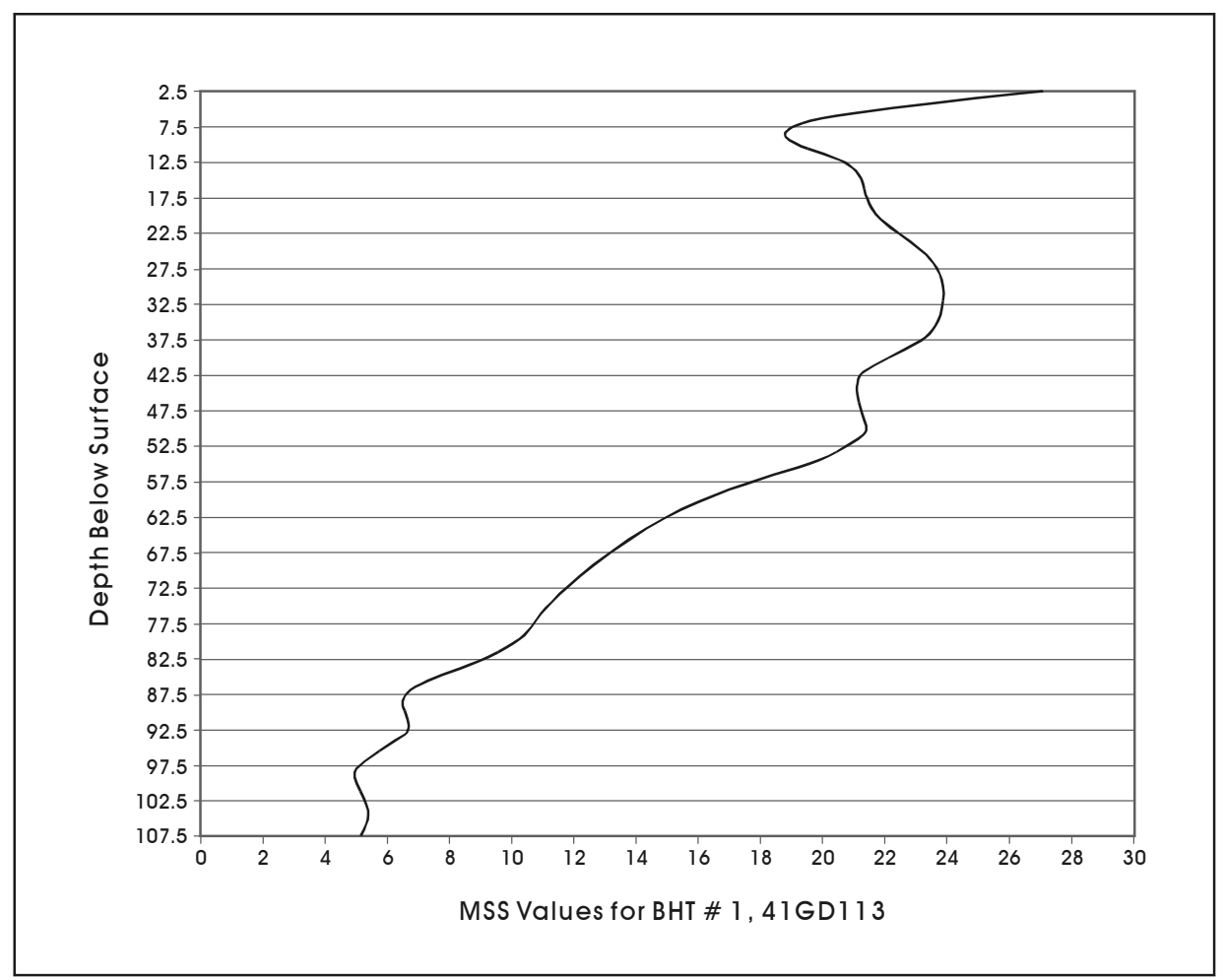

Figure C-2. Magnetic susceptibility values for BHT 1 at 41 GD113. 


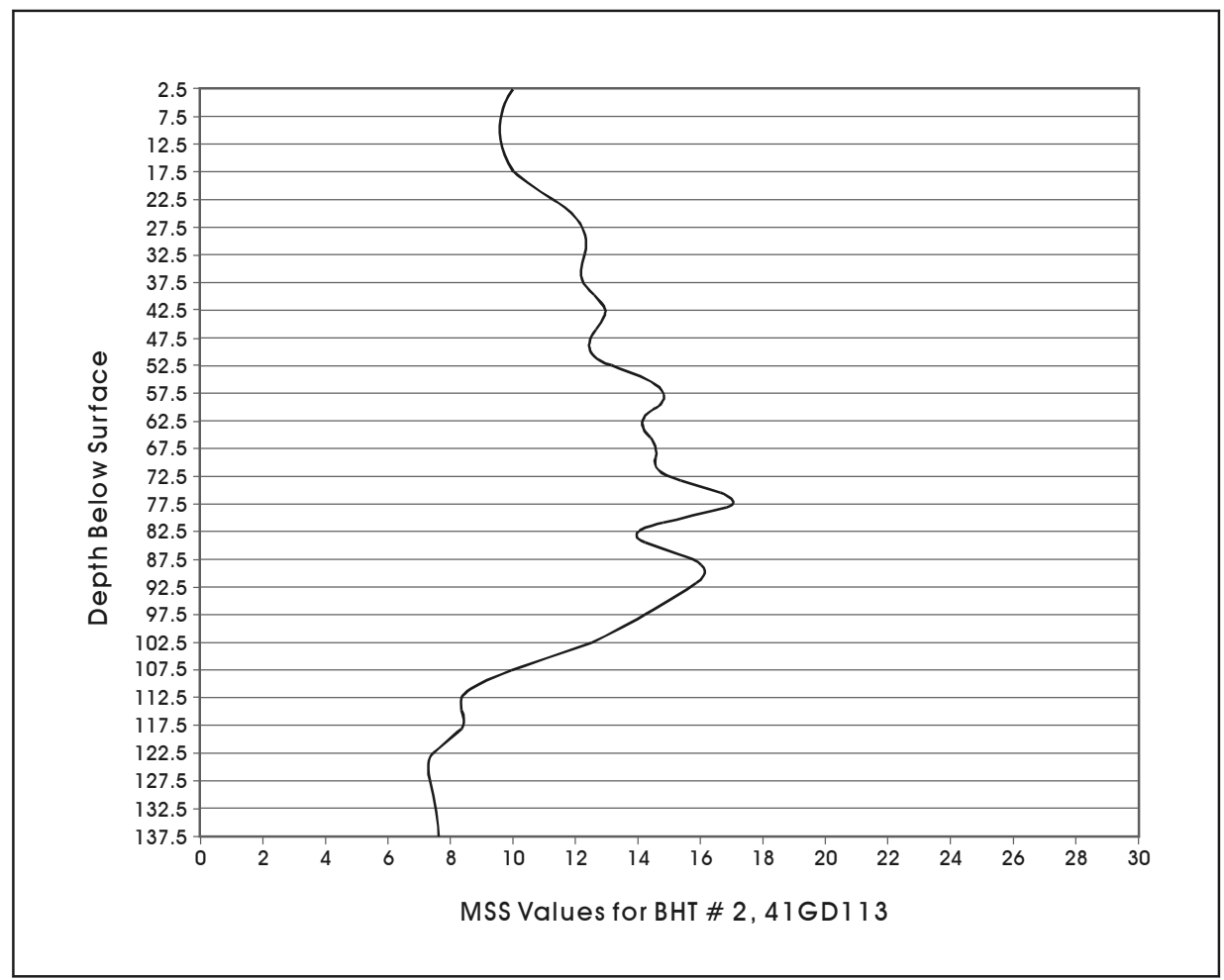

Figure C-3. Magnetic susceptibility values for BHT 2 at 41 GD113.

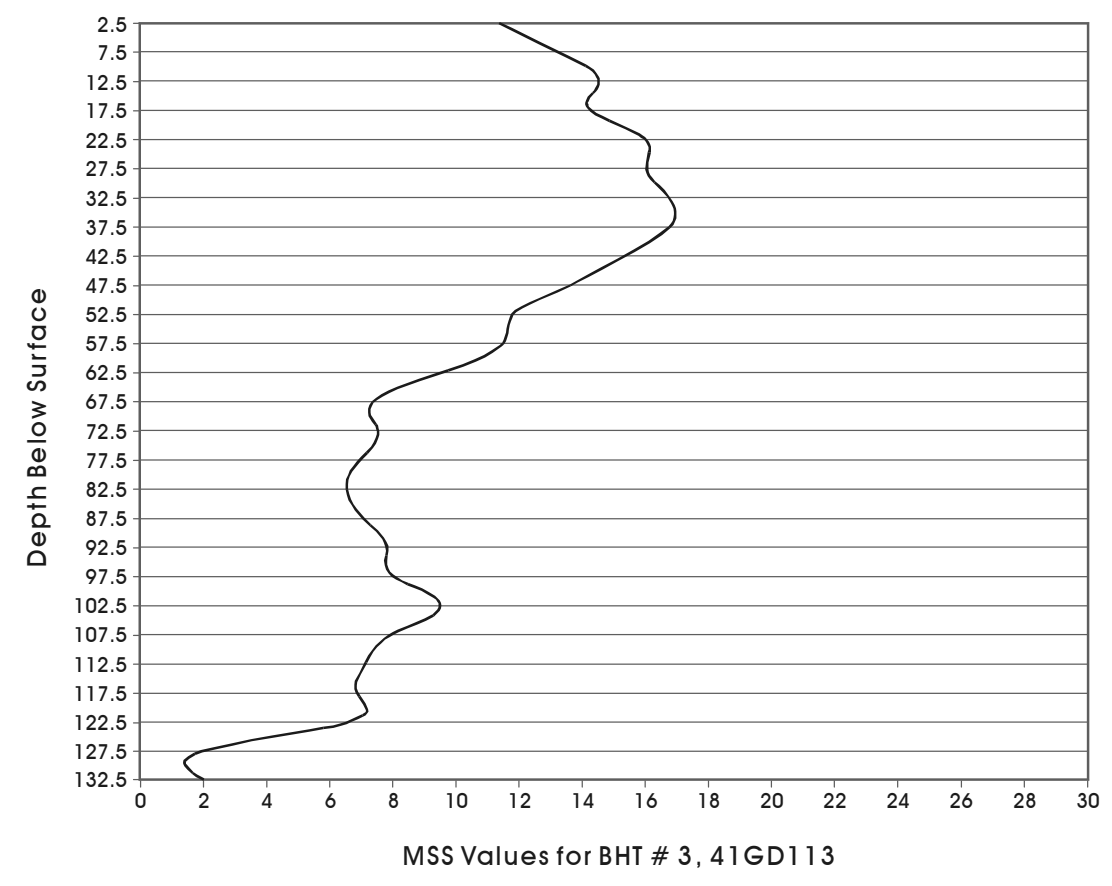

Figure C-4. Magnetic susceptibility values for BHT 3 at 41 GD113. 


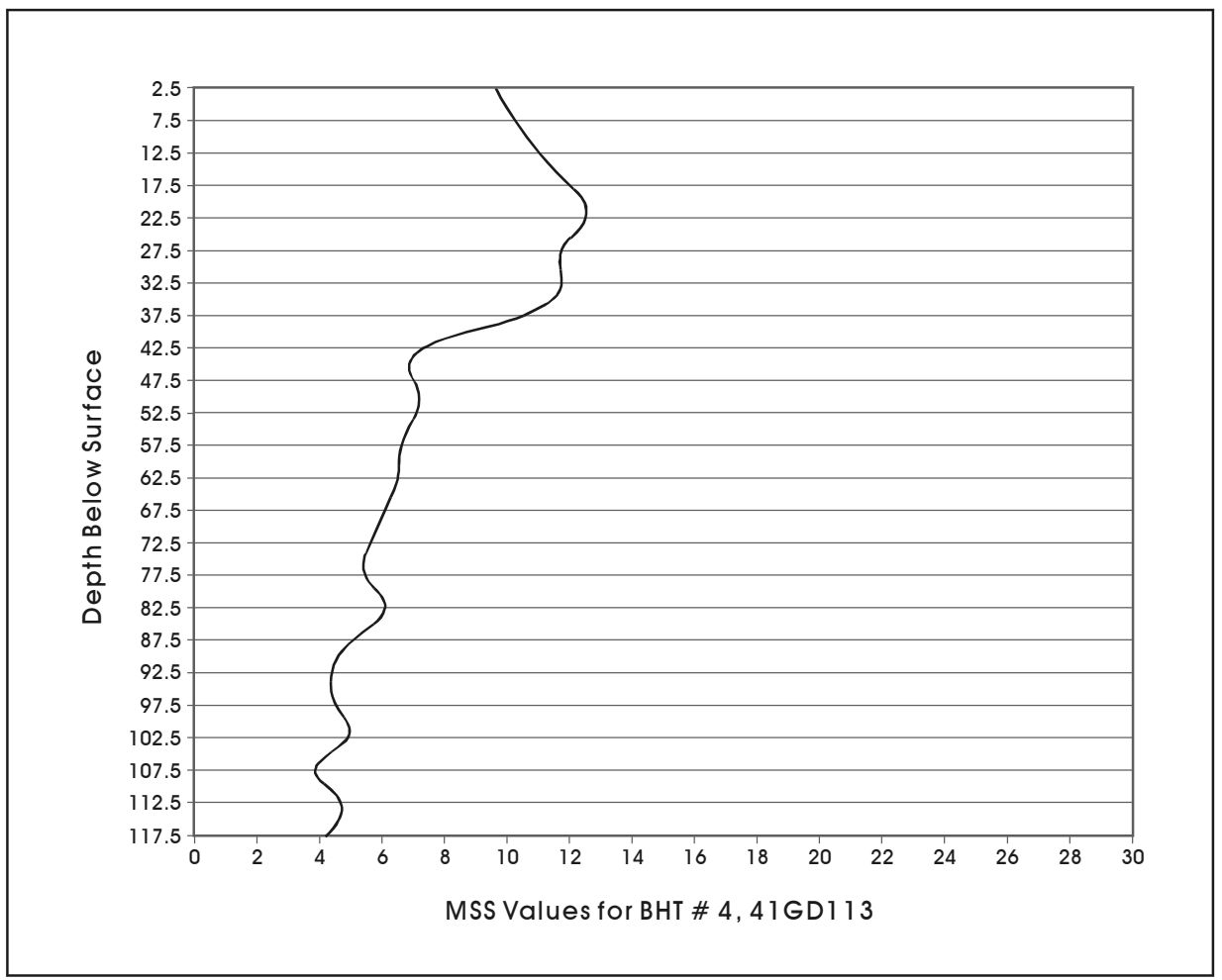

Figure C-5. Magnetic susceptibility values for BHT 4 at 41 GD113.

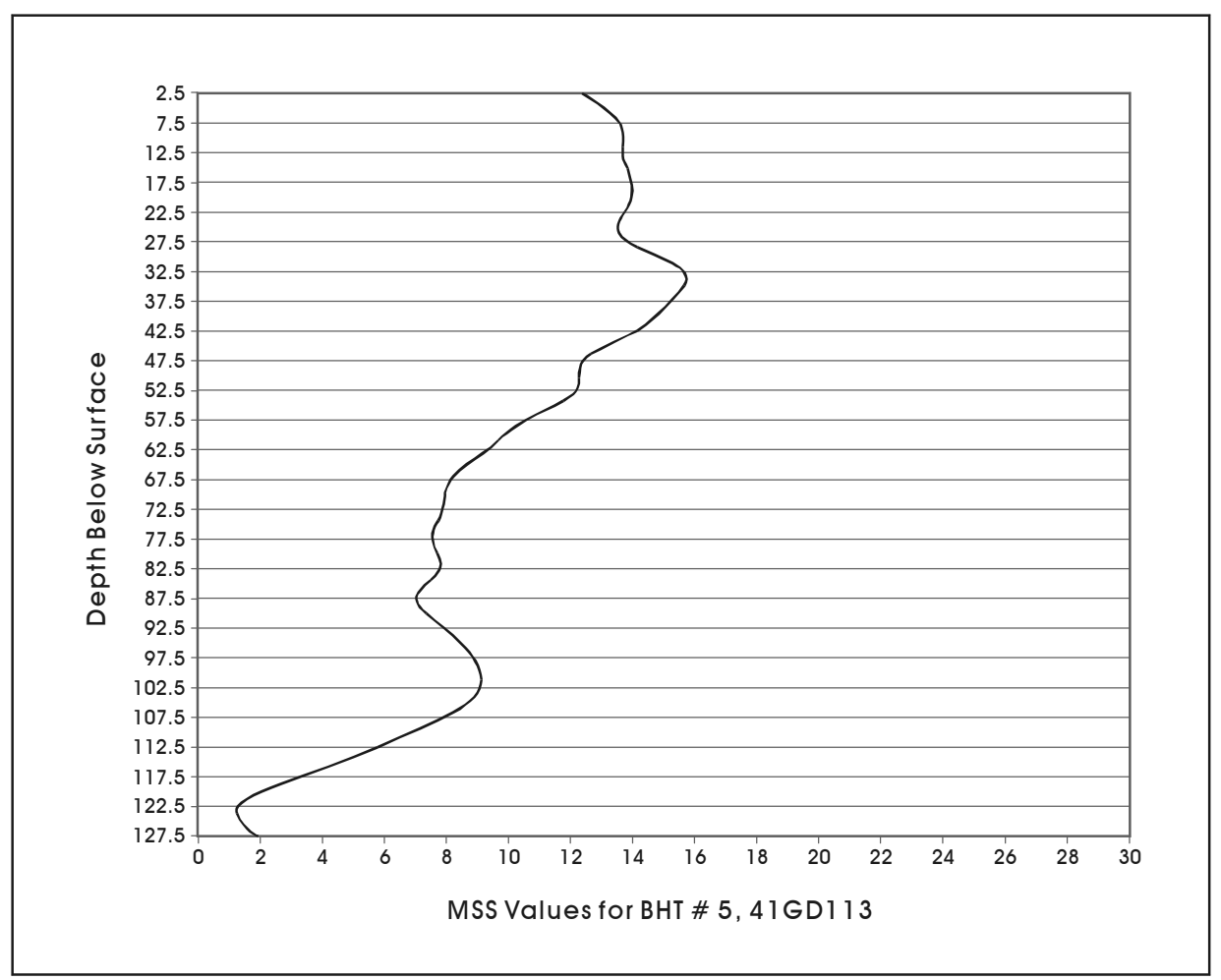

Figure C-6. Magnetic susceptibility values for BHT 5 at 41 GD113. 


\section{References Cited}

Collins, M. B., W. A. Gose, and S. Shaw

1994 Preliminary Geomorphological Findings at Dust and Nearby Caves. Journal of Alabama Archaeology 40:35-56.

Crowther, J.

2003 Potential Magnetic Susceptibility and Fractional Conversion Studies of Archaeological Soils and Sediments. Archaeometry 45:685-701.

Dearing, J.

1999 Environmental Magnetic Susceptibility. Chi publishing, Kenilworth, England.

Gose, W. A., and D. L. Nickels

2001 Archaeomagnetic and Magnetic Susceptibility Analyses. In Test Excavations at the Culebra Creek Site, 41BX126, Bexar County, Texas. D. L. Nickels, C. B. Bousman, J. D. Leach, and D. A. Cargill, pp. 204-214. Archaeological Survey Report, No. 265, Center for Archaeological Research, The University of Texas at San Antonio. Archeology Studies Program, Report 3, Environmental Affairs Division, Texas Department of Transportation, Austin.

Jordanova, N., E. Petrovsky, M. Kovacheva, and D. Jordanova

2001 Factors Determining Magnetic Enhancement of Burnt Clay from Archaeological Sites. Journal of Archaeological Science 28:1137-1148.

McClean, R. G., and W. F. Kean

1993 Contributions of Wood Ash Magnetism to Archeomagnetic Properties of Fire Pits and Hearths. Earth and Planetary Science Letters 119:387-394.

Morinaga, H., H. Inokuchi, H. Yamashita, A. Ono, and T. Inada

1999 Magnetic Detection of Heated Soils at Paleolithic Sites in Japan. Geoarchaeology 14(5):377-399.

Rasmussen, K. L.

2001 FOCUS: Provenance of Ceramics Revealed by Magnetic Susceptibility and Thermoluminescence. Journal of Archaeological Science 28:451-456.

Reynolds, R. L., and J. W. King

1995 Magnetic Records of Climate Change. U.S. National Report to I.U.G.G., 1991-1994. American Geophysical Union. <http://www.agu.ong/revgeophys/reyno100/reyno100.html> Accessed April 2001.

Singer, M. J., and P. Fine

1989 Pedogenic Factors Affecting Magnetic Susceptibility of Northern California Soils. Soil Science of America Journal 53:1119-1127. 